NURSE EDUCATION

AN EXPEERTIMENT IN INTTECRATION OF THEEORY AND PRACTICE IN NURSTING

Margaret F. Alexander

\author{
Vol. II \\ Ph. D \\ University of Edinburgh \\ July 1980
}

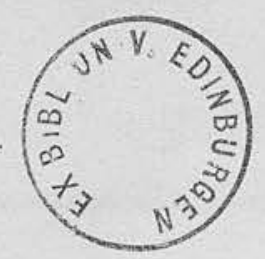


- 277 -

PART III

ANALYSIS AND RESULTS OF THE MATN STUDY 


\section{CHAPTER 12}

THE STUDENT NURSE OPINION QUESTIONNATRE RESULTS

\section{PRE-EXPERTINENT}

The composition of the sample of 119 student nurses who completed the pre-experiment opinion questionnaire is shown in Table 22, in terms of their training experience, and as they were distributed throughout the five colleges of nursing.

TABLE 22 Pre-experiment : Students Composition of Student Sample by College

\section{Colleges}

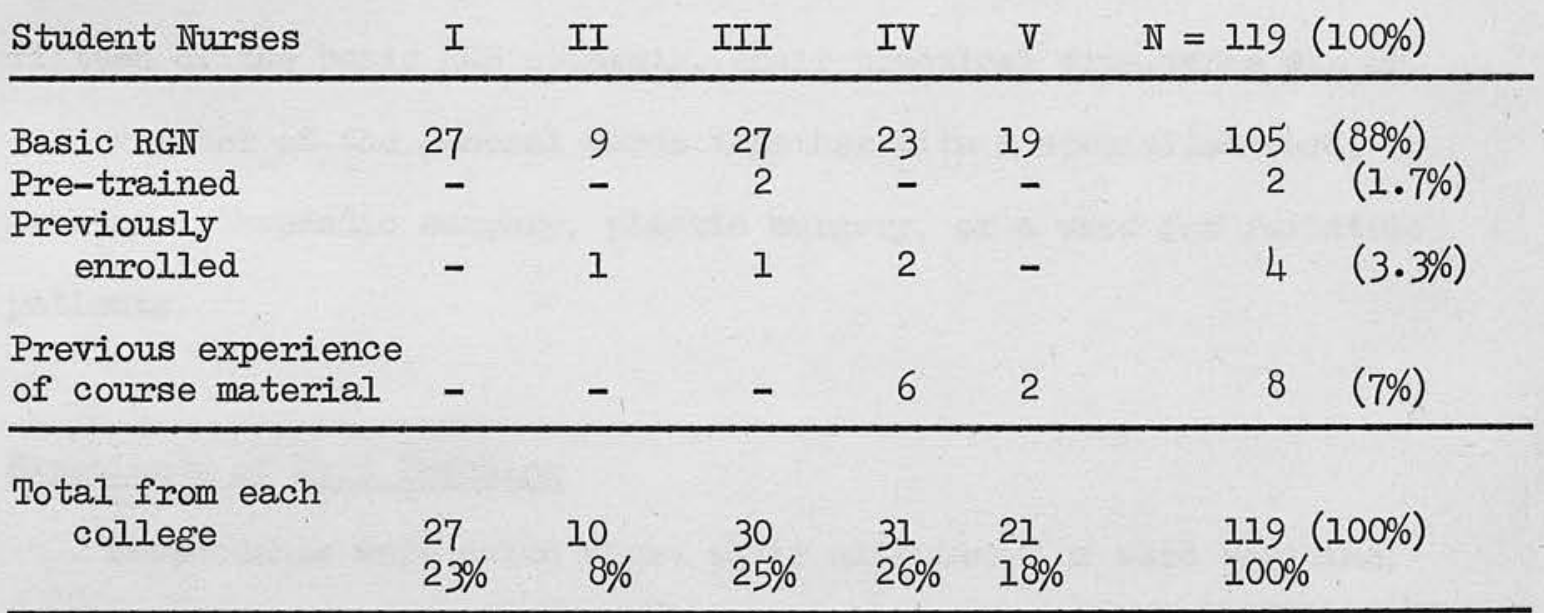

$88 \%$ of the sample were undertaking RGN training as a first and basic experience of nursing, and $12 \%$ had either a previous training or previous experience of the course material by some other means, e.g. because they were re-taking a part of their course. 
of the 119 students who were given the pre-experiment questionnaire, 119 completed it, i.e. a 100\% response rate. Students received the questionnaire while they were in class, and, although the researcher stressed that completion was not obligatory, no student showed any reluctance to respond. Most evinced interest in the exercise and several stated that it was good to be asked their opinion. In each class, when the questionnaires had been collected, there was an opportunity for discussion and this was always used by the students, some groups being more vocal and lively than others.

A majority of the students in the sample had practical experience in both general medical and general surgical wards. For fifteen of the basic RGN students, their practical experience was of one or other of the general wards together with a specialist ward, such as orthopaedic surgery, plastic surgery, or a ward for geriatric patients.

\section{Experience of Ward Teaching}

Respondents were asked about their experience of ward teaching, firstly with regard to having received supervision or practical demonstration, and secondly with regard to tutorials. As the focus of interest in this study was general medical and surgical nursing, it was emphasised in the text of the questionnaire that these two questions should be answered with reference to general medical and surgical wards only. This point was also stressed verbally when the questionnaire was handed out to respondents. 


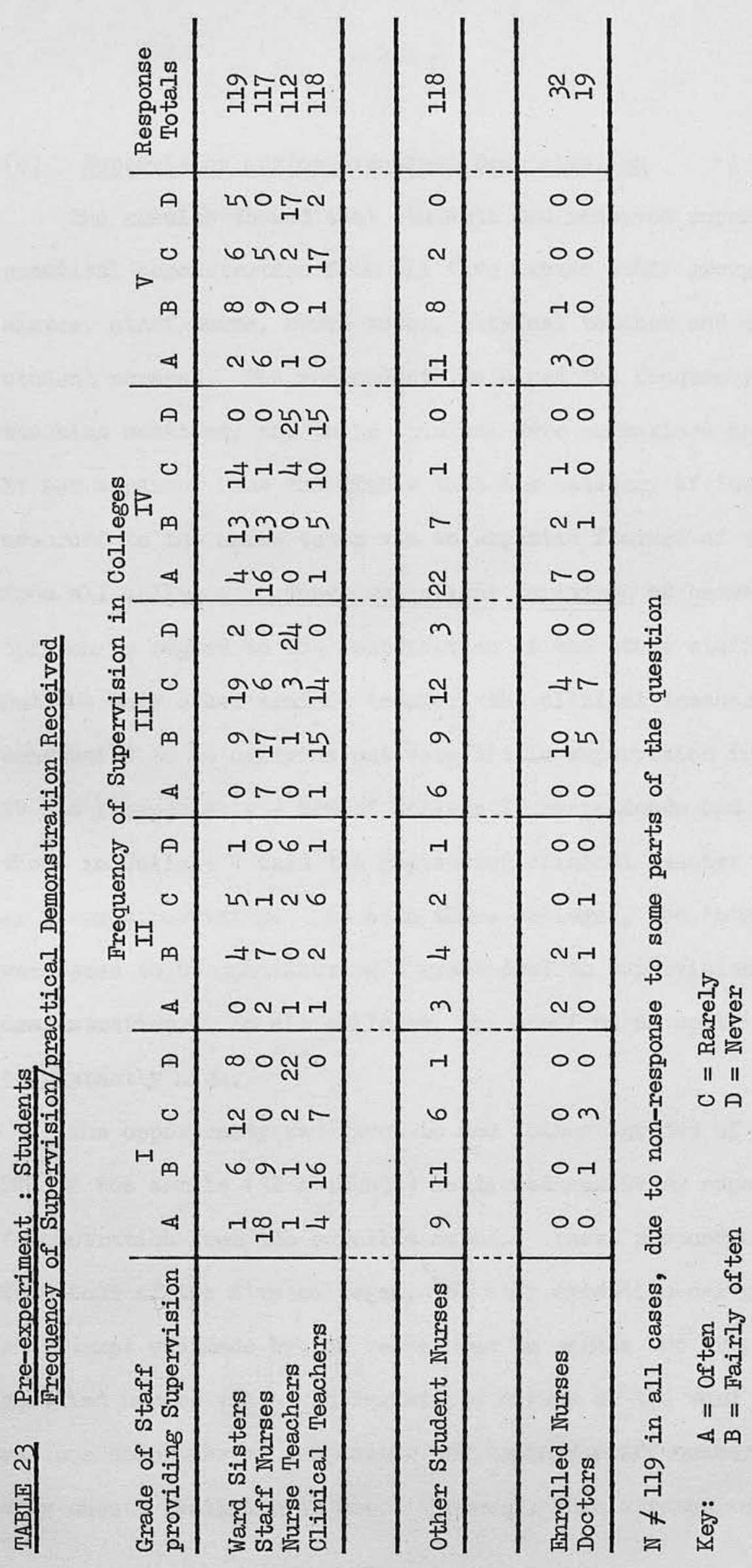




\section{(a) Supervision and/or Practical Demonstration}

The results showed that students had received supervision and practical demonstration from all five listed staff groups of ward sister, staff nurse, nurse tutor, clinical teacher and other student nurses. The respondents adjudged the frequency of such teaching sessions, and their opinions were summarised in Table 23. It was apparent from that Table that the category of 'never' accorded to the nurse tutor was an emphatic feature of the results from all colleges. There was slight variation of between-college opinion in regard to the contribution of the other staff groups, but the only other trained teacher, the clinical teacher, was considered to be carrying out very little supervision in Colleges IV and V especially - $81 \%$ of College IV respondents and $95 \%$ of those in College $\mathrm{V}$ said the registered clinical teacher was rarely or never supervising. In both these colleges, the 'other students' were seen to be contributing a great deal to supervision and demonstration. In all colleges, the staff nurse contribution was consistently high.

The opportunity was given to add 'other' grades of staff, and $27 \%$ of the sample (32 students) mentioned receiving supervision or demonstration from the enrolled nurse. Those respondents came from four of the five colleges, the only exception being College I. An attempt was made by the researcher to assess the proportion of enrolled nurses vis a vis registered nurses on the ward staff of the various hospitals by inspecting the trained staff numbers on the offduty sheets available to her. However, this attempt was not 
successful, as the designation of $S / \mathbb{N}$ or $E / N$ was not always stated. The researcher's subjective impression was that there were more enrolled nurses in the two hospitals attached to College III than in any other hospitals in the study.

Supervision by the doctor was noted by 19 students, the majority of whom came from College III. This was perhaps related to the fact that the College III students were part way through their third year of training. As the most senior students in the sample, they were likely to have the opportunity to work with the doctor more frequently than students in their first year of training.

Although the frequencies of 'often', 'fairly often', 'rarely' and 'never' in this question were unlikely to represent equal intervals, it was apparent, from the content of Table 24 , that the modal responses over all five colleges in regard to supervision by the different staff groups were as follows:

$\begin{array}{lll}\text { for other students } & - & \text { often } \\ \text { for staff nurses } & - & \text { fairly often } \\ \text { for ward sisters and } & & \\ \text { clinical teachers } & - & \text { rarely } \\ \text { for nurse teachers } & - & \text { never }\end{array}$


TABLE 24 Pre-experiment : Students

Supervision/Practical Demonstration given by different Staff Grades

\begin{tabular}{llllll} 
& \multicolumn{6}{c}{ Supervision given by } \\
\cline { 2 - 6 } $\begin{array}{l}\text { Frequency of } \\
\text { supervision }\end{array}$ & $\begin{array}{l}\text { Ward } \\
\text { Sister }\end{array}$ & $\begin{array}{l}\text { Staff } \\
\text { Nurse }\end{array}$ & $\begin{array}{l}\text { Nurse } \\
\text { Tutor }\end{array}$ & $\begin{array}{l}\text { Clinical } \\
\text { Teacher }\end{array}$ & $\begin{array}{l}\text { Other } \\
\text { Students }\end{array}$ \\
\hline Often & 7 & 49 & 3 & 7 & 51 \\
Fairly often & 40 & 55 & 2 & 39 & 39 \\
Rarely & 56 & 13 & 13 & 54 & 23 \\
Never & 16 & 0 & 94 & 18 & 5 \\
\hline Response $N=$ & 119 & 117 & 112 & 118 & 118 \\
\hline
\end{tabular}

\section{Attachment of a Weighted Score to the Frequencies}

A score or value was attached to the frequencies, as undernoted:

$$
\begin{array}{ll}
\text { often } & =\text { a score of } 3 \\
\text { fairly often } & =\text { a score of } 2 \\
\text { rarely } & =a \text { score of } 1 \\
\text { never } & =\text { no score }
\end{array}
$$

Thereafter it was possible to calculate a percentage score for each staff category in regard to their perceived contribution to supervision and practical demonstration. This calculation was done as follows - of 119 responses to the frequency of supervision by the ward sister (see Table 23) the actual score was 157. The tbest possible' score, had the ward sister received 119 ratings of 'often' was 357 , thus the percentage score was $44 \%$. Figure 37 below indicates the contribution of the listed staff categories using the weighted score. The registered nurse tutor, the staff member who 
had had most resources spent on the development of her skills as a teacher, remained at the bottom of the league, clearly not, in the view of the students, contributing to the teaching in the wards, where the students spend most of the 118 weeks of the practice component of their education and training programme. The clinical teacher, whose raison $\mathrm{d}^{\imath}$ être is teaching, was making virtually the same contribution to ward teaching as the ward sister.

Figure 37 Pre-experiment : Students Weighted Score Contribution to Ward Supervision/Practical Demonstration by Iisted Staff Grades

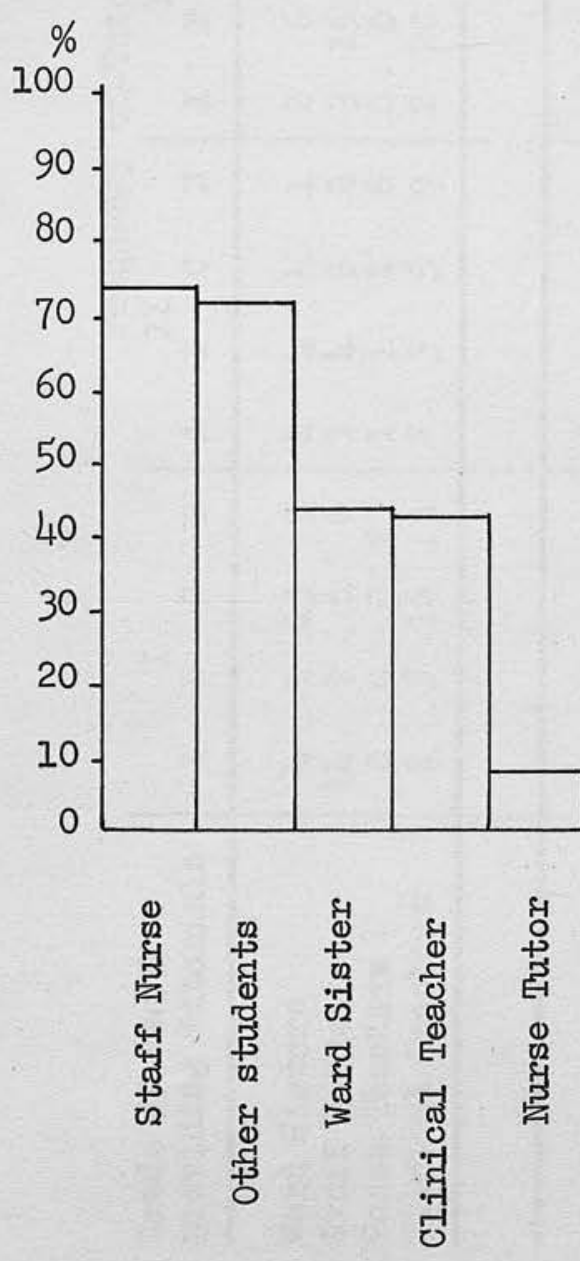



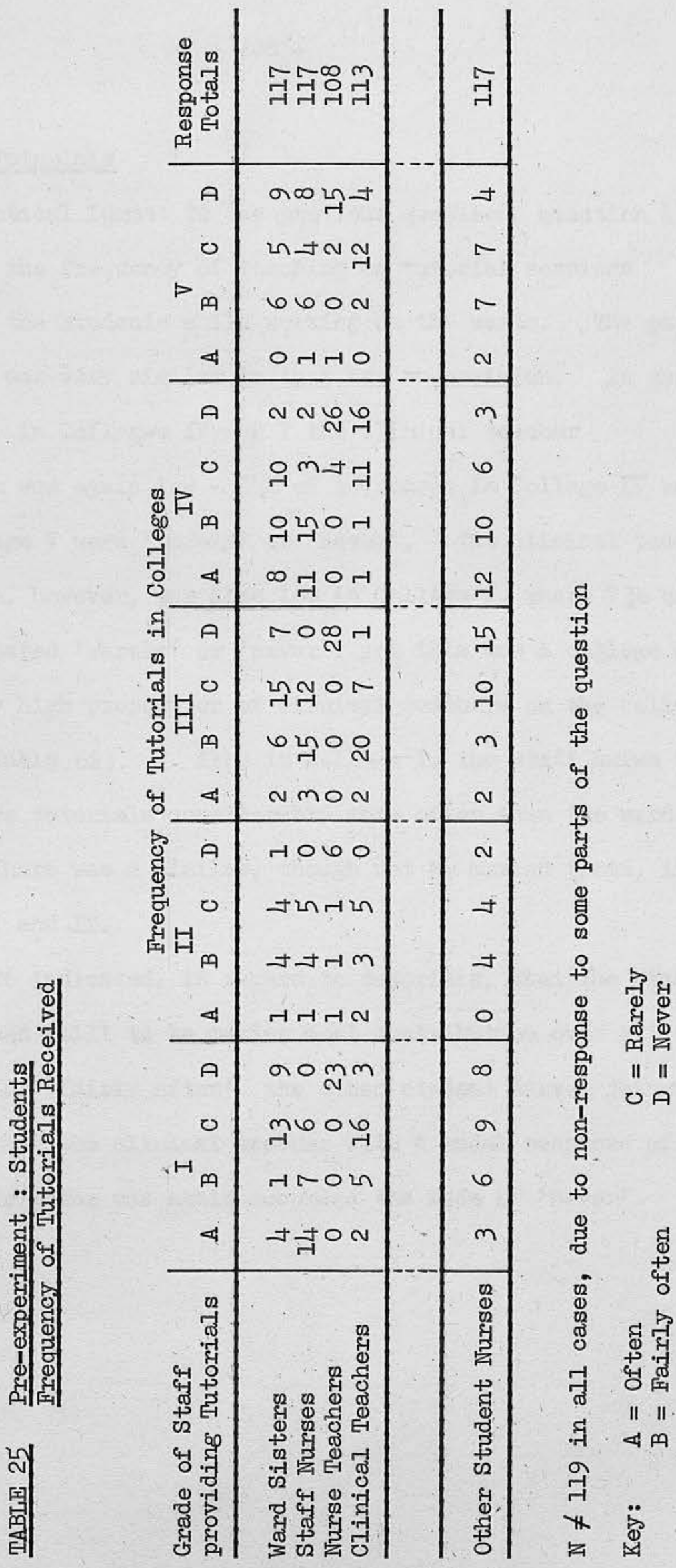


\section{(b) Ward Tutorials}

In identical format to the previous question, question 4 asked about the frequency of teaching or tutorial sessions received by the students while working on the wards. The patterm of response was very similar to that for supervision. As shown in Table 25, in Colleges IV and V the clinical teacher contribution was again low - $94 \%$ of responses in College IV and $89 \%$ in College $\mathrm{V}$ were 'rarely' or 'never'. The clinical teacher contribution, however, was also low in College I, where $73 \%$ of responses stated 'rarely' or 'never', yet this was a college with a relatively high proportion of clinical teachers on the college staff (see Table 62). Also in College I, the staff nurse was noted to give tutorials considerably more often than the ward sister. There was a similar, though not so marked trend, in Colleges III and IV.

Table 26 indicated, in regard to tutorials, that the staff nurse was seen still to be making most contribution over all colleges, with a mode of 'fairly often', the other student nurses joined the ward sister and the clinical teacher with a modal response of 'rarely', and the nurse tutor was again accorded the mode of 'never'. 
TABLE 26 Pre-experiment : Students Tutorials given by different Staff Grades

Tutorials given by

\begin{tabular}{llllll}
$\begin{array}{l}\text { Frequency of } \\
\text { tutorials }\end{array}$ & $\begin{array}{l}\text { Ward } \\
\text { Sister }\end{array}$ & $\begin{array}{l}\text { Staff } \\
\text { Nurse }\end{array}$ & $\begin{array}{l}\text { Nurse } \\
\text { Tutor }\end{array}$ & $\begin{array}{l}\text { Clinical } \\
\text { Teacher }\end{array}$ & $\begin{array}{l}\text { Other } \\
\text { Students }\end{array}$ \\
\hline Often & 15 & 30 & 2 & 7 & 19 \\
Fairly often & 27 & 47 & 1 & 31 & 30 \\
Rarely & 47 & 30 & 7 & 51 & 36 \\
Never & 28 & 10 & 98 & 24 & 32 \\
\hline Response $N=$ & 117 & 117 & 108 & 113 & 117 \\
\hline
\end{tabular}

Attachment of a Weighted Score to the Frequencies

When the same weighted score, or value, was given to the frequencies for tutorials, as was done to the above-reported findings on supervision and demonstration, an identical ordering of each grade's contribution was seen, although the 'other students' were shown to be using this method of ward teaching to a lesser extent than were the staff nurses (see Figure 38). 
Figure 38 Pre-experiment : Students

Weighted Score Contribution to Ward Tutorials by listed Staff Grades

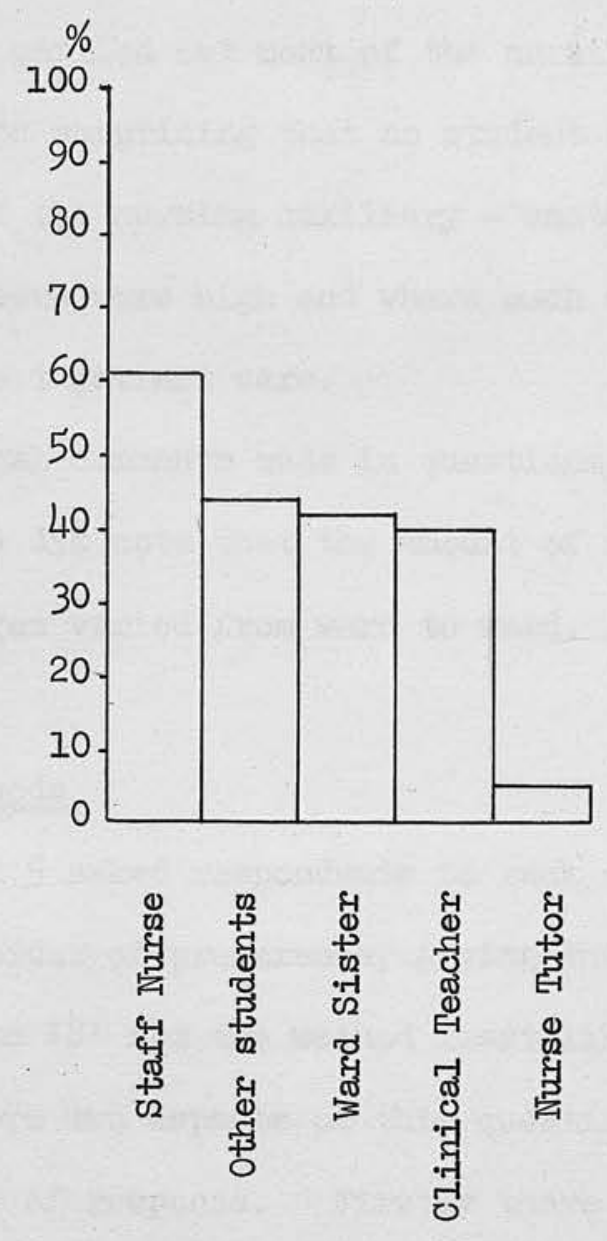

A small number of students commented that tutorials had been received from the enrolled nurse and the doctor - 11 (9\%) of the sample had been given tutorials by the $\mathrm{E} / \mathrm{N}$, and 17 (14\%) by the doctor. Of the latter, again the majority, 13, were the more senior student nurses in College III. 
It should perhaps be borme in mind when examining the results in relation to ward teaching that there were many more staff nurses and student nurses in the wards than there were ward sisters or clinical teachers. It was the staff nurses and other students who carried out most of the nursing care of patients. It was perhaps surprising that no student mentioned supervision or teaching from the nursing auxiliary - another staff grade where relative numbers were high and where much of the working day was spent in direct patient care.

Additional comments made in questions 3 and 4 were few: 10 students ( $8 \%)$ did note that the amount of supervision and of tutorials given varied from ward to ward.

\section{Teaching Methods}

Question 5 asked respondents to rank eight methods of teaching/ learning in order of preference, giving the rank 'I' for the method best liked, to 18 , for the method least liked.

There were two aspects of this question which might have led to unreliability of response. Firstly there was the individual student's interpretation of what was meant by the name given by the researcher to the different teaching/learming methods. In an effort to diminish ambiguity in this respect, the terminology used to describe the various methods was derived from the Block timetables scrutinised during the preliminary survey and also from the teachers ${ }^{2}$ answers in the Survey interviews, when they invariably touched upon the teaching methods they used. A second limitation 
or possible source of unreliability of response was the number of methods which the students were asked to rank, i.e. 8. It was quite possible, with this fairly large number of choices, that a second or third attempt at answering this question would have produced some variation, if not in the extremes of best and least liked methods, at least in the 'greyer' area in the middle, where the preference might not have been so clear-cut in the student's mind.

It seemed likely that doubt, or difficulty in assigning a rank, might be evidenced by the respondent scoring out, re-ranking or failing to complete the ranking. In an attempt to search for such difficulty, it was decided to count all those respondents who had made more than one change in their rank ordering when answering the question. The total number so doing was 7 (5.8\%) of the sample and two of these 7 student nurses did not complete the ranking. Therefore, it was likely that, for these student nurses, this question proved difficult. This was no guarantee that the 117 who completed the ranking ( $98 \%$ of the sample) would rank the methods again exactly as they did on this occasion. However, one recognised way of increasing the reliability of the results of a number of independent raters is to 'pool' them (Thorndike and Hagen, 1977, p.460).

In the results shown in Table 27, the students' rankings of the teaching/learning methods have been pooled across all five colleges, and a mean rank obtained for each method. 
TABLE 27 Pre-experiment : Students

Preference for Methods of Teaching/Learming:

Teaching/Learning Methods

(in order as listed in questionnaire)

Sum of Ranks Mean Rank

Formal lecture

Lecture with question and discussion time

Small group tutorial (in college)

Ward tutorials

Practical classes (in college)

with demonstration

Practical classes with

demonstration plus practice

opportunity (in college)

Study - guided

Study - self-directed

713

$483 \quad 4.12$

375

291

479

386

684

801
6.09

3.20

2.48

4.09

N according ranks $=117$

The resulting rank order, from I for 'best liked method of teaching/learning' to 8 for 'least liked method' is shown in graph form in Figure 39. The methods have been plotted in the order as given on the questionnaire, to show that there was no apparent link between the given ordering and the respondents' ranking, i.e. there was no evidence that methods were simply graded in order as they appeared on the list from best liked to least liked, or vice versa. 
Figures 39-44 Pre-experiment:Students

\section{Preference Profile - Methods of Teaching/Learning}

Figure 39 All Colleges

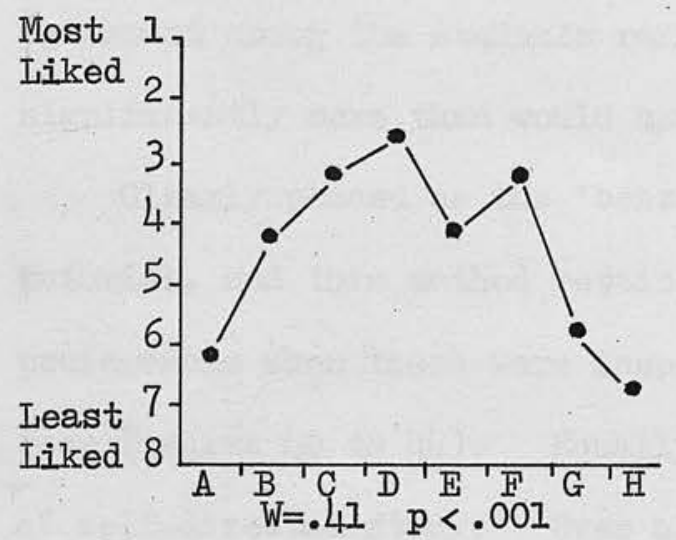

Figure 41 College II

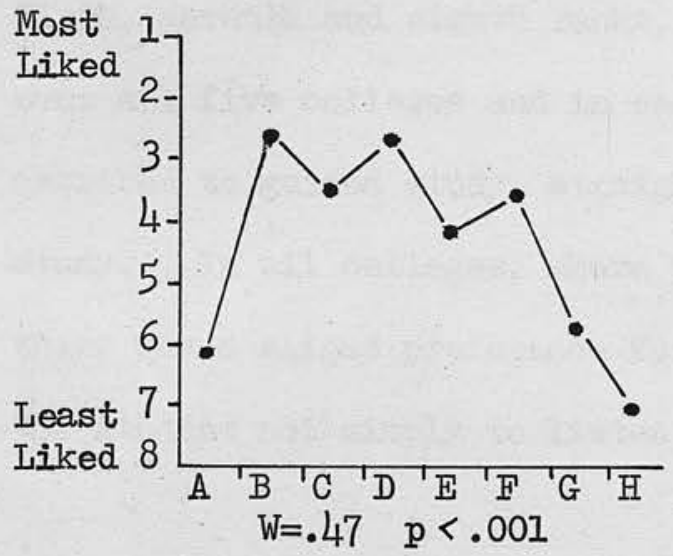

Figure 43 College IV

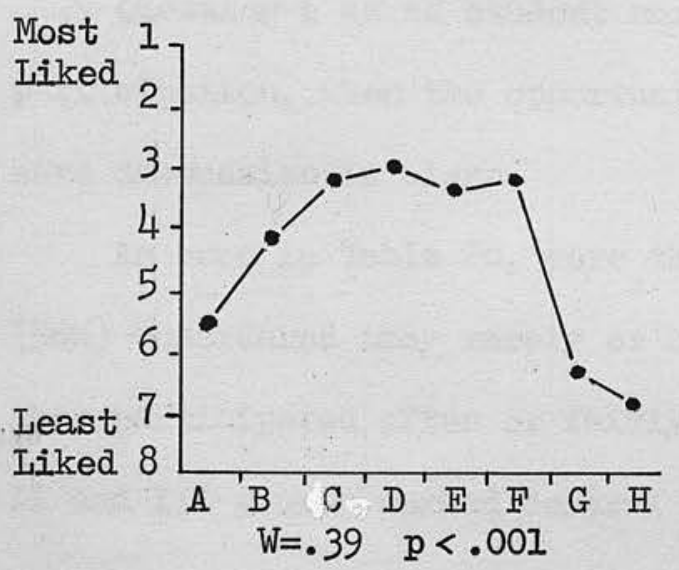

Figure 40 College I

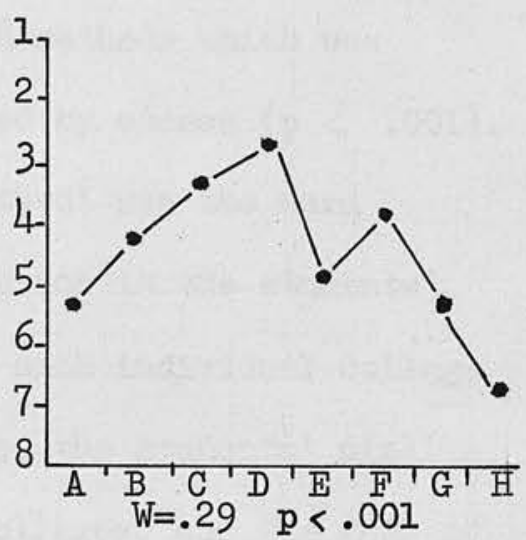

Figure 42 College III

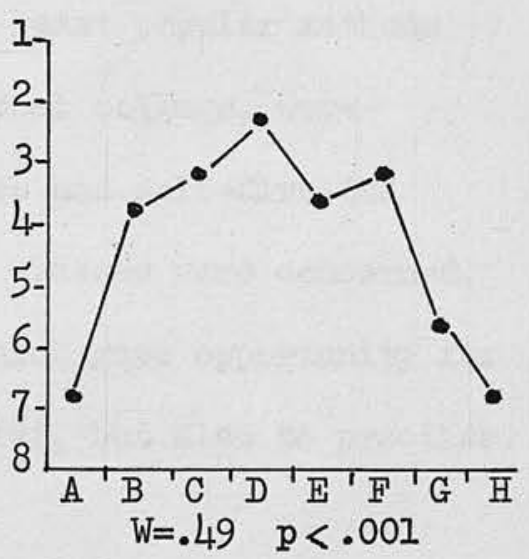

Figure L4 College V

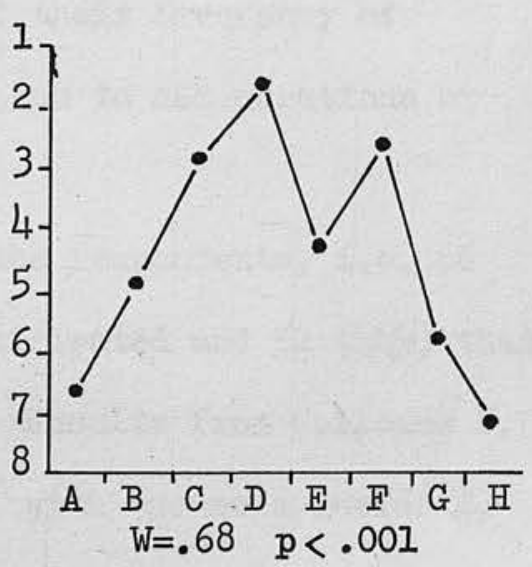

Key: A=Formal lecture

$B=I e c t u r e$ with time for questions or discussion

$\mathrm{C}=$ Small group tutorial (college)

$\mathrm{D}=$ Ward tutorial

$\mathrm{E}=$ Practical class which includes demonstration

H=Practical class which includes demonstration/practice

G=Guided study

$\mathrm{H}=\mathrm{Sel} f$-directed study 
Kendall's coefficient of concordance statistical test (Siegel, 1956, p.237) was applied to the student rankings, and the Kendall W of . 41 which was obtained, reflected a degree of agreement among the students ranking the 8 methods which was significantly more than would have occurred by chance ( $p<.001$ ).

Clearly placed as the 'best liked method' was the ward tutorial, and this method retained first place in the students? preferences when these were inspected for each individual college (see Figures 40 to 44 ). Equally clear was the students' dislike of self-directed study. Over all five colleges, and for four of the five individual colleges, this was the 'least liked method'. Sixth, seventh and eighth ranks, i.e. the least popular methods over all five colleges and in each individual college, were ascribed to guided study, straight lectures and self-directed study. In all colleges, where practical classes were concermed, there was a slight preference for those which gave opportunity for the student not simply to listen and observe, but also to practise.

\section{Participation in Class Discussions}

Question 6 asked student nurses about their frequency of participation, when the opportunity was given to ask questions or have discussion in class.

As seen in Table 28, more than half the respondents, i.e. 66 (56\%) considered they rarely or never participated and 52 (44\%) that they participated often or fairly often. Results from Colleges I, II and III show a marked central tendency, with the mode residing, 
albeit narrowly, in the 'fairly often' category. In Colleges IV and $V$ the mode is placed clearly in the 'rarely' category, with $23(77 \%)$ of College IV respondents and $13(62 \%)$ of College $\mathrm{V}$ respondents giving this response.

TABLE 28 Pre-experiment : Students Participation in Class Discussion

\begin{tabular}{lccccc} 
Colleges & Often & Fairly often & Rarely & Never & $N=$ \\
\hline I & 1 & 15 & 11 & 0 & 27 \\
II & 2 & 5 & 3 & 0 & 10 \\
III & 3 & 13 & 12 & 2 & 30 \\
IV & 2 & 5 & 23 & 0 & 30 \\
V & 4 & 2 & 13 & 2 & 21 \\
\hline \multirow{2}{*}{$N$ of responses } & 12 & 40 & 62 & 4 & 118 \\
& $10 \%$ & $34 \%$ & $52.5 \%$ & $3.5 \%$ & $100 \%$ \\
\hline
\end{tabular}

All teachers are aware that students - be they nurses or otherwise - and different classes within the same student groups, tend to vary in regard to participation. Undoubtedly some methods of teaching, such as the small group tutorial, encourage class participation more than do others, e.g. the formal lecture. It was within the scope of this research to examine the teaching methods utilised, with both the control and experimental groups of students in each of the main study colleges, and this was done in Chapter 11.

\section{Perceived difference between College and Ward Learming:}

Question 7, a forced-choice question, asked whether student nurses saw college and ward as different in terms of how much could be learned in either place. 
TABLE 29 Pre-experiment : Students

Place where PMost is Learned?

\begin{tabular}{lccccccc} 
& \multicolumn{4}{c}{ Colleges } & \multicolumn{3}{c}{ TOTAL } \\
\cline { 2 - 8 } Most is learned & I & II & III & IV & V & N & $\%$ \\
\hline In wards & 20 & 8 & 27 & 15 & 19 & 89 & 77 \\
In college & 7 & 1 & 3 & 14 & 2 & 27 & 23 \\
\hline$N=$ & 27 & 9 & 30 & 29 & 21 & 116 & $100 \%$ \\
\hline
\end{tabular}

Table 29 showed that, in all but College IV, where respondents were almost equally divided in opinion, a majority of students felt they learned most in the ward.

In general discussion with the researcher, after completion of the questionnaires, a very few student nurses commented on this question, and indicated that they felt they were leaming "different things" in the two places, but were unable to state exactly what was different.

\section{College Teaching in relation to Ward Practice}

Two questions looked at the teaching given in college - was it helpful when students were working on the wards and did it relate well to nursing as it was practised on the wards?

In regard to the former question, there was, overall, a positive response in that 113 students (95\%) felt college teaching was helpful when they were working on the wards. It would have seemed reasonable to assume that, if college teaching was considered 
helpful, it would also relate in a positive way to nursing practice. However, this was not so, as can be seen in Table 30. Only 41 of the 113 students who found college teaching helpful also considered it related well to practice. Conversely two of the five students who felt college teaching was not helpful to ward practice considered it related well.

TABIE 30 Pre-experiment : Students Relationship of College Teaching to Ward Practice and its helpfulness in Ward Work

Helpfulness of College Teaching to Ward Practice

Relationship of

College Teaching

to Ward Practice

Helpful

Not helpful

Relates well

Does not relate well

41

72

2

3

43

75

\section{3}

5

(c) College and Ward Fmphasis - Individualised Care or Task Assignment

Questions 9 and 10 were also directed towards seeking out differences, and therefore potential conflict areas between the two components of nurse education and training, this time in terms of emphasis. Firstly, in question 9, where did the emphasis lie, in the theoretical component - on care of the individual patient, or on technical aspects and nursing procedures? Secondly, in question 10, where did the emphasis lie in the ward practice component - on total nursing care or on routine procedures (see Tables 31 and. 32). 
TABLE 31 Pre-experiment : Students College Fmphasis

\begin{tabular}{lrrrrrrr} 
& \multicolumn{4}{c}{ Colleges } & \multicolumn{3}{c}{ TOTAL } \\
\cline { 2 - 9 } College Emphasis & I & II & III & IV & V & N & $\%$ \\
\hline Individualised care & 14 & 3 & 21 & 12 & $\begin{array}{r}4 \\
18\end{array}$ & $\begin{array}{l}54 \\
62\end{array}$ & $\begin{array}{l}47 \\
53\end{array}$ \\
\hline Technical aspects & 12 & 7 & 9 & 16 & 62 & 116 & $100 \%$ \\
\hline$N=$ & 26 & 10 & 30 & 30 & 20 & 116 \\
\hline
\end{tabular}

TABLE 32 Pre-experiment : Students Ward Emphasis

\begin{tabular}{|c|c|c|c|c|c|c|c|}
\hline \multirow[b]{2}{*}{ Ward Emphasis } & \multicolumn{5}{|c|}{ Colleges } & \multicolumn{2}{|c|}{ TOTAL } \\
\hline & $I$ & II & III & IV & $\mathrm{V}$ & $\mathbb{N}$ & $\%$ \\
\hline $\begin{array}{l}\text { Task orientation } \\
\text { Total patient care }\end{array}$ & $\begin{array}{r}20 \\
7\end{array}$ & $\begin{array}{l}9 \\
0\end{array}$ & $\begin{array}{r}22 \\
8\end{array}$ & $\begin{array}{l}19 \\
12\end{array}$ & $\begin{array}{r}19 \\
2\end{array}$ & $\begin{array}{l}89 \\
29\end{array}$ & $\begin{array}{l}75 \\
25\end{array}$ \\
\hline$N=$ & 27 & 9 & 30 & 31 & 21 & 118 & $100 \%$ \\
\hline
\end{tabular}

Only in College III was there a clear majority of students who saw the college emphasis on individual patient care. Opinion in the class in College I was almost equally divided, and the majority of students in the other three colleges saw the college emphasis as on technical aspects and nursing procedures.

The ward emphasis, for a majority of respondents in each college was on task assignment or 'routine to all', although for 29 students their ward experience had led them to see the emphasis on total nursing care. One of the most striking features of the responses 
depicted in Tables 31 and 32 was the very different perceptions of the individual students, in that there was no agreement as to either the college emphasis or the ward emphasis. With regard to the latter, the differences were not unexpected. It was very possible that the emphasis could have been different in different wards of the same hospital. However, all student nurses were, in their individual college groups, members of the same class. In all five colleges, the formal organisation was such that a class (or intake) was allocated to one group of nurse teachers and received most of their teaching from that same group of teachers. Although all classes had, in addition, visiting lecturers, these lecturers did not teach nursing - that subject was taught by the nurse teachers or clinical teachers of the individual college.

For how many students therefore did a potential conflict situation exist? Table 33 would suggest that this was the case for 53 students, who found the emphasis different in college and in hospital.

\section{TABLE 33 Pre-experiment: Students} Perception of Fmphasis in College and in Ward

Ward Emphasis Response

College emphasis Routine to all Total nursing care $\mathbb{N}=$

Task/procedure Individualised care 48 39

$\left(\begin{array}{l}42 \%) \\ (34 \%)\end{array} 14\right.$ $\left(\begin{array}{l}12 \%) \\ 12 \%)\end{array}\right.$ 62 53

$(76 \%) \quad 28$


It was not possible, from the results available, to explore whether the diversity of opinion in regard to the emphasis in college teaching had its origin in the individual student's perception of the situation, or in dissimilar approaches to the teaching of nursing by the teachers in a particular college. The results suggest, however, the possibility that there was no previously agreed consensus, or philosophy of approach to the teaching of nursing.

\section{Theory and Practice}

The remainder of the student pre-experiment questionnaire focused directly on theory and practice in nursing - on differences between what was taught in the college and what was practised in the wards and on opinions as to integration of theory and practice.

\section{Examples of Practice which differed from Teaching}

Students were asked whether they could recall instances where their own ward nursing practice had differed from the taught method. From all five colleges, a total of 71 students answered in the affirmative. The numerous examples which they cited were categorised, as in the Nuffield Job Analysis (1953), into basic, technical and affective nursing:

"basic nursing ... those nursing duties having their origin in the physical needs of the patient".

"technical nursing ... all nursing tasks that are concermed with the treatment of the disease from which the patient is suffering". (p.37) 


\section{"affective nursing ... social and psychological needs which have their origin in the fact that the individual has to adjust himself to his changed circumstances". (p.28)}

Table 34 gives the number of comments in these three categories. Some students gave several examples, others none, therefore the number of 77 comments was not equal to 77 respondents.

TABIE 34 Pre-experiment : Students

Recalled Fxamples of Practice which differed from

\begin{tabular}{|c|c|c|c|c|c|c|c|}
\hline \multirow[b]{2}{*}{$\begin{array}{l}\text { Nursing work } \\
\text { performed differently } \\
\text { from way taught }\end{array}$} & \multicolumn{5}{|c|}{ Colleges } & \multicolumn{2}{|c|}{ TOTAЈ } \\
\hline & I & II & III & IV & $\mathrm{V}$ & $\mathrm{N}$ & $\%$ \\
\hline $\begin{array}{l}\text { Basic nursing: } \\
\text { Technical nursing }\end{array}$ & $\begin{array}{l}13 \\
12\end{array}$ & $\begin{array}{l}3 \\
5\end{array}$ & $\begin{array}{l}4 \\
9\end{array}$ & $\begin{array}{l}9 \\
7\end{array}$ & $\begin{array}{l}3 \\
8\end{array}$ & $\begin{array}{l}32 \\
41\end{array}$ & $\begin{array}{l}42 \\
53\end{array}$ \\
\hline Affective nursing & 2 & - & 1 & 1 & - & 4 & 5 \\
\hline N. of comments & 27 & 8 & 14 & 17 & 11 & 77 & $100 \%$ \\
\hline
\end{tabular}

In the category of basic nursing, daily hygiene needs, especially bedbathing, came in for by far most comment:

"in college you are taught to wash the patient in a particular order and change the water half-way through. This is rarely done on the ward".

"giving bed baths - not particular about doing certain things like putting feet in water - only when clinical teacher is about".

"failing to give bed-rest patients a basin at night for hands and face, or basin for hands after using commode". 
There was evidence in several comments that the respondents, a majority of whom were junior students, had failed to grasp principles (or may not have been taught principles) and their adaptation to different patients' individual needs, e.g. again re bed-bathing:

\footnotetext{
"the patient was given a basin of water and told to wash areas he could reach himself and the nurse would wash his back and other areas he could not reach".

"Oral hygiene - using gloves instead of dressed artery forceps".
}

However, there was also evidence of the persistence of soap and water methods of giving pressure area care, in spite of a number of research findings to contra-indicate this.

"Pressure care - in wards the only way is patients get bottom rubbed with soap and water, when we were taught to do two-hourly turning of patients".

In the category of technical nursing, 41 examples were given and they included evidence of both careless, and at times dangerous practice in the wards:

"Naso-gastric feed - taught to introduce slowly - a senior member of staff showed the procedure and supervised me. The feed was introduced in a $50 \mathrm{ml}$. syringe and she used the plunger to push the feed in (student's underlining). I only used that method once".

"Recently three senior members of staff showed dressing technique, all three different and one definitely not aseptic".

"Doing the medicine round, the nurse handing out drugs rarely, if ever, waits to see the patient swallowing the tablets". 
In a number of comments, such as the latter, reference was made to details of care such as a student could very easily do, or not do, as she herself decided. There was obvious influence from what was seen to be done by others, i.e. the students might be said, in several cases, to be simply conforming, rather than acting in a thoughtful way.

Temperature taking, dressings and the giving out of medicines received most comment in this category, but also mentioned were procedures such as catheterisation, and catheter hygiene, intravenous infusion, taking of blood pressure, care of chest drains, application of Kaolin poultices and many others. It was noted that, in regard to both basic and technical nursing, all respondents mentioned only procedures. There was no evidence of care of the individual patient per se.

There was little comment on nursing which could be categorised as referring directly to social and/or psychological needs of patients - (an interesting comment in itself, on both the teaching and the practice of nursing). Two of the four comments received were:

\footnotetext{
"In college always taught to give patient complete privacy - on wards half the time it is not possible".

"Carrying out a procedure regardless of protests and with no explanation".
}

Seven students mentioned 'lack of time' in the wards:

"there tends not to be enough time on the wards to do everything by the book". 


\begin{abstract}
"Bed-bathing - the way we are taught takes too long when there are half a dozen more patients still to do, and we are often reprimanded for taking too long over bed-bathing or removing stitches".
\end{abstract}

Such comments may reflect differing priorities betwixt ward sister and teacher or possibly somewhat idealistic teaching, e.g. "There is not so much rigmarole in the method used on the wards as there is in college".

\title{
Integration of Theory and Practice in Nursing
}

The remainder of the student nurse pre-experiment questionnaire dealt directly with the subject of integration of theory and practice in nursing.

Question 13 asked respondents to give their understanding of the term 'integration of theory and practice in nursing'. Some respondents saw integration as a college responsibility mainly in terms of time-tabling or ordering of theory before practice.

"learning the aim of theory behind the practice and then using the skill with the patient soon afterwards".

For some, integration was a student responsibility:

"doing practical nursing work while remembering the theoretical part, i.e. why it's being done and the correct way of doing it".

In this category, several students mentioned that integration aimed to achieve better patient care, e.g. "translating or putting into practice what we've leamed in college to benefit the patients". 
Where did respondents find theory and practice of nursing well integrated and where not well integrated? The picture given by respondents was again one which emphasised differences between wards and individual differences between students.

\section{Well Integrated parts of Nurse Education and Training}

(1) Where basic and technical nursing was practised as it was taught, it was said to be well integrated by students from all colleges.

(2) Specific links between the two environments of college and hospital were mentioned - where students, while students, were taken from one place to the other:

"In Block I, we were given notes on bedbathing and then were taken to a ward for a morning to bedbath a patient". i.e. theory was taught and followed by practice - a time-tabling exercise or teaching method perhaps, but college-instigated.

(3) Others, in more general terms, said integration was good when college teaching promoted understanding when working on wards and some, the obverse, i.e. when ward tutorials were given which linked to what had been taught in college.

Understanding was important for many respondents, albeit mainly of reasons for procedures, rather than of how an individual patient might feel or of how or what they might explain to him:

"Biology and care of a person who has had an operation and a colostomy - no good if you don't know how and why it was performed".

However, for one student, well integrated theory and practice, was linked to understanding of individual needs: 


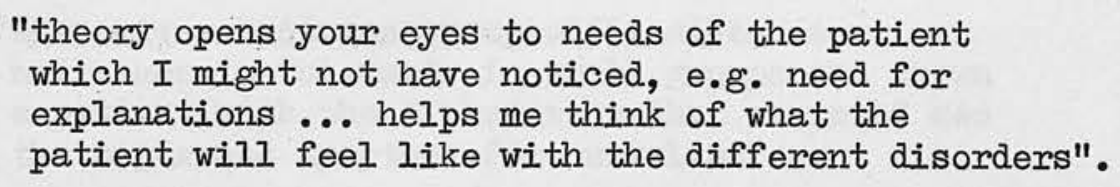

(4) Fifteen of the thirty one senior students from College III, the only students in the sample to have experienced the Block system and Study Days, commented very favourably on their experience of obstetrics and community care, when Study Days were the method of organising the theoretical component:

"we were applying what we were taught immediately afterwards, by spending one day per week in college and then practising on the wards and in the community".

\section{Lack of Integration in Nurse Education and Training}

Lack of integration was expressed by many examples which were the obverse of those given above:

(1) Where practice was not depicted realistically in the teaching:

"care of pressure areas, the passing of naso-gastric tubes when practice on a dummy is impossible".

"I think the administration of intramuscular injections was a complete shock to us, from doing it with a piece of sponge and then going on to the wards and doing it to a real patient".

The difficulty of portraying reality from the college was well expressed by the following respondent:

"Everything is easy to talk about in a warm friendly classroom, but having to do certain procedures can prove embarrassing or difficult, e.g. assisting with last offices - very hard to come to terms with".

(2) Where there was a lack of any physical link between college teaching and ward practice, where practice did not follow relevant theory: 


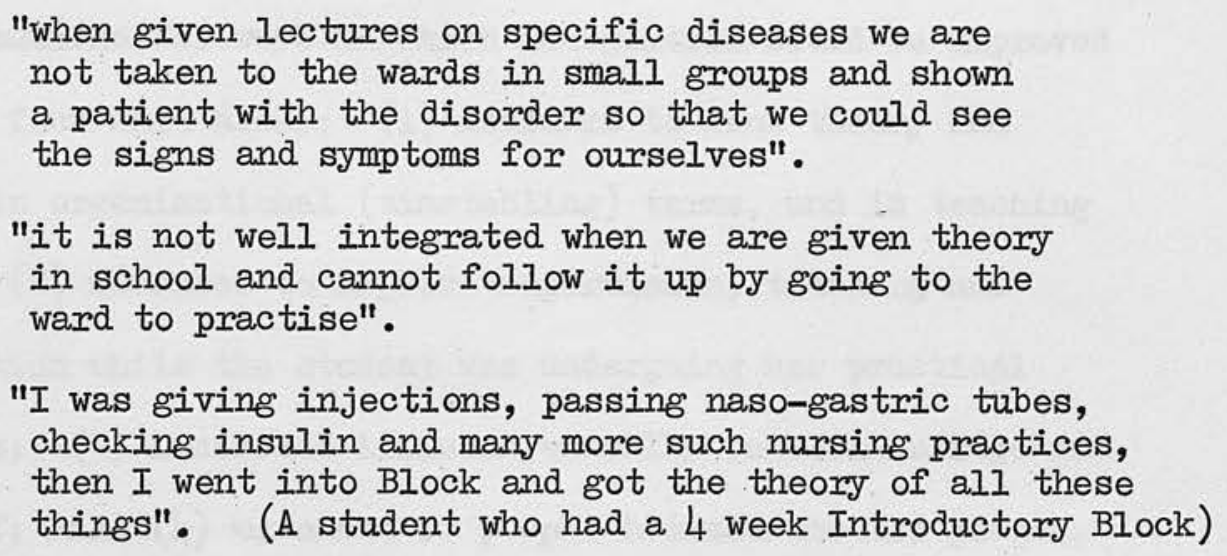

Other examples of lack of integration were when ward staff appeared to the student to be unaware of her stage of training and experience, i.e. of what she might or might not be able to do; when tutors appeared to be 'out of touch'; and when there seemed to be conflicting values betwixt the school and the ward:

"Every patient should be given individual attention and if there are problems he/she should be able to talk to the nurse - however, the nurse has no time to talk to the patient on this level at all".

"I must always be doing something - instead of spending more time getting to know the patient".

\section{Ways in which Integration of Theory and Practice could be Improved}

Improvements suggested in response to question 16 were in many cases very similar to answers given to the two preceding questions. Also, although no respondent was aware of the research experiment at this stage, nor had any knowledge of the objectives which the researcher had formulated for the experiment, analysis of responses to this question showed a marked similarity between students' suggestions for improvements and these objectives. 
Suggestions for ways in which integration could be improved fell into four main areas: (I) measures to link theory and practice in organisational (timetabling) terms, and in teaching methods; (2) measures to improve supervision, teaching and communication while the student was undergoing her practical experience; (3) increased liaison generally between college and ward staff; and (4) movement of people between the two places, i.e. college and ward in order to reduce the gap between what was taught and what was practised.

The greatest number of comments, 45 in all, were concermed with linking theory and practice:
"Arrange a nurse's training so that after lectures on specific subjects, e.g. surgical, the nurse would be sent to the wards to practise it. Often a nurse is sent to such a ward before the lectures are given and feels lost".
"During block, nurses should be taken to the wards to see patients suffering from diseases. They could be taken in small groups and the others could study in the college until they are taken. This could be done over a few days".

There were 24 comments about supervision and teaching during the practical component of training:
"More time should be given to the student while working on the ward, more clinical visits and help while working on the ward".

Liaison between college and ward brought 20 separate comments:

"By allowing all nursing staff, trained staff, sisters and nursing officers, to have seminars with the college staff on certain aspects of nurse training from time to time, along with the nurses in training, e.g. day courses". 


\section{"nurse tutors should go out to work on the wards for short spells to see exactly how things are being done".}

Other ward-related measures were felt necessary, such as meetings between senior and junior staff to discuss patients' conditions and progress and maintenance of higher standards by ward staff, although three students felt maintenance of standards was a personal responsibility.

In conclusion, student nurses responded to this opportunity to give their opinions about nursing education and training, as they knew it, with interest and in quite a number of cases enthusiasm. Many took time and thought to give copious comments. In addition to answering the questions, 62 students (52\%) gave additional comments. The researcher was impressed by the responsible way in which these young people responded - and by the many times, in discussion with the groups afterwards, that students expressed their hope that their comments would help those coming into nursing in the future. 


\section{CHAPTERR 13}

\section{THE EXXPERIEANCE OF THE EXXPERTMENTTAL GROUP STUDEHNTS}

There were 43 students in the main study experimental group all of whom completed the post-experiment questionnaire. Where the post-experiment questions were identical in both Main and Pilot Study questionnaires, the opinions of the 8 experimental group students from the Pilot Study College were added to this analysis, thus giving a total of 51 students, as shown in Table 35 .

TABLE 35 Post-experiment : Students Composition of Experimental Group

\begin{tabular}{ccc} 
College/Hospital & N in Group & $\%$ of Total N \\
\hline Pillot & 8 & $16 \%$ \\
II & 12 & $23 \%$ \\
III & 4 & $8 \%$ \\
II & 11 & $21 \%$ \\
V & 8 & $16 \%$ \\
\hline All Colleges & 8 & $16 \%$ \\
\hline
\end{tabular}

\section{General Impression of Experiment}

The first question asked of the experimental group students was, quite simply, 'did you enjoy the experimental method of teaching/learning?' The response was positive - $96 \%$ of the students choosing one of the two positive categories (see Table 36). 
TABLE 36 Post-experiment : Students

Enjoyment of the Experimental Method of Teaching/Learming

Positive Response

Negative Response

Total

College/Hospital Very much Moderately Not very much Not at all Response

\begin{tabular}{cccccr}
\hline Pilot & 7 & 1 & 0 & 0 & 8 \\
II & 0 & 10 & 2 & 0 & 12 \\
II & 1 & 3 & 0 & 0 & 4 \\
III & 6 & 5 & 0 & 0 & 11 \\
IV & 7 & 1 & 0 & 0 & 8 \\
V & 6 & 2 & 0 & 0 & 8 \\
\hline Totals & 27 & 22 & 2 & 0 & 51 \\
& $(53 \%)$ & $(43 \%)$ & $(4 \%)$ & & $(100 \%)$ \\
\hline
\end{tabular}

In College I, the 12 respondents were divided, 10 to moderate enjoyment and 2 who had a negative response. In this college, students normally spent approximately two hours per morning throughout 4 weeks of their 8 week Block, in the wards, carrying out care for one patient on a medical ward and one patient on a surgical ward, and writing up a nursing care study on these two patients. Such work was seldom supervised by college staff, although clinical teachers made an effort to spend at least one, and possibly two momings with each student. Inevitably, there were students who at no time during this period saw a member of the teaching staff. Choice of patient and supervision were therefore often left to the service personnel. As the experiment took place in addition to this case study work, it may well be that these young students (six months in training) felt their time in Block was being too much eroded. Their results may support the researcher's opinion that it is necessary to vary teaching methods, as those with more limited experience of going to the wards and 
Departments of the hospital from Block were much more positive in their endorsement of the method.

Although the researcher was aware of the pitfalls in asking questions such as this first one in the experimental group's postexperimental questionnaire, it was considered justified in this study, in that a very basic factor in all learning is enjoyment of the process of learning by the student. Learning is diminished in situations which give rise to boredom or which cause 'threat to self $f^{8}$ In any evaluation done by students, however, there is the tendency to rate the programme/teaching method as satisfactory simply in order to be kind or obliging, and, in the case of this particular experiment, it should also be borme in mind that the researcher was present in the classroom when all of the student questionnaires and tests were being completed. No student was directly observed while completing any of the work, nor was she required to hand over any papers personally to the researcher.

It was apparent to several observers and to the researcher that students in the experimental group appeared, on the whole, to be enjoying the experience. Quoted below is a comment from a teacher not involved with the experimental group:

"If it can be proved that lasting learning can be equated with an enjoyable learning experience, then whatever the experimental group learned will be retained".

The next two questions were a natural progression from the first, i.e. what did students especially like, and especially dislike, about the experimental course? 
Unfavourable Aspects of the Experimental Teaching/Leaming Method

Firstly, what were their dislikes or reservations? Nine

students had none, and eleven did not like to get up early.

Experimental group students began their day one to one and a half

hours earlier than on a normal Block day, and therefore than their colleagues in the control group. They did of course have a correspondingly early finish to their day, but there would seem no doubt that one advantage of the Block system in the students' eyes, is that it provides a later start to the day. This seemed a very natural comment, and was made by 11 students.

Lack of time was mentioned by 17 students, and there seemed little doubt that this was a problem for some of the students on some of the days. Even when two nurses shared the care of one patient, there were occasions when the students felt rushed.

"We did not have enough time to do everything we would like to have done and having to care for a patient only for two hours did not give us enough time to get to know him".

"There wasn't much time to look at notes, but that is really no great complaint as the patient told us most of the history".

The students were not only camrying out total patient care, but also had to read and then copy notes from the Kardex, and the patients' case history folder. For junior students, the latter was not a particularly familiar document. On a very few occasions, they were not familiar with the ward, and then it could take them a little longer to find equipment. Some of the students were 
carrying out care, such as dressings, of which they had no previous practical experience, and this therefore took longer than had they been skilled. The students who were concermed over lack of time were distributed evenly throughout all but one of the colleges. In College III, where the students were more experienced and senior, only one felt there was insufficient time to carry out the care required by the patients.

A feeling of a lack of security was reported by four respondents ( 3 from College I) as they had "fewer notes" than normally. Conversely, five students said that there was too much writing to do - and they cited the completion of the nursing care plans.

There was no doubt that the existence of a control group, imagined to be continuously writing down copious notes, heightened the feeling of lack of notes for some of the experimental group:

"I felt a bit insecure about lack of notes/theory compared to the control group at first".

"There was not enough time to carry out everything that was supposed to be done and all the screeds of notes that we were missing over in the school of nursing".

"I felt that we had to do too much writing and that this part of the experiment was very tiring, although I did learn by writing things down".

Three students commented upon feeling ill at ease because of the presence of the tutor, e....:

"Being with the tutors. They made me feel ill at ease and this I think affected my relationship with the patient. I do understand that they must be present". 
Favourable Aspects of the Experimental Teaching/Leaming Method

Most frequently mentioned (by 37 students) was the method of leaming. Among the many descriptive terms used were 'seeing', 'doing', 'talking over', 'associating', 'drawing together', 'finding out' - in other words, the active learning:

"I liked being able to take care of one patient without being too rushed, and I liked trying to join up what I had been taught in class with what I was seeing on the ward".

"You could see what you were discussing which made the theory easily understood and easy to remember".

"It drew together all the nursing care and the theory behind it for an individual patient".

"It brought out all the simple little things that made everything fit in".

Active experiential learning was often linked with the opportunity for patient contact. There seemed little doubt that many students were in their element in the wards, and contrasted this favourably with the classroom alternative. This patient contact was mentioned by 28 students:

"Working with patients, letting them explain their condition and how they feel, instead of being lectured to all the time".

"The work with patients, and leaming from their personal experiences, and the case notes, was easier than reading from books and was easier to understand".

Fifteen comments related to the teaching method, i.e. the students enjoyed the smaller groups, the use of less formal teaching methods and the contact with the individual tutors. 


\footnotetext{
"The idea of small study groups is good, as it encourages people to learn more, also they have to read more as they cannot hide behind others".

"I liked being on the wards with the patients, and also the discussion-type lectures which the students took an active part in".
}

\section{Fffect of Fxperimental Method on Patients}

Most students (35) commented that patients appeared to enjoy receiving the individual attention and having someone interested especially in them, but also, and a sign of sensitivity by the students, 18 said that there were patients who seemed to enjoy giving, i.e. they felt proud and pleased to help. It was most interesting, that, without putting it directly into words, students referred not only to the fact that they were meeting the patients? very basic physical needs for care and comfort (and for some who were very $i l l$ and weary it was simply that), but also that for some patients they were meeting needs of a higher order (cf. Maslow). It appeared that, by means of this experimental teaching/leaming method, needs for self-esteem, so often not met in hospital, were being met. Patients were enabled to feel useful, and important.

"I think the patients enjoyed it as they usually feel helpless, and I think they enjoyed being a part of something and helping".

"They enjoyed the attention, and they too were able to learn about their condition".

"The patients enjoyed the feeling of being useful, and they liked the total patient care and having the chance to talk".

"They felt very important because they could teach us". 
Two other effects upon patients were noted-(I) in the students' opinion, the patient was given a higher standard of care and in the main this was felt to be due to the lack of rush and to the individualised attention, and (2) in some cases, the students felt anxious lest they might have overtired the patient. In illustration of the latter point, one student said:

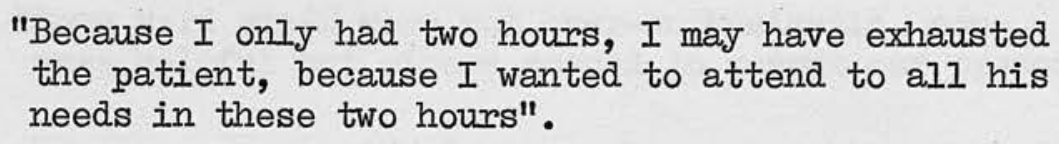

This aspect was commented on by 5 students, and in each case they were referring to their care of particularly ill patients who had required extensive dressings as well as total basic care.

The comments to this question provided evidence to suggest that, simply by altering the method of delivery of patient care from the fragmented task assignment model to the total patient care model, students were enabled to become aware of, possibly more sensitive to the patients' needs for rest. The possibility that their own well-intentioned efforts to 'care' may have detrimental effects for the patient is less easy to observe in a task assignment method of organisation.

\section{Fffect of Experimental Method upon Wards and Ward Staff}

The students were anxious not to cause disruption in the wards and several had mentioned this in preliminary discussions with the researcher. In the event, their fear that if the ward was busy they would be an upset to the routine was not borne out by the 
comments made. Rather, the opposite occurred in that the negative comments came from the lightest (in terms of workload) areas. As a result of strike action having reduced the number of patients, in two of the hospitals, students may have felt they were taking away experience from the ward student nurses and this may have been at the root of the following comment: "Some ward staff were not over-enthusiastic, some
were helpful but others seemed to resent our presence".

Most of the students felt they had been of help to the ward staff in that their presence on the ward led to some relief of the workload. A number added that ward staff seemed interested in and curious about the new method while others said they did not seem to notice anything untoward.

\footnotetext{
"For some reason or other I was quite surprised at the friendly atmosphere which was always there. Staff were most helpful".

"They liked the idea of the integrated nursing and teaching aspect".
}

One possible 'spin-off' effect was given by one student:

"I think they felt they had to be on their toes because the tutors were coming into the wards".

\section{How much was Learmed}

Question 5 asked whether students thought, by combining college and ward work as they did in the experiment, that they had leamed more, less or just the same as with the usual teaching methods. 
TABLE 37 Post-experiment : Students

How much was Learned with Fxperimental Method

\begin{tabular}{ccccc} 
Colleges & More & Same & Less & Total \\
\hline Pilot & 7 & - & - & 7 \\
II & 7 & 4 & 1 & 12 \\
II & 3 & 1 & - & 4 \\
III & 10 & 1 & - & 11 \\
IV & 8 & - & - & 8 \\
V & 7 & 1 & - & 8 \\
\hline & 42 & 7 & 1 & 50 \\
& $84 \%$ & $14 \%$ & $2 \%$ & $100 \%$ \\
\hline
\end{tabular}

The student who felt she had learned less was one of the two who in answer to question 1 had said she had not enjoyed the experimental method very much. Reference to this student's choice of lecture preferences in the pre-experimental questionnaire showed that she had a markedly different patterm of response from that of the sample overall - her first, second and third choices were of college-based lecture methods. Her fourth and fifth choices were the two study methods. Her seventh or second last choice was of ward tutorials. For this student, therefore, the experimental course (a) deprived her of lectures whilst her class colleagues received them, and (b) added an extra period away from college (she was a student in the college where it was the practice to have Block students attend the wards to camry out nursing care studies). She also said that the experiment coincided with a week of particularly onerous home commitments which restricted her ability to use methods of study which she normally found helpful. An exception - in this sample - but what is perhaps surprising is that 
she was the only exception and that there were no others who felt this method gave rise to less leaming. This student's final comment at the end of her questionnaire showed that she valued college, and also reinforced her dissatisfaction with anything which reduced time in college:

"Why not allow 'school' to be school, where we can learn and study".

She also suggested, as a means of raising standards of care in the wards:

"the answer would be for all third year nurses to go
through Introductory Block again just before qualifying".

There must have been others who preferred to remain in college, yet who, like the above student, were randomly allocated to the experimental group, yet they do not stand out in any way from the generally positive response to this teaching/learming method. The other student who in question I had not enjoyed the experimental method very much, had learned more, and also would like to see the method repeated. Of those 7 students who learmed the same as with more usual ways, 4 felt the method ought to be repeated in other subjects, 1 was unsure and 2 said no because:

"I cannot really commit myself until I see the results of the test".

The other felt the method was suitable for the gastro-intestinal system nursing as it covered such a wide spectrum of diseases but she would confine it to that one subject because: 


\footnotetext{
"it took up time and I think more studying has to be done outside of classwork which is another reason for confining this teaching to one subject".
}

Evident in the above two comments was the slight apprehension or fear of 'threat to self', and in the latter, the feeling that the experimental method, if extended, might engender too much work, or involvement in and responsibility for one's own learning.

\section{Supervision}

Table 38 showed replies to the question "with regard to the supervision you received while giving nursing care, do you think you required more, less or was it just right?"

TABLE 38 Post-experiment : Students Amount of Supervision

\begin{tabular}{ccccc} 
Colleges & $\begin{array}{c}\text { It was } \\
\text { just right }\end{array}$ & $\begin{array}{c}\text { More } \\
\text { required }\end{array}$ & $\begin{array}{c}\text { Less } \\
\text { required }\end{array}$ & Total \\
\hline Pilot & 5 & - & 2 & 7 \\
I & 8 & - & 4 & 12 \\
II & 2 & - & 2 & 4 \\
III & 8 & 2 & 1 & 11 \\
IV & 6 & 1 & 1 & 8 \\
V & 3 & - & 5 & 8 \\
\hline & 32 & 3 & 15 & 50 \\
& $64 \%$ & $6 \%$ & $30 \%$ & $100 \%$ \\
\hline
\end{tabular}

of the three students who felt more was required, 2 were from the senior group in College III. of the 15 who would have preferred less, all but 1 came from the students who had been only 
6 to 8 months in training and had practical ward experience of only $2 \times 8$ week periods. The reasons given as to why less was required, were that supervision was not necessary for basic care ( 5 students), that it made the nurse feel self-conscious ( 8 students), and in some cases was detrimental to student/patient relationships. Two students who said they felt self-conscious under supervision had previously said that they disliked the closer involvement of the tutor, which was a necessary part of the experimental method.

Some answers were most revealing of the dearth of ward teaching 'supervision' experienced by these very junior student nurses:
"At first it was difficult to work with supervision because I am not used to it, but it makes you more aware of yourself and the patient and gets rid of previously learnt bad habits". (Researcher's underlining)
"Supervision to do a bedbath or dressing seemed to be a waste of time since we have been doing these sorts of things by ourselves for the last 7 months". (i.e. 2 × 8 week periods on wards, the rest in Block)
"Supervision tends to make me nervous and therefore I can't talk freely with the patient. I don't think supervision is necessary for basic nursing care".

There were 13 positive comments, stating supervision aided leaming and helped the student gain confidence:

"Under supervision I noticed that I leamed more and had reasons for doing things, whereas most of the time I've been in the wards I just did things just for doing them".

"I felt I wanted to be supervised - tutors were very willing to do so, e.g. the removing of sutures, and I appreciated the fact that they trusted me and let me do my basic nursing care relatively unsupervised". 


\section{Fffectiveness of Experimental Method}

Question 7 asked about the effectiveness of the experimental method of teaching/leaming compared to the college-based methods. The method did place students in direct experiential confrontation with what was to be learned - for most ( 45 students) this was very effective, for two students, it was not, and three students were non-committal.

"I was able to understand better than I think I would have in the classroom. I was able to put a face to the disease we covered remembering in the patient's words what he had told me".

"Everything is much clearer when you can ... speak to patients who have had the condition/operation".

"For me, not as effective - felt a lot of it was irrelevant, i.e. an hour to bed-bath a patient taught me nothing about his ca. stomach".

The above comment indicated that many students do have to be taught to 'learn how to learn' from their daily work with patients. Indeed some respondents wrote of their difficulties in seeing what there was to learn at the beginning of the experiment, but that this resolved after a day or two.

Most equated effectiveness with active experiential learning, with easier recall, and the fact that they were more involved with their own learning.

"This method of learning is very effective for me personally, as I can learn things easier when I see it in practice rather than just being told about it. Also I learned how to deal with the patient in these situations".

"It has stuck with me, e.g. less learning from books". 
"I found I was reading textbooks more thoroughly and making better notes than I had been before. I could relate signs and symptoms better".

"Whch more effective. I found it a lot more interesting and even studied a bit more at night and read up a bit more of what we learned that day".

Should the Experimental Method be repeated for any other Subject in Nurse Education?

TABLE 39 Post-experiment : Students Should the Fxperimental Method be repeated?

\begin{tabular}{cccc} 
Colleges & Yes & No & Total \\
\hline Pilot & 8 & - & 8 \\
I & 9 & 3 & 12 \\
II & 3 & - & 3 \\
III & 11 & - & 17 \\
IV & 7 & 1 & 8 \\
V & 7 & 1 & 8 \\
\hline & 45 & 5 & 50 \\
& $90 \%$ & $2 \%$ & $100 \%$ \\
\hline
\end{tabular}

Again the response was very positive (see Table 39). The recurring theme was of learning by doing, and of the advantages to remembering and understanding in linking practical nursing with theory.

The patients too would benefit thought the undernoted enthusiastic young student:

"The patients would feel special and the leamers would feel they have achieved something after carrying out the necessary care for their individual patient. Also any mistakes made could be rectified easier and quicker as it would be easier to know who nursed that patient, thereby leaming more". 


\section{Meeting of Objectives}

As a part of the evaluation of the experimental teaching/ learning method, 5 specific objectives were presented to the experimental group students in question 9. They were asked to state whether the experimental method met these objectives 'more', 'Iess' or 'no differently' than other teaching methods which they had experienced in their nursing education. At no time prior to this had the students known about or seen these objectives. Their evaluation is given in Table 40.

\section{TABIE 40 Post-experiment : Students}

\section{Achievement of Objectives of Experimental Method}

Objectives

1. Integrate theory and practice in nursing +

2. Help you to relate theory and practice in nursing

3. Prepare you to return to work in the wards

4. Stimulate interest in your studies

5. Fnable you to take part in class discussions

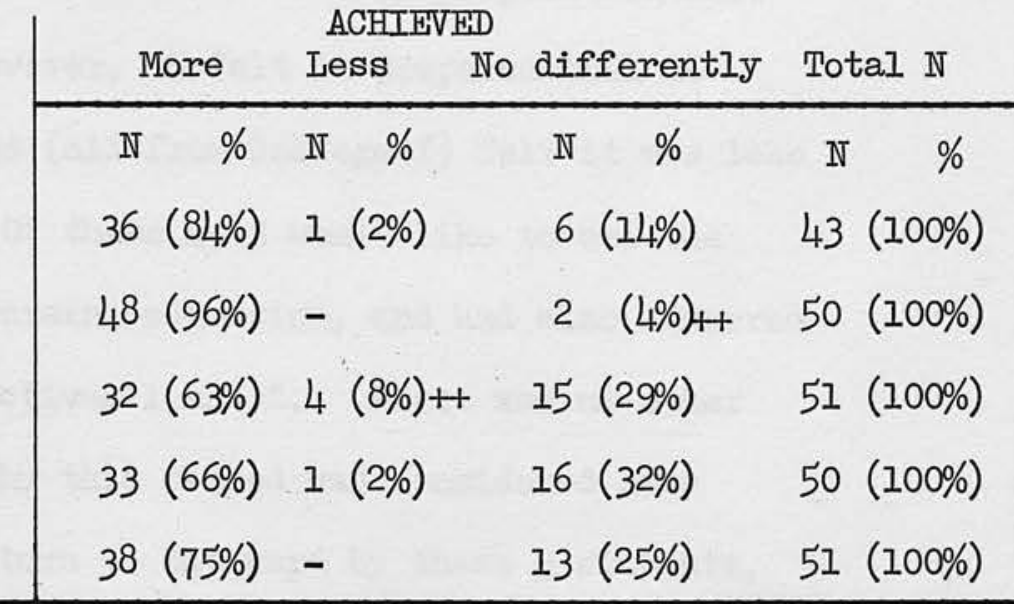

$+=$ Not asked in Pilot Study

++ All from College $I$

The principal aim of the research was to integrate theory and practice in nursing, and two objectives were framed to try to evaluate this most important aspect. The first was a statement in impersonal terms, the second was in personal terms, with underlining to stress this, i.e. help you to relate theory and practice in nursing. 
The achievement of both these objectives was strongly endorsed. In particular, the picture in the individual colleges showed that objective 2 had a unanimously positive evaluation in 4 Main Study Colleges and in the Pilot Study College. The two respondents who felt there was no difference were both from College I.

An important aim in all of nursing education is to prepare the student to return to work in the wards. Whether the experimental method achieved this more, less or no differently than other teaching methods the student had experienced was evaluated in responses to objective 3. Again, a clear majority of students considered the experimental method achieved this preparation more than the other methods. However, 15 felt it prepared them no differently and 4 respondents (all from College I) felt it was less effective in preparation. of these 4,3 would like to see the method used again in their nursing education, and had also answered positively in regard to objectives 1 and 2. There was no other evidence in the data as to why this method was considered less effective preparation for return to the ward by these 3 students, although it did seem that for two, the paucity of their notes was a problem.

The experimental method was evaluated as more stimulating of interest in their studies by 33 students. The fact that 16 students found it no more, and no less stimulating of interest than other methods may be because a majority of student nurses are, in any case, already interested in their studies. The within-colleges 
composition of the total evaluation of this objective showed that the Pilot College and College IV were each 100\% positive in their evaluation, while the other colleges were more evenly divided between the choices of 'more' or 'no differently'.

For 38 students, the experimental method enabled them to take more part in class discussions. For 13 this was no different.

Of the 38 who said they took more part, 30 had responded to the question about participation in class discussions in the preexperiment questionnaire - 3 already participated often and 9 fairly often, but 18 had previously participated rarely.

of those 13 who evaluated this objective as 'no differently' 7 were in any case often or fairly often taking part in class discussions, but 6 were rarely able to do so. For those latter students, therefore, the experimental method did not lead to any increase in their participation, in spite of the fact that more overt opportunity for participation was provided, (a) in the more informal methods of teaching which dealt with subject matter directly relevant to work the students had just been involved in, and (b) in the smaller group teaching.

\section{Total Patient Care or Task Assignment}

Students in the experimental group at no time went on to the wards to carry out specific procedures or tasks per se. They went in order to give total nursing care, to patients whose disease conditions were such that they linked directly with the students? 
current lectures. While in the wards, experimental group students worked in pairs. On some momings, a pair of students would share the care of one patient; on others, depending upon the amount and type of care required by the patients, the students might have one patient each. Two criteria were equipoised in making the decision about choice and number of patients - the students' learning needs, and the patients ${ }^{\text {? }}$ needs for care. After the experience of the experiment, students were asked 'if you had a choice between giving total patient care to a few patients, or giving patient care by task assignment, which would you prefer and why?

There was an overwhelming preference for total patient care. Only 1 student preferred task assignment and she said this was because "you learn more by trying to cram several subjects together at one time".

The 49 students (98\%) who opted for total patient care said this was better for the patients and also for the learners. 32 comments related to improved patient care, and 36 to enhanced learning for the students (the number of comments exceeded 49 as several students made more than one comment). Again the value of experiential learning was emphasised. Students also said that total patient care increased their job satisfaction and facilitated the teaching of junior nurses. Students' attitudes to their patients were revealed in these replies. Many set a value upon individualised care, i.e. attention to individual needs, upon a closer nurse/patient relationship, getting to know the patient, 
taking time with patients, and in some responses, contrasted the two forms of delivery of care to the detriment of task assignment. Two students used the factory and assembly line analogy in relation to task assignment. All quotations began:

"I prefer total patient care because..."

"... you get to know at least some of the patients this way; by task assigmment - none of them well. Also task assignment tends to be less interesting".

"... you become more concerned and involved with the patient rather than the tasks to be done".

One student, while seeing the advantage to the patient in total patient care, also showed her awareness of the inherent risk for the student of becoming ' too involved':

"... because we could learm the patient's needs and this would help the patient. However this would involve the risk of getting too involved with one patient".

"... you are more aware of the patient and you can meet his needs more fully as you see one need following on from the other. Also it is easier to meet his mental and social needs as you are communicating for a longer time".

"... as you could treat them more as individuals and get to know them better and you could carry out your own standard of nursing care to these patients".

These results indicated that, for some of the students in the experimental group, the affective objectives listed at the close of the learning objectives for the experimental course (see Appendix III) were achieved, i.e. they assigned a value to individualised care: 
"I prefer total patient care because having done task assignment, it is very apparent that patients are treated more as an individual with total patient care (not one number on a bathing list). They benefit more, in that the nurse has time to make more observations and the nurse then gets to know more about specific care of condition more easily". 
Erratum: Pagination incorrect - numbering omits Pages 330-339 


\section{CHAPTER 14}

\section{THE EXPERIEHNCE OF THE CONTROL GROUP STUDENTS}

A short questionnaire was given to all those class members who had remained in the college of nursing, i.e. the control group. Although there was essentially no change in their course content, or in the number of hours spent on the subject matter, it would have been unrealistic to consider this group's experience to have been totally unaffected by the research experiment. The class size was reduced, and certain unusual features were imposed upon the control group timetable. Doctors' lectures, and the related nursing lectures on care of patients with gastro-intestinal diseases were separated by more days than might have been the case in normal circumstances, in that approximately two-thirds of the medical staff lectures were given before the nursing lectures began. This was the case of course for both groups and was in order that the experimental group students did not go on to the wards without prior theoretical background. The nursing lectures, as a result, were concentrated into a shorter space of time and took place during the 4 to 6 days of the experiment - for the control group this was, as a general rule, in the first two periods and the last period of each day - with slight variations in each college.

Table 41 shows the composition of the control group for the purposes of this qualitative analysis only, i.e. students with previous nursing experience who were excluded from the test scores data were not excluded from the opinion questionnaire results. 
TABLE $4 I$ Post-experiment : Students

Composition of Control Groups

\begin{tabular}{llll} 
Colleges & Basic RGN & Previous nursing experience & Response $\mathbb{N}$ \\
\hline * I & 14 & - & 14 \\
II & 5 & 1 & 6 \\
IV & 15 & 8 & 23 \\
V & 11 & 2 & 13 \\
\hline & $45(80 \%)$ & $11(20 \%)$ & $56(100 \%)$ \\
\hline
\end{tabular}

* No control group in College III

Of the eleven students who had previous experience of the course material, three were previously enrolled nurses, six were re-sitting part of their course and two had other relevant experience from Degree courses in nursing. There was no control group in College III.

\section{Expressed Preference for Control or Fxperimental Groups}

The first question put to the control group students was whether, if the opportunity arose again to take part in a similar experiment, they would prefer to be in the experimental or control group, or not to take part. Table 42 showed that, of those who chose one or other group, $69 \%$ would prefer to be in the experimental group, and this proportion was higher in College V (85\%) than in any other college. 
TABLE 42 Post-experiment : Students

Control Group - Expressed Group Preference

EXXPRESSED PREFERENCE

To be in

To be in

College Experimental group Control group Total

\begin{tabular}{cccc}
\hline II & 7 & 6 & 13 \\
* & 4 & 2 & 6 \\
IV & $I 5$ & 7 & 22 \\
V & 11 & 2 & 13 \\
\hline & 37 & 17 & 54 \\
& $69 \%$ & $31 \%$ & $100 \%$ \\
\hline
\end{tabular}

* No control group in College III

NF 56 as 1 student "did not know"

1 student preferred not to take part

There was no apparent reason why this college should differ. All students there commented that they preferred to learn by 'doing' or 'seeing', but this was the general theme of all the answers to this question. Several students commented that they would like the opportunity to compare the two different ways of learning:

"It would be a chance to see if it helped me to learm more. It would also give me some idea how to approach patients with different conditions".

"I would like to compare the two methods of teaching and assess which I found most beneficial".

From those 17 students who preferred to remain in the control group, the reasons given were that they would have more notes, that they preferred what they were used to, and that they felt apprehensive if they did not know the outcome of something new. 


\footnotetext{
"Compared with the experimental group, we have more notes to look back on in later years".

"I learn better sitting at a desk with a tutor".

"I'd rather be doing what I'm used to, the experimental group didn't know the outcome of this, and it is an important subject".
}

Two students, diametrically opposed in terms of the amount of work they themselves preferred, commented in regard to the amount of involvement and work they thought the experimental method required:

The pro-control group viewpoint:

"I don't think I would like to take part in the experimental group as I feel I would have too much work to do on my own, therefore I would prefer not to take part".

The pro-experimental group viewpoint:

"I feel that I would have enjoyed learning in a situation where I would be using the skills I have already and building on them in a real situation. I think I would be more involved in my education in the experimental group".

It is interesting that these two control group students, with only 'hearsay' knowledge of the experimental group experience, had comprehended and commented upon one of the fundamental learning differences between their own teaching/leaming experience and that of the experimental group.

In summary of the comments to this question, it seemed that those who would choose to try out the experimental group were curious and/or preferred to learn by doing - the experiential or 
active form of learning; whereas those who preferred to be in the control group gave reasons which suggested that they were happier with the rather more passive type of teaching/leaming which predominated in the classroom. A most interesting factor emerged in support of this summary on examination of the rank ordering of the methods of teaching/leaming listed in question 5 of the student nurse pre-experiment questionnaire. Those who preferred to remain in the control group were the only group to deviate from the pre-experimental sample norm, whether viewed over all five colleges of the main study, or within each college, in that they did not place ward tutorials at the head of the ranks as the 'best liked method'. This was their fifth choice and they accorded first equal ranking to two classroom-based methods, 'lectures with time for questions or discussion' and 'practical classes which include demonstrations and opportunity to practise'. However, they were in agreement with the pre-experiment sample norm for the three least popular methods, i.e. guided study, straight lectures and self-directed study.

Figure 45 shows the lecture preferences for those who preferred to remain in the control group compared to that of the pre-experiment sample over all five colleges, and indicates the degree of agreement within the former group (Kendall $\mathrm{W}=.31$ ), a result which was unlikely to have occurred by chance $(p=<.001)$. For these students therefore, to remain in the classroom may have posed less 'threat to self' and given the security of the status quo - a not unnatural need, but at the same time also given more opportunity to experience their preferred teaching/leaming methods. 
Figure 45 Post-experiment : Students

Preference Profile - Methods of Teaching/Leaming. Pre-experiment Sample Compared with Post-experiment those preferring Control Group

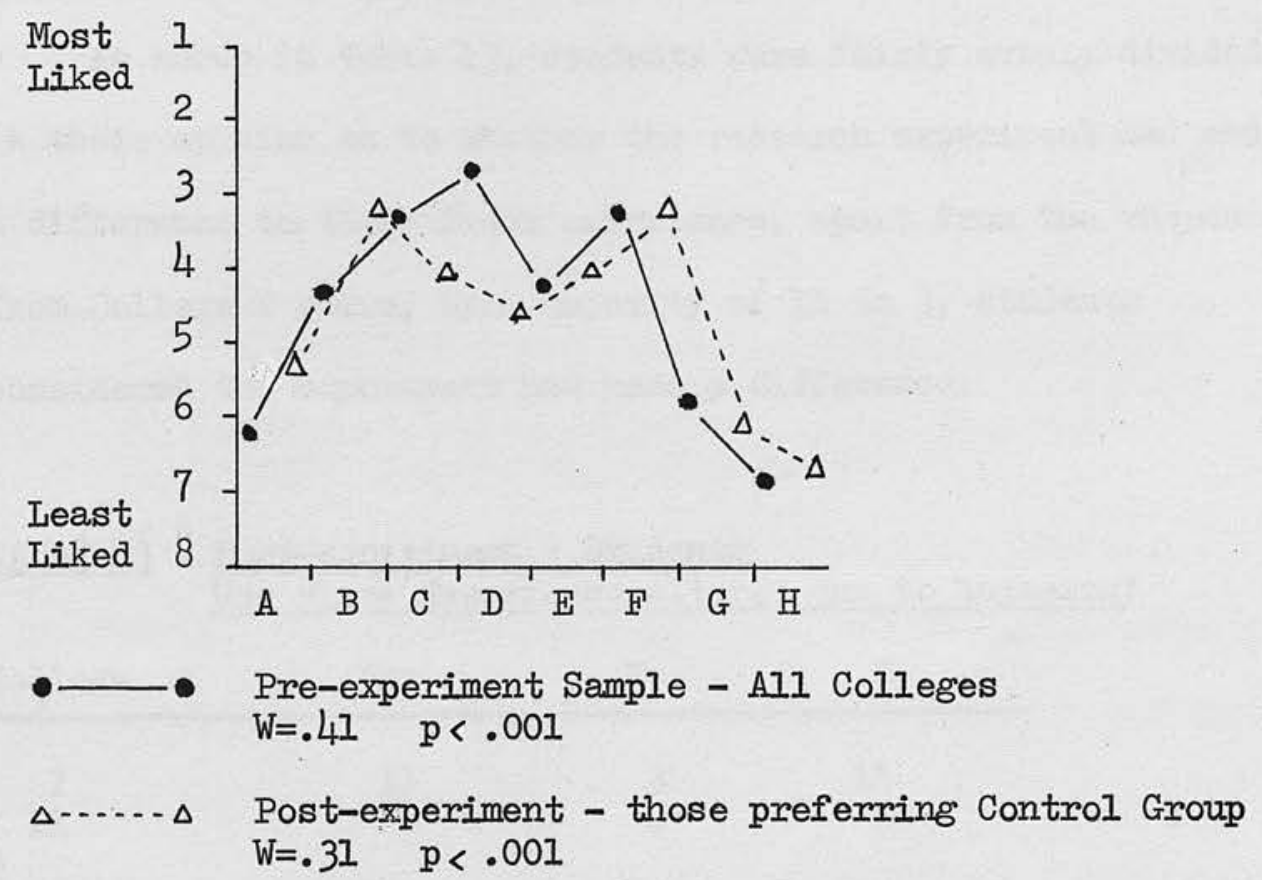

Those who 'preferred to be in the experimental group' demonstrated a similar patterm of teaching method preferences to the pre-experiment sample, and when the responses of the two discrete groups of actual control and experimental students were examined, their rankings also conformed to the pre-experiment sample - a point in support of the effectiveness of the randomisation process used in the allocation of students to these groups. It is interesting to conjecture whether, had the experimental group been formed of volunteers, those electing to 
remain in college would have shown the teaching/leaming method preferences of the slightly deviant group above.

\section{Effect of the Experiment upon Block Experience}

As shown in Table 43, students were fairly evenly divided in their opinion as to whether the research experiment had made a difference to their Block experience, apart from the respondents from College I where, by a majority of 11 to 3 , students considered the experiment had made a difference.

TABLE 43 Post-experiment : Students Was Block Experience altered due to Research?

\begin{tabular}{cccc} 
College & Yes & No & N \\
\hline I & 11 & 3 & 14 \\
* II & 2 & 4 & 6 \\
IV & 13 & 10 & 23 \\
V & 5 & 7 & 12 \\
\hline Total & $31(56 \%)$ & $24(44 \%)$ & $55(100 \%)$ \\
\hline
\end{tabular}

* No control group in College III

Of the comments to this question, 21 gave evidence of Hawthome effect, e.g.:

"It made the Block more interesting - something different, which enabled you to concentrate more because you felt you were of importance and helping some people. It also made me study at night, which I probably would not have done if it was not for the experiment". 
There was also evidence that the differences were seen to have a negative effect. There were 11 comments in this category, 9 of which came from College I. In this college, control group students described their own experience as "boring", "too much information all crammed together", "little attempt was made to vary the programme and teaching methods" and one student:

"I think this experiment caused a bit of interference and upset to the class. Also I felt more resentment towards my work, I felt as though I was being cheated in my learning as I know I have great difficulty in learning anything from intensive formal lectures. I also felt that since it was an experiment then it wasn't so important to learn my work".

The type of teaching methods experienced by the control group students during the period of the experiment may have influenced their perceptions of whether the effects of the experiment were positive or negative. The only instruction which had been given to the control group teachers by the researcher was that they should carry on with their teaching of the subject using, as far as possible, the methods they normally used. Reference to Chapter 11, Page 247, will show that in College I, $81 \%$ of the hours were spent receiving lectures with some opportunity for question or discussion. By contrast, a majority of respondents in the other large college in the Main Study made positive comments to this question, and again, on reference to Page 268, it is seen that a variety of teaching methods were utilised for the control group students in College IV. One of their comments was: 


\begin{abstract}
"More group work took place" ... "There was more practical and discussion time instead of always having formal lectures".
\end{abstract}

This was the college in which teachers said it was their practice to use more variety of teaching methods for this particular subject 'as it is such a heavy one'.

A few students had worked harder as a result of the experiment, one as a result of what she felt was a bad result on the pre-test; others said they worked less because of factors connected with the experiment.

Seven students commented upon the advantages of the smaller classes, and said this led to "a better staff/student relationship", "more personal". One student expressed disappointment that, al though the class size was reduced, no advantage was taken of this, i.e. no tutorials or discussions, and a laconic comment from one who felt the experiment made little difference:
"Block this time has just been the same as any other Block - except that the classes were smaller - and that was much better".

\title{
Should the Experimental Method be used in Nurse Education?
}

29 (52\%) of control group respondents felt they did not know whether or not the experimental method should be used in their education as nurses, and most of these students commented either that they did not know exactly what had been involved, or that they would prefer to wait to know the results before coming to a decision. $22(39 \%)$ said they would like to see it used and in all cases commented in favour of the method of leaming: 


\begin{abstract}
"I think it would be an excellent idea to link up college work with actual work on the ward. You would see and work with what you had just been taught".
\end{abstract}

Some said that it would depend upon the tutor/student ratio being suitable, and a few respondents added quite lengthy comments as to how in their opinion it might be achieved for all students.

5 students (9\%) of the control group said they would not like the experimental method to be used. Some reasons given were that they already got enough ward experience, that the student would have too much work to do 'in her own time' and to one student it seemed unrealistic:

\footnotetext{
"Two nurses, concentrating on one patient, doing procedures which are correct - you are rarely able to put this into practice on the ward, because you haven ${ }^{2} t$ got the time".
} 


\section{CHAPTWER 15}

OPINIONS IN RETROSPECT - EXPERTMIENTAL GROUP STUDENTS

At a date suitable to each college, and usually at the beginning of the students' next theoretical component or Block, the researcher administered the Retention of Learning tests, and, to experimental group students only, a brief follow up questionnaire.

Table 44 shows the number of students who gave their opinions of the experimental method in retrospect, and also the number of intervening weeks in each of the colleges, from the time of the experiment to the date of completion of the questionnaires.

TABLE 44 Retention Stage : Students Composition of Follow up Group by College and Number of Intervening Weeks from Experiment to Follow up

\begin{tabular}{llrr} 
College & Weeks intervening & \multicolumn{2}{c}{ Students } \\
& & Total & $\%$ \\
\hline Pilot & 29 & 12 & 16 \\
I & 27 & 4 & 83 \\
II & 16 & 11 & 21 \\
III & 22 & 8 & 16 \\
IV & 24 & 8 & 16 \\
V & 21 & 51 & $100 \%$ \\
\hline
\end{tabular}

It was interesting that, in spite of the passage of time, ranging from 16 weeks in College II to the maximum of 29 weeks in the Pilot College, the experimental group remained intact. The students did not know beforehand that the researcher was to appear on that day, therefore the numbers do not reflect any special effort to be present. 
The purpose of this questionnaire was to examine student opinions of the experimental method of teaching and learning about nursing in the light of their intervening practical experience.

\section{General Impression}

The first question was similar to that which introduced their post-experiment questionnaire, but this time asked "Looking back on it, did you enjoy that method of teaching/learning?" Comparison of Table 45 with Table 36 shows that responses remained fairly stable. Only four students had changed their opinion - two students in College $I$ and $I$ in College $V$ each had a more positive view. This small group included one student who had been the least satisfied of all experimental group students with the experimental method. One senior student from College III had a slightly less positive view.

TABLE 45 Retention Stage : Students

\section{Enjoyment of the Experimental Method in Retrospect}

Positive Response Negative Response Total

Colleges Very much Moderately Not very much Not at all $\mathbb{N}=$

\begin{tabular}{|c|c|c|c|c|c|}
\hline $\begin{array}{l}\text { Pilot } \\
I \\
I I \\
\text { III } \\
\text { IV } \\
\text { V }\end{array}$ & $\begin{array}{l}7 \\
1 \\
1 \\
5 \\
7 \\
7\end{array}$ & $\begin{array}{r}1 \\
10 \\
3 \\
6 \\
1 \\
1\end{array}$ & $\begin{array}{l}- \\
\overline{1} \\
- \\
- \\
-\end{array}$ & $\begin{array}{l}- \\
\overline{-} \\
\overline{-} \\
\overline{-}\end{array}$ & $\begin{array}{r}8 \\
12 \\
4 \\
11 \\
8 \\
8\end{array}$ \\
\hline Total & $\begin{array}{l}28 \\
55 \%\end{array}$ & $\begin{array}{l}22 \\
43 \%\end{array}$ & $\frac{1}{2 \%}$ & - & $\begin{array}{c}51 \\
100 \%\end{array}$ \\
\hline
\end{tabular}




\section{Recall of Information}

One way in which the effectiveness of learming can be assessed is to make some quantitative measure of the amount of relevant information which can be recalled. This is usually done in the form of a test, and immediately prior to completing the questionnaire, respondents had worked through the two retention of learning tests, from the results of which it was possible for the researcher to make a reasonably objective measure of their ability to remember information taught and learned during the experiment.

T he students' subjective assessment of their ability to recall was sought in the answers to the second question of the follow-up questionnaire, which asked them whether, as a result of the experimental method of teaching/learning, they felt that they had remembered more, less or much the same as they did with the more usual method.

Twenty nine students (57\%) felt that they had remembered more, 21 (43\%) that they had remembered the same and one (2\%) that she had remembered less.

\section{Total Patient Care}

Since their experience during the experiment, twenty three (45\%) students, from five of the six colleges, had had the opportunity to practise the method of giving nursing care used then, i.e. total patient care. The other twenty eight (55\%) had not. Further details on this question were not available from Pilot Study questionnaires, but were available from the main study. For seven of those twenty 
three who had given total patient care, this had been in only one ward, but for seven it had been in two different wards medical, surgical and specialty wards were mentioned. Seven of the students had been 'specialling' a patient when carrying' out total patient care. *

In three hospitals, those attached to Colleges III, IV and V, seven students said that they had worked on wards where sister organised the nursing by means of total patient care, but another six students, again from these same three colleges, had instigated this method of carrying out nursing care themselves, because they preferred to do it in this way.

"On night duty you were your own boss and you could run the ward and care for your patients as you felt".

"Whenever I had been left in charge of the ward, I always preferred, if possible, that the same nurse did as much for the patient at the one time, rather than having different nurses coming backward. and forward to carry out different procedures. I feel the patients appreciate total nursing care given by the one nurse at one session".

It is perhaps revealing of the system of nurse training that both the above students were one year and one month in training. However, it is also of interest that almost half of this small sample of students had worked in a situation where nursing care was

* The term specialling is used to denote that one nurse is responsible for all the care required by one patient, usually someone who is very ill, and that the nurse is not responsible during that time for the care of any other patient. 
organised with the emphasis on total patient care, rather than on the long dominant model of task assignment.

\section{Fffect of Experimental Course upon subsequent Nursing}

Mindful of the fact that the principal aim and function of nurse education is to prepare the student nurse for the work she must do, i.e. nursing, the final question asked experimental group students whether or not the experimental course had helped them in their nursing.

By a convincing majority, in all but one of the colleges, the course had helped. Forty (78\%) students recorded a positive response. In the Pilot College and Colleges IV and $V$ of the Main Study this was a unanimous decision. Two of the senior students in College III, one student in College II and seven students in College I made a neutral response - the course had had no effect for them. One student, again from College I, said that the course had created difficulties. There was unfortunately no clue as to these difficulties, as, although the student did add a comment, this was only about the experimental method per se:

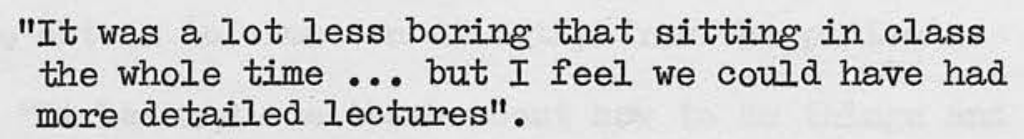

The response patterm to this question from students in College I was totally at variance with that of all other colleges, indeed the responses from students in College I had been quite different from the others on a number of occasions. There were two factors 
pertinent only to the students from this college which may have been of some influence on their opinions of the experimental method. As previously mentioned (see Page 310), firstly, the experimental method had been superimposed upon a Block programme which already included sessions when the students worked in the wards caring for two patients on whom they subsequently wrote up care studies. Secondly, College I students had no option to abstain from participation in the research.

From 39 of the 40 students who felt that the experimental course had helped them in their nursing, there was a wealth of comment available. Several had found it easier to learn and remember what they had been taught in college and use this knowledge in their work. They felt they understood their patients' conditions more fully. Some said they now took much more interest in their work, e.g. when a patient was admitted they would read up about his condition in case notes and books and could study more. Two students did mention that they felt there were some gaps in notes, and knowledge about certain diseases, which had not been dealt with in their course. Some mentioned that the course had increased their ability to obtain information directly from the patients.

"It has made me think about how to do things and why I do what I am doing and I don't have to keep asking about things because I can work them out for myself better".

"It has helped me to think more about how the patient's condition relates to his care - what he can do without causing pain, how long he needs total care and when he is able to do things for himself. Also to think more about why I am doing things and what the consequences will be if it is done properly or if he is given inadequate care". 
As nurses, many found it had affected their attitudes and approach to patients, and had improved their personal standards of nursing care. They felt they now nursed more efficiently, understood the importance of the patient as a person, the advantages of planned and organised care and of performing the entire care required by a particular patient "instead of doing one part and hoping someone else will do the rest".

"It has helped in viewing the patient as a whole
person more. Though that was always the intention,
in the experiment I realised how often patients are
left ignorant of what is happening in and being done
to their bodies. That there still is a lack of
communication between nurses and medical staff as to
how much the patient knows, who told them, and has
anyone bothered, thinking someone else has".

The experimental method had also helped some students in dealing with patients ${ }^{2}$ relatives, and others said that they gained in confidence. One student illustrated this in regard to being in charge of a surgical ward on night duty and being able to think back to similar situations in dealing with patients on the experimental course.

Two students 8 comments referred specifically to effects of their experience not just upon themselves but upon others:

"My own personal standards are higher than they were and I hope it has rubbed off on some of the others".

This student had already found that some of the other nurses in the ward would not accept her way, nor the way they had been taught. A final percipient comment: 
"Although being part of the experiment has helped me in my nursing, on some occasions when certain procedures have been carried out in the wards I tend to feel I would like to change the system which I suppose could lead to problems". 


\section{CHAPTEER 16}

\section{WARD SISTER AND STAFF NURSE OPINION QUESTIONNATRE RESULTS} PRE- EXPERTTMERINT

The ward sister and staff nurse opinion questionnaire was issued to all trained staff working in the general medical and surgical wards of the hospitals which provided the practical experience for students from the five colleges of nursing included in the research experiment. Each hospital was identified by the same Roman numeral as its associated college, e.g. Hospital I is the hospital for College I. However, seven hospitals appear listed below in Table 46 , because, for Colleges I and III respectively, two hospitals were available and utilised to provide the general medical and surgical experience for the experimental group students. The results from these A and B hospitals were seldom markedly different from each other, therefore they were reported separately only on those few occasions when they did differ.

\section{Characteristics of the Sample}

Table 46 shows the distribution of the three grades of trained staff in the sample, throughout the hospitals. 
TABLE 46 Pre-experiment : Ward Trained Staff Distribution of Sample by Staff Grade and Hospital

\begin{tabular}{|c|c|c|c|c|c|}
\hline Hospital & $\begin{array}{l}\text { Ward } \\
\text { Sisters }\end{array}$ & $\begin{array}{l}\text { Staff } \\
\text { Nurses }\end{array}$ & $\begin{array}{l}\text { Enrolled } \\
\text { Nurses }\end{array}$ & $\begin{array}{c}\text { Total } \\
\mathbb{N}\end{array}$ & $\%$ \\
\hline $\begin{array}{ll}\text { I } & A \\
\text { II } & B \\
\text { III } & A \\
\text { IV } & B \\
\text { V } & \end{array}$ & $\begin{array}{r}19 \\
1 \\
9 \\
4 \\
2 \\
18 \\
14\end{array}$ & $\begin{array}{r}73 \\
7 \\
13 \\
11 \\
5 \\
24 \\
11\end{array}$ & $\begin{array}{l}- \\
- \\
- \\
7 \\
5 \\
1 \\
-\end{array}$ & $\begin{array}{r}92 \\
8 \\
22 \\
22 \\
12 \\
43 . \\
25\end{array}$ & $\begin{array}{r}(41 \%) \\
(4 \%) \\
(10 \%) \\
10 \%) \\
(5 \%) \\
(19 \%) \\
111 \%)\end{array}$ \\
\hline Totals in each Grade & $\begin{array}{l}67 \\
30 \%\end{array}$ & $\begin{array}{l}144 \\
64 \%\end{array}$ & $\begin{array}{l}13 \\
6 \%\end{array}$ & $\begin{array}{l}224 \\
100 \%\end{array}$ & (100\%) \\
\hline
\end{tabular}

Within the total sample number of 224 trained staff, there were six male nurses - five charge nurses and one staff nurse, from two hospitals, i.e. IV and V.

Figure 46 indicates the length of time in their present grade of the ward sisters and staff nurses. 
Figure 46 Pre-experiment : Ward Trained Staff cumulative Percentages of Numbers of Trained Staff and Length of Time in Present Grade
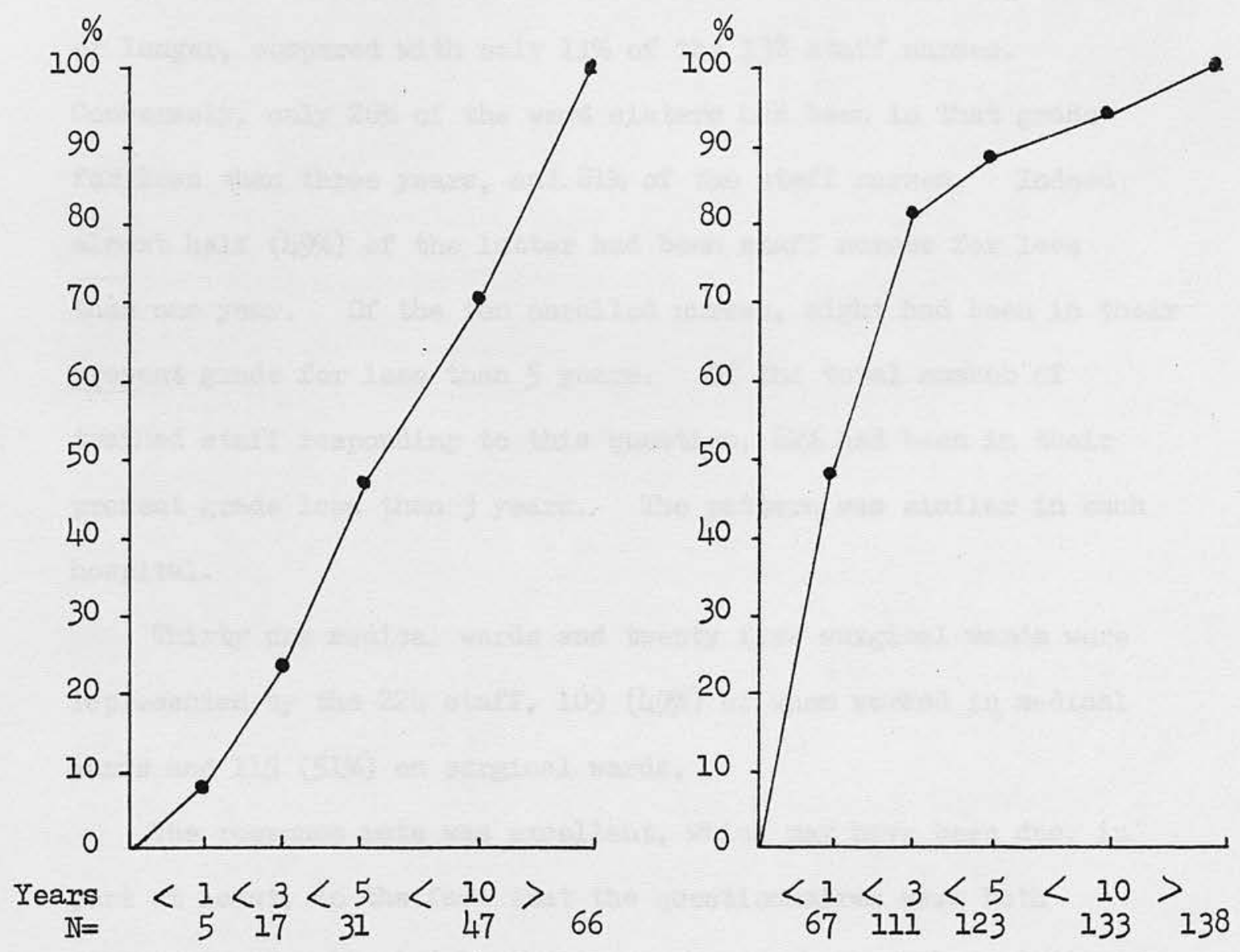

WARD SISTERS 
There was a very different composition of these two grades of staff in the sample, in terms of time-span in present grade. Of the 66 ward sisters, $53 \%$ had been in that grade for five years or longer, compared with only $11 \%$ of the 138 staff nurses. Conversely, only $26 \%$ of the ward sisters had been in that grade for less than three years, and $81 \%$ of the staff nurses. Indeed almost half (49\%) of the latter had been staff nurses for less than one year. Of the ten enrolled nurses, eight had been in their present grade for less than 5 years. Of the total number of trained staff responding to this question, $62 \%$ had been in their present grade less than 3 years. The pattern was similar in each hospital.

Thirty one medical wards and twenty five surgical wards were represented by the 224 staff, 109 (49\%) of whom worked in medical wards and 115 (51\%) on surgical wards.

The response rate was excellent, which may have been due, in part at least, to the fact that the questionnaires were both delivered and collected by the researcher on her regular visits to the wards.

The response was as follows:

$\begin{array}{ll}\text { Hospital I } & -93 \% \\ \text { Hospital II } & -100 \% \\ \text { Hospital III } & -92 \% \\ \text { Hospital IV } & -96 \% \\ \text { Hospital V } & -93 \%\end{array}$


Ratios of Staff to Leamers and Stability of Staff and Student Numbers

Reported ratios of staff to learners (i.e. both student and pupil nurses) were never lower than $1: 2$ and in a majority of both medical and surgical wards these ratios ranged from $1: 1.5$ to 1 : 1. Fluctuations in numbers of trained staff were reported as rare by a large majority in Hospitals I, II and V although the picture in Hospitals III and IV was of slightly more frequent fluctuations.

Ninety three per cent of the sample reported fluctuations in learmer numbers as occurring often or fairly often. It was not possible to deduce from the data the extent of fluctuation from week to week in any one ward. However, in one hospital, the senior nursing officer offered the researcher figures pertaining to this, for four surgical wards, each of 23 beds. The figures related to the three months prior to the research and showed a weekly variation in the student allocation numbers to these 4 wards as follows:

$$
\begin{aligned}
& \text { Ward A - between } 3 \text { and } 8 \\
& \text { Ward B - between } 4 \text { and } 9 \\
& \text { Ward C - between } 5 \text { and } 9 \\
& \text { Ward D - between } 4 \text { and } 8
\end{aligned}
$$

\section{Ward Teaching of Students}

The first question to introduce this subject sought opinion as to whether the student nurse should receive teaching while working on the wards, i.e. in the apprenticeship part of her training. It was felt that there might be some, in the profession, who did not 
agree that this should be done. This was thought to be a possibility because of the recurring appearance, in the nursing journals, of complaints by learners about the dearth of ward teaching, and that little encouragement was given to students to ask questions on some wards. However, there was no evidence at all of doubt about whether ward teaching ought to be given, in so far as this particular sample was concermed - 223 responded and unanimously answered 'yes'.

Both teaching methods given in the text of this question were considered appropriate to ward teaching by 191 (86\%) of the sample, i.e. (a) practical demonstration and/or supervised practice and (b) tutorials. However, 30 respondents (12 ward sisters, 15 staff nurses and 3 enrolled nurses) felt ward teaching should be only by demonstration and/or supervision.

By whom should Ward Teaching be Done?

The responses to the two questions on this subject were summarised, and are shown in Table 47 below:

\section{TABLE 47 Pre-experiment : Ward Trained Staff Responsibility for Ward Teaching}

Ward Joint - education Education Service Response

Main responsibility Responsibility 
(a) The Main Responsibility

When asked who should take the main responsibility for this ward teaching, 73 respondents named only the clinical teacher, while a further 68 felt this should be shared between the clinical teacher and the ward trained staff. Three respondents, all staff nurses, included the other student nurses as sharing this main responsibility. Sixty eight did not include any teachers among those mainly responsible and forty of this number confined ward teaching responsibility to the ward sister or staff nurse. Only fifteen respondents (7\%) mentioned the Registered Nurse Tutor - two staff nurses felt the RNT alone should take the main responsibility, three respondents felt the tutor and clinical teacher should share the main responsibility, and ten that it should be shared between the RNT, the RCT and the ward trained staff.

(b) Responsibility if no clinical teacher available

For those respondents who had chosen the Registered Clinical Teacher as being mainly responsible for ward teaching, or as sharing the main responsibility with others, the next question asked who should assume this responsibility if no clinical teacher was available, i.e. if none were on the staff, or there were too few to work in each ward of the hospital? of 137 responses, 123 (90\%) stated ward teaching of students should then be the responsibility of ward trained staff. Sixty three of these respondents mentioned only the ward sister and staff nurse, eight (four each from Hospitals IV and V) said only "the Unit Nursing Officer" and the remainder included all ward trained staff with two again including the student 
nurses. Only fourteen respondents (10\%) gave any ward teaching responsibility to the other grade of teacher, the RNT. Five (four ward sisters and one staff nurse) gave her sole responsibility, in the absence of a clinical teacher, and nine felt the RNT and ward trained staff should share responsibility. The summary in Table 47 indicates that, while 156 respondents saw the college teachers as having some share in the main responsibility for ward teaching, 68 did not see education (college) staff as having any responsibility for this. Of those respondents who included the RCT in their allocation of main responsibility, 137 replied to the question of who should be responsible "if no RCT was available", and very few indeed saw the RNT as having any role as ward teacher.

\section{Involvement of Ward Trained Staff in Ward/College Teaching of Students}

Respondents were asked how often they personally were involved in teaching student nurses, in any of three given areas their own ward, other wards and in the college of nursing. If they were so involved they were asked to explain what they did.

\section{(a) Teaching in other Wards}

There was comparatively little teaching done by ward trained staff in wards other than their own. Only six respondents from Hospitals I and III considered they taught fairly often in other wards - one sister, three staff nurses and two enrolled nurses. Twenty five respondents from all hospitals and all three staff 
grades acknowledged teaching in other wards, but rarely. The only explanation offered as to the form of this "other ward" teaching was that occasionally tutorials were given on "chosen subjects" to students from a small number of adjacent wards or from a unit, e.g. "cardiac arrest".

\section{(b) Teaching in College}

Only 9 out of the 224 ward trained staff taught in the college of nursing - 4 fairly often and 5 rarely. Those respondents came from Hospitals I and IV and one from Hospital III(B).

(c) Teaching in own Wards

From 222 responses, only 2 (both from staff nurses in Hospital I), indicated no involvement in teaching within their own wards. The pattern of response, in terms of frequency of teaching, was similar in all hospitals and results were therefore amalgamated in Table 48.

TABLE 48 Pre-experiment : Ward Trained Staff Frequency of Teaching in own Ward

\begin{tabular}{lcccc}
$\begin{array}{l}\text { Frequency of } \\
\text { teaching }\end{array}$ & $\begin{array}{l}\text { Ward } \\
\text { Sister }\end{array}$ & $\begin{array}{l}\text { Staff } \\
\text { Nurse }\end{array}$ & $\begin{array}{l}\text { Enrolled } \\
\text { Nurse }\end{array}$ & $\begin{array}{l}\text { Frequency } \\
\text { Totals }\end{array}$ \\
\hline Often & 40 & 67 & 5 & 112 \\
Fairly often & 24 & 60 & 8 & 92 \\
Rarely & 2 & 14 & - & 16 \\
Never & - & 2 & - & 2 \\
\hline Total Respondents & 66 & 143 & 13 & 222 \\
\hline
\end{tabular}


When a weighted score was attached to the frequencies, exactly in the manner described on Page 283, it was possible to calculate a percentage score for the contribution to ward teaching by the above staff grades, and in Figure 47 this is shown, to the right of the score attributed to the ward sister and the staff nurse by the student nurses (extracted from Figures 37 and 38 ).

Figure 47 Pre-experiment : Ward Trained Staff Weighted Score Contribution to Ward Teaching, compared with Student Perception of same

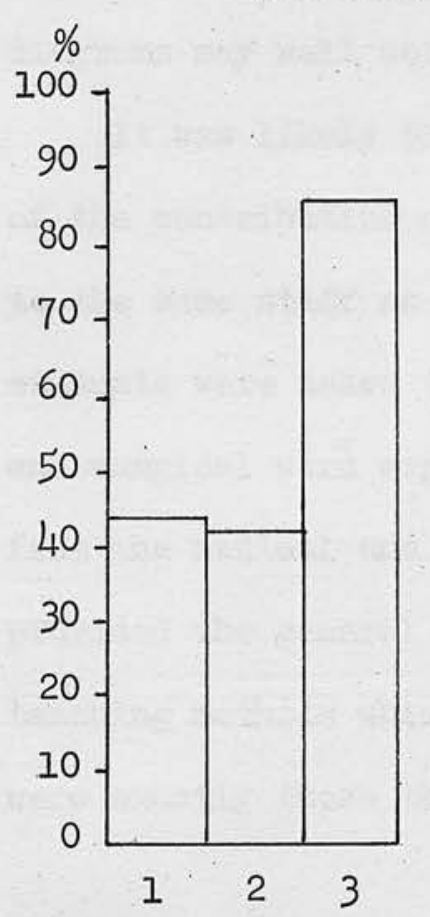

WARD SISTHERS

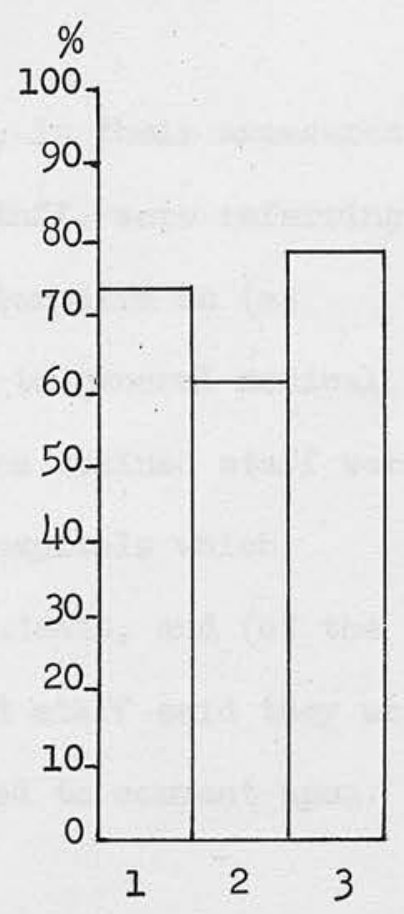

STAFF NURSES

Key: $1^{*}$ = Score accorded by students - re supervision and/or practical demonstration

$2^{*}=$ Score accorded by students - re tutorials

3 = Score accorded by staff member, e.g. ward sister or staff nurse Information for 1 and 2 above extracted from Figures 37 and 38 
Ward sisters were shown to perceive their contribution to ward teaching as considerably more than was thought by the students, whereas staff nurses were somewhat more in line with what was adjudged by the students. However, the comparison in Figure 47 should be viewed bearing in mind that there were twice as many staff nurses as there were ward sisters in the general medical/surgical wards represented in this sample. Thus, if more people were available to be seen by the students as contributing to, or providing the teaching, then these column diagrams may well not indicate any anomaly.

It was likely that many of the students, in their assessment of the contribution of these two grades of staff, were referring to the same staff as responded to this questionnaire as (a) students were asked to direct their thoughts to general medical and surgical ward experience only, (b) all the trained staff were from the medical and surgical wards of the hospitals which provided the general experience for these students, and (c) the teaching methods which a majority of the ward staff said they used were exactly those the students had been asked to comment upon. 


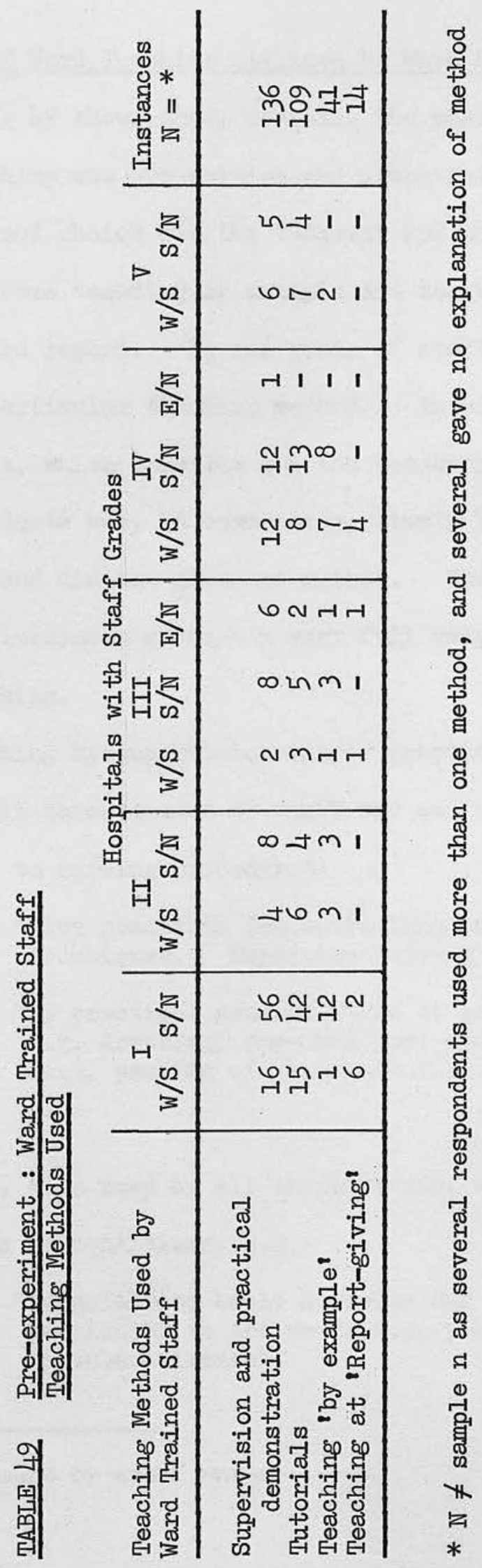


Methods of Ward Teaching utilised by Ward Staff

Table 49 shows that, overall, the most popular method of ward teaching was supervision and practical demonstration. A close second choice was the tutorial and less frequently reported were teaching by example and teaching during the giving of the ward report. No one grade of staff was found to favour any one particular teaching method. In addition to the above categories, which describe how the teaching was done, there were 21 respondents who, in commenting, simply listed procedures taught by them, and did not give any method. There were thus 321 separate instances given - a very full response in explanation of ward teaching.

Teaching by supervision and/or practical demonstration was used by all three grades of staff and was mainly explained with reference to nursing procedures:

"Give practical demonstrations of surgical techniques. Supervise nursing procedures". S/N *

"By practical demonstration of procedures, e.g. dressing, pre- and post-operative care, passing of naso-gastric tubes etc."

Tutorials, also used by all three grades, were sometimes on procedures or conditions, e.g.:

"Tutorials on basic subjects and items particular to the ward, e.g. peripheral vascular disease". 
In addition a number of responses in this category referred to the patient rather than a procedure, e.g.:

"We discussed a certain patient who has undergone surgery. We start with the anatomy right through the pre- and post-operative care, until the patient is discharged. This way they can relate their lectures to practical nursing".

There was evidence of organised planning of teaching sessions:

"Tutorials for at least 5 hours per week, every week, plus a nursing care plan in operation".

Many mentioned the influence of time, especially with regard to tutorials:

"Give tutorials when ward is quiet - about
conditions of patients in the ward at that time" -
and this is one of those few who are also
teaching in "other wards - "occasionally give
tutorials about cardiac monitoring or cardiac
arrest to staff from other units".

Teaching by example was not often elaborated upon, however, teaching at report-time had a more articulate devotee:

"Giving a full report and teaching session when giving the ward reports. Giving time for discussion with all grades of staff at this time. I feel the Ward Report is a very important teaching factor".

This particular method was mainly mentioned by the ward sister grade. Only $2 \mathrm{~S} / \mathrm{Ns}$ and one $\mathrm{E} / \mathrm{N} *$ said they taught by means of the Report.

W/S - Comment by ward sister or charge nurse

$\mathrm{E} / \mathrm{N}$ - Comment by enrolled nurse 
Teaching by example was perhaps the method least likely to be appreciated, or seen as teaching, by some leamers.

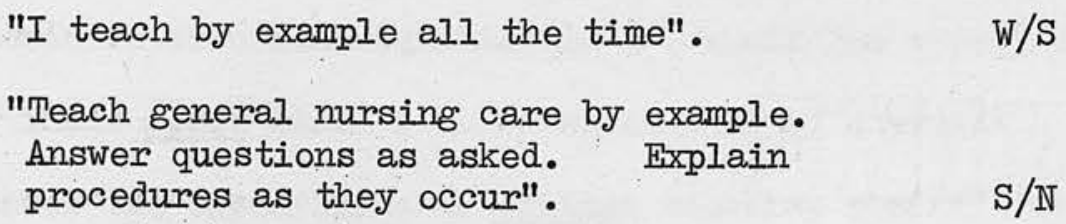

Such methods depend, for their use and their usefulness, upon the learmer being able, or feeling free, to ask the question or to see the example. Also it is hardly realistic to expect that a 'good' example can be set at all times.

\section{Ward staff Perceptions of Frequency of College Staff Involvement} in Ward Teaching

Ward sisters and staff nurses were asked how often college staff were involved in teaching student nurses in their wards.

Their responses conformed to the patterm shown in the students results. Ward staff considered the major contribution by the trained teachers was made, not surprisingly, by the clinical teacher. The contribution to ward teaching of the two grades of nurse tutor was small. The senior tutor, in all but Hospital V, was deemed to contribute less to the ward teaching than the RNT. There were two differences within the otherwise similar trend. In Hospital III, the tutor contribution relative to that of the clinical teacher was exceptionally low, and in Hospital IV, ward staff recorded all three grades of teacher as sharing the task of ward teaching to a greater extent than in any other hospital. 


\section{College Supervised Ward Teaching of Supermumerary Students}

Ward staff were asked the question "Do you think student nurses should receive some teaching in the wards for a certain amount of their Block time, i.e. as supernumerary students working under the supervision of college teaching staff?" (see Table 50). There was a positive reaction in that $89 \%$ were in favour. Those not in favour came from all hospitals and comprised 8 ward sisters and 17 staff nurses.

TABLE 50 Pre-experiment : Ward. Trained Staff College Supervised Ward Teaching of Supernumerary Students

\begin{tabular}{|c|c|c|c|c|}
\hline Staff member & In favour & Age & inst & $N=100 \%$ \\
\hline $\begin{array}{l}\text { Ward sisters } \\
\text { Staff nurses } \\
\text { Enrolled nurses }\end{array}$ & $\begin{array}{r}59 \\
126 \\
13(88 \%) \\
(100 \%)\end{array}$ & $\begin{array}{r}8 \\
17 \\
-\end{array}$ & $\left(\begin{array}{l}12 \%) \\
12 \%)\end{array}\right.$ & $\begin{array}{r}67(100 \%) \\
143 \\
13(100 \%) \\
100 \%)\end{array}$ \\
\hline All staff $N=$ & (89\%) & 25 & (11\%) & $223(100 \%)$ \\
\hline
\end{tabular}

Ward staff were then asked a hypothetical question, i.e. if this type of teaching became a part of the student nurses education, should it be (a) in the form of supervised nursing care given to individual patients, whose conditions linked to current lectures (b) in the form of tutorials on the wards, or (c) should it take both the above forms?

Table 51 below shows that almost half of those responding (49\%) considered such teaching should be only in the form of supervised practice. 
TABLE 51 Pre-experiment : Ward Trained Staff

Possible form of Ward Teaching of Supernumerary Students

\begin{tabular}{|c|c|c|c|c|c|}
\hline Staff Grades & $\begin{array}{l}\text { Both supervised } \\
\text { practice and } \\
\text { tutorials }\end{array}$ & $\begin{array}{l}\text { Onlj } \\
\text { prac }\end{array}$ & $\begin{array}{l}\text { supervised } \\
\text { tice }\end{array}$ & $\begin{array}{l}\text { Only } \\
\text { tutorials }\end{array}$ & $\begin{array}{l}\text { Total } \\
\text { N }\end{array}$ \\
\hline $\begin{array}{l}\text { Ward sisters } \\
\text { Staff nurses } \\
\text { Enrolled nurses }\end{array}$ & $\begin{array}{cc}30 & (48 \%) \\
67 & (48 \%) \\
4 & (31 \%)\end{array}$ & $\begin{array}{r}31 \\
66 \\
8\end{array}$ & $\begin{array}{l}50 \%) \\
47 \%) \\
61 \%)\end{array}$ & $\begin{array}{ll}1 & (2 \%) \\
7 & 5 \% \\
1 & (8 \%)\end{array}$ & $\begin{array}{r}62 \\
140 \\
13\end{array}$ \\
\hline All staff $N=$ & 101 (47\%) & 105 & (49\%) & $9 \quad(4 \%)$ & $\begin{array}{l}215 \\
100 \%\end{array}$ \\
\hline
\end{tabular}

There were 57 explanatory comments, related to (i) the advantages for the student of reinforcement in learning, e.g.:
"It is easier to relate lectures on subjects if at the same time you are involved in caring for a patient with that particular illness".
"This sort of teaching would give a student the chance to implement total patient care as opposed to performing isolated tasks".

and (ii) raising doubts lest it upset ward routine, upset the patients, or deny experience to students currently on the staff of the ward, e.g.:

"I feel patient must have certain amount of privacy, and should be nursed by people familiar to him/her".

"I think the nurse should meet the patient and talk but not do all the nursing care as the nurse doing her stint on the ward needs the experience. The case notes and $\mathrm{X}$-rays should be shown and explained". $\mathrm{S} / \mathrm{N}$

A cautionary note by one respondent:

\footnotetext{
"The college teaching staff will need to be up to date in current ward practice".
} 
Meetings between College Staff and Ward Staff

This was one of the questions where the responses from the two smallest hospitals, i.e. I(B) and III(B) differed from the general pattern as shown in Table 52 and also differed from each other. No one in Hospital I(B) met college staff often or fairly often, and ward staff in Hospital III(B) were evenly divided, $50 \%(6)$ in each of the aforementioned categories.

There was some difference between the three grades of ward staff. Proportionately more enrolled nurses and sisters felt they had contact than did staff nurses.

TABLE 52 Pre-experiment : Ward Trained Staff Frequency of Meetings with Education Staff Frequency of Meeting

\begin{tabular}{|c|c|c|c|c|c|}
\hline Staff Grade & Often & Fairly often & Rarely & Never & $\mathbb{N}=$ \\
\hline $\begin{array}{l}\text { Ward sister } \\
\text { Staff nurse } \\
\text { Fnrolled nurse }\end{array}$ & $\begin{array}{lr}4 & (6 \%) \\
3 & (2 \%) \\
3 & (23 \%)\end{array}$ & $\begin{array}{cc}13 & (20 \%) \\
17 & (12 \%) \\
1 & (8 \%)\end{array}$ & $\begin{array}{c}36(54 \%) \\
59(41 \%) \\
4(31 \%)\end{array}$ & 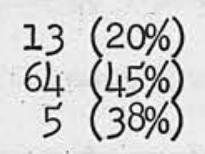 & $\begin{array}{r}66(100 \%) \\
143(100 \%) \\
13(100 \%)\end{array}$ \\
\hline All Grades $N=$ & $10 \quad(4 \%)$ & 31 (14\%) & $99(45 \%)$ & 82 (37\%) & $222(100 \%)$ \\
\hline
\end{tabular}

The use of the term "College Staff" in this question was in order to include all grades of teacher. There was thus evidence of complete lack of communication in over one-third of the total sample number and of a larger proportion in terms of staff nurses and enrolled nurses. The staff nurses were the group contributing most to ward teaching, yet according to their responses $45 \%$ of their number never met or 
consulted with any of the trained teachers. A majority of those ward staff who commented said meetings related to the assessment and/or teaching of learners. For many, this was the only contact with the teachers, which begs the question as to how much contact there might be if learners spent very much less time on the wards than they do at present. of the 63 respondents who mentioned teaching and/or assessment of leamers, 31 said this contact was only with the clinical teacher.

"When the clinical teacher comes to teach". $\mathrm{E} / \mathrm{N}$

"Contact is with the clinical teacher who spends one week in three on the ward teaching students. No contact is made with any other college staff".

Assessment was related to the progress of students and for the most part appeared to be somewhat informal. It took place mainly with clinical teachers. There was evidence, from one college, however, that efforts were being made by college staff to visit learmers during each ward experience, if possible about half way through their allocated time there - so called "interim visits" - in order to assess progress.

"Fairly often with clinical teachers, rarely with tutors, except for interim visits".

Less formal assessment of progress, e.g.:

"The clinical teacher comes to the wards and asks how the student is coping, then has a chat with the student or watches her carry out a procedure". 
There was evidence, in many responses, of visits triggered off by 'problems' or difficulties, e.g.:

"Usually to discuss poor performance or difficulties encountered by student/pupil nurse".

or

"Only if there is a "bad" student nurse".

No tutor mentioned contact with ward staff due to teaching, but all had previously answered separate questions in regard to their ward teaching, thus the omission is unlikely to be significant.

Meetings between education and service staff also took place for the purpose of up-dating knowledge. There was evidence that the clinical teacher, especially, was seen as a resource person.

"I often consult with the clinical teacher, as she can advise as to what the student is allowed to do in the ward, and is up-to-date in new methods, and can offer valuable advice".

A few comments dealt with meetings for administrative reasons, to do with learner allocation. In only two hospitals did some of the respondents mention formal meetings between education and service staff - in one, these meetings did not include staff nurses, only ward sisters. In the other the Procedure Committee was the venue of joint co-operation.

The dependence of teachers upon ward staff to 'permit' them to work with patients was inherent in the following 'purposes of contact': given by ward staff: 


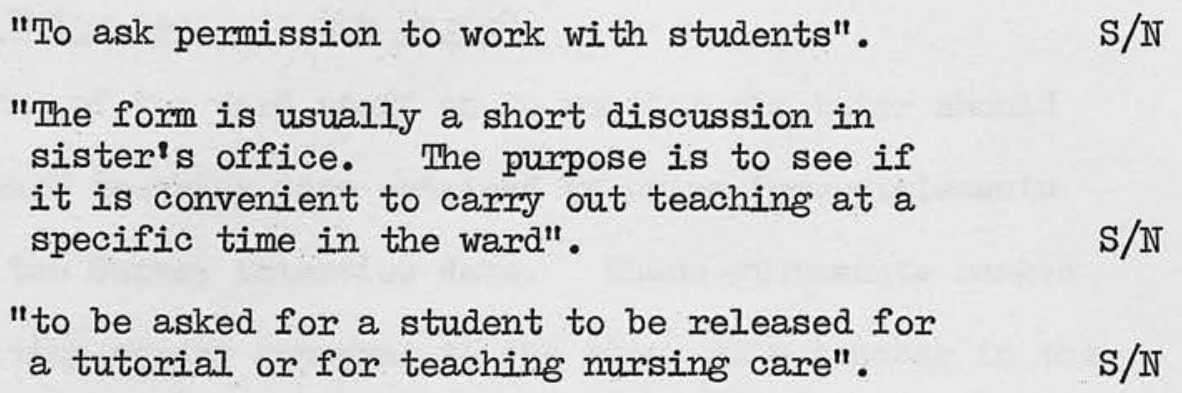

It is interesting that no teacher mentioned 'asking permission' possibly one reason was that they did not directly refer to these meetings as concermed with teaching of students.

There was no evidence of meetings or contacts initiated by the ward staff apart from the seeking of information from the clinical teacher when she was present in the ward, i.e. education had come to service in the first instance.

\section{Ward Staff Knowledge of Students' Theoretical Preparation for} Specific Ward Work

Of 223 respondents, only 65 (29\%) knew whether or not a student nurse had had the relevant theoretical preparation for the work she was required to do in their particular ward. $70 \%$ of the sample acknowledged that they did not know. These respondents were from all three grades. Enrolled nurses had not experienced the RGN programme of training, but all ward sisters and staff nurses had done so, yet 1 : 2 ward sisters, $1: 2.5$ staff nurses and 1 : 3 enrolled nurses felt they did not know whether a student had had the relevant theoretical preparation. There was no evidence of a relationship between knowledge of student preparation and length of time in grade of the respondents. 


\section{Should the Tutor teach in the Wards?}

Opinions of the ward staff as to whether the tutor should carry out ward teaching were obtained by using four statements taken from the Survey interview data. These statements ranged from one giving strong approval to the tutor as a teacher in the wards, to a completely negative attitude - see question 20, Ward Sister and Staff Nurse Opinion Questionnaire, Appendix VIII.

Table 53 shows that a positive response was received from 191 (86\%) of the ward staff.

TABLE 53 Pre-experiment : Ward Trained Staff Opinion re Thutor Teaching in Ward

Grades

Strongly Approve Not sure Disapprove $N=$
approve

Ward sister Staff nurse Enrolled nurse

10
39
5 $\left(\begin{array}{l}15 \% \\ 27 \% \\ 39 \%\end{array}\right)$

44
85
8 $\left(\begin{array}{l}67 \%) \\ 59 \%) \\ 61 \%\end{array}\right)$

$\left(\begin{array}{lll}9 \%) & 6 & (9 \%) \\ 8 \%) & 7 & (5 \%)\end{array}\right.$

A slightly higher proportion of the staff nurses and enrolled nurses, than of the ward sisters, felt strongly that the tutor should teach students in the wards.

In only one hospital was there any particular difference from the overall picture - this was in Hospital V where only 16 (66\%) felt positively towards the tutor as a ward teacher and 8 (33\%) felt unsure or completely negative. 
The Role or Function of the Tutor vis a vis the Clinical Teacher as Ward Teachers

Ward staff were asked - "Do you think there is any difference between the tutor's function as a ward teacher and the clinical teacher's function as a ward teacher?"

Table 54 shows that opinion was somewhat similarly divided on this question for ward sisters and staff nurses, whereas a clear majority of enrolled nurses considered functions did not differ between the two grades of teacher. Only in Hospital II did a majority of all respondents consider the functions did not differ.

TABLE 54 Pre-experiment : Ward Trained Staff Does difference exist between Tutor/Clinical Teacher Function as Ward Teacher?

\begin{tabular}{|c|c|c|c|}
\hline $\begin{array}{l}\text { Staff } \\
\text { Category }\end{array}$ & Functions differ & $\begin{array}{l}\text { Functions do } \\
\text { not differ }\end{array}$ & $\begin{array}{c}\text { Response } \\
\mathbb{N}=\end{array}$ \\
\hline $\begin{array}{l}\text { Ward sisters } \\
\text { Staff nurses } \\
\text { Enrolled nurses }\end{array}$ & $\begin{array}{r}37 \\
84 \\
3\left(\begin{array}{l}55 \%) \\
60 \% \\
(25 \%)\end{array}\right)\end{array}$ & $\begin{array}{l}30(45 \%) \\
56(40 \%) \\
9(75 \%)\end{array}$ & $\begin{array}{r}67 \\
140 \\
12\end{array}$ \\
\hline Totals & $124(57 \%)$ & $95(43 \%)$ & 219 (10 \\
\hline
\end{tabular}

A large majority of all those who responded perceived a clear division of role or function - the tutor was concermed with theory, the clinical teacher with practice. This was a striking finding in that it occurred in varying emphasis, in 90 of 101 responses, a number of which also added that the clinical teacher should link theory and practice. 
"I feel the tutor's function should be solely theoretical whereas that of the clinical teacher is obviously of a more practical nature in the ward situation".

"From habit, I have always expected the tutor to be more concerned with the theoretical side of nursing, e.g. anatomy and physiology, and her function is mainly that of lecturer, whereas I have always thought of the clinical teacher as being more concermed with the practical side of nursing. I think she should be responsible for relating the student's theoretical training to what goes on in the ward she (the student) is working in".

"Tutors should concentrate on theory. The marrying of theory to practice is the function of the clinical teacher".

Some respondents saw the ways or methods of teaching as different:

"As each ward differs from another - the tutor

is giving a general teaching, whereas the clinical teacher can perform specific treatments in one particular ward, e.g. preparation of patient before and after aortic surgery".

This view of the CT as a clinical expert was stated plainly by a few:

"Clinical teacher should be a clinical expert in the working area".

Two opposing viewpoints:

"There is a difference at present, but ideally I think their function should be the same".

and

"If there were adequate numbers of clinical teachers to provide the link between theoretical classroom teaching and the practical aspect, there would be few occasions for the tutor to be in the wards at all". 
There was evidence of a somewhat unrealistic view of the college or classroom, perhaps pointing to the necessity to bridge the gap and increase communication between service and education.

\footnotetext{
"The clinical teacher is at ward level - amongst the intermuptions and the complications. This is at nurse-patient level - in the classroom there is a situation of peace and calm all the time which does not always happen on the ward".
}

The Role or Function of the Ward Sister/Staff Nurse vis a vis the Clinical Teacher as Ward Teachers

Ward trained staff were asked whether they thought their function as a ward teacher differed from that of the clinical teacher. Table 55 shows that, for each grade, there is an emphatic majority opinion that functions do differ.

\section{TABLE 55 Pre-experiment : Ward Trained Staff Does difference exist between Clinical Teacher/Ward Sister Function as Ward Teacher?}

\begin{tabular}{|c|c|c|c|}
\hline $\begin{array}{l}\text { Staff } \\
\text { Category }\end{array}$ & Functions differ & $\begin{array}{l}\text { Functions do } \\
\text { not differ }\end{array}$ & $\begin{array}{l}\text { Response } \\
\mathbb{N}=\end{array}$ \\
\hline $\begin{array}{l}\text { Ward sisters } \\
\text { Staff nurses } \\
\text { Enrolled nurses }\end{array}$ & $\begin{array}{r}45 \\
100 \\
10\end{array}\left(\begin{array}{l}67 \%) \\
71 \%) \\
77 \%)\end{array}\right.$ & $\begin{array}{l}22 \\
47(33 \%) \\
3(23 \%)\end{array}$ & $\begin{array}{r}67 \\
141 \\
13\end{array}\left(\begin{array}{l}100 \%) \\
100 \%) \\
100 \%)\end{array}\right.$ \\
\hline Totals & $155(70 \%)$ & $66(30 \%)$ & $221(100 \%)$ \\
\hline
\end{tabular}

In Hospitals IV and V responses deviated from the overall trend. In the former, $58 \%$ of the 43 ward staff considered the functions differed compared with $42 \%$ who did not, and Hospital V had 
the largest majority of staff who considered functions differed, i.e. $92 \%$ of their 25 respondents. The differences in function between the ward staff and the clinical teacher, as ward teachers, were, by 83 respondents, related to the fact that priorities differed between the two groups of staff. The clinical teacher was considered to have more time to spend with the student and thus more opportunity to plan teaching.

"My first priority is the patients. The clinical
teacher's first priority is the students".
"The clinical teacher enters the ward for one
purpose only - to teach. The ward sister's
duties are many".
"The clinical teacher's responsibility is
primarily to nurses and teaching, whereas the
ward sister's is towards patients and ward
management".
"The difference lies in the fact that trained staff
may not be able to spend time in teaching due to
work pressures, and my tuition tends to be "ad
lib" - the clinical teacher can however plan and
prepare her tuition according to her assessment
of the students needs".

Forty one commented that the preparation differed - the clinical teacher was trained to teach, whereas they were not and she was also in touch with the college of nursing, by inference they were not. "She is trained to teach juniors - we are not". S/N

"Time? - and he knows how to teach and put over his knowledge to nurses. Also, his experience, on the whole will be greater than most of the ward staff". 
The background knowledge of the ward staff and the teacher differed, therefore, said 35 respondents, what they taught and how they taught differed. However, opposite viewpoints were expressed in regard to this:

"Clinical teacher will specialise in one subject at a time - whereas staff may talk of ward as a whole".

"As. a permanent member of ward team I will know more about the patients, i.e. background, temperament and previous history also about the present condition over a longer period of time. Much of this information the clinical teacher will not have therefore she is teaching about a condition and not a patient with that condition".

The clinical teacher was seen by some as a link between school and ward for the student.
"CT - helps the nurse to bring together the theoretical and practical teaching in the ward situation. Mine - help the nurses to appreciate the day to day care and management of the patients' needs and progress of their disease, or improvement". W/S
"She is a link with the students' classroom and is already known to the student - a form of continuity with the classroom".

Finally, the responses to the two questions on the functions of the ward and college staff as ward teachers were examined together. From Table 56 it is seen that 31 ward staff, $14 \%$ of those responding to both questions, saw one function for all engaged in ward teaching, while $41 \%$ saw the nurse tutor as having a different function from the clinical teacher, and the clinical teacher as having a different function from the ward trained staff. They have 
been categorised in this Table as seeing a different

function for all - but did they - that precise question was

not asked, and beneath the Table appears one young staff

nurse ${ }^{8} \mathrm{~s}$ comment.

TABLE 56 Pre-experiment : Ward Trained Staff

Perception of Function as Ward Teacher of RNT, RCT, WS and SN

\begin{tabular}{|c|c|c|c|c|c|}
\hline $\begin{array}{l}\text { Staff } \\
\text { category }\end{array}$ & $\begin{array}{l}\text { One function } \\
\text { for all }\end{array}$ & $\begin{array}{l}\text { RNT/RCT } \\
\text { same } \\
\text { RCT/WS } \\
\text { different }\end{array}$ & $\begin{array}{l}\text { RNT/RCT } \\
\text { different } \\
\text { RCT/WS } \\
\text { same }\end{array}$ & $\frac{\text { All }}{\text { different }}$ & $\begin{array}{l}\text { Response } \\
\text { N } \\
\text { per } \\
\text { grade }\end{array}$ \\
\hline $\begin{array}{l}\text { Ward sister } \\
\text { Staff nurse } \\
\text { Enrolled nurse }\end{array}$ & $\begin{array}{r}10(15 \%) \\
19(14 \%) \\
2(17 \%)\end{array}$ & $\begin{array}{c}20 \\
36 \\
7\left(\begin{array}{l}30 \%) \\
7\end{array}(58 \%)\right.\end{array}$ & $\begin{array}{cc}12 & (18 \%) \\
22 & (16 \%) \\
1 & (8 \%)\end{array}$ & $\begin{array}{l}25 \\
61 \\
2\end{array}\left(\begin{array}{l}37 \%) \\
417 \%\end{array}\right)$ & $\begin{array}{r}67 \\
138 \\
12\end{array}\left(\begin{array}{l}100 \%) \\
100 \%) \\
100 \%\end{array}\right.$ \\
\hline & 31 (14\%) & 63 (29\%) & $35(16 \%)$ & $88(47 \%)$ & 217 (100\%) \\
\hline
\end{tabular}

"I find myself teaching about medical conditions and not about practical technique - in fact doing as the tutors could be doing". 


\section{CHAPTER 17 \\ THE EXPERTMEENT - OPINIONS OF WARD TRATNED STAFF}

The experimental method of teaching/learning involved co-operation between both service and education staff, and student nurses, and no description of the results could be considered complete if it contained only the opinions of the students and their teachers. It should be borme in mind that the experiment took place over a very brief period, i.e. from four to six mornings in the various hospitals, and most of the ward staff respondents would have been involved for only some of these mormings. To off-set the brevity of the experience upon which their comments and evaluation were based, was the fact that every respondent had first-hand experience of managing her ward while the experimental group students were at work there. Each respondent had been responsible for giving, and receiving, the report of the patients cared for by the experimental group students, and had shared in the decision about the choice of patients with the researcher and teacher(s). It was considered most important that post-experiment responses should constitute a report of actual experience and not hearsay evidence, therefore ward trained staff who had been on duty, but not in charge of the ward while the students and their teacher(s) were there, were not given a questionnaire.

Sixty one questionnaires were issued and fifty eight were returned - a 95\% response rate, compiled as undernoted: 


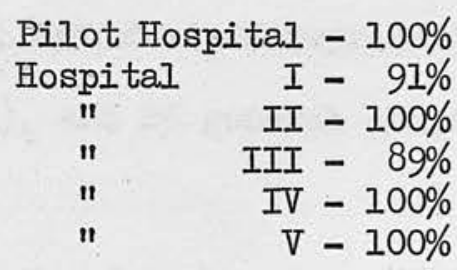

Questionnaires were individually addressed, and enclosed with each was a covering letter (see Appendix XXIX). The envelope was either handed to the potential respondent, or left for her in the Ward Duty room, from where the completed form was later collected by the researcher.

\section{Characteristics of the Sample}

Post-experiment information was available from 58 ward trained staff - 29 ward sisters, 24 staff nurses and 5 enrolled nurses, distributed throughout the hospitals as shown in Table 57. Where questions were identical in both the Pilot and Main Study questionnaires, data from Pilot Study ward staff have been included.

TABLE 57 Post-experiment : Ward Trained Staff Distribution of Sample by Staff Grade and Hospital

\begin{tabular}{|c|c|c|c|c|c|c|c|c|c|c|}
\hline \multirow[b]{3}{*}{ Staff Grade } & \multirow[b]{3}{*}{ Pilot } & \multicolumn{5}{|c|}{ HOSPITALS } & \multirow[b]{3}{*}{ IV } & \multirow[b]{3}{*}{$\mathrm{V}$} & \multirow{3}{*}{\multicolumn{2}{|c|}{$\begin{array}{l}\text { Total } \\
\text { per grade }\end{array}$}} \\
\hline & & & I & & & II & & & & \\
\hline & & A & B & II & A & B & & & & \\
\hline Ward sister & 3 & 7 & - & 1 & 2 & 2 & 8 & 6 & 29 & $(50 \%)$ \\
\hline Staff nurse & 4 & 11 & 2 & 3 & - & 1 & 2 & 1 & 24 & $(41 \%)$ \\
\hline Enrolled nurse & 1 & - & - & - & 3 & - & - & 1 & 5 & (9\%) \\
\hline $\begin{array}{l}\text { Total per } \\
\text { hospital }\end{array}$ & 8 & 18 & 2 & 4 & 5 & 3 & 10 & 8 & 58 & (100\%) \\
\hline $\begin{array}{l}\% \text { of sample from } \\
\text { each hospital }\end{array}$ & $14 \%$ & $34 \%$ & & $7 \%$ & & $.4 \%$ & $17 \%$ & $14 \%$ & & $100 \%$ \\
\hline
\end{tabular}


The 58 ward staff represented eight general medical wards (10 staff), and 25 general surgical wards (48 staff).

\section{Fffect of the Experiment on Ward Routine}

Crucial to the success of any type of ward teaching programme is that it should fit in with the ward routine. Recently, the term ward routine has been commented upon somewhat disparagingly and while, at times, it can seem to take undue precedence, it cannot be entirely dispensed with in the efficient management of a general medical and/or surgical ward. A fear expressed by both students and teachers - and no doubt in the minds of some ward staff - when the researcher first broached the possibility of carrying out the experiment was that it would disrupt ward routine.

The first question addressed to ward trained staff was "did you find the experiment in which Block students came to give care to some of your patients each morning in any way disruptive of ward routine?"

TABLE 58 Post-experiment : Ward Trained Staff Was Experiment disruptive of Ward Routine?

\begin{tabular}{lccc} 
Staff grade & Yes & No & Total \\
\hline Ward sisters & 1 & 28 & 29 \\
Staff nurses & 4 & 20 & 24 \\
Enrolled nurses & - & 5 & 5 \\
\hline & 5 & 53 & $\begin{array}{c}58 \\
(91 \%)\end{array}$ \\
\hline
\end{tabular}


Results given in Table 58 indicated very little disruption as a result of the experiment. Four of the five respondents who found it disruptive of routine came from Hospital I, and I, a staff nurse, was from the Pilot Hospital. Causes of dismuption were stated as (a) a delay in ward staff gaining the use of the bath/shower for their patients, (b) an occasion when neither the students nor their tutor were considered to be au fait with the ward and (c) that the arrival time of the experimental group students on the ward was not suitable. The latter comment was from the ward sister.

That the experiment was capable of implementation in eight different hospitals and 33 different wards and caused so little negative comment would suggest that the design details were both robust and flexible.

\section{Disadvantages of the Experimental Method}

Ward staff were asked what they saw as the disadvantages of the experimental method of teaching. A majority found none - one senior ward sister remarked only that "the newness and all the staff took us by surprise". There were in all 18 comments about disadvantages, 7 of which mentioned that there was too little time spent with the patient, and that neither students nor patients had continuity, i.e. the same students did not always return to nurse the same patient on a second day.

Other disadvantages mentioned were of unfamiliarity with the ward layout, of students being unfamiliar with the patient, that 
two very junior students were working together, and that supervision was not continuous. Two comments were in regard to ward student nurses being deprived of experience and both were from wards where there were fewer patients than usual as a result of strike action by hospital ancillary staff. From 3 comments, it was revealed that the respondents were not really aware of the students' leaming needs. One staff nurse said "The nurses will gain little idea of the work of the ward as a whole". This was not of course the purpose of the ward practice for these junior students. One sister said the teaching was unrealistic:

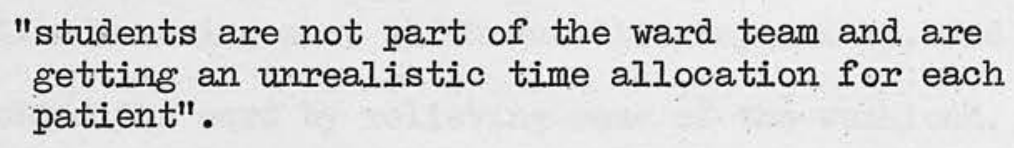
getting an unrealistic time allocation for each patient".

This comment showed a certain lack of appreciation of the fact that the student was learning as she was working, and of the fact that extra time is essential if teaching and learning is taking place. However, this same respondent saw the advantage of the experimental method in terms of the students' learning, i.e. that the students gained an overall picture of the patients ${ }^{2}$ condition which was related to lectures, which, she considered, must be of benefit.

\section{Advantages of the Experimental Method}

There were in all 76 comments about advantages of the experimental method, the majority of which referred to the enhancement of students' leaming, e.g. (a) the student was supernumerary so could 
concentrate on the patient without pressure and without intermuptions, (b) the direct patient contact gave the opportunity to relate theory to practice immediately, (c) faults could be quickly picked up and rectified, (d) the total patient care gave the nurse opportunity to develop more insight, (e) there was realistic practice, yet in a controlled situation and ( $f$ ) supervision and teaching was available from a tutor who was primarily concerned with the student and the patient she was nursing.

Several respondents felt the experimental method was of advantage to the patients, in that they benefitted from the individualised nursing care which was also supervised, and a few said it helped the ward by relieving some of the workload.
"For the patient - the advantage of the individual attention for most of the morning. For the nurses - the advantage of being able to concentrate on one patient at a time and learn as much as possible about his/her care without the distraction of other routine work".
"More time for ward staff to attend to other patients, so helping ward nurses. Giving student more of an insight into total needs and care of patient, allowing patient to help in training of nurses and allowing patient to 'give'".

"I feel it brought the nurse and tutor closer together working in a "real' situation".

\section{Should more Teaching be done in this way?}

There was very marked endorsement of the experimental method in the replies to this question. Of the 56 respondents, 52 (93\%) would like to see more teaching done in this way, and 4 (7\%), 1 ward sister 
and 3 staff nurses, would not. The 4 who preferred not to have the experimental method repeated were quite clearly against change:

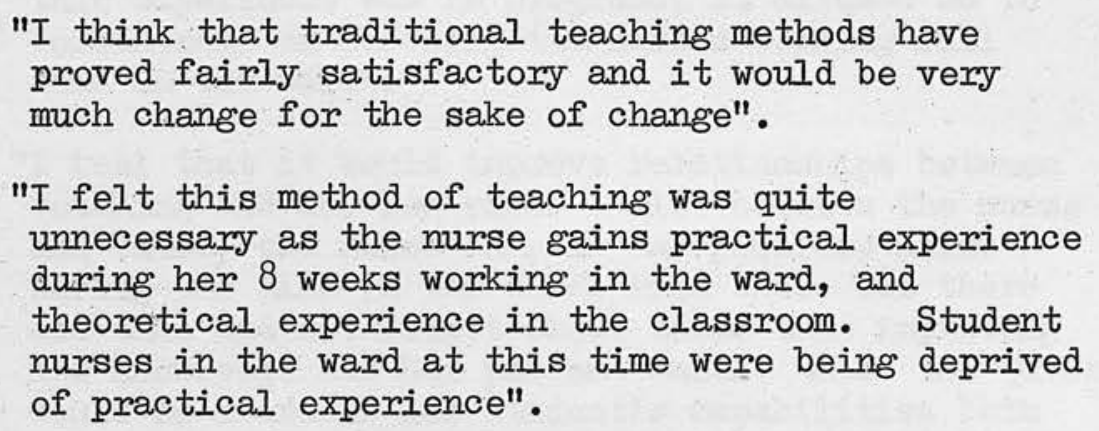

Those in favour again stressed the benefits to students' learning of the experimental method. Thirty respondents valued the integration of theory and practice per se, feeling that the reality of the practice aided the theory, and the obverse, that the theory illuminated the practice.
"What is taught in Block can be very different to the nurse in reality. So before actually working on a ward the nurse can see exactly what, or very closely the tutor has been talking about and she can also see what difficulties can or may arise".
"I feel nurses would be able to recall their theoretical teaching if it were followed quickly by short sessions with patients directly affected by the particular illnesses they are currently being taught about".

Other reasons for extending the use of the experimental method were that it would help the students adapt to the ward, allow ward staff to concentrate on 'their own' students, i.e. those currently on the ward staff, and would improve relationships between education and service. 
"I think the student nurse who has had practical experience in the ward with tutors adapts more easily to ward routine".

"If the ward is particularly busy, as it was when this experiment was in progress, it allowed us to concentrate on teaching the nurses working full time on the ward".

"I feel that it would improve relationships between teaching and service side. Also between the nurse and tutor, the nurse can, if any problems arise during the time in the ward, iron these out there and then and not forget about them, thus improving her knowledge and her patient care. Also the tutor would be aware of her student's capabilities both theoretically and practically and of the ability to combine the two".

Three respondents from Hospital I, who had prior experience of Block students coming to their wards, relatively unsupervised, in order to carry out nursing care studies, gave a positive answer to question 4, but stated that their approval was conditional upon supervision being provided by, and the responsibility of the college teachers.

It was interesting to note that several of the reasons given by the ward staff for repeating the experimental method were identical to or closely in line with the objectives formulated by the researcher for this method of teaching/learning.

Effects of the Experimental Method

Ward staff assessed the effects of the experimental method upon the patients directly involved, and upon the wards and ward staff in very similar vein to the students. 


\section{Effect upon Involved Patients}

A majority said the patients had both enjoyed and benefitted from the individualised attention, and again the feeling that they were able to give, to help the nurses, was referred to:

\footnotetext{
"Unrushed nurses - calmer atmosphere - patients must be allowed to 'give' and to feel needed. Good standard of care".

"I think they felt very important and special".
}

There were three comments to the effect that, because experimental group students were with the patient for a longer time than was usual, the patient felt tired. One instance given was of a patient who had had an operation only the day before. This very important criticism was one which was made also by some students. It was very probable that in this example both staff and students referred to the same patients, as, although patients ${ }^{2}$ names were not given, this small group of staff and students shared a common ward. This situation, although mentioned by so few, nevertheless highlights one of the reasons why the choice of patients for this type of ward teaching must be decided upon by the teacher and the ward trained staff together - the former au fait with the learners' needs and the latter with the needs of the patient.

\section{Effect upon other Patients in the Ward}

Because, in early discussions, the researcher had heard fears voiced about the effects of the experimental method upon other patients in the ward, principally that they might feel neglected, a question about this aspect was included in the ward trained staff and 
teacher questionnaires. These fears were not at all borne out by the reality. Forty six respondents said there was no effect upon the other patients in the ward, that indeed many were unaware of anything untoward, six said the other patients benefitted in that more time and care was available for them, and four that several patients seemed interested in and curious about what was going on. In each case, the latter comment came from staff in wards where there was a cubicalized design. The resultant closer contact between patients and staff in these areas, compared to the situation in Nightingale wards, meant that other patients, if fairly fit and alert, were more aware of what was going on and did indeed take an interest. On many occasions, especially towards the end of an experiment, the researcher found herself in conversation with all 4 patients in a cubicle, both hearing about themselves and being asked by them about 'the young lassies' as the students were often called.

One sister commented:

"no one complained of the patients having preferential treatment - most important".

\section{Effect upon Wards and Ward Staff}

The experimental method was very well accepted by ward staff. There were only two negative comments - I staff nurse felt she had less "feedback" from experimental group students than she should have had, and one staff nurse, in a strike affected ward said "because the ward was so quiet, experience was taken away from the ward nurses". 
There were twenty five comments as to positive effects, e.g. there was a slightly lessened workload, with consequently more time for other patients, and added stimulus and interest from the presence of the tutor and the students in the wards, al though one respondent said:

"Some were uneasy about the presence of the teaching staff on the ward, but this could help keep them on their toes. On the whole, quite interested in what was happening".

One ward sister said:

"A feedback was, and I quote 'I would like to do that" ".

\section{Effect upon the Nurse in Charge}

The questionnaire was issued only to the nurse who was in charge of the ward when the experimental group students were there. This nurse was responsible for the ward work and organisation, and in addition had to liaise with the tutor, and the researcher, and give the report to the experimental group students. She also was the person to whom the students gave their report prior to leaving the ward each morning. Hence, a section was added to question 5 "what was the effect of the experimental method upon yourself?" The researcher felt this question might point to areas of potential difficulty, especially if there was a relatively inexperienced nurse in charge. However, there was no indication at all in the responses, of problems in regard to ward organisation. More than half said there was no effect. A very few respondents mentioned 
the giving of the report, and the explanation about the patients to the experimental group students and their tutor, but said the effect was minimal. All other comments reiterated remarks made above in regard to general stimulus and interest and a lighter workload. One charge nurse said:

"It ensured we did not forget we had a teaching commitment"

and a ward sister:

"I appreciated all the information given to me prior to the experiment and the information given to me each day. I think this is an excellent idea all round".

Supervision of Experimental Group Students in Wards

Ward staff, in Main Study hospitals only, were asked if they considered the experimental group students required more or less supervision than they were given. Only 2 (4\%) respondents, both ward sisters, felt that less was required, and 9 (18\%) - 3 ward sisters and 6 staff nurses - that more was required. The remaining 39 (78\%) respondents felt the amount of supervision was 'just right'.

\section{Achievement of Objectives of the Experimental Method}

Ward trained staff, in the penultimate question of their postexperiment questionnaire, were presented with the objectives of the experimental method of teaching/leaming. Prior to receiving this questionnaire, there had at no time been any mention of these objectives. 
Respondents were asked to evaluate by expressing their opinion as to the degree of achievement or non-achievement of each objective on a six point, equal-appearing interval scale, (Tuckman, 1978, p.179) as shown below. A tick was to be placed in the appropriate box.

\begin{tabular}{l} 
Positive \\
\multicolumn{3}{|c|}{ Negative } \\
\begin{tabular}{|l|l|l|l|l|l|}
\hline++ & + & + & - & - & - \\
\hline & & & & & \\
\hline
\end{tabular}
\end{tabular}

TABLE 59 Post-experiment : Ward Trained Staff Achievement of Objectives of Experimental Method

\begin{tabular}{|c|c|c|c|c|}
\hline & Positi & & Negative & $\mathrm{N}$ \\
\hline Objectives & $H+H$ & + & 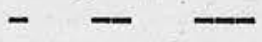 & (100\%) \\
\hline
\end{tabular}

1. Help the student integrate theory and practice

$\begin{array}{llllll}35 & 16 & 6 & - & - & -\end{array}$

2. Increase communication between tutorial staff and ward staff

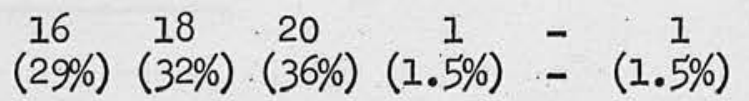

3. Lessen the gap between the ideal and reality in nurse education

$23 \quad 19 \quad 11 \quad \frac{1}{4}-\frac{1}{4} \quad 55$

4. Bridge the gap between education and service

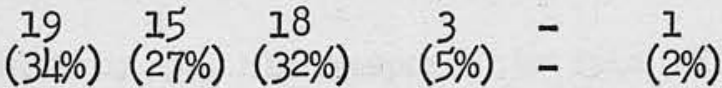

5. Better prepare the student nurse for her ward work and responsibilities

$\begin{array}{llllll}21 & 16 & 14 & 3 & - & 1 \\ (38 \%) & (29 \%) & (25 \%) & (6 \%) & - & (2 \%)\end{array}$

6. Improve ward staff's understanding of what a student nurse can do at various stages of training

7. Improve standards of nursing by supervising the student nurse in giving planned and. individualised patient care 
Their evaluation of the experimental method is given in Table 59 above. This was a most encouragingly positive evaluation of the objectives of this method of teaching/ learning, and was particularly important because, in the view of the researcher, no ward teaching programme can succeed unless it has the endorsement of the service staff.

Further analysis of the ward staff's evaluation of the objectives was undertaken by 'scoring' the positive/negative scale as indicated below, in order to provide a 'best possible score' of 6 for each objective from each individual respondent.

\begin{tabular}{lllllll}
\multicolumn{2}{c|}{ Positive } & \multicolumn{3}{|c}{ Negative } \\
++ & ++ & + & - & - & - \\
\hline 6 & 5 & 4 & 3 & 2 & 1 \\
\hline
\end{tabular}

Thereafter it was possible to add the 'actual scores ${ }^{8}$ from all respondents evaluating each objective, and to calculate mean scores to represent the evaluation by (a) all respondents from all hospitals, (b) respondents in each individual hospital, and (c) each grade of staff, i.e. ward sisters, staff nurses and enrolled nurses (see Table 60). 


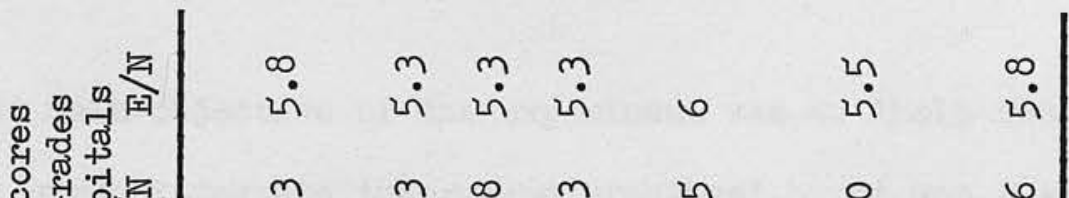

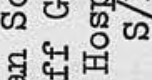

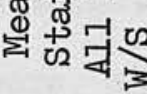

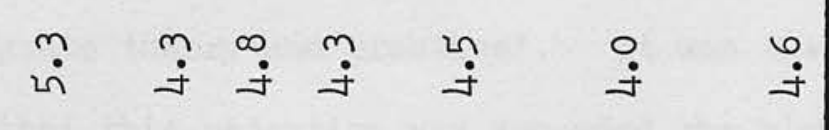

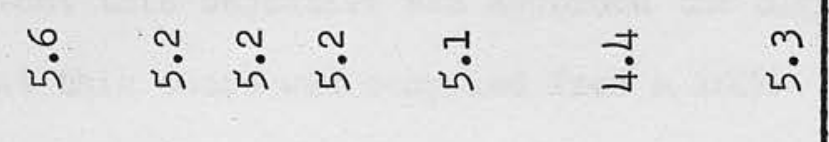

苟 瑝

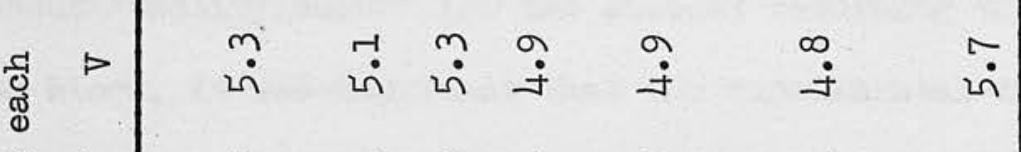

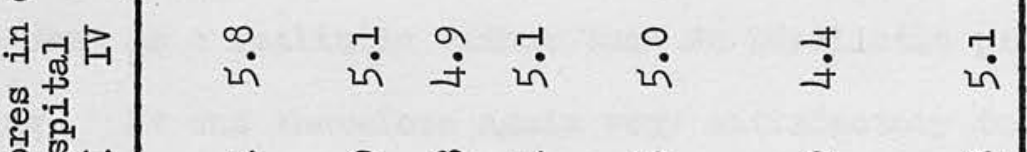

일

龸

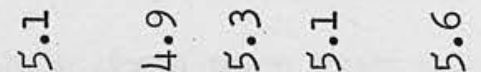

iำ

in

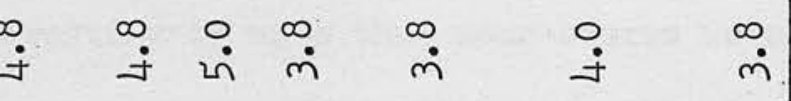

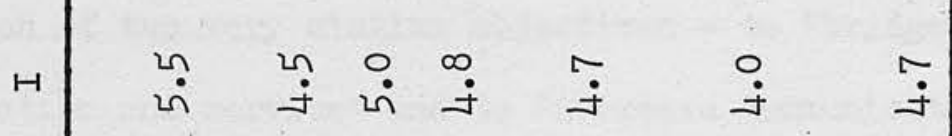

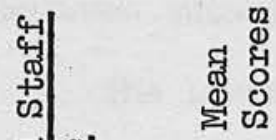

经

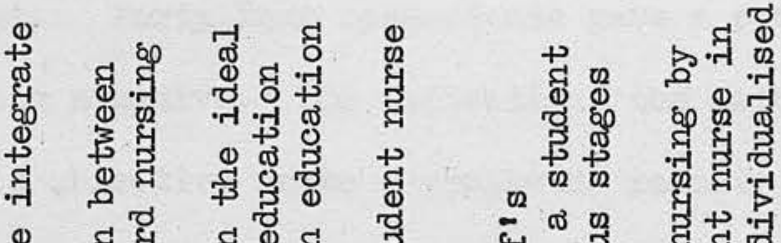

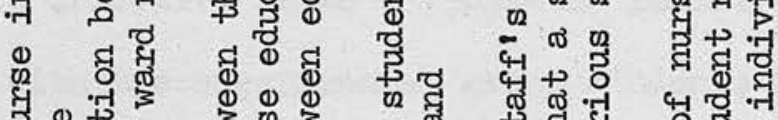

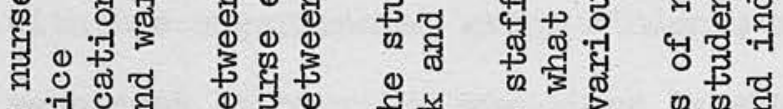

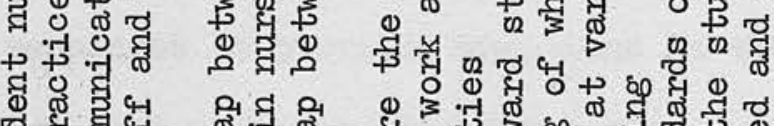

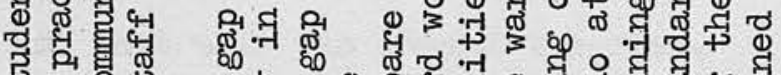

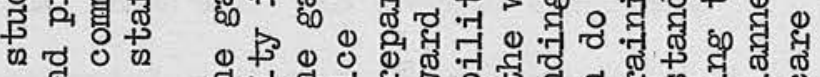
क † 等。 
The main objective of the experiment was to 'help the student nurse integrate theory and practice'. It was therefore most satisfactory that this objective was accorded the highest mean score, and that this score was compiled from a $100 \%$ positive response.

In the current situation in nurse education, where there is concern about 'reality shock' for the student returning to the wards from Block, it was important that the experimental method should be seen as a realistic rather than an idealistic preparation for nursing. It was therefore again very satisfactory to find that the relevant objectives were very positively evaluated.

It was also interesting to note that mean scores were tied in the evaluation of two very similar objectives - to 'bridge the gap between education and service' and to 'increase communication between tutorial staff and ward staff?.

The lowest mean score was given to the objective 'improve ward staff's understanding of what a student nurse can do at various stages of training'. Forty four respondents gave a positive evaluation, and 10 a negative. On reflection, the rather lower evaluation for this objective seems a realistic result, as ward staff involvement with the experimental group students was intended to be minimal and responses to previous questions in their questionnaire confirm that this was indeed the case.

Were the experimental method to come into use, it might be that, as more students and teachers came to the wards - the students at differing stages and therefore caring for patients with differing 
degrees of dependency - ward staff would gain an understanding of what could be expected of students at the various stages of their training.

There was very little evidence of response rigidity in the scoring by the 58 respondents. Only four respondents made consistent use of a single column - one sister and 1 staff nurse scored each objective with one plus, and 1 sister and $I$ enrolled nurse scored all with three plus. All other respondents used more than one column, and the negative scores were not consistently from any one individual.

of the three staff grades evaluating the experimental method, the staff nurses allocated the lowest mean scores. Ward sisters recorded a higher mean score than the staff nurses on every objective. The enrolled nurses gave the highest scores.

When scores accorded each objective were examined by hospital, and ranks assigned, descending from first for the hospital recording the highest mean score on an objective to fifth equal or sixth for the hospital recording the lowest mean score on that objective, a response pattern emerged. Table 61 below shows that ranks 1 to 4 were occupied almost exclusively by Hospitals III, IV, V and Pilot, although no one of these hospitals had the monopoly of any particular rank. Hospitals I and II were fairly consistently in the lowest ranks, i.e. allocated the lowest scores. 
TABLE 6I Post-experiment : Ward Trained Staff Rank Order of Mean Scores accorded each Objective by Hospital

\begin{tabular}{lllllll} 
Objective & I & II & III & IV & V & Pilot \\
\hline \multicolumn{7}{c}{ Rank Order of Scores } \\
\cline { 2 - 7 } & $2=$ & 6 & 5 & 1 & 4 & $2=$ \\
2 & 6 & 5 & 4 & $1=$ & $1=$ & 3 \\
3 & $4=$ & $4=$ & $2=$ & 6 & $2=$ & 1 \\
4 & 5 & 6 & $1=$ & $1=$ & 4 & 3 \\
5 & 5 & 6 & 1 & 3 & 4 & 2 \\
6 & $5=$ & $5=$ & 1 & $3=$ & 2 & $3=$ \\
7 & 5 & 6 & 3 & 4 & 1 & 2 \\
\hline
\end{tabular}

In summary, a majority of the ward staff evaluated positively all of the objectives of the experimental method. The method was seen as most effective in regard to the basic aim of the programme, i.e. the integrating of theory and practice in nursing. Integration, however, is of value only if it enables (a) a better preparation of the student nurse for her ward work and responsibilities, and (b) an improvement in standards of nursing. There were two objectives which dealt with these aspects, and both were well achieved. 


\section{CHAPTTHR 18}

REGISTTERED NURSE TTEACHER AND REGISTHERED CLINICAL TWACHER OPINION QUESTIONNATRES - PRE-EXPPERTINEITT

All teachers * in the five colleges of nursing which participated in the research experiment were invited to respond to the opinion questionnaires which were handed out by the researcher prior to the experiment. There were two separate questionnaires for teachers, one for the registered nurse teacher and one for the registered clinical teacher.

Table 62 shows the distribution of these two grades of teacher throughout the five colleges of nursing.

TABLE 62 Pre-experiment : Teachers Distribution of Grades Throughout Colleges

Registered Nurse

\begin{tabular}{|c|c|c|c|c|c|}
\hline \multirow[b]{2}{*}{ College } & \multicolumn{2}{|c|}{ Teachers } & \multicolumn{3}{|c|}{ Total } \\
\hline & SNT & RNT & $\mathrm{RCT}$ & & $=(100 \%)$ \\
\hline I & 2 & 13 & 10 & 25 & $(35 \%)$ \\
\hline II & 1 & 3 & 2 & 6 & $(8 \%)$ \\
\hline III & $\overline{4}$ & 6 & $12 * *$ & 22 & (31\%) \\
\hline IV & 2 & $4^{*}$ & 2 & 8 & (11\%) \\
\hline V & 2 & 5 & 4 & 11 & (15\%) \\
\hline Totals & 11 & $31^{*}$ & $30 * *$ & 72 & (100\%) \\
\hline
\end{tabular}

$\%$ of each grade $58 \%$ $42 \%$ (100\%)

* includes one unregistered teacher

** includes one unregistered clinical teacher

* Where the full title of each of the two grades of nurse teacher, i.e. the Registered Nurse Teacher (which includes SNT and RNT) and the Registered Clinical Teacher (RCT) is not given, the RNT is referred to as the tutor, and the RCT as the clinical teacher. Where both grades are referred to, the term teacher is used. 
The total number of teachers responding was 72 , of whom 70 were on the General Nursing Council Register of Teachers. Two experienced ward sisters were on the teaching staff of two colleges, but had not yet obtained formal teaching qualifications. One was acting as a tutor, and teaching in both college and hospital, the other was acting as a clinical teacher, teaching mainly in the wards.

The response rate was high. To some extent this may again have been due to the method of delivery and to the researcher's presence in the college which no doubt facilitated the return.

The response was as follows:

$\begin{array}{lr}\text { College I } & 89 \% \\ \text { College II } & 100 \% \\ \text { College III } & 100 \% \\ \text { College IV } & 80 \% \\ \text { College V } & 100 \%\end{array}$

The Registered Nurse Teachers : Characteristics of the Sample

Tutors were asked about their length of experience in terms of (a) how long they had been in their present grade, and (b) how long they had been a ward sister or charge nurse prior to becoming a tutor. Figure 48 (a) shows that, of 39 respondents, no registered nurse teacher had been in her present grade for less than one year, although $46 \%$ had been so for less than 3 years. In Colleges I and III (those with the highest numbers of teaching staff) $53 \%$ and $50 \%$ respectively had been in their present grade for less than three years. Otherwise in all colleges, staff were spread fairly evenly across the time range. 
Figure 48 (a) Pre-experiment : Teachers

Cumulative Percentage - Registered Nurse Teacher Length of Time in Present Grade

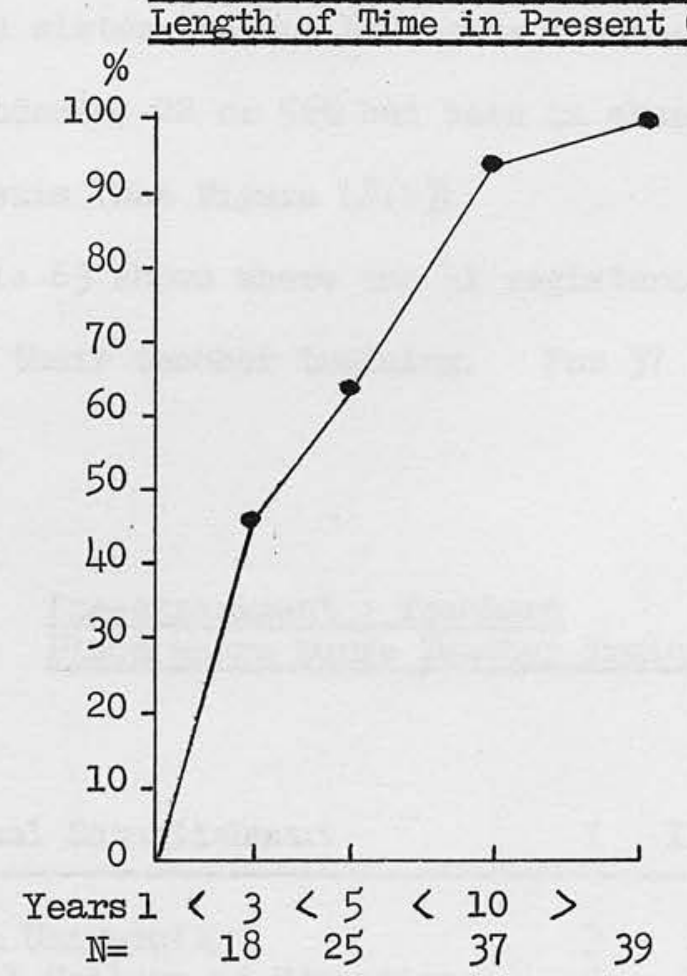

Figure 48 (b) Pre-experiment : Teachers

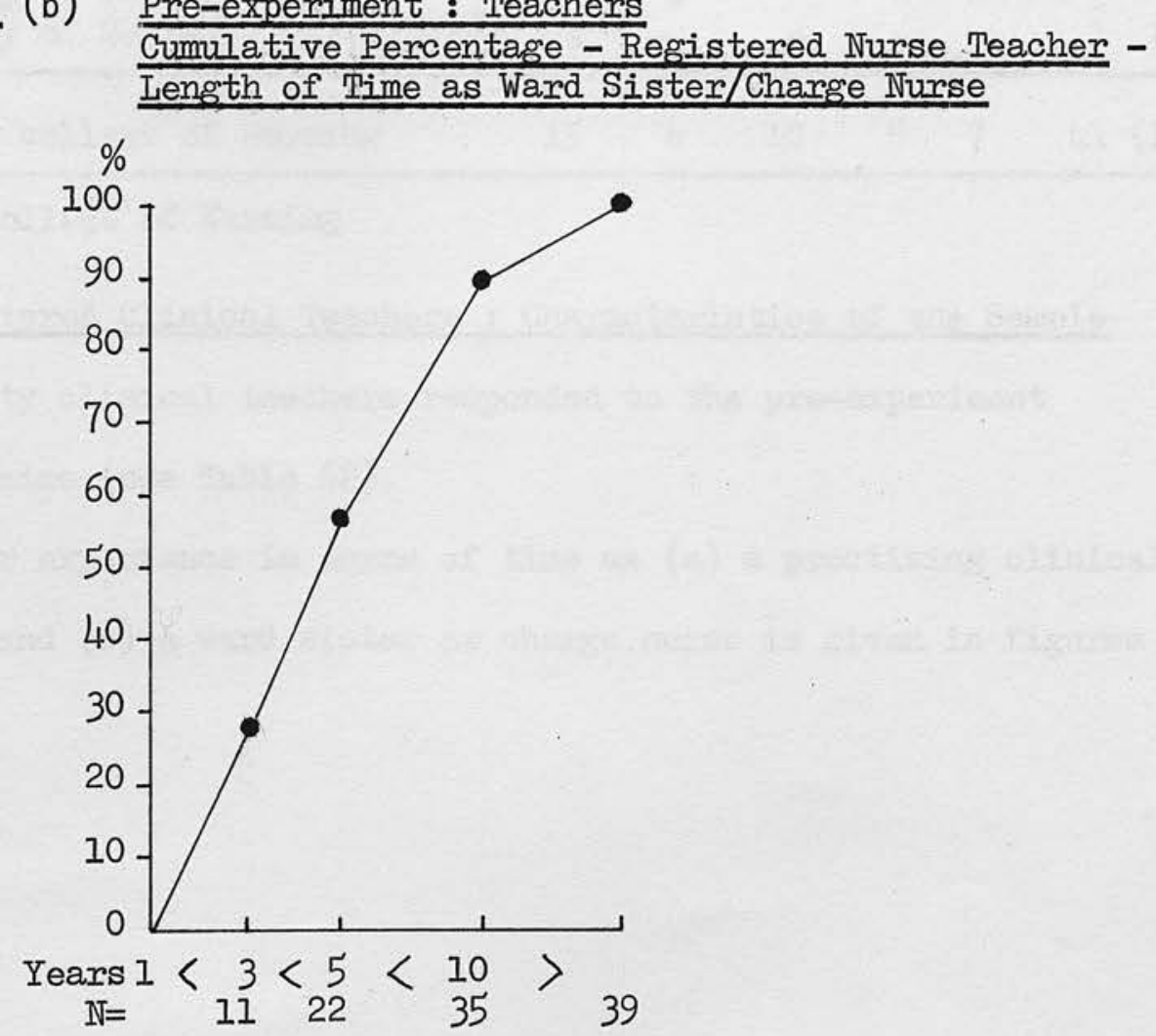


One tutor did not respond to the question about experience as a ward sister and one had never been a ward sister. Of the 39 respondents, 22 or $56 \%$ had been in charge of a ward for less than 5 years (see Figure $48(\mathrm{~b})$ ).

Table 63 shows where the 41 registered nurse teachers obtained their teacher training. For 37 (90\%) this was in Scotland.

TABLE 63 Pre-experiment : Teachers Place where Nurse Teacher Training Undertaken

\begin{tabular}{|c|c|c|c|c|c|c|c|}
\hline \multirow[b]{2}{*}{ Educational Establishment } & \multirow[b]{2}{*}{$I$} & \multicolumn{3}{|c|}{ Colleges } & \multicolumn{3}{|c|}{ Total } \\
\hline & & II & III & IV & V & N & \\
\hline Edinburgh University & 3 & 1 & 7 & 4 & 3 & 18 & $(44 \%)$ \\
\hline Jordanhill College of Education & 9 & 1 & 3 & 1 & 4 & 18 & $(44 \%)$ \\
\hline Teacher Training College (Dundee) & - & 1 & - & - & - & 1 & $(2.5)$ \\
\hline University of London (R.C.N)* & 2 & 1 & - & - & - & 3 & $(7 \%)$ \\
\hline University of Surrey & 1 & - & - & - & - & 1 & $(2.5)$ \\
\hline N in each college of nursing & 15 & 4 & 10 & 5 & 1 & 41 & $100 \%)$ \\
\hline
\end{tabular}

* Royal College of Nursing

The Registered Clinical Teachers : Characteristics of the Sample

Thirty clinical teachers responded to the pre-experiment questionnaire (see Table 62).

Their experience in terms of time as (a) a practising clinical teacher, and (b) a ward sister or charge nurse is given in figures $49 \mathrm{a} / \mathrm{b}$ below. 
Figure 49 (a) Pre-experiment : Teachers

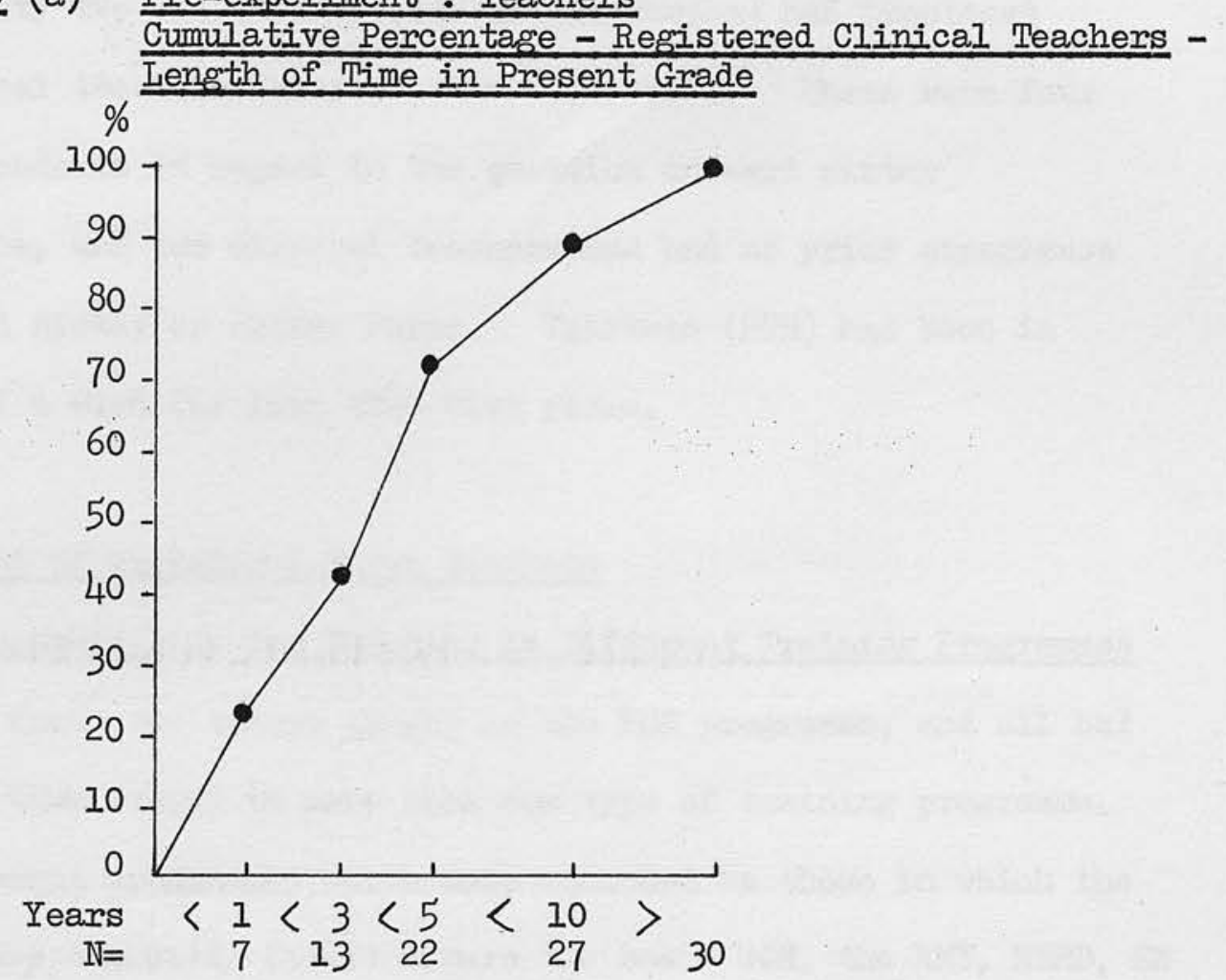

Figure 49 (b) Pre-experiment : Teachers Cumulative Percentage - Registered Clinical Teachers Length of Time as Ward Sister/Charge Nurse

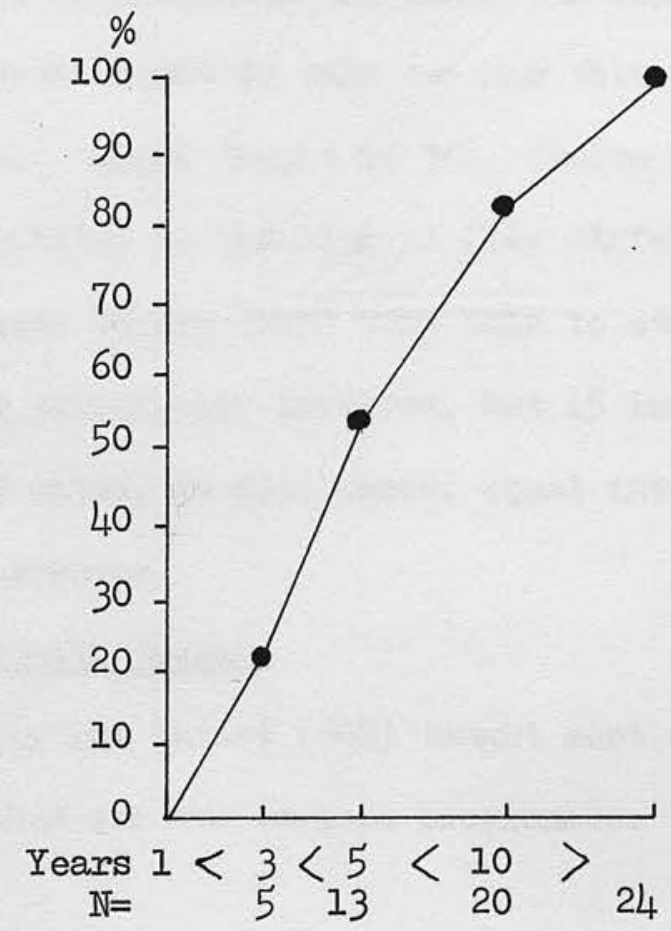


Twenty two respondents ( $73 \%$ of the sample) had practised as clinical teachers for less than five years. There were four non-respondents in regard to the question on ward sister experience, and two clinical teachers had had no prior experience as a ward sister or charge nurse. Thirteen (50\%) had been in charge of a ward for less than five years.

\section{Deployment of Registered Nurse Teachers}

(a) Responsibility for Teaching in Different Training Programmes

All forty two tutors taught in the RGN programme, and all but seven of them taught in more than one type of training programme. The different programmes which were recorded as those in which the sample were currently involved were the basic RGN, the RMN, RNIM, ENN and comprehensive trainings, together with a number of postregistration and post-basic courses. The number of different programmes in which any one tutor was teaching varied from one to five - seven taught in only one and that was the basic RGN programme. Fight taught in two, twelve in three, nine in four, and six contributed to teaching in five different types of programme. Twenty seven tutors (64\%) were able to state one programme with which they were principally involved, but 15 tutors (36\%) were unable to do this, and cited, in some cases, equal involvement in three different basic programmes.

(b) Subjects Taught

Thirty six tutors (86\%) taught most of the subjects given in the GNC Syllabus for the various programmes. Twenty five of these tutors 
also had administrative responsibility for one or more intakes of students. Five tutors (12\%) taught 'all subjects in the Syllabus' and three of these tutors also had administrative responsibilities, and only one tutor (2\%) taught 'only a few subjects'. Those seven tutors who taught in the RGN programme only, were all in the $86 \%$ above who taught most subjects in the syllabus.

\section{(c) Administrative and other Responsibilities of the Tutor}

Twenty eight tutors (67\%) including the eleven senior tutors, had overall administrative responsibility for groups or intakes of leamers throughout the leamers' training period and 32 tutors (76\%) acted as personal tutor to groups of learners, ranging in number from 14 to 82 , and in the case of one senior tutor, 150.

With regard to the duties and responsibilities of a 'personal tutor', 28 respondents mentioned 'counselling' and 22 of those gave no further explanation. Examples given of counselling included careers advice, advice in personal matters and/or problems, and from one tutor:

\section{"Discuss progress, counsel and support in professional matters, am available to help them in any way I can".}

Another just stated: "listening".

Hleven tutors mentioned teaching and academic guidance, including the provision of 'inter-Block' work to help any student who had problems with the theory aspect of her training. 
Four included 'disciplinary matters' under their responsibilities as personal tutor, one example was dealing with 'absenteeism'.

Four said they had a responsibility to make ward visits to students to whom they were personal tutor and to discuss their ward assessments with them.

\section{Deployment of Clinical Teachers}

As shown in Table 64, twenty seven clinical teachers (90\%) worked in both college and wards. Of the latter, ten, all from College III, spent $20 \%$ of their time, i.e. one day per week, in college and the remainder in the wards - this was college policy. Nine other RCTs were unable to state exactly how their time was divided in this respect and eight spent a very small amount of time in college teaching, i.e. $10 \%$ or less.

The college teaching commitment for the 27 clinical teachers was, in the main, teaching "practical nursing" - several specifically mentioned "practical classes for Introductory Block nurses, e.g. bedbathing, admission of patients", or simply "practical skills".

Four clinical teachers came into college mainly to teach their 'specialist' subject - i.e. "intensive care nursing", "theatre technique", "Ear, nose and throat and ophthalmology", "gerontology".

In College III, clinical teachers were responsible for and did most of the teaching during one week in college for students just prior to their 24 week pre-registration period. 
Seven clinical teachers, two in College I and five in College III taught nurses at all stages and in a variety of practical nursing and specialist subjects, including management classes. Two of these teachers mentioned "clinical teaching". This was the only suggestion in all the pre-experiment questionnaires that students were "taught about teaching", and neither respondent explained exactly what was meant.

The only clinical teacher to work entirely in the college was from College III. He taught "most subjects in the syllabus, except Psychiatry and Mental Deficiency".

of the 29 clinical teachers who taught in the wards (see Table 64) none worked in only one ward or unit. One did, however, work in all operating theatres and this person was outstanding as the one teacher whose role resembled, to some extent, that of the clinical nurse specialist. She taught only the subject of her 'specialty', i.e. Theatre Technique, and this to students in the basic RGN programme only, although she commented:

\footnotetext{
"auxiliaries and ODA trainees (Operating Department Attendant) join in tutorials at times".
}

In addition, she was responsible for a very small amount of college teaching again of her 'specialty' subject only.

The other 28 clinical teachers all taught in several wards. Twenty three teachers worked with all learners, including postregistration students and four of these teachers also taught postbasic learners. Five teachers taught only student and pupil nurses. 
Only two clinical teachers worked entirely in the wards. One would have preferred to include some college teaching in her work, the other would not.

A wide variety of different types of ward were represented in the sample of clinical teachers. A majority had medical and/or surgical wards in their teaching areas but also mentioned were geriatric wards, orthopaedic, ENT., Eyes, psychiatric, paediatric and the Departments of Accident and Emergency and Theatres.

The picture presented, therefore, by this particular sample was almost exclusively that of the clinical teacher as a generic type of ward teacher, peripatetic, endeavouring to do some ward teaching, here and there, for many learners.

Deployment of Tutors and Clinical Teachers in regard to Teaching in Ward and College

When all teachers in this sample were considered, Table 64 shows the numbers teaching in the two areas of college and ward. 
TABLE 64 Pre-experiment : Teachers

Place where Teaching

\begin{tabular}{|c|c|c|c|c|c|c|c|c|}
\hline \multirow[t]{2}{*}{ College } & \multicolumn{3}{|c|}{$\begin{array}{l}\text { Teaching in } \\
\text { College only }\end{array}$} & \multicolumn{3}{|c|}{$\begin{array}{l}\text { Teaching in } \\
\text { College and Ward }\end{array}$} & \multirow{2}{*}{$\begin{array}{l}\text { Teaching in } \\
\text { Ward only } \\
\text { RCT }\end{array}$} & \multirow[t]{2}{*}{$\mathbb{N}=$} \\
\hline & SNT & RNT & $\mathrm{RCT}$ & SNT & RNT & RCT & & \\
\hline I & 1 & 4 & - & 1 & 9 & 9 & 1 & 25 \\
\hline$I \bar{I}$ & 1 & - & - & $=$ & 3 & 1 & $I$ & 6 \\
\hline III & 3 & 1 & 1 & 1 & 5 & 11 & - & 22 \\
\hline IV & - & - & - & 2 & 4 & 2 & - & 8 \\
\hline \multirow[t]{2}{*}{$\mathrm{V}$} & - & 1 & - & 2 & 4 & 4 & - & 11 \\
\hline & 5 & 6 & 1 & 6 & 25 & 27 & 2 & 72 \\
\hline
\end{tabular}

of the tutors, $74 \%$ were currently teaching in both college and ward, compared with $90 \%$ of the clinical teachers who taught in both areas. Of the eleven tutors who did not teach in the wards, nine said that they would prefer to do so. Nine of the 28 tutors who had stated that they had administrative responsibilities for student intakes, taught only in college. One senior tutor explained:

"administrative capacity of senior tutor makes it rather difficult to plan ward teaching for individual learners, except through clinical teachers".

A tutor who taught in the RGN., RMN., FN and post-registration programmes and who had administrative and personal tutor responsibilities for two intakes of learners said yes he would prefer to teach in both college and ward but:

"Only in a restricted capacity. It is impossible to teach in both general and psychiatric wards. If, however, my teaching was restricted to psychiatric nursing, I would like to be involved in ward teaching". 


\section{Frequency of Ward Teaching by Tutors}

Only three tutors considered that they taught often in the wards, 8 taught fairly often, 20 rarely, and 11 not at all. The proportion of tutors in the often and fairly often categories, compared to those in the rarely or never categories were $1: 5$ in Colleges I and III, and I : 3 in the other three colleges.

When a weighted score was attached to the frequencies, exactly in the manner described in Page 283, it was possible to calculate a percentage score for the contribution to ward teaching by the 42 tutors in the sample, and in Figure 50 this is shown, to the right of the score attributed to the registered nurse teacher by the student nurses (taken from Figures 37 and 38 ).

Figure 50 Pre-experiment : Teachers

Weighted Score Contribution to Ward Teaching (RNT)

Compared with Student Perception of Same

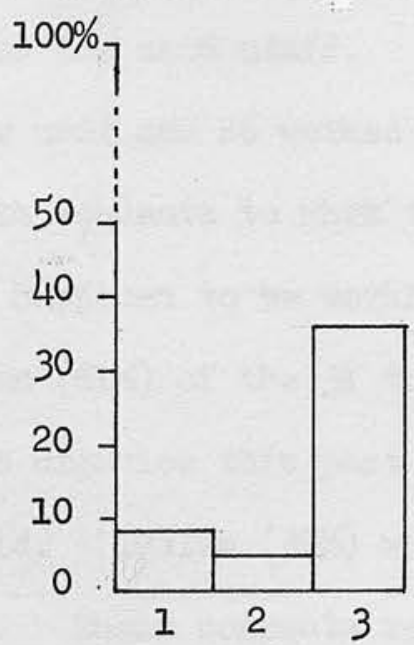

Key: 1* Score accorded by students - re Supervision and/or

Practical Demonstration

2* . Score accorded by students - re Thtorials

3 Score accorded by RNT

* Information for 1 and 2 above extracted from Figures 37 and 38 
Although it would appear that the tutors viewed their contribution to ward teaching as rather more than was thought by the students, the comparison in Figure 50 should be viewed bearing in mind that there are few tutors and many students. (The clinical teacher was not asked how often she was teaching in the ward).

\section{Patterm of Ward Teaching Commitment by Tutors}

There was no discemible pattern to the tutors' ward teaching commitment in any of the five colleges. With regard to who were the recipients of such teaching - only five tutors confined their ward teaching to Introductory Block students, only 2 to students to whom they were personal tutors, and 2 to "apprentice" learners only, as opposed to Block, or supernumerary students. All others taught leamers at all stages, either as supermumerary students or as members of the ward staff. Five tutors worked always in the same ward or unit and 26 worked in a number of different wards, 14 of these with students to whom they were personal tutor, wherever the student happened to be working.

Nineteen (61\%) of the 31 tutors engaged in ward teaching preferred to organise this part of their work in the way they currently did. Twelve (39\%) would have preferred to organise it differently. Their comments related to a wish for increased ward involvement, both with students on the ward staff and with supermumerary students, to the need for college policy or some regular commitment to ward teaching and to attachment to one unit 
with resulting specialist, rather than generalist role, e.g.:

"I would like to be attached to a unit, complementing the N.0. (Service) - I see R.N.Ts as resource people and supportive to clinical staff".

"Regular time-tabled involvement in medical wards".

"Equal time to be spent in college and wards".

"All aspects of nursing care in all theoretical

blocks taught in the ward situation, moving with learners into areas where theory may be linked to practice".

"A consensus decision in college re the role of the tutor in the wards. Some specialisation".

\section{Subjects of Specialist Knowledge or Experience}

All teachers were asked if they had any area or subject of specialist knowledge. Thirty one (74\%) of the tutors considered they did have, and 29 taught in their specialist subjects. Twenty three $(77 \%)$ of the clinical teachers considered they had one or more areas of specialist knowledge and twenty taught their special subjects. There were therefore five teachers who did not teach either in the areas, or the subject matter of their specialty.

A wide range of specialties was listed (see Table 65). The emphasis, in the listing, was on the 'medical model', rather than on nursing - a reflection in part of the syllabus, but also, possibly, of much of the current thinking at ward and teacher level. 
TABLE 65 Pre-experiment : Teachers

Subjects of Specialist Knowledge or Experience

Specialty in respondents ${ }^{2}$ terminology

No. of times mentioned by

RNT

RCT

Medicine/Medical Nursing

Surgery/Surgical Nursing

Psychiatric Conditions/Psychiatric nursing

Geriatrics/Care of the Elderly

Paediatrics/Care of Children

Alimentary System/gastro-intestinal surgery

Cardiology/Cardio-vascular nursing

Community Health

ENT

Gynaecology

Haematology

Infection

Intensive care nursing

Mental Deficiency

Neurological/Neurosurgical nursing

Oncology

Ophthalmology

Oral Surgery

Plastic Surgery and Burns

Psychology

Rehabilitation

Respiratory diseases

Sociology

Theatre Technique

Urology

$\begin{array}{ll}6 & 6 \\ 8 & 3 \\ 6 & 2 \\ 3 & 5 \\ 1 & 1 \\ 2 & 1 \\ 1 & 1 \\ 1 & - \\ 1 & - \\ 1 & 2 \\ -1 & 1 \\ 1 & - \\ -1 & - \\ 1 & - \\ 4 & 1 \\ 1 & - \\ 6 & - \\ 2 & - \\ 1 & 1 \\ 3 & 1 \\ 2 & - \\ 1 & 1 \\ 1 & \end{array}$

Some of the differences between the tutors and the clinical teachers in regard to the specialities listed were (a) no tutor mentioned specialising in intensive care nursing of any type, (b) social science subjects, e.g. psychology and sociology were named by tutors only, and (c) although the emphasis for both grades of teacher was on disease conditions, there was, proportionally, slightly more mention of nursing subjects by the tutors. There were altogether 23 instances of general medical and surgical nursing being 
seen as specialties. In both grades of teachers, some quoted two or three specialties.

Twenty one teachers gave comments on the subject of specialisation. Some comments revealed the influence of the system of formal organisation within the college, e.g. a 'team' of teachers responsible for several student intakes throughout their training period.

Four teachers said their teaching of their particular specialty was confined to students within their own 'team? responsibility:

"Sole responsibility for my specialty (ophthalmology) within the team".

"Within my own group of students I do (teach specialty subjects) but in a rather isolated way, I would like the opportunity to teach them (special subjects) more often".

Only one tutor mentioned teaching "gynaecological nursing within other teams".

Problems and advantages of specialty teaching were also given:

"As senior tutor it is not easy to keep up to date with clinical nursing practice. Continual teaching of one subject is economical of time and can be of more value to the students".

"There are some areas which I used to consider my specialty, but there has been some erosion by the need to teach most things".

"The longer you are away from running the ward, the more difficult it is to keep up to date with your specialty, particularly regarding new drugs and treatments". 
"We specialise to some extent within the team. This enables the teacher to visit clinical areas of her specialties in an attempt to keep abreast of changes".

\section{Allocation of Teaching Commitment}

Teachers were asked in what way their teaching commitment was decided.

\section{TABLE 66 Pre-experiment : Teachers Allocation of Teaching Commitment}

Method of allocation RNT RCT Total $\mathrm{N}=$

By senior tutor

All college staff discuss Team discuss All RCTs discuss Other method

$\begin{array}{rrr}7 & 9 & 16 \\ 4 & 7 & 11 \\ 22 & 7 & 29 \\ - & 4 & 4 \\ 9 & 3 & 12\end{array}$

Totals

42

30

72

Table 66 shows that the most common method of arriving at the individual tutor's teaching commitment was to have discussion within a 'team' headed by a senior tutor. Twenty two tutors and seven clinical teachers from four of the five colleges said this applied in their case. Four of the eleven senior tutors said their teaching commitment was self-allocated - two added that this was in consultation with the Director of Nurse Education. The four tutors and 2 clinical teachers who said it was decided by discussion with all college staff all came from College II, the smallest college in 
the sample. There were five tutors, all RNTs, and working within the type of formal organisation which gave them administrative responsibility for one or more complete intakes of students, who said the allocation of their own teaching commitment was their own personal responsibility. One said:

"I am given responsibility for an intake and the teaching commitment within that remit is technically my choice, but it is dependent on what support I can get from my colleagues".

The clinical teacher in College I who worked very much as a clinical specialist said her commitment was decided by liaison between 'Theatre Office (Service side) and Tutors'.

The formal organisation in all five colleges was based on the Salmon structure. Staff worked in teams, headed by a senior tutor and, apart from College II, where staff in the two teams intermingled and tended to share the workload, there were, in effect, a number of virtually autonomous small schools within each college, and no common policy as to allocation of teaching commitment, across the teams.

For clinical teachers, teaching commitment was also influenced by the exigencies of the hospital, the wards, and the number of learners available.

"Much of the teaching commitment depends on the allocation of learners to the wards in which I teach. This is outside the control of the college staff".

Therefore, a number commented that once allocated, e.g. by a senior tutor, the day to day teaching commitment was at the clinical teacher's own discretion. 


\section{Ward Teaching of Students}

Of the teachers, only the tutors were asked if they considered student nurses should receive ward teaching while undertaking their practical experience. It was assumed, rightly or wrongly, that clinical teachers, whose raison d'être was such teaching, would have answered in the affirmative. Forty one of the 42 tutors said such teaching should be given, one felt it should not.

The same teaching methods as had been given in the ward trained staff questionnaire, were repeated for both groups of teachers. Of the 41 tutors, 40 favoured the use of both (a) practical demonstration and/or supervised practice and (b) tutorials and one preferred only demonstration and/or supervised practice. All clinical teachers answered this question, 29 in favour of both teaching methods and one in favour of (a) only. This result was similar to that from sisters and staff nurses, although there was a larger proportion of the latter sample who considered ward teaching should be confined to method (a).

\section{By Whom should Ward Teaching be done?}

Both tutors and clinical teachers were asked who they thought should take the main responsibility for teaching the students during their practical experience, i.e. on the wards, and the results were summarised in Table 67. 
TABLE 67 Pre-experiment: Teachers Responsibility for Ward Teaching

\begin{tabular}{lcccc}
$\begin{array}{l}\text { Ward } \\
\text { teaching }\end{array}$ & $\begin{array}{l}\text { Joint education } \\
\text { and service }\end{array}$ & $\begin{array}{l}\text { Education } \\
\text { staff only }\end{array}$ & $\begin{array}{l}\text { Service staff } \\
\text { only }\end{array}$ & $\begin{array}{c}\text { Response } \\
N=\end{array}$ \\
\hline $\begin{array}{l}\text { Main } \\
\text { responsibility } \\
\begin{array}{l}\text { Responsibility } \\
\text { if no CT } \\
\text { available }\end{array}\end{array}$ & $7(26 \%)$ & $32(45 \%)$ & $21(29 \%)$ & $72(100 \%)$ \\
\hline
\end{tabular}

\section{(a) Main responsibility}

Eighteen (43\%) of the tutors and fourteen (47\%) of the clinical teachers felt this was entirely the responsibility of the college teachers. Only two of these eighteen tutors felt their grade should be mainly responsible, 13 felt it should be the clinical teacher and 3 that they should be jointly responsible, whereas of the 14 RCTs, 12 felt it was their own responsibility and only 2, that it should be shared with the tutor.

Eleven tutors (26\%) and eight clinical teachers (26.5\%) felt both education and service staff should share the main responsibility.

However, 13 tutors (31\%) ascribed the main responsibility solely to the ward trained staff, as did 8 clinical teachers (26.5\%), therefore for these 21 teachers (29\% of the total teacher number) ward teaching, while the student was in the 'apprenticeship' component of her training, was not primarily the responsibility of the educator, but of the untrained teachers, i.e. the ward staff.

(b) Responsibility if no Clinical Teacher was Available

The question with regard to who should take responsibility for ward teaching if no clinical teacher was available, was again 
addressed only to those who had included the RCT in their answer to the previous question. Four tutors felt it should be their own responsibility, four thought it should be shared between themselves and the ward staff and 13 felt it was a ward staff responsibility. of the 16 clinical teacher respondents, 3 felt it was the tutor's responsibility, 3 that tutor and ward staff should share it, and 10 that it was the responsibility of the ward staff - eight of these ten clinical teachers said specifically, and only, the ward sister. 5 of these 8 clinical teachers had given themselves alone as mainly responsible. It must be concluded that for these 5 (17\%) of the clinical teacher sample, it was an 'either-or' situation in regard to responsibility for ward teaching in the apprenticeship component of the student nurses training if not the clinical teacher, then the ward sister - no one else had that responsibility.

\section{College-supervised Ward Teaching of Supermumerary Students}

Teachers were asked whether they thought students should receive some teaching in the wards for a certain amount of their Block time, i.e. as supernumerary students, working under the supervision of college teaching staff. There was a positive response to this question, in that $88 \%$ were in favour, although rather more clinical teachers were against this form of ward teaching than were tutors (see Table 68). 
TABLE 68 Pre-experiment : Teachers

College-supervised Ward Teaching of Supernumerary Students

\begin{tabular}{|c|c|c|c|}
\hline Teacher Grade & In favour & Against & Total $\mathbb{N}=$ \\
\hline Nurse tutors & $40 \quad$ (95\%) & $2 \quad(5 \%)$ & 42 (100\%) \\
\hline Clinical teachers & $23(77 \%)$ & $7 \quad(23 \%)$ & $30(100 \%)$ \\
\hline Both grades $N=$ & $(88 \%)$ & $(12 \%)$ & $72(100 \%)$ \\
\hline
\end{tabular}

Teachers were then asked a hypothetical question, i.e. if this type of teaching became a part of the student nurse's education, should it be (a) in the form of supervised nursing care given to individual patients, whose conditions linked to current lectures, (b) in the form of tutorials on the wards, or (c) should it take both the above forms?

Table 69 shows that $73 \%$ of those responding considered such teaching should be by both supervised practice and tutorials. This compared with approximately half of the ward staff sample who elected for both methods.

TABLE 69 Pre-experiment : Teachers Possible Form of Ward Teaching of Supernumerary Students

\begin{tabular}{lllllll} 
Teacher Grade & $\begin{array}{l}\text { Both supervised } \\
\text { practice and } \\
\text { tutorials }\end{array}$ & $\begin{array}{l}\text { Only supervised } \\
\text { practice }\end{array}$ & $\begin{array}{l}\text { Only } \\
\text { tutorials }\end{array}$ & $\begin{array}{c}\text { Total } \\
\mathbb{N}=\end{array}$ \\
\hline $\begin{array}{l}\text { Nurse tutors } \\
\text { Clinical teachers }\end{array}$ & $\begin{array}{l}30 \\
21\end{array}\left(\begin{array}{l}73 \%) \\
73 \%)\end{array}\right.$ & $\begin{array}{l}9 \\
7\end{array}\left(\begin{array}{l}22 \%) \\
24 \%)\end{array}\right.$ & $\begin{array}{l}2 \\
1\end{array}$ & $\left.\begin{array}{l}5 \% \\
3 \%\end{array}\right)$ & $\begin{array}{l}41 \\
29\end{array}\left(\begin{array}{l}100 \%) \\
100 \%)\end{array}\right.$ \\
\hline Both grades $N=$ & $51(73 \%)$ & $16(23 \%)$ & 3 & $(4 \%)$ & $70(100 \%)$ \\
\hline
\end{tabular}


Fourteen tutors and one clinical teacher commented in regard to supernumerary students receiving ward teaching. Although there was general endorsement of this concept as useful, on educational grounds, several raised doubts about the feasibility of supervision by teachers, given the present teacher/ student numbers.

Two opposing viewpoints expressed below sum up the divided opinions of the teachers:
"An unrealistic concept since tutors are at a premium. Clinical experience should be confined to clinical secondment, otherwise orderly educational programme is disrupted".
"From limited experience, the learner adapted more quickly to the ward situation and appreciated patients' needs, if she had been introduced to the theory at the bedside".

\section{Experience of Ward Teaching of Supermumerary Students}

Both tutors and clinical teachers were asked if they had experience of teaching supermumerary students. 
TABLE 70. Pre-experiment : Teachers

Experience of Ward Teaching of Supermumerary Students

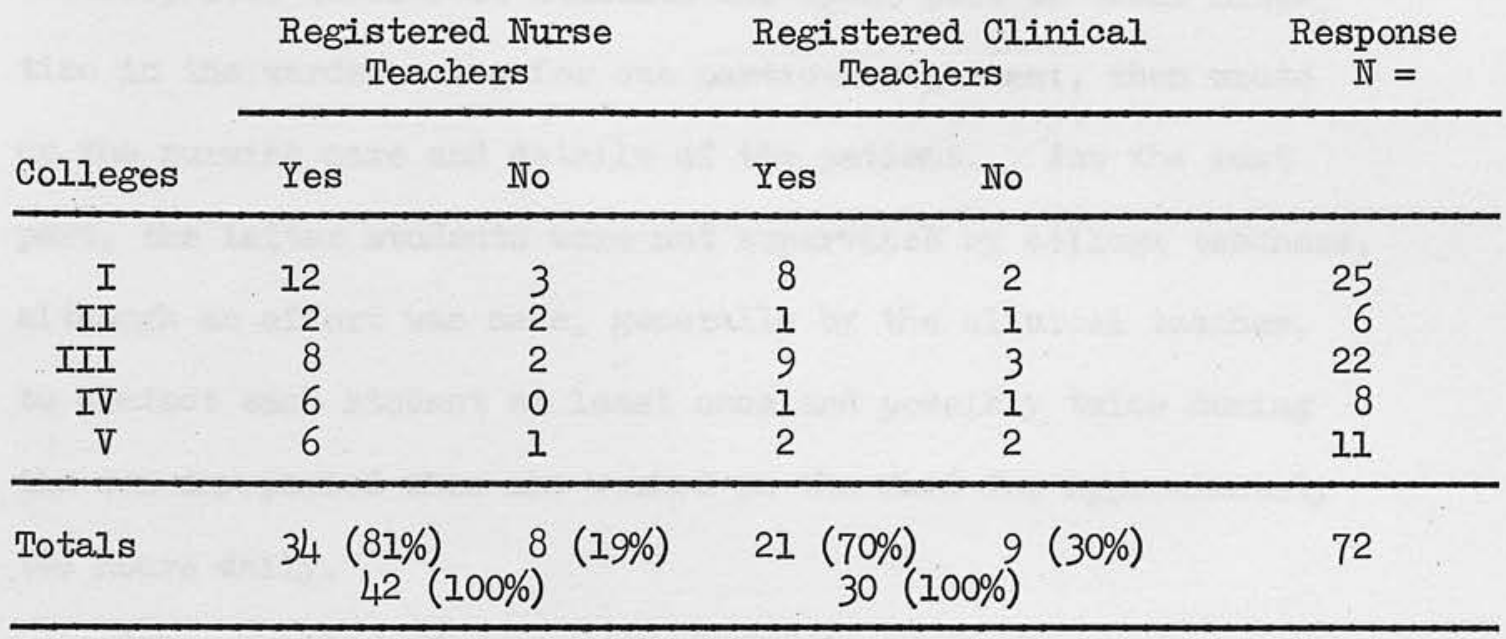

From those teachers who had participated, 49 examples were given of this teaching, and 45 stated they had worked with students in Introductory Block. Twenty nine (19 RNTs and 10 RCTs) had no experience other than with these most junior students and a majority spoke in terms of procedure-based nursing in the wards, e.g. "bedbathing, T.P.Rs, dressings".

"This is restricted at present to leamers during introductory module - type of activities - bed making, giving and taking bedpans, oral hygiene, taking of temperature, pulse and respiration, helping to feed patients. This is not patient centred care".

Fifteen teachers had experience of teaching supermumerary students, both at Introductory Block stage and at later stages. With the more senior students, there came more mention of patient orientation, rather than the procedure emphasis, e.g.:

"Following theory by practice, simple tasks in junior groups, i.e. taking temperatures, making beds. 'Total' nursing care for half-day in more senior groups". 
A few said they supervised students writing nursing care studies, i.e. these were students who spent part of their Block time in the wards caring for one particular patient, then wrote up the nursing care and details of the patient. For the most part, the latter students were not supervised by college teachers, al though an effort was made, generally by the clinical teacher, to contact each student at least once and possibly twice during the ten-day period when she worked on the ward for approximately two hours daily.

Other mention of supermumerary students was in connection with ward visits or tutorials related to Block work.

\section{Meetings between Tutors and Ward Staff}

Tutors were asked how often they met, or consulted with ward trained staff in connection with their work. All had some contact with ward staff - seven tutors, from all but College II, said they met often, and twenty six said meetings occurred fairly often. Clinical teachers were not asked this question, as it was felt that the majority were daily in the wards. In response to a request to comment on the form and purpose of such contacts, it appeared that most occurred because the learners were in the wards, and were in connection with discussing, or checking upon their progress. No tutor mentioned contact with ward staff as a result of teaching in the ward, but as a question on ward teaching had previously been answered the omission may have been due to that fact. 
Fifteen tutors mentioned contact and visits to wards in connection with assessment of learners' progress, e.g.:

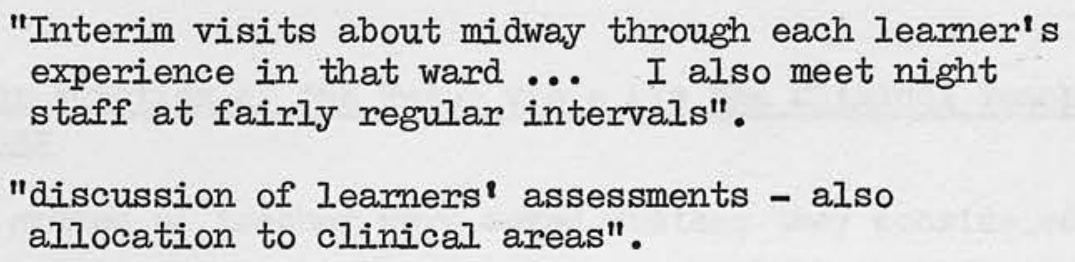

Five teachers quoted administrative reasons, such as learner allocation, as one cause of contact:

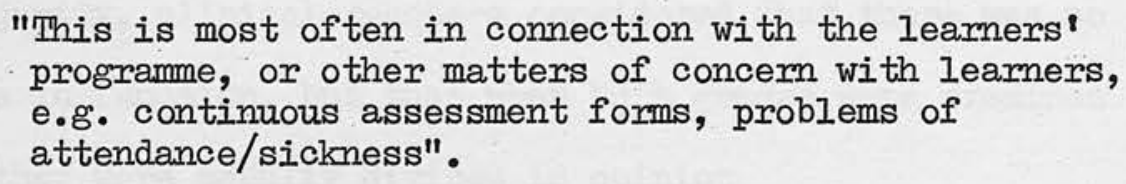

Twenty tutors spoke of the necessity to consult ward staff - to update lectures, to exchange information, e.g.:

"To keep up to date with changing techniques".

"Contact with ward nursing staff to find out about new treatments, investigations and also drugs currently used. Also to see new equipment being used".

There was evidence, from ward staff responses to a similar question, that this was a reciprocal process, albeit mainly between the ward staff and the clinical teacher.

A very few comments looked towards the importance of communication for service/education relations, e.g.:

"To build up good relationships, so I am welcome. To keep track of new things".

"To maintain a continuity between self and service staff". 
Informality in approach was universal, with only three respondents mentioning provision for formal meetings.

The Role or Function of the Tutor vis a vis the Clinical Teacher as Ward Teacher

Both grades of teacher were asked whether they considered there was any difference in function between them in regard to ward teaching. Table 71 shows that by a fairly narrow majority tutors considered that there was a difference, and by an almost equally narrow majority, clinical teachers considered that there was no difference in function, but that when both grades were examined together they were equally divided in opinion.

TABLE 71 Pre-experiment : Teachers Does Difference exist between Thtor/Clinical Teacher Function as Ward Teacher?

\begin{tabular}{llcl} 
Staff Category & Functions differ & $\begin{array}{c}\text { Functions do not } \\
\text { differ }\end{array}$ & $\begin{array}{c}\text { Response } \\
\text { N }=\end{array}$ \\
\hline $\begin{array}{l}\text { Tutors } \\
\text { Clinical teachers }\end{array}$ & $23(55 \%)$ & $19\left(\begin{array}{l}45 \%) \\
16(53 \%)\end{array}\right.$ & $\begin{array}{l}42 \\
(27 \%)\end{array}$ \\
\hline $35(50 \%)$ & $35(50 \%)$ & $70(100 \%)$
\end{tabular}

In Colleges IV and V none of the clinical teachers thought there was any difference in function.

Comments from the tutors as to differences endorsed some of the views given by the ward staff and also by the clinical teachers, i.e. (a) that the course preparation of the two grades was different, and thus (b) the teaching methods tended to differ, (c) that priorities 
were different - the clinical teacher having no or few commitments other than ward teaching whereas the tutor had college commitments as well as ward teaching, and (d) that the clinical teacher was the clinical expert.

Five tutors referred to a difference in preparation:

"The tutor, unless a trained clinical teacher, has not been taught to teach in the ward area".

In all, 13 tutors commented that what was taught, or the methods or approach to teaching, differed, e.g.

"Clinical teacher deals with specific subjects and is involved with situational teaching. Tutor more involved with general principles".

The theory practice division was evident in some of the comments:

"The CT should be predominantly involved in the teaching of psychomotor skills. Tutors? function is to impart general principles".

Five tutors saw the difference between tutor and clinical teacher in terms of the amount of time each devoted to ward teaching, perhaps a difference in priorities:

"Clinical teachers are part of a continuous team effort, whereas the tutors" ward visits are sporadic".

A number of tutors, and clinical teachers, suggested one grade of teacher would be preferable, and from the latter group, some felt the difference was not great. 


\begin{abstract}
"At present there is, by virtue of $\mathrm{CT}^{\mathrm{t}} \mathrm{s}$ current practical skills they are better at demonstrating these than most tutors. One grade of teacher would be better".

"I do not agree with two grades of nurse teacher but at the moment the "C.T." appears to concentrate more on manual skills and the 'tutor' more on theoretical aspects".

"We complement each other's teaching, perhaps just emphasise different aspects".

"If they (RNT) taught in the wards I would hope their function there would be similar to mine".
\end{abstract}

A number of clinical teacher comments included reference to the difference in preparation of the two grades of teacher, although no clinical teacher had first-hand experience of a tutor's training course.

\footnotetext{
"The clinical teacher can make his teaching 'patientcentred'. This is more difficult for the RNT as he does not know the patients or the ward situation. The CT has been specially prepared for this type of teaching".

"At present RNTs are not given any instruction on how to teach in the clinical area. Those I have known to teach on the wards tend to do only tutorials, not one to one teaching. With proper training there should be no difference in their function".
}

The Role or Function of the Clinical Teacher vis a vis the Ward Sister/Staff Nurse as Ward Teachers

Clinical teachers were asked whether they thought their function as ward teachers differed from that of the ward trained staff. of 29 respondents to the question, 23 (79\%) considered that a difference did exist. 
The differences they instanced were very similar to those which ward staff had also explained in relation to this same question. The registered clinical teacher wrote of her training in teaching as "a distinct advantage", and linked this with the fact that her priority was the student, whereas the ward sisters' and staff nurses' priorities lay with the patients and ward management. Again, as in the ward staff responses, there was mention of the different approach to teaching, of the use of different methods and of the clinical teachers' ability to link theory and practice. It was interesting to note the clinical teachers ${ }^{2}$ suggestion of the theoretician/practitioner division of function in ward teaching between themselves and the ward trained staff. This was a very marked finding in the responses of the ward trained staff in relation to differences in function between the registered nurse teacher and the registered clinical teacher see Page 380. Other differences mentioned by clinical teachers, were that ward staff teaching tended to be more superficial than their own, and that the ward staff were often unaware of a learner's specific needs.

\footnotetext{
"The clinical teacher has undergone a course of teaching methods and related subjects, e.g. psychology. The teacher has a greater understanding of the learners' requirement and the individuals' previous theoretical and practical attainments. Ward staff frequently have their teaching sessions intermupted which is not usually the case with the clinical teacher".

"Their training for registration did not prepare them to be teachers; that role is traditional, vague and haphazard".
} 


\begin{abstract}
"It is part of the ward sisters' responsibility to teach student and pupil nurses and sometimes the teaching may be incidental to the work. The clinical teachers' main responsibility is to teach student and pupil nurses and any work done is incidental to the teaching. Many ward sisters lack knowledge of how to teach, therefore they function differentiy 'as teachers'".
\end{abstract}

There was some comment that although the ward sister lacked training in how to teach, her knowledge of the patient was often as extensive as the clinical teacher's.

"I find the ward sisters in my experience (also looking back to myself in this position) have not the knowledge/confidence to teach - often ask for advice from myself. Ward sisters lack the necessary training to become a teacher although their practical knowledge of their speciality is excellent".

"The ward sister/staff nurse do more teaching by example and demonstration. My teaching more often is by following up these demonstrations with a tutorial and answering any queries the learner may have concerning medical conditions".

of the six clinical teachers who saw no difference in

function in regard to ward teaching between themselves and the ward trained staff, five also considered there was no difference between themselves and the registered nurse teacher - thus, one function for all, whether trained or untrained as teachers.

Opinions as to whether the Tutor should Teach in the Wards

Opinions of both grades of teacher as to whether the tutor should carry out ward teaching were obtained by asking respondents to choose from four statements, abstracted from the Survey interview 
data, the one which came closest to their opinion. The statements ranged from one giving strong approval to the tutor as a teacher in the wards, to a completely negative attitude thereto, see below:

(a) I feel very strongly that tutors should spend some of their time in the wards teaching student nurses

(b) I think it is quite important that the tutor should do some teaching in the wards

(c) I am not sure that the tutor should teach in the wards at all

(d) The tutor's place is in the classroom, not the wards.

Results were as follows:

TABLE 72 Pre-experiment : Teachers Opinion re Thutor Teaching in Ward

Staff Grade

Strongly Approve approve

Not sure

Thutors $18(43 \%)$

21
16 $(50 \%)$

$2(5 \%)$

$1(2 \%)$

$42(100 \%)$

Clinical teachers

$13(43 \%) \quad 16(53 \%)$

$1(4 \%)$

$30(100 \%)$

$31(43 \%) \quad 37(51.5 \%)$

$3(4 \%)$

$1(1.5 \%)$

$72(100 \%)$

(Rounding to nearest 0.5 )

A very marked majority of both tutors and clinical teachers considered that the registered nurse teacher should carry out ward teaching of student nurses. Only two tutors were unsure on this point and they rarely taught in the ward. Both did, however, approve of students, while in Block, spending some time on the wards under 
the supervision of college staff, as did the clinical teacher who also felt unsure of the tutor as a ward teacher.

One tutor felt that the tutors' place was in classroom not the wards. The latter respondent, a senior tutor, did, on rare occasions, teach students in the wards but only those to whom he was personal tutor. He also considered students should not go to the wards from Block - that the theoretical component and the clinical or practical component should be kept separate. The three tutors and one clinical teacher whose opinions were not positive had each a different length of experience as teachers ranging from $2 \frac{1}{2}$ years to over 20 years.

\section{Reasons why the Tutor does not teach in the Ward}

Again, utilising responses from the survey interviews, a list was compiled of possible reasons why the tutor did not teach in the wards. Respondents were asked to indicate their own opinion, by ranking these statements, assigning from 1 , for the most likely reason, to 5 for the least likely. If they completely disagreed with any reason, they were asked not to assign a rank.

The five reasons listed were as follows:

The tutor does not teach in the ward because:

(a) College commitments prevent her doing so

(b) Ward staff resent her presence

(c) The creation of the Clinical Teacher grade has made it easy for her to opt out

(d) She has lost contact with the reality of nursing care

(e) She lacks confidence in her ability to cope in the ward. 
With regard to the rank ordering of the reasons, both tutors and clinical teachers ranked as the most likely reason for the tutor not teaching in the wards, that the creation of the clinical teacher grade had made it easy for her (the tutor) to opt out of such teaching. Both grades of teacher were also in agreement that the least likely reason was that of ward staff resentment of the tutor's presence, and both agreed in ranking in third place that the tutor lacked confidence in her ability to cope in the ward. The possibility that college commitments might prevent the tutor from carrying out ward teaching was ranked second by tutors and fourth by clinical teachers, and that she had lost contact with the reality of nursing care, fourth by tutors and second by clinical teachers. There was thus considerable consensus by the two grades of teacher prepared to assign a rank, i.e. agreeing with the possible reasons why the tutor did not teach in the ward. 
TABLE 73 Pre-experiment : Teachers

Percentage of Sample agreeing with suggested reasons why Tutor does not teach in Ward

Reason why tutor does not teach in ward
Percentage of $N$ in each Grade prepared to assign a rank - thus agreeing with the reason

$$
\operatorname{RNT}(42=100 \%)
$$

(a) College commitments prevent

(b) Ward staff resent tutor's presence

(c) Creation of clinical teacher grade made it easy for tutor to opt out

(d) Tutor has lost contact with reality of nursing care

(e) Tutor lacks confidence in her ability to cope in ward

$90 \%$

$55 \%$

$93 \%$

$73 \%$

$64 \%$

$87 \%$

$48 \%$

$70 \%$

$64 \%$

$83 \%$

From Table 73 it was evident that a higher proportion of clinical teachers were prepared to agree with each reason, than were the tutors themselves, although, in the survey interview each one of the reasons had been proferred by a registered nurse teacher. Less than half the tutor sample in the pre-experimental questionnaire were prepared to agree with reason (d), i.e. that they had lost contact with the reality of nursing care, and only 55\% agreed that ward staff resentment of the tutor's presence was a relevant factor in the non-appearance of tutors in the wards as teachers. 


\section{CHAPTERR 19}

THE EXXPER IEHNCE OF THE EXXPERTMEHNTAT GROUP THEACHERS

Eleven teachers were involved in the experimental group teaching, eight tutors and three clinical teachers. The same questionnaire was issued to both grades of teacher. Two tutors and one clinical teacher were from College I, one tutor from College II, one tutor and two clinical teachers from College III, two tutors from College IV and two tutors from College V. There were two senior tutors in the group, one from each of the latter two colleges. Opinions of the tutor and clinical teacher in the Pilot College have been excluded in this analysis as during approximately half of the experiment in that college, the researcher and her colleague undertook teaching, and may have influenced teachers' opinions.

Both grades of teacher are reported as one group. It was an essential feature of the experimental teaching method that there was to be no difference in the role or function of the registered nurse tutor and the clinical teacher.

\section{The Role of the Experimental Group Teacher}

All respondents considered it was a part of their role to teach student nurses in the wards in this supermumerary capacity and as a part of their Block programme. Their comments to this question dealt with various aspects of student learning, which was felt to be more meaningful both because of the type of teaching method they used, and because the tutor was there to help the student nurse make the link 
between theory and practice. The experimental method was also seen as helpful for the tutor (a) in keeping her/him up to date, (b) in providing for increased rapport with ward nursing staff, and (c) "it showed students that teachers can nurse".

\section{Effect of the Experimental Method upon Teachers}

Teachers were asked if they found the experience of the experiment enjoyable or stressful. All found it enjoyable and most commented that it had led to more job satisfaction:

"teaching as it should be, directed towards the patient".

One anxiety expressed was that the ward component of the teaching method had revealed some dangerous practices, e.g. dressing technique with faulty asepsis (two comments). Two other teachers were concermed about the classroom component of the method - they felt they did not have enough time to complete the amount of lecture material they had previously decided to include.

It was observed by the researcher that, in most of the colleges, much more time than had been anticipated was taken by the students in discussing with their teachers the contents of their nursing care plans. This student-initiated teaching and learming was a very encouraging feature of the seminars and was remarked upon by all the teachers. However as a corollary there was less time available for material the teachers had planned to include in the seminars. One teacher commented: 


\begin{abstract}
"This is much more exciting, active learning for the students, but we feel less secure as we have not "covered" all we meant to do in a session".
\end{abstract}

\title{
Effectiveness of the Experimental Method as a Teaching Method
}

All eleven teachers considered this an effective way to teach, and all commented upon their answer. Effectiveness was equated with more opportunities for active learning, with reinforcement of learning, and with the emphasis on specific and individual needs of patients. Reservations were expressed as to a lack of time with the patient, and a lack of continuity of care, in that the student was not able to care for the patient throughout the course of his hospitalisation. Two teachers felt it was important to judge effectiveness in terms of long term effect and to see whether the experimental or control group students were better, both theoretically and practically.

\section{Disadvantages of the Experimental Method}

Whereas quite a number of the ward staff and students saw no disadvantages in the method, all teachers were aware of one or more disadvantages. Almost all were related to time. Eight of the teachers mentioned this aspect - not enough days in which to get used to the method of teaching and of learning, not enough time in the wards, not enough time when back in the college.

$$
\begin{aligned}
& \text { "Students were just settling down to it when it } \\
& \text { was over". (This comment from the college with } \\
& \text { the shortest time of four experimental mormings). }
\end{aligned}
$$


"Lack of time - much of this due to my own inability to adjust the content of what was being taught".

Two teachers commented that patients were not always available with just the right, clear-cut condition at precisely the right time.

\section{Advantages of the Experimental Method}

Where ward staff had dwelt on the value of practical

experience per se and integration of theory and practice, teachers tended to describe the advantages of the method by detailing aspects of student learning. Although lack of time had been a disadvantage, teachers pointed out that the experimental method did give more time than a student would normally have available to her to learn while giving patient care. The method made available opportunities for the student to learn how to learn from her work with the patients a vital feature in nursing education.

"The learner has the opportunity to learn how to apply the principles of nursing care, and to learn to adapt the same to the individual needs of the patient".

Some teachers valued the closer relationship with the nurses, and the fact that the method made possible greater observation of the students' practical work, thus enabling the teacher to help the student more.

\footnotetext{
"Feedback much more quickly from nurses in relation to co-ordinating theory and practice. A chance to see at first hand and hear directly the attitudes of the learner to new situations. Closer relationships with ward staff".
} 
Should the Experimental Method be Repeated?

All respondents considered the experimental method should be repeated, mainly because of its perceived efficiency as a learning method.

Fffect of Fxperimental Method upon Patients, Ward Staff and Ward Organisation

As with ward staff and students, teachers were asked what they considered the effects of the experimental method were on the patients directly involved, i.e. those receiving care from the experimental group students. The teachers were also asked about the effects on the other patients in the wards, and on the ward nurses and ward organisation. Their responses were similar to those of the ward staff on all these points. Ten of the eleven teachers pointed to the fact that the patients had enjoyed the experience of giving to the students and that they had indeed helped with the teaching.

\footnotetext{
"The patients were assisted in recovery being stimulated by the eager students and too felt happy to be seen as of help in teaching the nurses".
}

Teachers mentioned only positive effects upon ward staff, mainly in terms of interest, and noted no adverse response to their presence in the wards. 


\section{Supervision of Students}

A majority of the teachers considered supervision was 'just right?. Four teachers felt the students needed more but that this depended very much on the individual student's ability. One teacher of the senior students felt that initially with this method of teaching, her students had required very close supervision but that they quickly grasped the different approach which permitted less supervision.

The Camrying out of Ward Work other than what had been planned

The spectre of 'pairs of hands' arose many times when the researcher broached the possibility of the experiment with college teachers and students. It was said that ward staff would 'use' students in the sense that it would be they (the ward staff) who would decide on the patients to receive care. Several felt that ward staff would ask students to look after very 'heavy' patients, in a sense that they would not take kindly to students as 'students', nor to teachers who had a say in which patients were to receive care from the experimental group students. In the event, none of these fears were realised. No teacher reported that any of her students had been asked to do work in the ward other than that previously arranged and directly related to their lectures. 
Roles of Registered Nurse Tutor and Registered Clinical Teacher in Experiment

The presence of the two grades of teacher in nurse education has been a matter of professional debate and concern for some considerable time. It was intended that there should be no difference in role or function for the nurse tutors and the clinical teachers who participated in the teaching of the experimental group students, and responses to the relevant question confirmed that this was indeed the case in the two colleges where the two grades were involved together. In Colleges I, II and IV only registered tutors were involved.

The three clinical teachers were questioned about the amount of their college commitment during the experiment. Two were quite satisfied but one felt that he should have had more time in college and in formal teaching. Should the experimental method become a part of their college programme, all three clinical teachers felt that they had a role to play - one confined this to "teaching my specialty only"; another said:

"I would like my function to be what it was during the experiment - I had a feeling of teaching the whole nurse!" (Respondent's underlining')

The eight registered nurse tutors were asked if they considered their course prepared them to do ward teaching such as they had done during the experiment. Three teachers, all of whom had undergone a University course and none of whom had been clinical teachers, said their course had prepared them adequately. Five teachers, four of 
whom were trained at Jordanhill College of Education and one at University, said their course had not prepared them for ward teaching. Four of these five were previously registered clinical teachers and each said that a clinical teachers' course was essential preparation for teaching such as was required of them during the experiment.

\section{Alteration to Job Satisfaction}

Job satisfaction was enhanced for nine of the eleven teachers during the experiment, due to patient contact, to increased communication with patients, ward staff and students, and to closer working relationships with teacher colleagues. One said:

"I feel I had the best of both worlds".

For one teacher, job satisfaction was diminished as she felt "a little frustrated that some things were not covered due to the time factor".

\section{Ways in which the Experimental Method could be Improved}

Teachers were more forthcoming than ward staff had been in regard to ways in which the experimental method could be improved, especially in regard to student learning and patient needs. The dominant note was of the need for more time - students it was felt would benefit from a longer period of time with the patients, as would the patients. Suggestions given were that students might remain in one ward for several days, returning to the same patient, 
or patients, on each day; that the time when they came to give care might be varied to take account of differing activities at different times of the day; that they might follow through care for patients with similar disease conditions but at various stages, e.g. on admission, pre-operatively, post-operatively and then when convalescing, if possible including the after-care of the patient. Three of the teachers felt there was a need for more college time to be given to the seminars.

\section{Achievement of Objectives of the Experimental Method}

Teachers were presented with the objectives of the experimental method of teaching/learning and asked to evaluate them using the same six-point scale as was presented to ward trained staff (see Page

Table 74 below shows their evaluation, which is very encouragingly positive. 
TABLE 74 Post-experiment : Teachers

Achievement of Objectives of Experimental Method

Objectives

Positive
$+++++-{ }^{\text {Negative }} \quad \mathrm{N}=$

1. Help the student integrate theory and practice

2. Increase communication between tutorial staff and ward staff

3. Lessen the gap between the ideal and reality in nurse education

4. Bridge the gap between education and service

5. Better prepare the student nurse for her ward work and responsibilities

6. Improve ward staff's understanding of what a student nurse can do at various stages of training

7. Improve standards of nursing by supervising the student nurse in giving planned and individualised patient care

8. Diminish stress for the ward teacher by making the student nurse supernumerary

9. Diminish stress for the teacher by giving a measure of control in the choice of patients and consequently a measure of predictability of teaching

10. Diminish stress for the student nurse by making her supernumerary while she was giving care and being taught on the ward

$\begin{array}{llllllll}5 & 5 & - & - & - & - & 10 \\ 8 & 2 & 1 & - & - & - & 11 \\ 5 & 3 & 1 & 1 & - & - & 10 \\ 6 & 2 & 3 & - & - & - & 11 \\ 5 & 4 & - & 1 & - & - & 10 \\ 3 & 2 & 3 & 2 & - & - & 10 \\ 8 & 1 & 2 & - & - & - & 11 \\ 7 & 2 & 2 & - & - & - & 11 \\ 8 & 2 & - & - & - & -11 \\ 8 & 1 & 2 & - & - & & & \end{array}$

When further analysis was undertaken by 'scoring' the positive/ negative scale, in the same way as was done with ward staff responses, the mean scores for each objective were as shown in Table 75. 
The first seven objectives listed were identical to those presented for evaluation by the ward trained staff. The last three were evaluated only by the teachers. Teachers seldom gave a negative rating, and when they did, chose the single-negative box. Overall, their mean scores were slightly higher than those given by the ward staff. The group whose scores approximated most closely to those given by the teachers, were the ward sisters.

TABLE 75 Post-experiment : Teachers Mean Scores for each Objective

1. Help the student integrate theory and practice

2. Increase communication between tutorial staff and ward staff

3. Lessen the gap between the ideal and reality in nurse education

4. Bridge the gap between education and service

5. Better prepare the student nurse for her ward work and responsibilities

6. Improve ward staff's understanding of what a student nurse can do at various stages of training

7. Improve standards of nursing by supervising the student nurse in giving planned and individualised patient care

8. Diminish stress for the ward teacher by making the student nurse supermumerary

9. Diminish stress for the teacher by giving a measure of control in the choice of patients and consequently a measure of predictability of teaching

10. Diminish stress for the student nurse by making her supernumerary while she was giving care and being taught on the ward 
With regard to the first seven of the listed objectives, i.e. those also evaluated by the ward trained staff, the main objective of the experimental method "to help the student nurse integrate theory and practice" achieved a $100 \%$ positive rating and a mean score only .I lower than the objective "to increase communication between teaching staff and ward nursing staff". The latter gained the highest mean score in the teachers' evaluation of these seven objectives. Improvement of standards of nursing achieved the same mean score as the integration objective, which was a very satisfactory outcome, and next in order of scores came the objective dealing with the preparation of the student nurse for ward work and responsibilities.

There was only one exception to an otherwise uniformly high scoring of the objectives by the experimental group teachers. They, like their service colleagues, gave the lowest mean score to the objective of improving ward staff understanding of what the student nurse is able to do at the various stages of training.

Objectives 8, 9 and 10, which were presented only to the teachers, dealt with the very real problem of stress associated with ward teaching, both for the teacher and for the student nurse. Their evaluation showed that the experimental method was seen as a very effective way of diminishing this stress.

Feasibility of the Experimental Method : Control and Experimental Group Teacher Opinion

Teachers of both the control and the experimental groups were asked to comment on the feasibility or otherwise of the altered teaching method, as one possible method of teaching student nurses at certain stages of their training. 
The researcher felt it was reasonable to expect that control group teachers would have formed an opinion about the method as, al though they did not have first hand experience, they could not but be aware of what was happening, as they were in daily contact with the experimental group students and their teachers. All but one of the control group teachers considered it to be feasible, and approved the method. The difficulties they saw were in relation to the numbers of teachers they thought would be needed to put it into operation, and the problem of organisation when class numbers were large.

Opinions of the experimental group teachers in regard to feasibility were considered to be most important, based as they were on their direct experience of the method, albeit for a fairly short period. Apart from one clinical teacher, who felt she had insufficient knowledge about the Block programme to enable her to comment, all experimental group teachers considered the method to be feasible.

\footnotetext{
"This method of teaching is possible at all stages of training and must be commenced in Introductory Block to set foundation for more senior learning experience".
}

One teacher intended to put the experimental method into immediate use, and another to discuss the possibility of its use, within a management Block, with her colleagues in both education and service. 


\begin{abstract}
"It is feasible as a method of teaching student nurses while in Block, particularly postregistration nurses whose training is short. It would also be ideal for nurses in the preregistration period to teach them what to look for as a staff nurse. I am going to use this method of teaching with in the first instance postregistration nurses doing general training".
\end{abstract}

(Note: This respondent did in fact go on to use the method and reported that it was most satisfactory, and very well received by the post-registration student nurses).

The other respondent referred to above said that, although it would take a good deal of organisation with a large group, she believed it could be done, and added:

"I would be delighted to try this with ward management as well as patient care. This would require even more co-operation with senior ward staff".

Although three teachers mentioned the factors of time, staff numbers, and/or organisation, their approach was more pragmatic than that of their control group colleagues, no doubt because of the fact that they had experience of the method. One teacher said that with large groups the method could be used 'on rotation', i.e. some students in class and others in the ward for certain topics. Two felt that, as the GNC Syllabus stood at the moment, it would not be possible to cover every topic if teachers used this method of teaching to a great extent. This response of course begs the question - is it necessary, even advisable, to 'cover' every topic? 
However, from the experimental group teachers, there was affirmation of this method of teaching nursing:

"We must not wait too long before introducing this method ... when one considers how short the leamer's clinical experience is, this method is invaluable in certain areas". 
CHAPTTHR 20

THE FXXPERTENCE OF THE CONTROL GROUP TTEACHERS

There were eight teachers involved with the students of the control group - five tutors, two clinical teachers and one uncertificated teacher.

Two tutors and one clinical teacher were from College I, one tutor from College II, one tutor and one uncertificated teacher from College IV, and one tutor and one clinical teacher from College V. There were no teachers from College III in this number as there was no control group there. Teachers in the Pilot College were not included, as a certain amount of teaching of the control group was shared with the researcher. The first two questions of the control group teachers' post-experiment questionnaire were not dissimilar - the first asked whether the experiment had caused any alteration in the control group experience of the subject, apart, that is, from the reduction in numbers of students in the classroom, and the second whether it had caused any disruption. The first question deliberately used a non-emotive term - simply was the control group experience altered, made different whereas the second made use of the more value-laden word 'disruption' - broken up.

\section{Alteration of Control Group Experience of Subject}

Three teachers said there was no alteration as a result of the experiment. One clinical teacher did not know, as she did not normally teach in classroom during this particular Block, and four 
said there was some alteration. Teachers from two of the colleges said that the nursing lectures were concentrated into a shorter period of time than was usual, and, again from two colleges, that there was an unnatural lag between the start of the medical staff lectures on the subject and the start of the related nursing lectures.

\section{Disruption of Control Group Fxperience of the Subject}

Six teachers said there was no dismuption, and one that the time lag referred to above may have had a disruptive effect. Two tutors, both from College I, felt that there was disruption. One said the control group experienced boredom to some degree with the very long sessions, and the other that:

"they felt they were being 'saturated' with the one subject and at times seemed less receptive to the teaching given".

\section{Effect of the Experiment on Control Group Students}

The effect of the experiment on the control group students was considered to be slightly detrimental by the two tutors in College I, because there was "too much of one subject at one time". Teachers in Colleges II and V felt the experiment had very little effect, apart from arousing some curiosity and the feeling amongst the control group students that they "just might be missing out"; and in College IV a Hawthorne effect was reported, e.g. "a competitive aspect which seemed to stimulate them and maintain their interest". 
Observed Effect of the Experiment on Experimental Group Students

Four of the teachers said they had very little contact with the experimental group students and four observed that they appeared to be enjoying the experience.

\section{Effect upon the Teachers}

Teachers were asked whether the experience of the experiment had proved to be enjoyable or stressful? Four teachers quite clearly found it an enjoyable and interesting experience. The others were less sure, and chose neither altermative. Two commented that it was 'a bit of both', one that it was no different from usual, and one that she considered it had been less enjoyable than teaching normally was.

\section{Feasibility of the Experimental Method}

The control group teacher responses are to be found on Page 450 reported together with the responses of the experimental group teachers to the same question. 


\section{CHAPTHER 21 .}

\section{RESULTS OF THE TTESTS AND ESSAYS}

Complementary to the qualitative evaluation, in terms of opinions about the experimental method of teaching nursing from all those involved, was the quantitative evaluation in terms of test scores obtained by the students who had experienced the experimental method and those who had experienced the usual college method.

There were two parts to this latter evaluation. In the first, Part $A$, the main and basic question was in regard to the relative instructional effectiveness of the two methods of teaching nursing care of patients with disease of the gastro-intestinal tract. These two teaching methods were described in detail in Chapter 6 and will therefore be only briefly outlined. Experimental group students experienced teaching which combined supervised ward practice of relevant nursing with concurrent college lectures and/ or tutorials - hereinafter referred to as "the experimental method" or "the treatment". Control group students were taught by entirely college-based methods - hereinafter referred to as "the control method".

The second part of the evaluation, Part B, was not concermed with any comparison of teaching methods, but with the relationship between multiple choice tests and essays in nursing examinations, and also with the reliability of the marking of essay scripts. 


\section{Introduction to Parts A and B}

Recapitulation of Certain Factors Relevant to the Tests and Essays

A brief synopsis of information relevant to the administration, marking and analysis of the tests and essays follows. This material is already to be found in various chapters in Part II, but is repeated here, together with other relevant information, in order to obviate the necessity for the reader to refer back to these different chapters.

The tests which are referred to throughout are the previously validated Multiple Choice (objective) test, hereinafter referred to as the test, and the essay type tests, hereinafter referred to as the essay. The test was identical at all three stages of the experiment, and across all colleges. The essays were identical at both stages of the experiment, but were college-specific. Although similar in content, i.e. selected from the subject matter of the course as outlined in the GNC (Scotland) syllabus, the specific questions were not identical across colleges (see Appendix XVIII "the College essays").

All scores used to evaluate this experiment derived from these two types of test. Scores on the test were calculated by a short programme added to the Rasch Item Analysis Model (Wright and Mead, 1977) which had been used for the item analysis when this test was constructed and validated. Scores on the essays were obtained by issue of the scripts to three neutral markers, all of whom were General Nursing Council for Scotland Examiners, i.e. they were responsible for correcting the essay type Final State Fxamination 
scripts. In addition to the marks provided by the three neutral examiners, post-experiment essay scripts from each college were marked by that college's own tutors. This was necessary, so that each college could quickly obtain results to 'feed back' to the students, and to include in their own records. These college marks were subsequently amalgamated with those of the neutral markers, to produce an average post-essay score for each student. There was no college mark for the retention essays so as to preserve confidentiality for the students, i.e. they were all informed that none of their marks would be divulged to their college tutors. Thus there were only the three neutral markers scores available for the retention essay.

Before any questions as to the effectiveness, or relative effectiveness of the two teaching methods could be answered, it was essential to know, in relation to each student, her 'starting-off point', or baseline in terms of knowledge of the subject matter of the course. This was obtained by the administration of the pretest, the scores from which provided that baseline from which any gain, or loss, could be calculated.

This pre-testing of students was a most important feature of the experimental design, as was explained in Chapter 6.

The difficulty of controlling the variable of prior relevant experience was overcome by the administration of the previously validated test $\left(\mathrm{O}_{1}\right.$ and $\mathrm{O}_{4}$ in Figure 15) which tested prior knowledge of the relevant subject matter and yielded scores on which students were 'paired', i.e. these pairs of students were like each 
other in terms of relevant knowledge. These students were matched lst with 2nd, 3rd with 4 th and so on throughout their class, and then one from each pair was assigned at random to the experimental and control groups - the basis for the randomised blocks design. Due to the small and variable size of the groups in each college, it was considered most appropriate to analyse results across all four colleges - and a total of 32 matched pairs resulted - 12 pairs from College I, 4 pairs from College II, 8 pairs from College IV and 8 pairs from College V 64 students in all. At the particular point in the analysis when within-pair differences were being examined, only intact pairs could be used. Thus, if one member of a pair was missing, her partner was also 'lost' to the statistical analysis, and this resulted in a gradual decrease in the numbers of pairs from preexperiment to the final retention of learning tests and essays (see Table 76). Of 32 pairs at the start of the experiment and pre-test, 31 remained at the post-test stage (one control group student was absent, thus losing 1 pair); by retention of leaming stage, the same control group student plus one other was absent for the test and altogether 3 control group students were absent for the essay. In addition one experimental group student was absent at this stage, therefore the original figure of 32 pairs was finally reduced to 28 at the point when the differences between post-essay and retention essay were considered, and to 29 pairs for the analysis of the post-test with the retention test. However, when gain or loss scores, at the different stages of the experiment, 
were considered, intact groups were used, i.e. not pairs. The number of subjects contributing to each test mean score is specified on each occasion.

\section{The Students in College III}

There were a number of differences in regard to College III. There was no control group, therefore no pairing of students. All students were taught by the experimental method. Each student had prior knowledge of the subject matter as the experiment took place during a revision block, which was scheduled immediately before all students went to the wards for relevant nursing experience. As an essay was not required by this college, the only scores which were available to assess the effectiveness of the teaching for these students were the test scores. For all of the above reasons, the analysis of results, and the reporting, was undertaken as a separate entity, within Part A.

\section{PART A}

\section{The Sample in Part A}

Table 76 shows the sample of students to which the first part of the analysis refers, i.e. the comparison between the two methods of teaching to which, respectively, the control and experimental groups of students were exposed. 
TABLE 76 Tests and Essays : Sample of Students for Part A

Multiple Choice Test

Essay Test

College Pre-test Post-test Retention test Post-essay Retention essay

$\begin{array}{lllllllllll}C & \mathrm{E} & \mathrm{C} & \mathrm{E} & \mathrm{C} & \mathrm{E} & \mathrm{C} & \mathrm{E} & \mathrm{C} & \mathrm{E}\end{array}$

\begin{tabular}{rrrrrrrrrrr}
\hline I & 12 & 12 & 11 & 12 & 10 & 12 & 11 & 12 & 10 & 12 \\
II & 4 & 4 & 4 & 4 & 4 & 4 & 4 & 4 & 3 & 4 \\
IV & 8 & 8 & 8 & 8 & 8 & 7 & 8 & 8 & 8 & 7 \\
V & 8 & 8 & 8 & 8 & 8 & 8 & 8 & 8 & 8 & 8 \\
\hline Total N $=32$ & 32 & 31 & 32 & 30 & 31 & 31 & 32 & 29 & 31 \\
\hline
\end{tabular}

Note: $\quad C=$ control group students

$\mathrm{E}=$ experimental group students

College III students were omitted from the Table, as there was no control group to contribute test scores in this college. There were however ten students in the experimental group who undertook all three multiple choice tests and their scores were analysed within their own college only. This separate analysis was also appropriate as these students were the 'one-off' group of more senior students.

\section{The Pre-test}

The internal validity of the experiment, i.e. that the differences in the dependent variables or test scores resulted from the different independent variable or treatment, rested upon the demonstration of effective pairing or blocking. The result of the pre-test showed a mean for the experimental group students of 52.531 , and for the control group students of 52.625 . There was no statistically significant difference between the experimental and control pairs on pre-test, and a high positive correlation between the two sets of scores was demonstrated. The mean difference was 0.094 , standard error 0.576 , the $t$ value -0.16 , which with 31 degrees of freedom was not significant. The Pearson $r=0.935$. A histogram, showing the distribution of the 
two sets of scores is shown in Figure 51.* The initial equivalence of the pairs of students in regard to knowledge of the subject matter of the course was therefore very satisfactorily confirmed by these results.

\section{The Demonstration of Leaming}

The first and fundamental question to be answered, in regard to all the students, irrespective of group, was whether they had learned as a result of the teaching - whether their scores were higher at the end of the course than at the beginning. The answer was clearly positive. For the 31 matched pairs of students, this first exposure to the course content resulted in gain scores of 15.86 for the experimental group students, and 14.98 for the control group students, a difference of 0.88 in favour of the experimental group.

There can be no doubt that the main reason for the gain scores exhibited by students in both groups from pre- to post-test was that the appropriate subject matter had been taught. However, apart from this not unexpected increase in scores, a further interesting point to emerge was the negatively-skewed distribution for the post-tests for both groups of students, as shown in Figure 52 . This was in part due to the major intervention of the teaching, but testing effect must also be borme in mind. The nature of the experimental design was such that test-retest effect was controlled, and there was some evidence for this control in the very similar distributions for both control and experimental group students. However the fact 
that the students had worked through the test before cannot but have affected the post-test scores. As there was no preexperiment essay, only test scores were considered in the evidence of immediate recall.

Before examining in more depth the above results, two other basic questions required an answer - (a) had there been retention of learning over time, i.e. did scores remain higher on retention testing than on pre-testing, and (b) was there any evidence of forgetting over time, i.e. when the post-test results were compared with the retention-test results?

\section{Demonstration of Retention of Learning}

Retention of learning was demonstrated for students in both groups. For the, by now, 29 matched pairs of students, the gain score from pre-test to retention test in the experimental group was 16.47, and in the control group was 14.37.

Figure 53 shows the experimental group mean to be 69.00 and the control group mean 67.00, a difference of two points in favour of the experimental group. With regard to question (b) above, there was no evidence of forgetting over time for the experimental group, who in fact demonstrated a minimal gain of 0.61 marks from post-test to retention test. There was very slight evidence of forgetting from the control group who showed a loss of 0.61 marks from postto retention test. Again the histograms maintained the negative skew, shown at the recall stage, and whereas the distribution was remarkably similar at the two stages for the experimental group 
students, there was slightly less dispersion about the mean among the control group students, as evidenced by the smaller standard deviation, i.e. from 8.04 at post-testing to 6.99 at retention testing. It is likely that many of the students would remember items in the test which was, at this retention stage, presented to them for the third and final time, and so testing effect must again be considered in viewing the results. There was one further factor which was considered as of influence on test results at this stage of the experiment, and that was the intervening practical experience of nursing on the wards. This was investigated and reported later in this chapter.

Until this point, only the test scores have been discussed, but at post- and retention stages the essay scores were also available for comparison. The essays presented a totally different distribution picture from the tests. In Figures 54 and 55 the negative skew was absent, and there were markedly lower mean scores when compared to the tests. There were also clear loss scores betwixt post-experiment and retention of learning assessments. There was a loss score of 5.52 marks for the experimental group students between the post-essay and the retention essay, and of 8.74 marks for the control group students.

As there was no pre-experiment essay, testing effect was a factor to be considered only in regard to retention essay scores, and there was no evidence of this effect in these results, possibly because there was very little in the essay type questions to trigger recall. The effect of forgetting over time was more evident in the 
essay scores, and this effect was less, by 3.22 marks, for the experimental group students than for the control students. It was possible that, because the retention essay always preceded the retention test, the effort to recall for the former might have been a positive aid to memory for the latter. This might, in part, explain the consistently higher scores for tests than for essays in both groups of students at both stages of the testing. This difference was quite marked. In the experimental group the post-test mean was 8.62 marks more than the post-essay, and in the control group it was 8.19. At the retention stage, the difference between the test and essay means was, for the experimental group students, 14.75 and for the control group students, 16.32 . 
Figure 51 Histogram of Pre-test Scores : Matched Pairs

EXXPERTMENTTLL

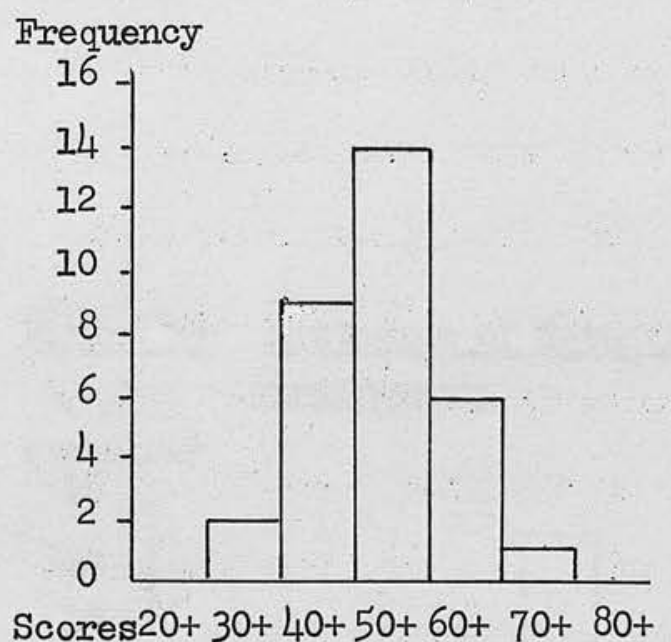

$\mathbb{N}=32$

$\mathrm{M}=52.53$

$\mathrm{SD}=8.6$

$\mathrm{SE}=1.52$
CONTIROL

Frequency

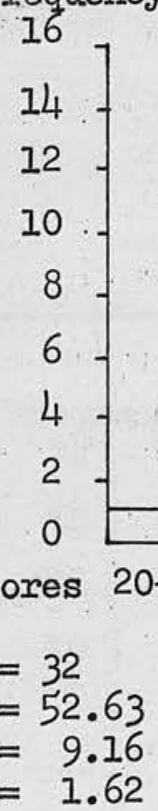

Figure 52 Histogram of Post-test Scores : Matched Pairs EXPERTIMHENTAL

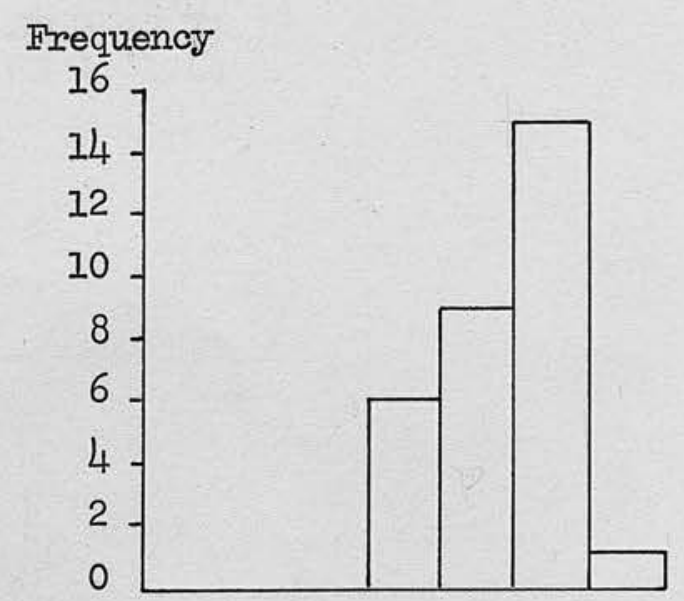

Scores $20+30+40+50+60+70+80+$
CONTROL

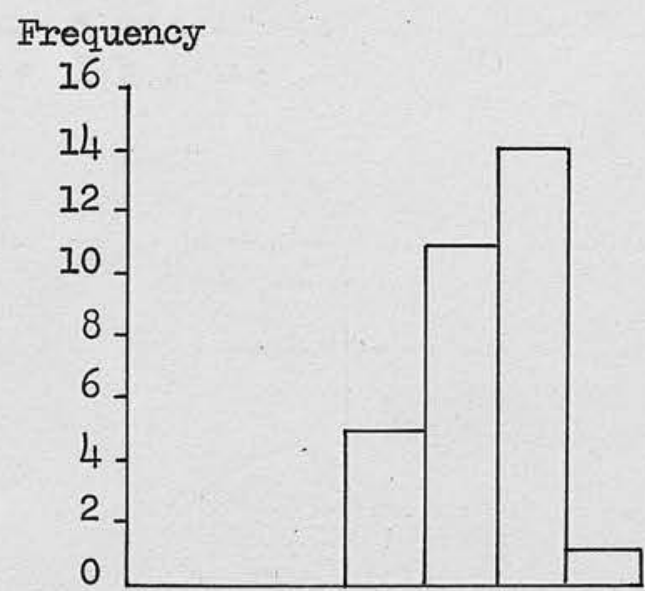

Scores $20+30+40+50+60+70+80+$

$$
\begin{aligned}
\mathbb{N} & =31 \\
\mathrm{M} & =67.61 \\
\mathrm{SD} & =8.04 \\
\mathrm{SE} & =1.45
\end{aligned}
$$


Figure 53 Histogram of Retention test Scores : Matched Pairs

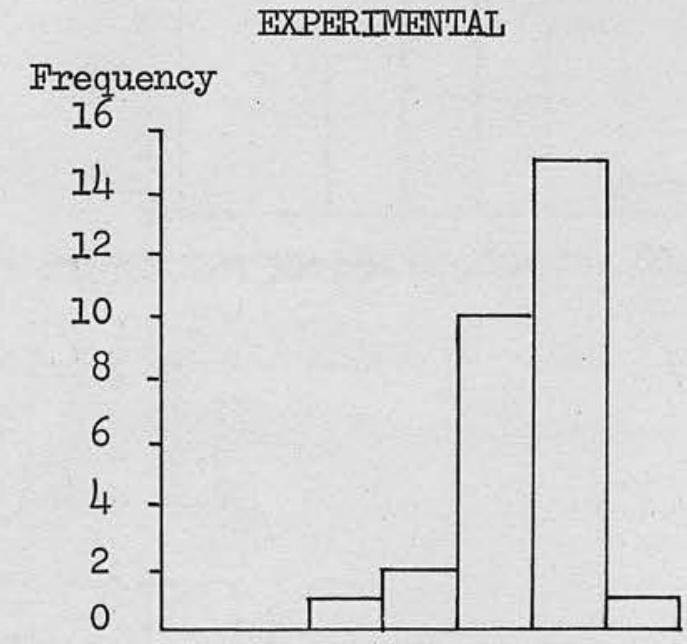

Scores $20+30+40+50+60+70+80+$

$$
\begin{aligned}
N & =29 \\
M & =69.00 \\
S D & =7.77 \\
S E & =1.44
\end{aligned}
$$

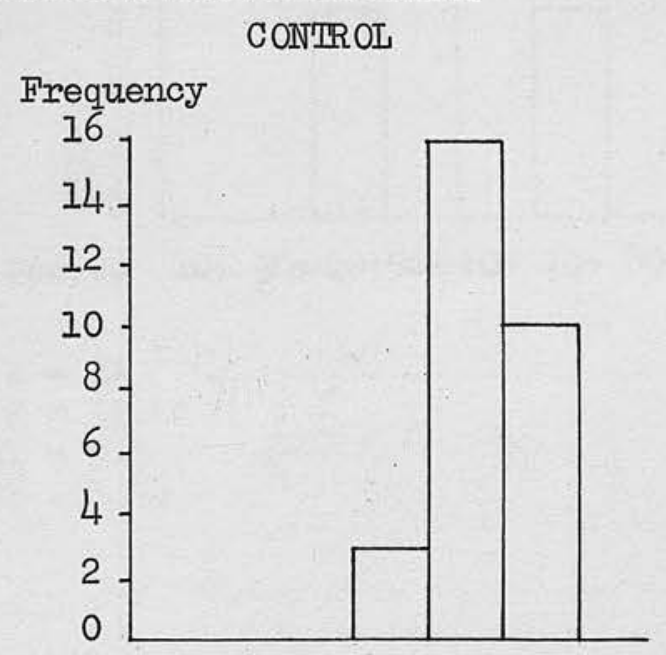

Scores $20+30+40+50+60+70+80+$ $\mathrm{N}=29$

$\mathrm{M}=67.00$

$\mathrm{SD}=6.99$

$\mathrm{SE}=1.3$ 
Figure 54 Histogram of Post-essay Scores: Matched Pairs

FXXPERTIIENTAL

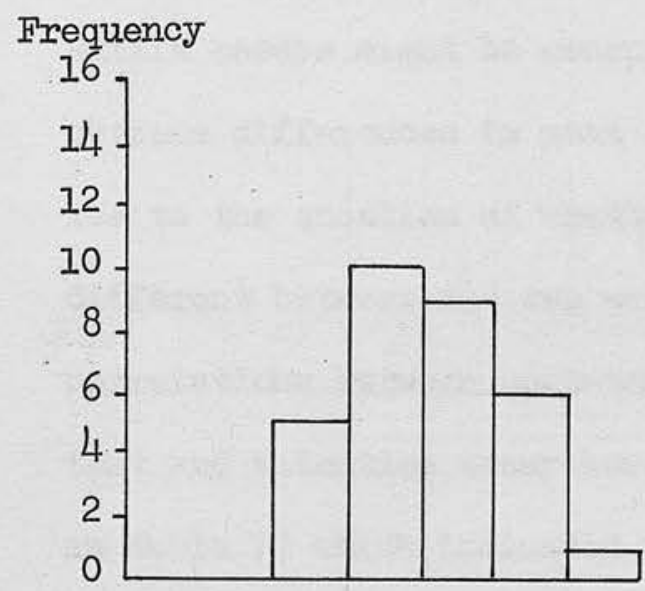

Scores $20+30+40+50+60+70+80+$

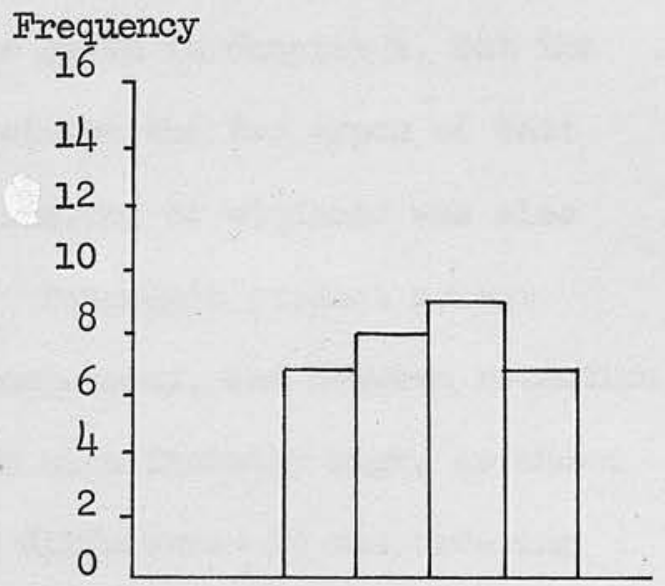

Scores $20+30+40+50+60+70+80+$

$$
\begin{aligned}
\mathrm{N} & =31 \\
\mathrm{M} & =59.77 \\
\mathrm{SD} & =10.6 \\
\mathrm{SE} & =1.9
\end{aligned}
$$

$$
\begin{aligned}
\mathrm{N} & =31 \\
\mathrm{M} & =59.42 \\
\mathrm{SD} & =9.7 \\
\mathrm{SE} & =1.74
\end{aligned}
$$




\section{Correlations of Tests with Essays}

A discussion of testing, and just what type of cognitive skills essays might be measuring, was given in Chapter 4, but the obvious differences in mean scores between the two types of test led to the question of whether the ordering of students was also different between the two measures. Pearson's product moment correlations between post-test and post-essay, and between retention test and retention essay however were significantly high, as shown in Table 77 which indicated no great differences in the ordering of the students, within their groups, on the two test variables.

TABLE 77 Tests and Essays (within groups) : Pearson Product Moment Comrelations

\begin{tabular}{lllll} 
Tests & \multicolumn{1}{c}{ Groups } & N & r & s \\
\hline & Experimental & 32 & 0.70 & 0.001 \\
$\begin{array}{l}\text { Post-test with } \\
\text { Post-essay }\end{array}$ & Control & 31 & 0.48 & 0.01 \\
$\begin{array}{l}\text { Retention test } \\
\text { with }\end{array}$ & Experimental & 31 & 0.48 & 0.01 \\
$\begin{array}{l}\text { Retention essay } \\
\text { Control }\end{array}$ & 29 & 0.53 & 0.01 \\
\hline
\end{tabular}

In summary therefore, all students, whether taught by the experimental or the control method, had demonstrated by a gain in test scores that they had learned as a result of the teaching, and all had retained much of that learning over time. However, when essay scores were examined there was evidence of knowledge decrement over time. At every stage of the testing, the 
experimental group students were marginally better than the control group students. The next step in the evaluation was to look more closely at the differences between those taught by the experimental method and those taught by the control method.

\section{Demonstration of Differences : i.e. Treatment Effect}

Firstly, the question was simply to establish whether, within each pair, the experimental student had achieved a higher score than her control partner on each of the post- and retention dependent variables. The Sign test for large samples ( $n>25$ ) was used to analyse the signs of the differences within the pairs on the postand retention tests and essays. The advance prediction was that the number of positive signs would be significantly greater for the experimental pair members than for the controls. In the event this did not happen. Table 78 shows that when positive and negative differences were counted, there was no statistically significant result. There was, at the post-experiment stage, very little difference between the two groups, al though again the experimental group was slightly ahead of the control group, but by the retention of learning stage the difference, though still not significant, had widened considerably in favour of the experimental group. 
TABLE 78 Tests and Essays : Sign Test - Direction of Differences within Pairs

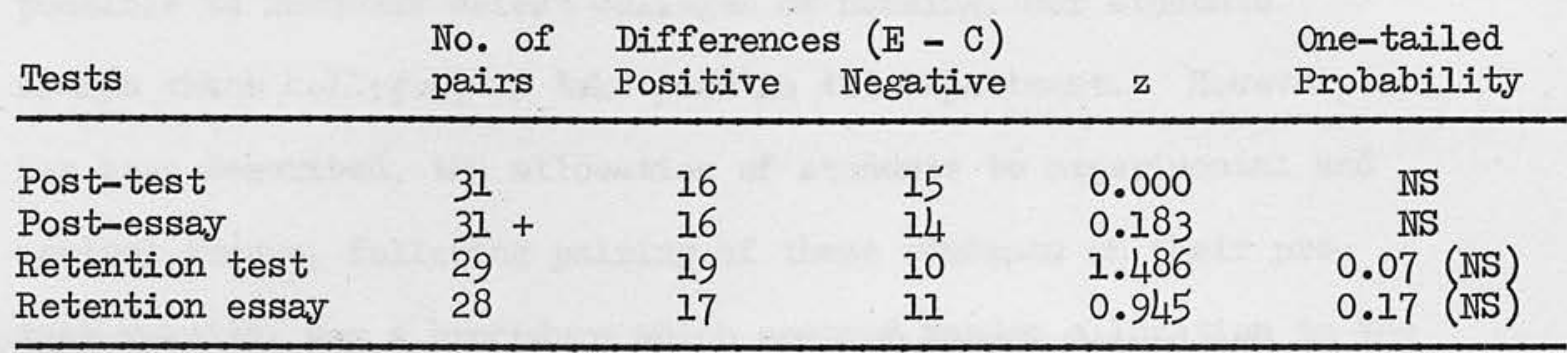

$+=$ one 'tied' pair

The final stage of the evaluation of the treatment effect made use of the more powerful parametric tests. The data, collected as they were in the form of scores, i.e. interval level, were suitable for such detailed analysis, and in particular, for the use of Student's t-test of the significance of the differences between the means. Where within-pairs differences were examined, as was done here, the efficiency of the randomised-blocks design came to the fore, in that it eliminated the inter-block or inter-pair variation, thus allowing the calculation of the standard error on the irreducible minimum within-block or within-pair variation. The larger value of $t$ which resulted was very slightly offset by the reduction in the degrees of freedom which were calculated on the $\mathrm{N}$ of blocks (32) minus one, and not N (64) minus one. During the course of the experiment the original N of blocks of 32 was reduced, at retention essay, to 28 .

The question now therefore was whether, at any point in the experiment, differences demonstrated by this small sample were of such magnitude as to be generalisable to the population of student nurses in Scotland from which the sample was drawn. The important 
limitation to generalisation of the results was that it was not possible to randomly select colleges of nursing, nor students within these colleges, to take part in the experiment. However, as has been described, the allocation of students to experimental and control groups, following pairing of these students on their pretest results, was a procedure which ensured random allocation to the two groups, controlled the variable of entering knowledge, and also ensured a spread of ability within the two groups of students.

\section{The Gain Scores}

Firstly, the gain scores achieved by students in both experimental and control groups from pre-test to post-test and from pre-test to retention test were tested for significance. The comparison was therefore between the same individual on the tests at the two stages of the research experiment, i.e. she was paired with herself. As a gain, therefore direction was predicted, a one-tailed test of significance was used. Table 79 showed a mean gain pre- to post-test for the 32 experimental group students of 16.0312 ( $t$ value 12.08, $p<0.001$ ) and for the 31 control group students of 14.8065 ( $t$ value 10.50, $p<0.001$ ). Mean gains pre- to retention tests were, for the 31 experimental group students 16.7097 ( $t$ value 14.55, $p$ $<0.001$ ) and for the 30 control group students 14.5 . ( $t$ value 10.58, $\mathrm{p}<0.001)$. It was therefore concluded that student nurses experiencing either teaching method were likely to make a significant gain score between pre- and post-testing, and to retain a significant gain between pre- and retention testing, as all results were well 
beyond the critical value of $t$ for the relevant degree of

freedom. It appeared therefore that both courses of instruction were effective. 


\section{The Loss Scores}

When knowledge decrement was examined, i.e. the same individual was compared on her post- and retention scores, and a one-tailed test of significance used, there was a different result for the tests and for the essays. There was a gain of 0.4516 for the 31 experimental group students and a loss of 0.4333 for the 30 control group students. These were minimal differences and neither result was statistically significant. The loss score on the essays however was significant. For the 31 experimental group students, an average of 5 marks was lost, and for the 29 control group students the average loss was 9.2069 marks. Thus, not to have a significant loss score in the population of student nurses, given the course of instruction and teaching methods experienced by students in the sample, could only happen by chance, once in 1,000 times. (See Table 80) The relative stability of the test scores was commented upon in an earlier section. 


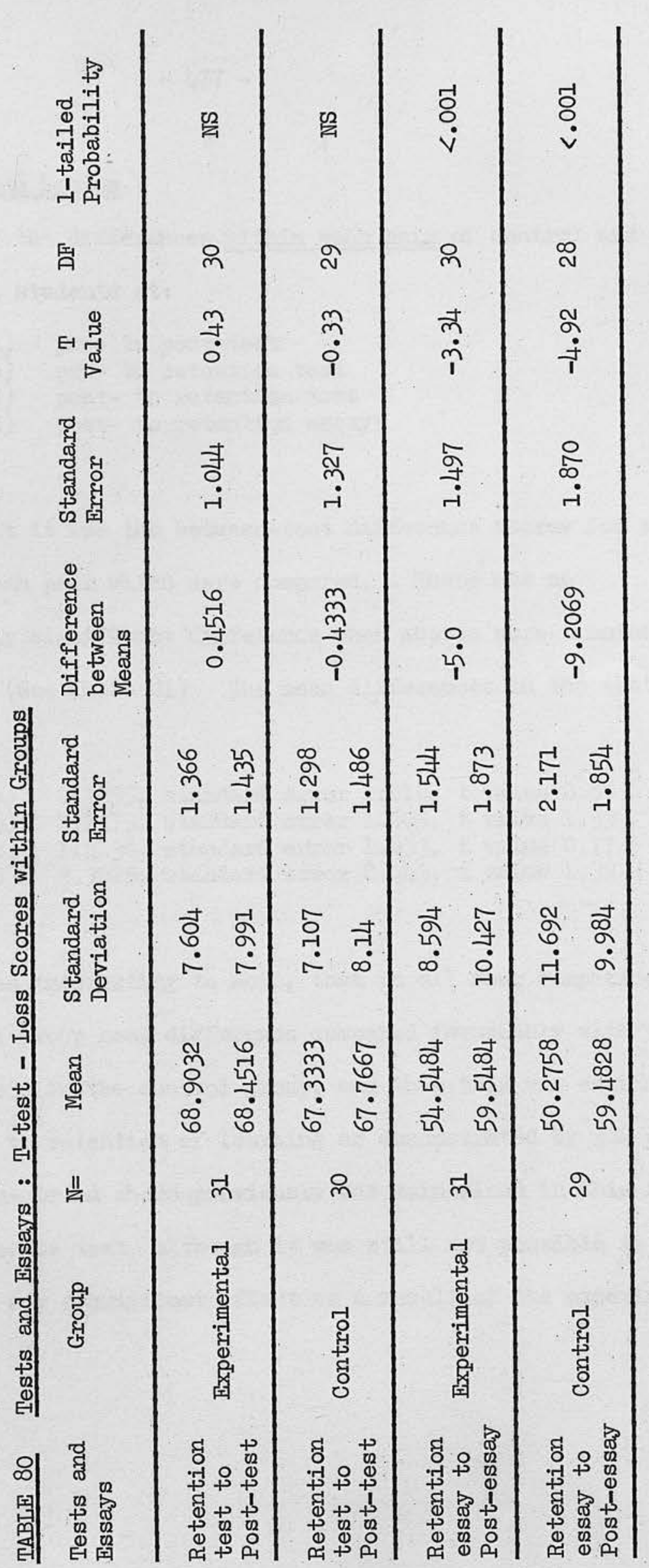


The Difference Scores

What of the differences within each pair of control and experimental students at:
(a) pre- to post-test
(b) pre- to retention test
c) post- to retention test
(d) post- to retention essay?

At this point it was the between-test difference scores for each member of each pair which were compared. There was no statistically significant difference when scores were examined in this way. (See Table 81) The mean differences on the tests as above were:
(a) 0.9355 , standard error 1.618 , $t$ value 0.58
(b) 2.1379 , standard error 1.605 , $t$ value 1.33
c) 1.4138 , standard error 1.833 , $t$ value 0.77
(d) 3.3929 , standard error 2.443 , t value 1.39

Again, it was interesting to note, that in all four comparisons the experimental group mean difference compared favourably with that of their partners in the control group, and that this was especially so with regard to retention of learning as demonstrated by the essay scores. The trend shown previously was maintained in this final and most precise test, although it was still not possible to demonstrate any significant effect as a result of the experimental method. 


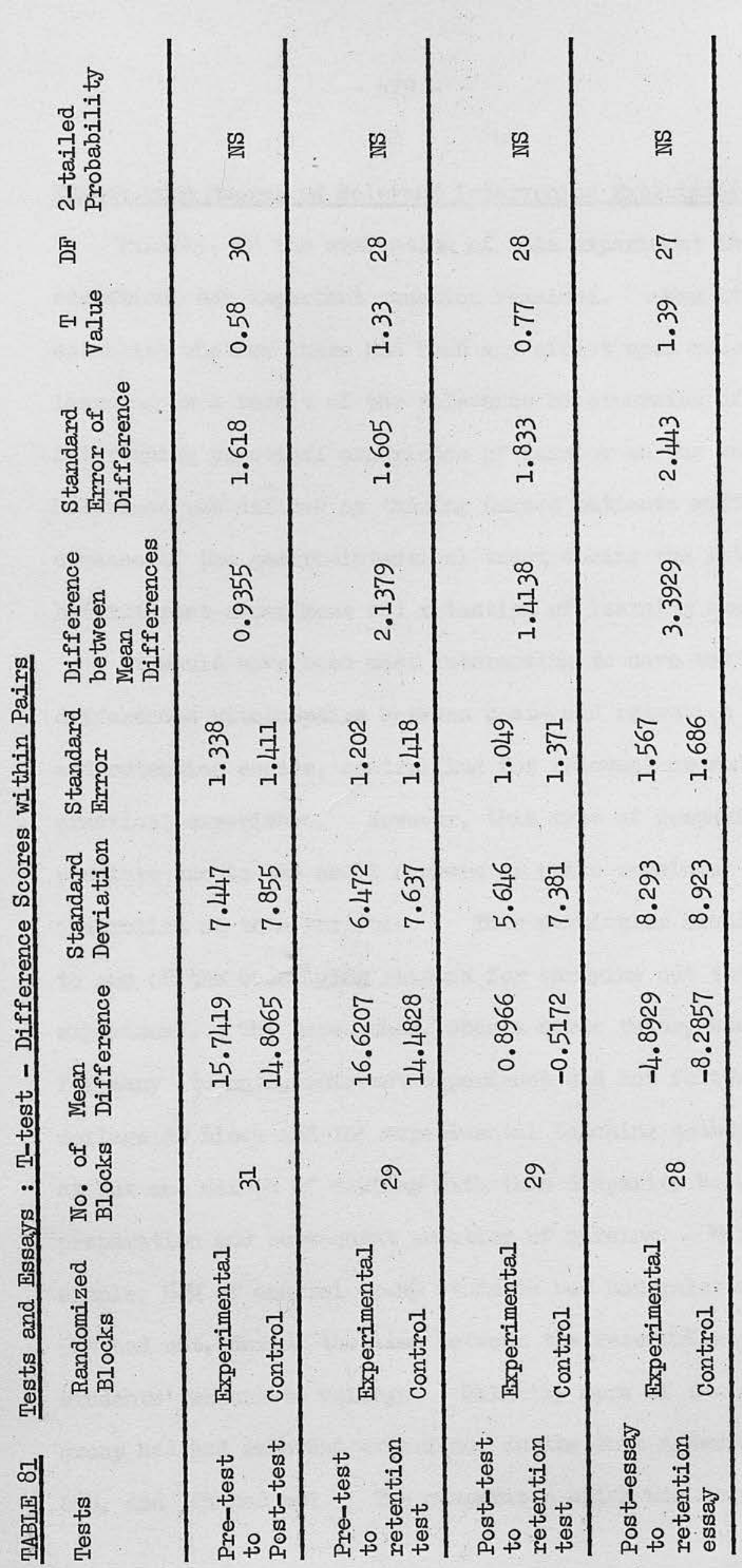


Effect upon Scores of Relevant Intervening Experience of Nursing

Finally, in the evaluation of this experiment in nursing education, one important question remained. Was it possible to establish whether there had been any effect upon retention of learning as a result of the relevance or otherwise of the intervening practical experience of nursing on the wards? Relevance was defined as 'having nursed patients suffering from disease of the gastro-intestinal tract during the intervening period betwixt post-experiment and retention of leaming assessment?

It would have been most interesting to have tested for the differences within-pairs between post- and retention tests and postand retention essays, controlling for relevant or non-relevant practical experience. However, this type of comparison was not possible due to the small numbers of pairs remaining ( $N=3$ ) when controlled on this variable. This particular finding lent weight to one of the underlying reasons for carrying out the research experiment. The researcher, when a nurse tutor, was concermed that, for many students, relevant experience did not follow a period in college or Block and the experimental teaching method was proposed as but one method of dealing with this disparity between theoretical preparation and subsequent practice of nursing. Within this small sample, $50 \%$ of control group students had had relevant experience and $50 \%$ had not, during the time between the research experiment and the students' returm to college. Slightly more of the experimental group had had relevant experience during this intervening period $68 \%$, and $32 \%$ had not. The comparison which was made therefore was 
of the between tests and between essays difference scores, within the groups, for those who had and those who had not had relevant experience. The t-test used was that for independent groups and the results, tabulated in Table 82 indicate that there was no statistically significant difference between the mean differences for students in either control or experimental groups as a result of the intervening experience of nursing and its relevance or otherwise. There was, however, on each measurement, a tendency for those students who had had the opportunity to put their theoretical knowledge to practical use, to do better than those students who had not had that opportunity. 


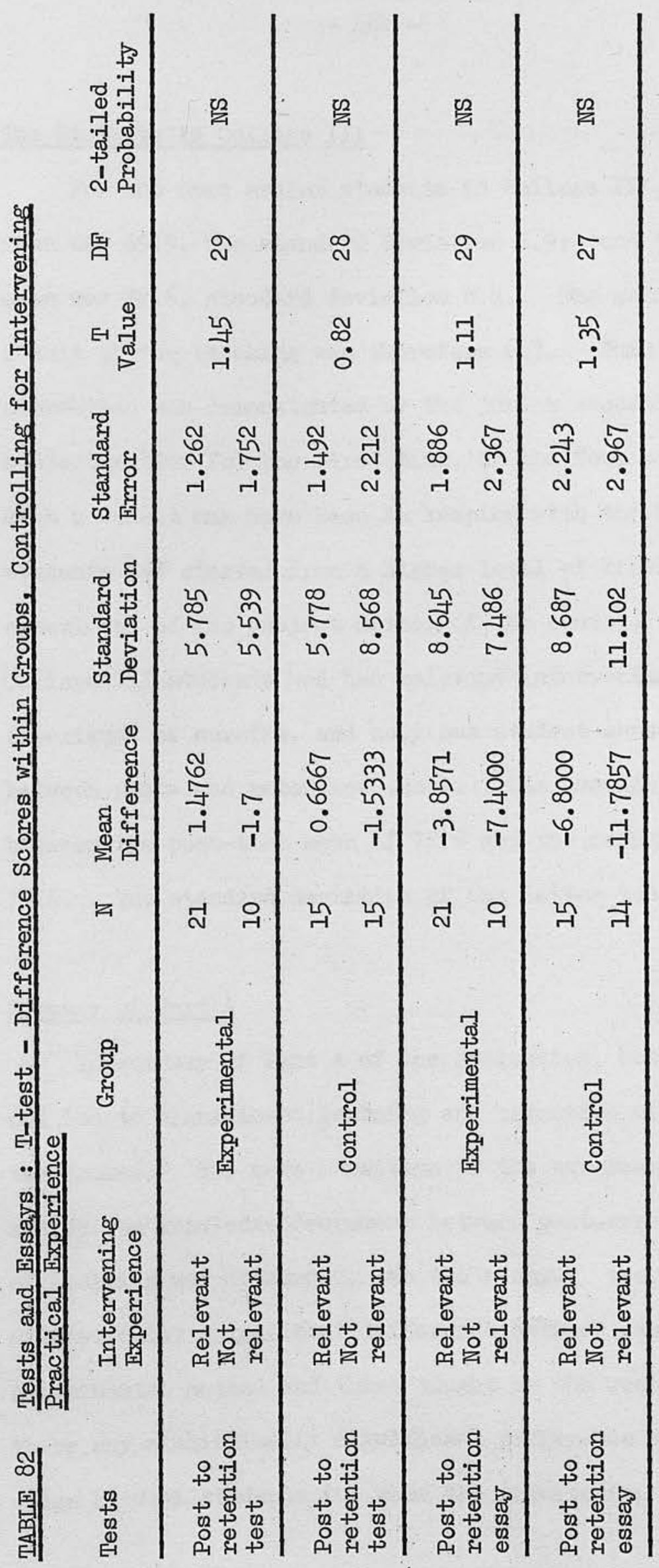




\section{The Students in College III}

For the more senior students in College III, the pre-test mean was 65.9 , the standard deviation 5.9; and the post-test mean was 72.6 , standard deviation 8.4 . The gain score as a result of the teaching was therefore 6.7. This was a lower gain score than was demonstrated by the junior students meeting the subject matter for the first time, in the four other colleges, but such a result may have been in keeping with the fact that College III students had started from a higher level of knowledge, and practical experience of the subject matter of the course. Each one of the College III students had had relevant intervening practical experience of nursing, and only one student showed a loss score between post- and retention tests. The average gain was of 3 marks between the post-test mean of 72.6 and the retention test mean of 75.6. The standard deviation of the latter test was 8.28.

\section{Summary of Part A}

In summary of Part A of the evaluation, both teaching methods had led to significant leaming and retention of the subject matter of the course. The more sensitive of the two measures, insofar as the search for knowledge decrement between post-experiment and retention of learning was concermed, was the essay. There was no statistically significant difference between students taught by the experimental method and those taught by the control method nor was there any statistically significant difference at retention of learning stage between students for whom the intervening practical experience of 
nursing had been relevant and those for whom it had not. In spite of the fact that experimental group students spent much less time than did control group students in classroom activities such as lectures and note-taking, there was a consistent trend for them to perform better on both tests and essays. This trend was extremely small at the post-experiment stage of immediate recall but, as might have been hoped, was more marked at the retention of learning stage. This finding was in keeping with the theories of learning, which state that active, experiential learming is more lasting. Such theories were also supported by the findings in relation to the effect of relevant nursing experience.

\section{PART B}

In this part of the evaluation, the relationship between tests and essays, and the reliability of the marking of essays was examined, in relation to the slightly larger sample of students indicated in Table 83. This sample number included all those students who appeared in Part A of the evaluation, (with the exception of College III students who did not take an essay examination) together with their classmates who were a part of the control group classes throughout the course, but were 'unmatched'. These students were all undertaking their RGN training and none was previously registered. In this section of the evaluation, the teaching methods per se were no longer under scrutiny, nor was the treatment versus no treatment effect. Rather it was the 
examination methods, the marks and the markers which were surveyed and Table 83 gives the number of students who took the various tests and essays in the four colleges.

TABIE 83 Tests and Essays : Sample of Students for Part B

Multiple Choice Test $\quad$ Essay Test

College Pre-test Post-test Retention test Post-essay Retention essay

\begin{tabular}{rlllll}
\hline I & 26 & 26 & 25 & 26 & 25 \\
II & 10 & 10 & 10 & 10 & 9 \\
IV & 24 & 24 & 22 & 24 & 22 \\
V & 21 & 21 & 20 & 21 & 20 \\
\hline Total N $=$ & 81 & 81 & 77 & 81 & 76 \\
\hline
\end{tabular}

Correlations between tests and essays, and between the markers will deal only with results from the neutral markers. The fact that inevitably college essay markers would have been able to identify examinees would have introduced a further source of variation, and so their marks were omitted from this part of the analysis.

The essays were marked by three neutral markers, all of whom were on the GNC (Scotland) Panel of Examiners, and all of whom were tutors and currently practising in that role. Instructions to the markers, from the researcher, were to mark the scripts in the way they normally did when correcting Final State essay scripts. Two of the markers, Marker B and Marker C, said that they were in the habit of constructing a marking key, which they then used to arrive at a score for each section of each script. Marker D was an 
'impression marker', i.e. she read all the scripts through completely, then re-read each, section by section, and allocated an appropriate mark to each section based on her impression of its 'worth'. She did not use a marking key. None of the neutral markers would have been able to identify any of the students, as no names appeared on any of the scripts, nor was it possible for them to know which colleges were involved in the research. Scripts were sent to the markers by post, and returned by them in the same way to the researcher. The college test paper which accompanied each set of scripts was devoid of any identifying mark as to the college of origin. Markers did know whether it was a post-essay or a retention essay they had received for marking, but were not told that the latter had been presented to the students without prior warning. Essays, as tests, are frequently criticised, mainly on grounds of unreliability and subjectivity of the marking. The reason why the essay was used in the experiment was because it is in common use in nursing education, as a measure of the instructional effectiveness of a course of teaching. Indeed the final professional examinations in nursing take this essay format, prior to registration on any of the registers of nurses in Scotland. In this research, the essay was combined with that other type of test the multiple choice or objective test. The use of the two different types of measurement permit the first set of comparisons to be made in this part of the evaluation, i.e. the relationship between tests and essays in the nursing examinations for this sample of students. 


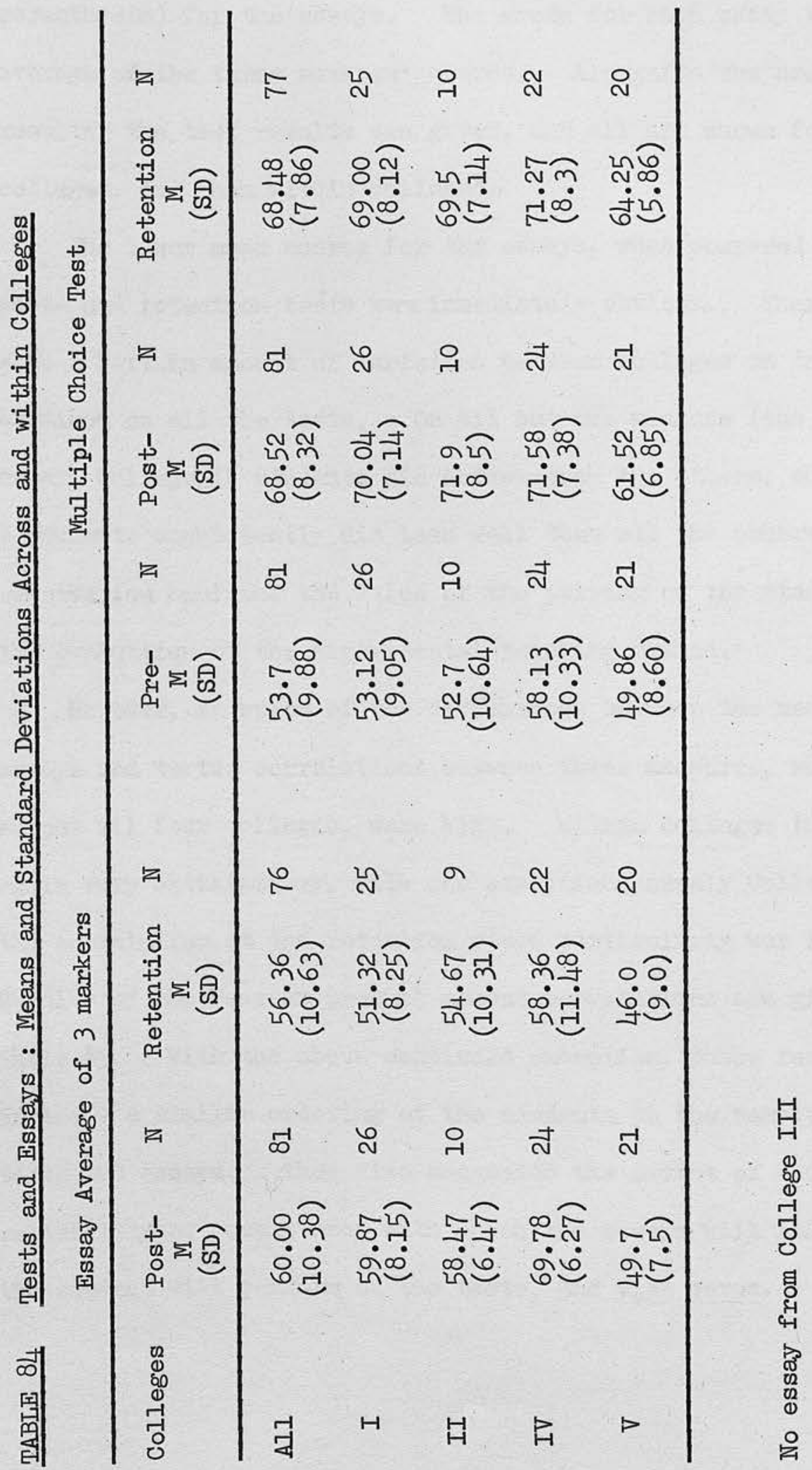


Table 84 shows the means and standard deviations (in parenthesis) for the essays. The score for each essay was an average of the three markers' scores. Alongside the essay results, the test results are given, and all are shown for all colleges, and then within colleges.

The lower mean scores for the essays, when compared to the post- and retention tests were immediately obvious. There was also a certain amount of variation between colleges on the marks attained on all the tests. On all but one measure (the postessay) College IV students did better than the others, and College V students consistently did less well than all the others. This observation confirms the value of the pairing of the students for the evaluation of the experimental teaching method.

However, in spite of the differences between the means for the essays and tests, correlations between these measures, when viewed across all four colleges, were high. Within colleges they were again very satisfactory, with one exception, namely College I, where the correlation, at the retention stage particularly, was low. Results of the Pearson product moment correlations are given in Table 85 . With the above mentioned exception, these results indicate a similar ordering of the students in the sample on both tests and essays. They also suggested the extent of the reliability or consistency with which the essays will indicate how the student will perform on the tests, and vice versa. 


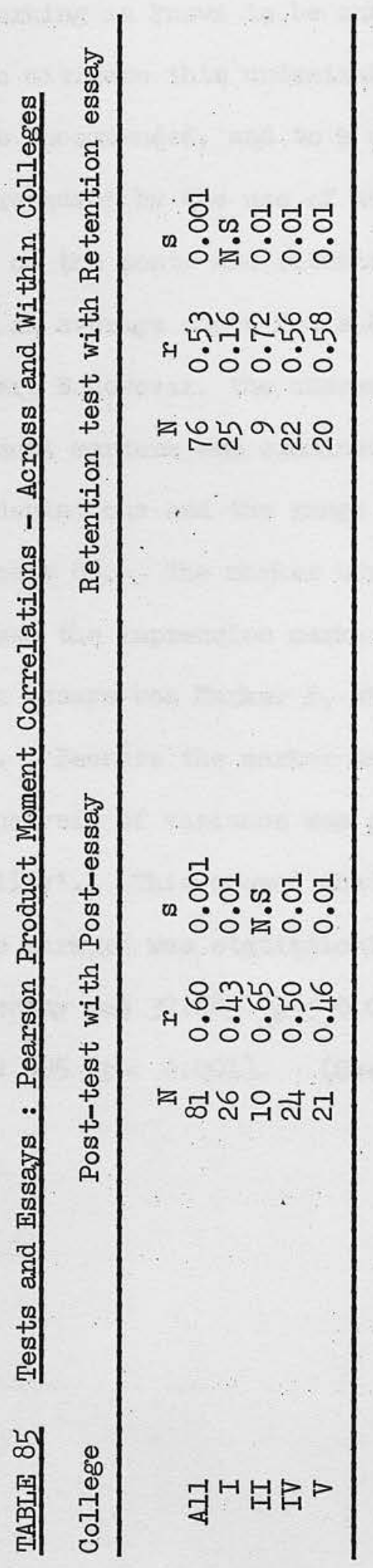




\section{Inter-marker Reliability or Agreement}

Although essay marking is known to be subjective, steps can be taken to try to mitigate this undesirable effect. Multiple judgments are recommended, and to a certain extent this was achieved in this research by the use of the three neutral markers, whose scores on the post- and retention essays were aggregated to produce an average score for subsequent calculations. In the remainder of Part B hqwever, the characteristics of the marking by the individual markers were examined.

Means, standard deviations and the range of marks used by each marker are shown in Table 86. The marker who gave the lowest mean score on both essays was the impression marker, Marker D. The most lenient marker on both essays was Marker B, who also made use of the widest range of marks. Because the marker means quite obviously differed, a one-way analysis of variance was performed, using the SPSS Program 'Reliability'. This showed that the difference between the means of the three markers was statistically significant. The F-ratio for the post-essay was 32.689 ( $p<0.001$ ) and for the retention essay was 22.895 ( $p<0.001$ ). (See Tables 87 and 88 ) 


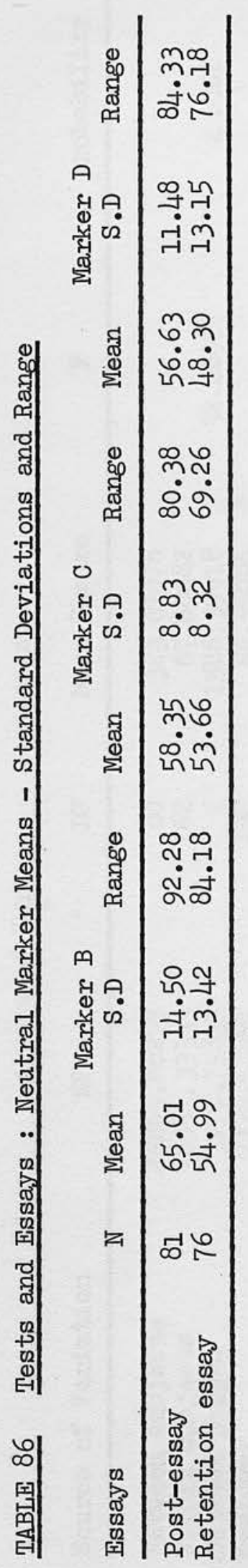




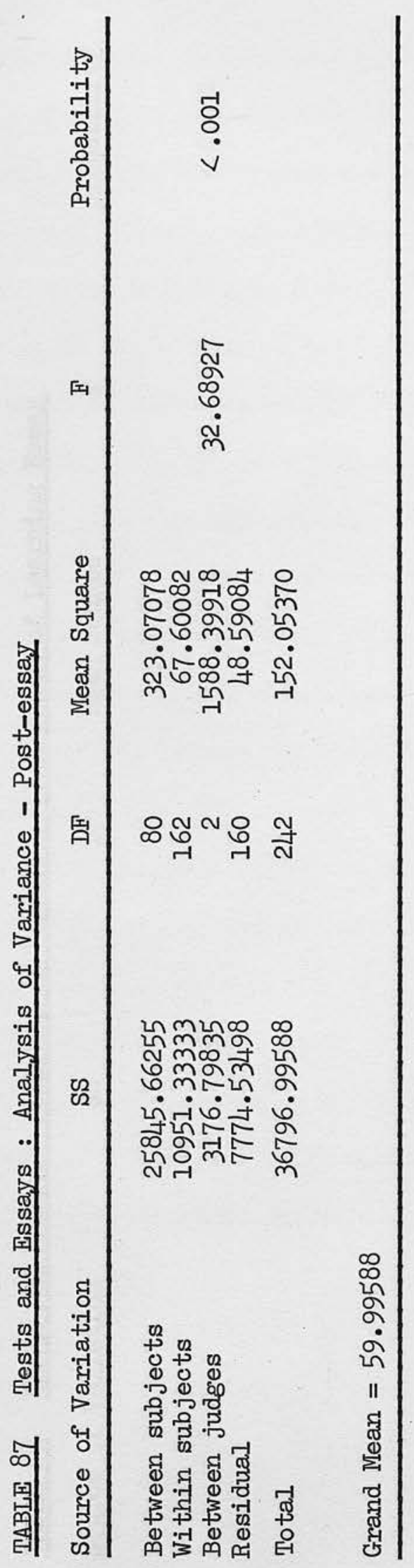




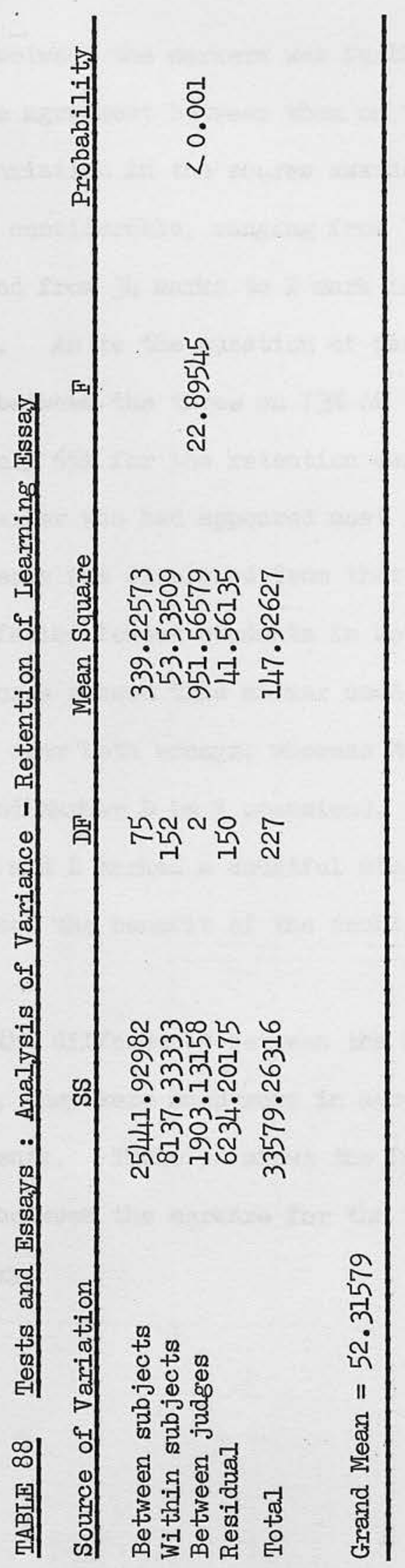


The differences between the markers was further explored. There was no complete agreement between them on the score for any one student. The variation in the scores awarded to any one student was at times considerable, ranging from 33 marks to 1 mark in the post-essay, and from 34 marks to $I$ mark in the retention essay (see Table 89). As to the question of passing or failing, there was agreement between the three on $73 \%$ of the students for the post-essay, but on only $65 \%$ for the retention essay. This is shown in Table 90. The marker who had appeared most lenient on observation of the means was displaced from that position in Table 91 by Marker C, who failed fewest students in both tests. Inspection of the scores showed this marker used the 50\% mark altogether 19 times, over both essays, whereas Marker B used this score only 3 times and Marker $D$ on 7 occasions. It was possible that where Markers B and D marked a doubtful student below the pass mark, Marker $\mathrm{C}$ gave her the benefit of the doubt, but that is only speculation.

In spite of all the differences between the actual scores awarded by the three markers, they were much more in agreement as to the ordering of the students. Table 92 shows the Pearson product moment correlations between the markers for the two essays, which were very satisfactory. 


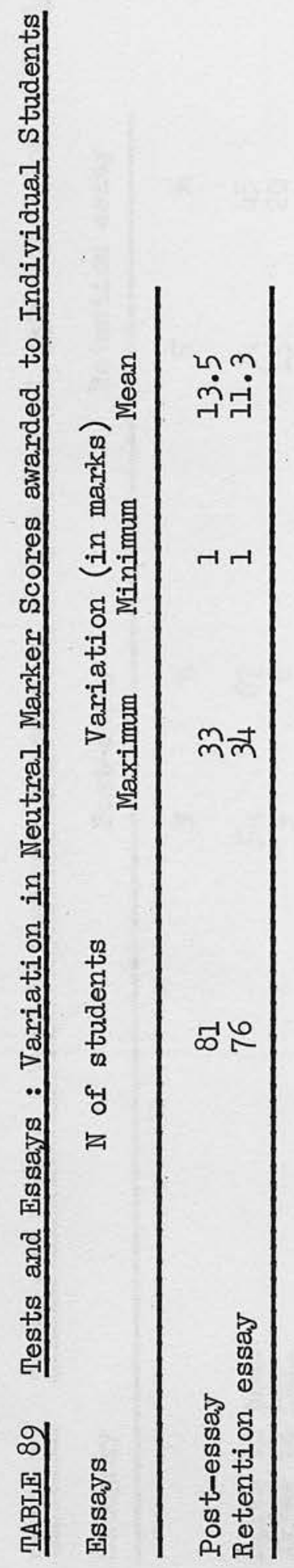




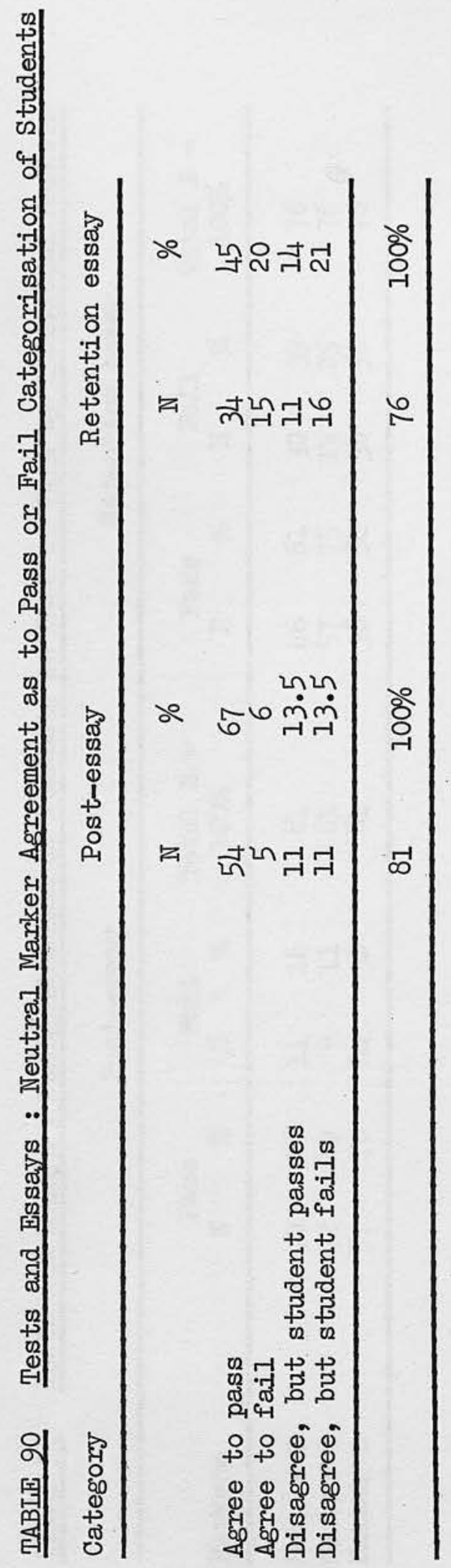




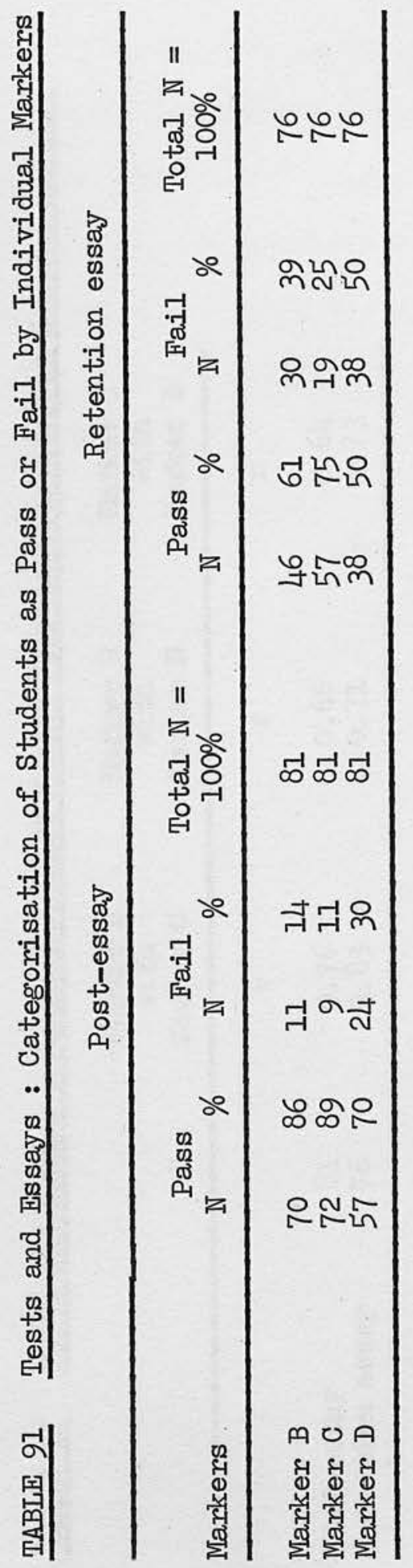




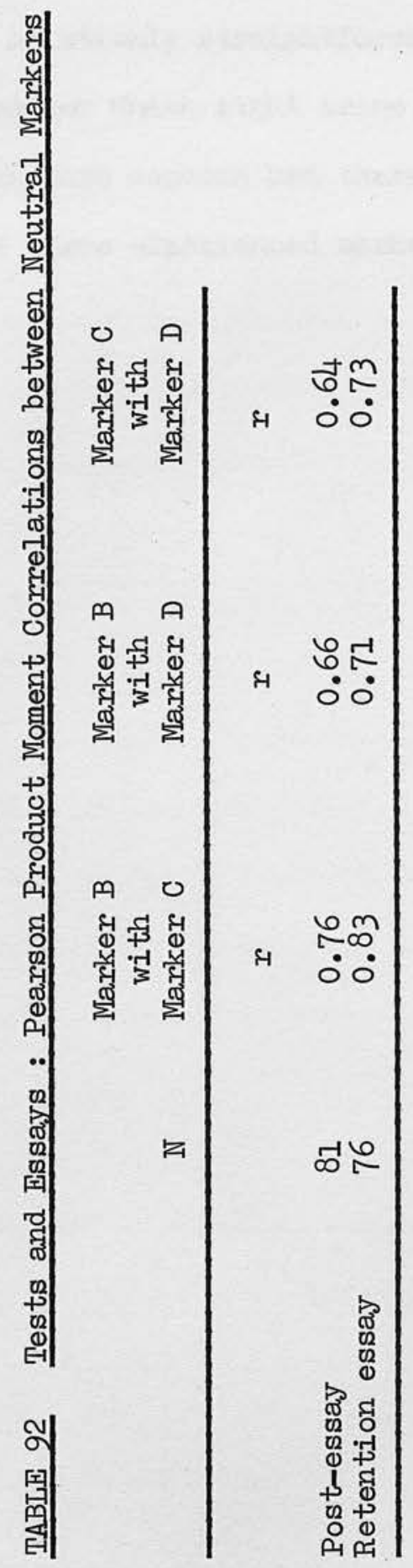


Summary of Part B

In summary, while there were significant differences between the means and thus the marks awarded by the three neutral markers, there was very little difference in their rank ordering of the students. It is relatively straightforward to re-adjust marks to correct discrepancies which might arise from such sources. It would have been of much more concerm had there been a low correlation between these three experienced markers of nursing examination scripts. 


\section{CHAPTEER 22}

\section{STUDENT NURSE STUDY PATTWERNS}

Throughout the course of the experiment, in all colleges, students kept a daily study diary (see Appendices XIX and XX).

These diaries were filled in each day very willingly, although towards the end of the experiment it was necessary for the researcher to remind students more often. Quite frequently, the appearance of the researcher in the classroom in the morning was sufficient for the students to flourish completed diaries, and for those who did not have them ready, to create a rush to the pile of diary blanks so that they could fill in the required information.

For the reasons described in Chapter 8, in particular the fact that the diaries from both control and experimental group students were completed during the very abnormal circumstances of the research and the experiment, none of the findings presented below could be considered descriptive of student nurse study patterns in general. However, they did provide an interesting indication of study done, by this small sample of students, during a somewhat unusual time in their Block.

\section{The Sample who Completed the Diaries}

Table 93 shows the sample of students whose completed diaries contributed the information for analysis, and the number of Block days and of weekends represented in the diaries. 
TABLE 93 Number of Students who Completed Diaries by College and Number of Days represented in the Diaries

$\begin{array}{llll}\text { No. of } & N \text { of Block days } & N \text { of } & \text { No. of weekends } \\ \text { days of } & \text { represented in } & \text { weekends represented in } \\ \text { College Students } & \text { experiment } & \text { diaries } & \text { in expt. diaries }\end{array}$

\begin{tabular}{rllccc}
\hline I & 27 & 6 & $159 *$ & 1 & 27 \\
II & 10 & 5 & 50 & 1 & 10 \\
III & 11 & 4 & 44 & - & $18 *$ \\
IV & 24 & 5 & $119 *$ & 1 & 17 \\
V & 21 & 5 & $103 *$ & 1 & $72 *$ \\
\hline Totals & 93 & 25 & $475 *$ & 4 & \\
\hline
\end{tabular}

Note: The Number of Block Days (or of weekends) represented in the diaries was calculated by multiplying the number of students by the number of days of the experiment in each college (or by the number of weekends in each college). Discrepancies occur when a diary was missing for a day or a weekend from one or more students. This is indicated by an asterisk. An overall total of 6 daily diaries and 10 weekend diaries were missing. Response rate was therefore high - 547 diaries out of a possible $563=97 \%$.

Altogether, 93 students, representing all five colleges, completed study diaries. This number included 43 experimental group students, 46 control group students, and 4 'others', i.e. class members who were undertaking RGN training but were ineligible for the afore-mentioned groups because they had previous experience of the subject matter of the experimental course. The total possible number of diaries which could have been completed by these students was 481 daily diaries, of which 475 were actually completed, a 99\% return; and 82 weekend diaries, of which 72 were completed, a $87 \%$ return. Table 94 shows the number of these daily diaries which were completed by students in the experimental, control and 'others' groups. 
TABLE 94 Number of Block Days (i.e. not weekends) represented in Diaries by Student Group

\begin{tabular}{lll} 
Student Group & N & N of Block Days Represented \\
\hline Experimental & 43 & 215 \\
Control & 46 & 242 \\
Others & 4 & 18 \\
\hline & 93 & 475 \\
\hline
\end{tabular}

\section{Officially Designated Study Time}

The proportion of available Block or classroom periods which were officially designated as study time is shown in Table 95. Out of an overall total of 2,731 classroom periods, during the 475 Block days represented by the student diaries, only 243 (9\%) were allocated to study on the timetable. A classroom period did not equate with any particular time interval. It varied across colleges, and within colleges, throughout the day, but none was less than half an hour and none more than one hour. 
TABLE 95 Available Classroom Periods Officially Allocated to Study

\begin{tabular}{|c|c|c|c|c|c|}
\hline College & $\begin{array}{l}\text { N of } \\
\text { Block days } \\
\text { represented } \\
\text { in diaries }\end{array}$ & $\begin{array}{l}\text { N of classroom } \\
\text { periods daily }\end{array}$ & $\begin{array}{l}\text { IN of total } \\
\text { available } \\
\text { periods }\end{array}$ & $\begin{array}{l}\text { N of total } \\
\text { study } \\
\text { periods }\end{array}$ & $\begin{array}{l}\text { Study periods } \\
\text { as percentage } \\
\text { of total } \\
\text { periods }\end{array}$ \\
\hline $\begin{array}{r}I \\
I I \\
\text { III } \\
I V \\
V\end{array}$ & $\begin{array}{r}159 \\
50 \\
44 \\
119 \\
103\end{array}$ & $\begin{array}{l}6 \\
6 \\
6 \\
5 \\
6\end{array}$ & $\begin{array}{l}954 \\
300 \\
264 \\
595 \\
618\end{array}$ & $\begin{array}{r}98 \\
34 \\
8 \\
41 \\
62\end{array}$ & $\begin{array}{r}10 \% \\
11 \% \\
3 \% \\
7 \% \\
10 \%\end{array}$ \\
\hline All & 475 & - & 2731 & 243 & $9 \%$ \\
\hline
\end{tabular}

There was thus a very small amount of the available time allocated for study. The students in College III, where the proportion of study time was least (only $3 \%$ of the whole) were taking part in a one-week revision course, preparatory to working in their pre-registration period on the wards. All other students were in the course of an eight-week Block.

Of the 243 study periods, rather more were available to the control group students, than to the experimental group students. The former had 156 out of the 243 periods, and the latter $74 . *$ In part this imbalance was due to the fact that very seldom was study time allocated to the experimental group students during the first three periods of each day, i.e. while the experiment was in progress, whereas there were several occasions when control group students recorded study time at that time of day.

* The remaining 13 periods were available to the 'other" students 
Use of Officially Designated Study Periods

A majority of students in each college made use of the official study periods for study purposes, although only 4 students used all of these periods for the purpose for which they were intended, and 10 used none. All 4 'others' students were in the latter category. Figure 56 indicates, over all colleges, the proportion of the total available class periods allocated for study, and the proportion of that time which was actually used for study, and in Table 96 the use made of the designated study periods is indicated for the individual colleges.

Figure 56 Organised Opportunities for Study as a Proportion of all Class Periods. Fxcised Section indicates use made of these Study Periods, over all Colleges

Total Class Periods available $=2731$

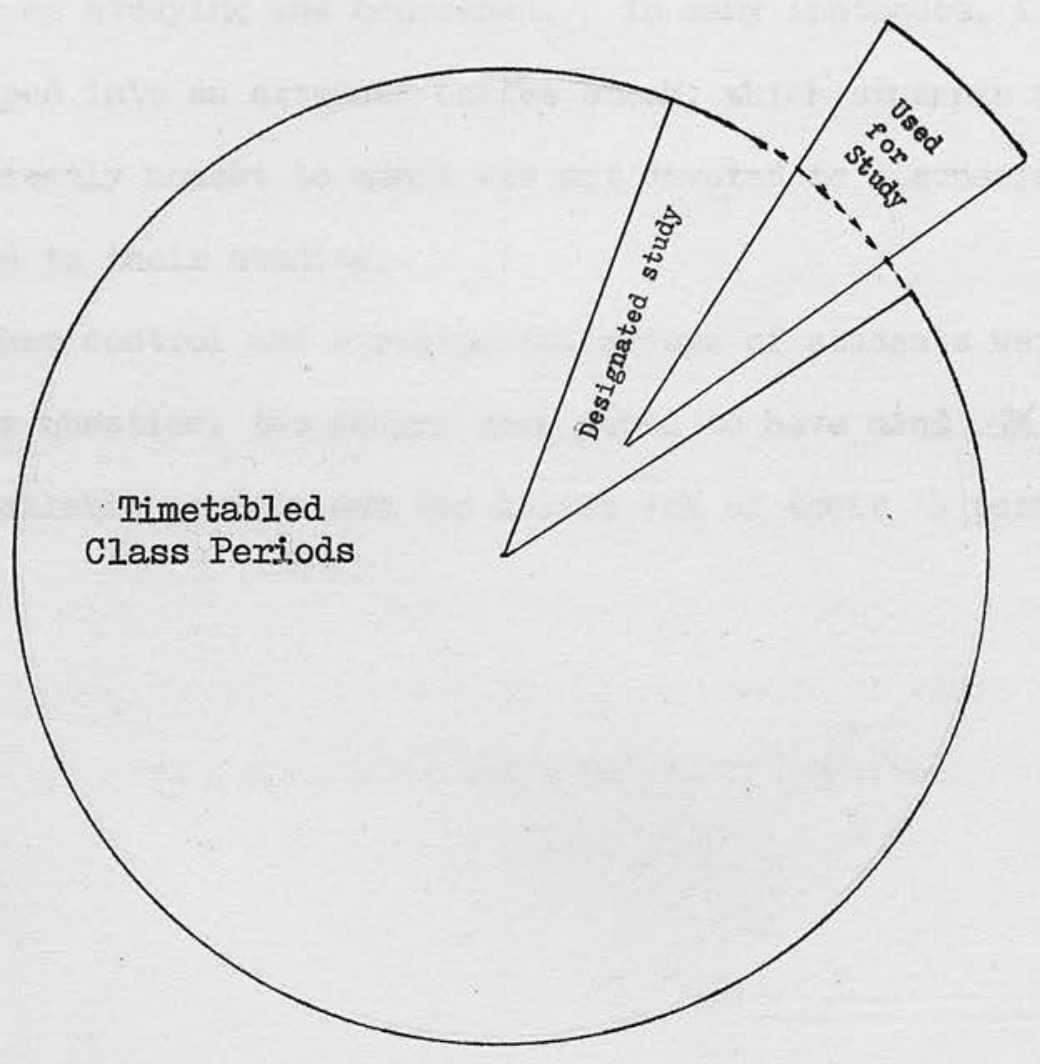


TABLE 96 Proportion of Designated Study Periods which were used for Study, by College

\begin{tabular}{cccc} 
College & $\begin{array}{l}\text { Periods designated } \\
\text { 'study' }\end{array}$ & $\begin{array}{l}\text { Study periods } \\
\text { used }\end{array}$ & $\begin{array}{l}\text { Used as percentage } \\
\text { of designated }\end{array}$ \\
\hline I & $N$ & $N$ & $\%$ \\
II & 98 & 64 & 65 \\
III & 34 & 21 & 62 \\
IV & 8 & 6 & 75 \\
V & 41 & 36 & 88 \\
\hline AII & 62 & 34 & 47 \\
\hline
\end{tabular}

The two colleges in which the lowest percentage use of study periods for study purposes was recorded, were College $V$ and College II. In these two colleges, it was daily practice to designate the half hour immediately after the morning coffee break as a study period. This appeared to be a particularly unproductive period so far as studying was concerned. In many instances, it developed into an extended coffee break, which students were sufficiently honest to admit was not devoted to discussion which related to their studies.

When control and experimental groups of students were compared on this question, the former were found to have used $65 \%$ of their 156 available periods and the latter $72 \%$ of their. 74 periods. 


\section{Self-initiated Study}

There were 244 reported instances of study being done other than at the designated study times, during the 475 days under discussion. Six students recorded that they at no time did any self-initiated study, and 34 that they did so on less than half of the experiment days. More than half the sample, i.e. 53 students reported studying on half or more of the available days, and 8 of these students studied for some time every day. When both types of study, i.e. designated and self-initiated, were taken into consideration, there was no student in the sample who had done no study whatsoever during the course of the experiment in her college.

\section{Time Devoted to Study}

Students recorded total study time per day in minutes, and were not asked to distinguish between college-allocated time and selfinitiated study time. Table 97 gives the average daily study for the students in each of the colleges. In Colleges I, II and IV, experimental group students studied for longer than their control and other colleagues, and this in spite of the fact that there was less college-allocated time available to them to include in their figures. In College $V$, where the least amount of time was spent in study, the control and other group students studied longer than the experimental group. The average times quoted in Table 97 were arrived at from a very wide range of individual study times. Eight 
students studied one hour or less over the entire period of the experiment in their college, and five students studied for ten hours or more - the maximum period being 11.75 hours by a control group student.

TABLE 97 Average Daily Study Time (in minutes) for Experimental and Control Group Students, by College

Average Daily Study Time per Student

\begin{tabular}{lccccc}
\hline Group & I & II & $\begin{array}{c}\text { Colleges } \\
\text { III }\end{array}$ & IV & V \\
\hline Experimental & 57 & 85 & 42 & 84 & 35 \\
Control and & $(12)$ & $(4)$ & $(11)$ & $(8)$ & $(8)$ \\
'others: & 51 & 58 & - & 80 & 40 \\
& $(15)$ & $(6)$ & & $(16)$ & $(13)$ \\
\hline
\end{tabular}

\section{Weekend Study}

The amount of weekend study done by students appeared, not unexpectedly, to bear a positive relationship to the occurrence, and proximity of an 'end of subject matter' assessment (an essay type of test). In College I, the weekend occurred after only two days of the six day experiment, the assessment was a full week ahead, and only $22 \%$ of students did any weekend studying - an average of 90 minutes each. In College $\mathrm{V}$, where students completed the course on a Friday, the weekend and a public holiday intervened before their assessment, and $48 \%$ of students spent an average of 105 minutes each in weekend study. Students in Colleges II and IV, who had recorded the highest average weekday study times, were also 
those who studied most at the weekend. In both colleges, the assessment was scheduled for a Monday. All students in College II studied, for an average of 4.5 hours, and $75 \%$ of students in College IV did so for 2.5 hours on average.

\section{Methods of Study}

Students were presented, in this question, with a list of study methods, which had been compiled from replies to a similar, but open-ended question in the Pilot Study diaries. If more than one method had been used on any day, students were instructed to indicate all the methods they used, and to tick the main method. As this latter instruction was forgotten on a number of occasions by students, the incomplete information which resulted was not analysed. Table 98 therefore indicates the number, and percentage of students in each college who used the listed study methods. The most popular method, when ranked by number of recorded instances of use, was 'reading over notes', and this was followed by the method 'reading from textbooks'. Ranked third, but considerably less often used, was 'writing notes neatly'. Next in order of recorded instances was 'making own notes from textbooks', with 'discussions with other students' coming fifth in rank order. The remaining three methods were used relatively infrequently. 


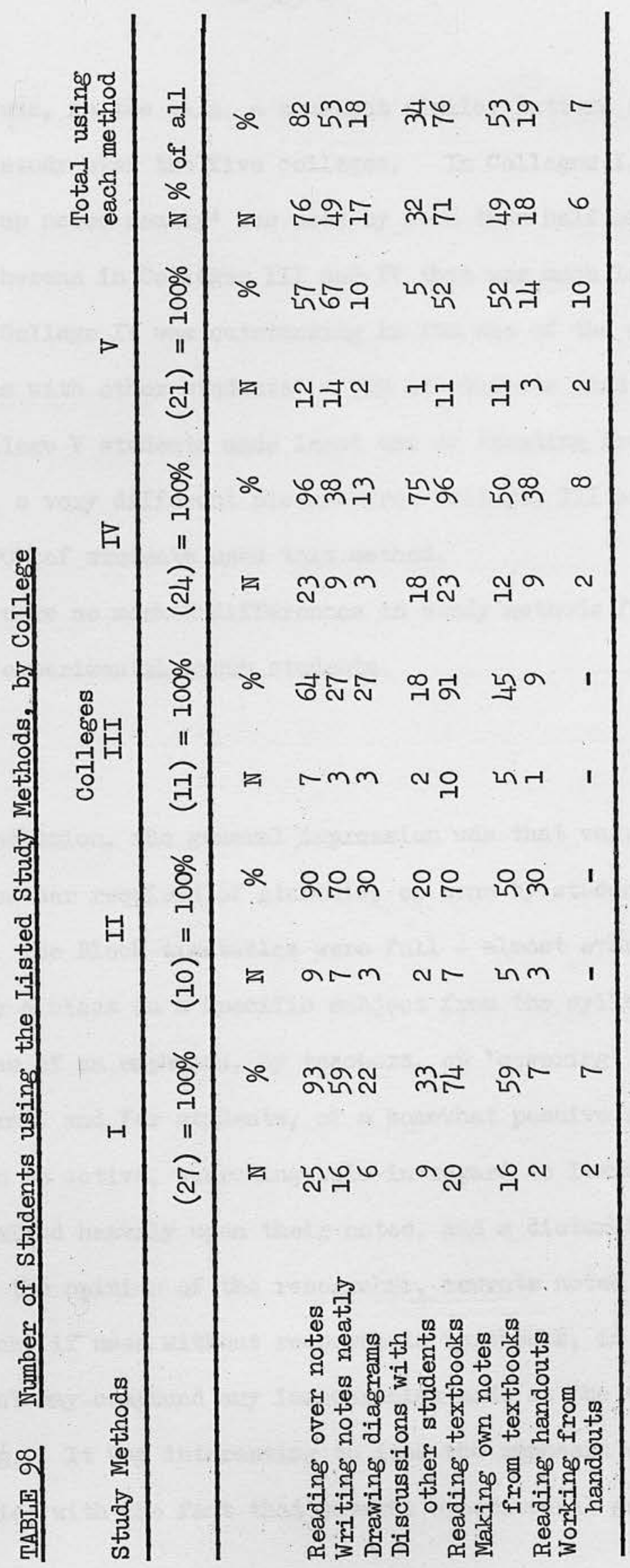


There was, in the main, a somewhat similar pattern in the methods of study over the five colleges. In Colleges I, II and V 'writing up notes neatly' was used by more than half of the students, whereas in Colleges III and IV this was much less popular. College IV was outstanding in its use of the method 'discussions with other students' $-75 \%$ of students said they used this. College $V$ students made least use of 'reading from textbooks', a very different picture from Colleges III and IV where more than $90 \%$ of students used this method.

There were no marked differences in study methods favoured by control or experimental group students.

\section{$\underline{\text { Summaxy }}$}

In conclusion, the general impression was that very little study was either required of students, or done by students in their own time. The Block timetables were full - almost every period occupied by a class on a specific subject from the syllabus. The evidence was of an emphasis, by teachers, on 'covering' the content of the course, and for students, of a somewhat passive recipient role, rather than an active, searching role in regard to learning. Many students relied heavily upon their notes, and a disturbingly high number, in the opinion of the researcher, rewrote notes neatly, a method which, if used without recourse to textbooks, is not only passive, but may compound any inaccuracies made at the time of the note-taking. It was interesting to link the emphasis upon notes in these diaries with the fact that several experimental group students 
felt 'lack of notes' to be a disadvantage of the experimental teaching method.

Study - whether required or done - reflects upon teacher as well as the taught. It can be presumed that the habit of study, or self-directed education, was not valued by teachers as so little appeared in the timetables. The study value may also not be inculcated in students if teachers do not look for the results of study, i.e. in papers or project work. It seemed unlikely that very much of that type of work was required of students when the average amount of time devoted to study was so very individual and so varied. The college where most study was recorded by students (College IV), was the one where the most variety of teaching methods was employed and one could speculate as to whether this led to more participation by students in their own learming, and to more being demanded of them in terms of self-directed leaming, but that is a very tentative speculation, based as it is on such small numbers of students and on such a short and unusual period in their Block.

Study, insofar as the students in this sample were concermed, was the least popular method of teaching/leaming, and was only very infrequently made use of in their daily work in Block. 
- 511 -

PART IV

SUMMARY, CONCLUSIONS, DISCUSSION AND RECOMMENDATIONS 


\section{CHAPTEER 23}

\section{SUMMARY AND CONCLUSIONS}

This study was concermed with nurse education and training, in particular with the traditional college of nursing/hospitalbased programme in Scotland, and the preparation of student nurses for the qualification of Registered General Nurse.

The question at the heart of the study was - how can integration of theory and practice in nursing be facilitated? The main aim of the study was the facilitation of such integration.

In pursuit of that aim, and of one possible answer to the question, an experiment was designed in which a planned programme of concurrent theory and directly relevant and supervised practice of nursing, i.e. of college and ward-based instruction, was experienced by student nurses randomly allocated to an experimental group. While their peers, in a control group, received teaching on the care of patients with gastro-intestinal disease by entirely college-based methods, the experimental group both received teaching and carried out nursing care of such patients, during the hours allocated to that particular subject in their curriculum.

Prior to the designing, implementation and evaluation of the experiment, a literature review, and a survey of four colleges of nursing were carried out.

First to be examined in the literature review was the system by means of which students learn to become nurses - the system of nurse education and training within which the problems of integration of 
theory and practice had arisen. Because integration, the putting together of relevant parts to make a coherent and meaningful whole, was considered to be essentially an individual matter and a part of the active, ongoing process of learning, the next section of the literature review dealt with certain aspects of learning, in particular with active experiential learning and some of the ways in which students learn. The third and last part of the literature review dealt with the measurement and evaluation of learning and of educational programmes. In the Survey, factual matters relating to the formal organisation of the colleges and the education and training programmes were ascertained, as were opinions of the teachers about the relationship of theory and practice in nursing. Thereafter, the development and design of the experiment proceeded.

The pre-test, post-test, control group design (Campbell and Stanley, 1966) was chosen as most appropriate, including as it did random allocation of subjects to control and experimental groups on the basis of their performance on a relevant pre-test - in this case a specially constructed, and validated multiple choice test on the subject matter of the course. To this basic design, a third stage was added, in which the students ${ }^{8}$ retention of learning was assessed, and their opinions, in retrospect, about the experimental method of teaching and learning, were obtained.

The research approach adopted in the evaluation of the experiment was that of illuminative evaluation. In accordance with this approach, pre-experiment opinions of students, ward trained staff and 
teachers as to aspects of the leaming milieu were obtained, the day to day conduct of the experiment was documented, and the outcome measures included the opinions from all the participants as to the advantages and disadvantages of the innovation, their evaluation of whether the objectives of the experiment had been achieved, and the test and essay scores of the students in both control and experimental groups.

To these ends, pre- and post-experiment questionnaires for all groups of staff and students involved, a multiple choice test, student study diaries, nursing care plans and various other data collection forms were designed, used in pilot form, and adapted as necessary before use in the main study.

The selection of colleges, and student groups within the colleges, was not random, but depended upon the situation of the college, within a reasonable radius of the researcher's base in Edinburgh, and the presence in the college of a suitable Block, at a time which suited the researcher's timetable. It also depended upon the willingness to participate of the education and service staff and the student group.

Prior to the pilot study in one college of nursing and its associated hospital, and the main study, which took place in five colleges and their associated hospitals, procedures leading to the implementation of the experiment included (1) meetings with education and service staff and with the student nurses for the purpose of giving information about the study and requesting permission to carry it out, (2) preparation of the nurse teachers, 
for it was they who carried out all the teaching of the experimental and control group students throughout the period of the experiment, (3) general administrative matters such as accommodation for the researcher during the experiment, and (4) selection of patients to receive care by the students in the experimental group. Ethical considerations, especially related to the latter point were discussed and dealt with during the preparatory stages above mentioned.

The limitations of the research are dealt with in detail on Pages 27/28 and Page 234, and were mainly those inherent in educational research which is conducted within the 'untidy' reality of the classroom, as opposed to the much more controlled setting of the psychological learning laboratory. They were compounded in this study by the fact that the teaching and learning also took place in the hospital wards, where there were many additional uncontrolled variables. Hawthorne effect, as in any experiment, was a relevant interfering variable. The main weaknesses of the study were the subjective nature of much of the data and also the inexperience of the researcher, not in regard to the field of the research, but in regard to the carrying out of the study, i.e. the research process. Against these threats to the validity and the generalisability of the results of the study must be viewed the fact that the experiment was replicated, following its implementation in the pilot and first of the main study colleges, in four other main study colleges and their associated hospitals. 
The findings and conclusions of the main study are summarised below. These were compiled from the contributions of an overall total of 119 student nurses, 224 ward trained staff and 72 teachers from the five main study colleges of nursing and their associated hospitals. These five colleges represented $26 \%$ of the nineteen colleges of nursing and midwifery in Scotland.

1. Findings and conclusions from pre-experiment data The Learning Milieu in General Nurse Education and Training

\subsection{Ward Teaching and Leaming:}

\subsubsection{Ward Teaching Received by Students on Ward Staff}

Most of the ward teaching which students received while working on general medical and surgical wards was carried out by the staff nurses. Their contribution was consistently high, whether the teaching took the form of supervision and practical demonstration, or of short teaching and tutorial sessions. Other student nurses contributed almost as much to the former type of ward teaching as did the staff nurses, and considerably more than either the ward sister or the clinieal teacher. The contribution of the registered nurse teacher was so small as to appear negligible. When the giving of tutorials was considered, the students in this sample considered the contribution of fellow student nurses to be less than that of the staff nurses, but very slightly more than that of the ward sister and the clinical teacher. Again, the contribution of the registered nurse teacher was negligible. $80 \%$ of the sample of students had never received supervision or practical demonstration on the wards 
from the registered tutor, and $91 \%$ had never received ward tutorials from her.

The students' perceptions appeared to be corroborated by the tutors' responses to a question about their contribution to ward teaching. Only 3 registered nurse teachers ( $7 \%$ of the sample) said they taught often in the wards, $74 \%$ taught there rarely or not at all. However, ward sisters were found to perceive their contribution to ward teaching as rather more than was thought by the students. A majority of ward sisters said they often taught in their own wards, and indeed $97 \%$ of ward sisters considered they taught often or fairly often. Of the staff nurses, $89 \%$ considered they taught often or fairly often. of ward trained staff, only two (both staff nurses) acknowledged that they never taught student nurses in the wards.

The methods of teaching used by the ward staff were predominantly the two above mentioned, namely teaching by supervised. practice and demonstration, and by giving tutorials. $18 \%$ mentioned teaching by example, and only $6 \%$ teaching while giving the ward report.

When students were asked whether they learned most in the college or when working on the wards, $77 \%$ of the sample said that most was learned on the wards, yet it can be concluded that this was the place where the contribution of the two grades of trained teachers was least, in terms of ward teaching, and that of the untrained teachers most. The registered nurse tutor, on whom most resources have been spent in teacher training, made almost no contribution, and the 
clinical teacher, whose raison d'être is ward teaching, made virtually the same contribution as the ward sister, and less than the staff nurses or other student nurses.

\subsubsection{Ought Students to receive Teaching while Working on the Wards?}

Ward trained staff were unanimous in their agreement that students should receive teaching while they were working on the wards, as part of the ward staff, and $86 \%$ considered that such teaching should include both methods above mentioned, although $14 \%$ considered tutorials an inappropriate method of teaching for use in the wards. Registered nurse teachers, with one exception, also thought students should receive teaching while they were working on the wards. Only one from each grade of trained teacher considered such teaching should include only supervision and demonstration.

It can be concluded therefore that there was very strong support for the necessity for ward teaching of the student while she is undergoing the practical component of her training.

\subsubsection{Responsibility for Ward Teaching}

When ward trained staff were asked who should take the main responsibility for ward teaching of students, $35 \%$ saw this as entirely the responsibility of the trained teachers, $35 \%$ considered it should be shared by education and service staff and $30 \%$ that it should be entirely a service staff responsibility. However, when 
those who had included the registered clinical teacher in their allocation of main responsibility for ward teaching were asked who should be responsible if no clinical teacher was available, very few indeed saw the registered nurse teacher as having any responsibility for ward teaching and $90 \%$ considered themselves, the untrained teachers, as solely responsible, in the absence of the clinical teacher.

of the trained teachers, $71 \%$ considered the main responsibility for ward teaching should be either their own, or should be shared with service staff, but $29 \%$ considered it should be entirely the responsibility of the ward trained staff. of those who had included the registered clinical teacher in their allocation of main responsibility for ward teaching, $62 \%$ considered that, in circumstances where no clinical teacher was available, only the ward trained staff (the untrained teachers) should bear responsibility. It can be concluded that a majority of ward trained staff and of trained teachers did not consider that the registered nurse teacher had a responsibility to provide ward teaching for student nurses.

1.1.4 The Differing Functions of the Trained Teachers and the Ward Trained Staff as Ward Teachers

According to $57 \%$ of the ward trained staff, the functions of the tutor and the clinical teacher, in regard to ward teaching, were different. Of the examples given, $89 \%$ viewed the tutor as a theoretician and the clinical teacher as a practitioner of nursing, 
although a few of the ward staff added that the clinical teacher should link theory and practice. The trained teachers were evenly divided in their opinions, in that $50 \%$ considered functions of the two grades of teacher did differ, and 50\% that they did not. The examples of differences given by the teachers were of their different course preparation, i.e. teacher training, whereby tutors were not prepared for the type of teaching required in the clinical area. Their expertise lay in teaching methods more suited to college teaching. Teachers also considered the priorities of the two grades of teacher were very different - the clinical teacher having no, or very few teaching commitments other than in the ward, and the tutor having a considerable teaching commitment in the college.

of the trained teachers, only the clinical teachers were asked if they considered functions differed between ward trained staff and themselves in regard to ward teaching, and $79 \%$ answered in the affirmative. $70 \%$ of ward trained staff also considered functions differed, and there was considerable agreement between clinical teachers and ward staff as to where the difference lay. Priorities were different - for the clinical teacher these lay with the student, for the ward staff with the patient; both groups saw the teacher training a distinct advantage, leading to differences in approach to teaching, and familiarity with various teaching methods for the clinical teacher. The latter's familiarity with the learners' needs, and links with the college of nursing were also quoted as examples leading to differences in function between the clinical teacher and 
the ward staff as teachers in the ward. There was a suggestion of the theoretician/practitioner division again, this time with the clinical teacher seeing herself as more able to teach theoretical aspects, than were the trained ward staff.

One function for all, whether trained or untrained as teachers, was the view of $14 \%$ of the ward trained staff and of $17 \%$ of the clinical teachers.

\subsubsection{Ward Teaching of Supermumerary Students, supervised by Trained Teachers}

In regard to the question of student nurses going from college to the wards, as supernumerary students under the supervision of their college teachers, there to undertake nursing practice, $89 \%$ of ward staff and $88 \%$ of the trained teachers were in favour. $47 \%$ of ward staff considered both supervised practice and tutorials as appropriate methods for this teaching, as did $73 \%$ of the trained teachers. $49 \%$ of ward staff and $23 \%$ of teachers preferred that such teaching take the form of supervised practice only.

Ward staff commented on the advantages to the students ${ }^{\text {s }}$ leaming which they considered would accrue from such directly linked college and ward teaching, although some raised doubts that the presence of the supernumerary students and their teachers could upset ward routine, upset patients, or deny experience to students currently on the ward staff. The teachers, on the other hand, while endorsing this method of organising ward teaching, on educational grounds, raised doubts about its feasibility in terms of supervision by teachers, given the present teacher/student numbers. A majority of 
tutors and of clinical teachers had experience of teaching supernumerary students, but $92 \%$ of the examples cited were of work with the most junior students, i.e. those from the Introductory Block, and concermed procedures, such as bed-bathing. Work with more senior students was mentioned by $21 \%$ of the trained teachers and here there was slightly more mention of patient care, as compared to the procedures emphasis of the other comments.

\subsection{Methods of Teaching/Leaming preferred by Students}

The ward tutorial was ranked as clearly the "best liked method" of teaching and learning for the students in this sample. Equally clear was their dislike of self-directed study. The three least popular of eight listed methods were the only two study methods given, i.e. guided and self-directed study, and also the formal lecture.

From this it was concluded, again, that ward-based teaching and leaming was paramount for the students. However, they did not appear to like methods which called for a certain amount of independent organisation and initiative or responsibility for their own learning, in that they disliked both methods which involved study. Somewhat at odds with the latter conclusion was the fact that they also disliked one of the most passive of teaching methods in terms of student participation. It was also noted that, although the pattern differed in the different colleges, an overall majority of $56 \%$ of the sample considered they rarely or never participated in class discussion. 


\subsection{Evidence of Differences between College and Ward, Theory and Practice}

\subsubsection{Difference in Emphasis}

Task assignment, or the carrying out of routine procedures for all patients was seen by a majority of the students as the most realistic description of their ward work, although for $25 \%$ of the sample, their ward experience had been predominantly that of total patient care. Differences in responses to this question were not unexpected, and it can be concluded that a number of wards are now using, at least for some of the time, the alternative to the task assignment method of organisation of daily nursing work, i.e. organisation by means of total patient care.

However, somewhat less explicable was the divided opinion of the student members of the same class, in the different colleges, as to the emphasis in the teaching or the theoretical component of their course. It was not possible to conclude from the data available whether the diversity of opinion in this regard had its origin in the individual student's perception of a basically similar approach and philosophy in the teaching of nursing, or in a lack of consensus amongst the teachers.

What could be concluded was that, for $46 \%$ of the respondents, the emphasis was seen to be different between college and ward.

\subsubsection{Relationship of College Teaching to Ward Practice}

96\% of the sample found college teaching helpful to ward practice, but of that number, $36 \%$ considered it did not relate well to practice. 


\subsubsection{Evidence of Practice Differing from Teaching}

From all colleges, a total of $60 \%$ of the sample recalled instances when their own ward nursing practice had differed from the taught method. Most examples quoted referred to procedures classified as technical nursing (Nuffield Job Analysis, 1953). Many also mentioned basic nursing and only $5 \%$ of the examples referred to affective nursing.

The following conclusions could be drawn from the comments:

(a) respondents, many of whom were students only six months in training, had either failed to grasp principles of nursing care, or had not been taught principles; (b) certain nursing practices were clearly still in existence, in spite of many research findings to contraindicate their continued use; (c) there was evidence of careless, and at times dangerous practice - in particular in relation to naso-gastric feeding of patients, the administration of medicines and the carrying out of surgical dressings, and (d) there was evidence of the existence of many rather than rare differences between theory and practice. Only 5\% of the comments made referred to a patient, $95 \%$ referred only to procedures. It is possible that this may have been a result of the phrasing of the question.

\subsection{Integration of Theory and Practice}

Integration of theory and practice was explained by some students as a college responsibility, a matter of appropriate timetabling or sequencing of theory and practice in their education and training programme, and by others as an individual responsibility of the 
student, to translate or put into practice what she had been taught.

Students considered their training programme lacked integration when (1) practice was not depicted realistically in the teaching, (2) theory was not followed by relevant ward practice, (3) ward staff appeared unaware of the students' stage of training and experience, and (4) there was evidence of conflicting values between college and ward. Theory and practice were considered well integrated when teaching, either in ward or college, was complementary and promoted students' understanding of patient needs, when specific links existed between the two environments, i.e. students went from college to the wards to carry out practice in relation to theory just taught. The senior students in the sample commented very favourably on their experience of study days, which they considered promoted integration of theory and practice by providing one day per week of theory which was directly relevant to current practice.

Students ${ }^{8}$ suggestions for ways in which integration of theory and practice could be improved included measures designed (1) to link theory and practice in organisational (timetabling) terms and in teaching methods, (2) to improve supervision, teaching and communication while the student was undergoing practical experience, and (3) to increase liaison between college and ward staff. It can be concluded that, by viewing both sides of the coin as above, further evidence is revealed of different facets of the problem of integration of theory and practice in nursing. In the students' suggestions of measures to improve integration, there was 
a strong resemblance to some aspects of the experimental method, of which no student, at that time, had any fore-knowledge.

\subsection{Meetings between Education and Service Staff}

All registered nurse teachers considered that they had some contact with ward trained staff, mostly on matters directly connected with learners' progress, or allocation to wards. Some tutors mentioned meeting with ward staff in order to up-date their knowledge on matters related to nursing practice, and a very few mentioned meetings in order to maintain communication and good relationships. Of the ward trained staff, more than one third never met or consulted with teaching staff, and $45 \%$ of staff nurses never had contact with trained teachers, yet it may be recalled that it was the staff nurses who had made most contribution to the ward teaching of students. A majority of those ward staff who did have contact with the teachers said that this was in connection with the teaching of learners, or to discuss their progress, or on matters related to administration such as allocation of students to wards. Of $28 \%$ of the ward staff sample who met with ward staff in connection with teaching or assessment of learners, half said their contact was only with the clinical teacher.

The only contact which three staff nurses mentioned, was when a teacher asked them for permission to work with a student on the ward staff. No teacher gave any indication of asking permission to work with students. 
Formal meetings between college and ward staff were mentioned by very few respondents, in only two colleges/ hospitals. In one hospital, only ward sisters had the opportunity to attend such meetings.

It can be concluded from the evidence that meetings between college and ward staff took place mainly at the instigation of the former, were principally on matters directly connected with learners, and for $82 \%$ of the ward trained staff occurred rarely or never.

\subsection{Ward Staff Knowledge of Students! Theoretical Preparation for Specific Ward Work}

$70 \%$ of ward trained staff did not know whether or not a student nurse had had the relevant theoretical preparation for the work she was required to do in their particular ward. This number comprised 1 : 2 ward sisters, $1: 2.5$ staff nurses and $1: 3$ enrolled nurses, and was independent of any relationship with length of time in grade of the respondents.

\subsection{Ward Staff/leamer Ratios}

While fluctuations in leamer numbers on the ward staff occurred fairly frequently, over all hospitals, it was found that the ratio of ward trained staff to learners was never lower than $1: 2$ and in a majority of the general medical and surgical wards the ratio ranged from $1: 1.5$ to $1: 1$ 


\subsection{Formal Organisation of Teaching Commitment}

There was no evidence of a common policy within four of the five colleges as to the allocation of teaching commitment. The most usual method of deciding this matter appeared to be that of discussion, between the members of a team of teachers, headed by a senior tutor, but differences of policy existed between these teams within the same colleges.

\subsection{Generic Role of Teachers}

A majority of the tutors (86\%) taught most of the subjects in the General Nursing Council (Scotland) syllabus, and $67 \%$ of tutors had, in addition, overall administrative responsibilities for one or more intakes of students. All but one clinical teacher taught in a number of different wards and in a variety of subjects. $75 \%$ of the trained teachers considered that they had an area of specialist knowledge or expertise, and of that number, $80 \%$ did some teaching of their specialist subject.

However, it was concluded that, quite clearly, for both grades, their function was that of a generic type of teacher.

\subsection{Opinions as to whether the Tutor should Teach in the Wards}

A clear majority of ward trained staff and of teachers considered the tutor should carry out ward teaching, but $8 \%$ of ward staff and $4 \%$ of teachers were unsure, and 1 tutor and $13(6 \%)$ of the ward trained staff considered the tutor's place to be in the classroom and not in the ward. 
The most likely reason why tutors did not teach on the wards was considered, by both grades of teacher, to be that the creation of the clinical teacher grade had made it easier for the tutor to opt out of ward teaching. However, $36 \%$ of tutors and $13 \%$ of clinical teachers did not agree that this was a valid reason. The least likely reason, on which again both grades of teacher were agreed, was that the ward staff might resent the presence of the tutor on the ward. Not surprisingly, the least controversial of the proferred reasons for the tutor not teaching on the wards, in that it was ranked by most teachers, was that college commitments prevented her doing so. Tutors ranked this as the second most likely reason, whereas clinical teachers accorded it fourth place among the five possible reasons for the extremely low contribution made by the tutor to ward teaching of students.

\section{Addendum}

Whereas $74 \%$ of the tutors and all but one of the clinical teachers had some degree of ward teaching commitment, only $4 \%$ of the ward trained staff did any college teaching. These staff were from three of the hospitals.

\section{Findings and Conclusions from the Post-experiment Data}

\subsection{The Experience of those involved with the Experiment}

Opinions as to what it was like to participate directly in the experiment were available from 51 student nurses, 11 teachers and 58 ward staff. 
2.1.1 It proved to be an enjoyable leaming experience for $96 \%$ of the students, and an enjoyable teaching experience for all their teachers.

\subsubsection{The experiment was implemented in 7 hospitals and} 33 wards, and $91 \%$ of ward staff considered it caused no disruption to ward routine.

\subsubsection{Advantages of the Experimental Method of Teaching/leaming}

The most frequently expressed advantage was that of active, experiential learning. Terms used by students to describe their learning experience were 'finding out', 'talking over', 'drawing together', 'seeing', 'doing', 'associating'. All three groups of respondents considered it realistic learning. Students expressed approval of the less formal teaching methods and opportunities for more contact with tutors, and with the patients. Ward staff saw advantages for the students in their freedom from pressures and interruptions of ordinary ward work, and considered the opportunity for them to participate in total patient care was beneficial.

Teachers commented upon the opportunities for students 'to learn how to learn', in that they had more time to devote to one patient's care than was normal, and they received explicit encouragement to link theory and practice. Advantages for the teacher were in observing students at work, rectifying faults immediately, and co-ordinating theory and practice. 


\subsubsection{Disadvantages of the Experimental Method}

One disadvantage mentioned by all three groups was that of lack of time. There were occasions when the two hours spent in the wards each morming were insufficient for the students to carry out the nursing care required by their patients and also to consult case notes and ward Kardex and then make their own notes. Teachers would also have preferred more time, both in the ward and in college in the seminar periods.

Some students felt a certain lack of security in that they had fewer notes than normal - a feeling intensified by an impression of the control group assiduously amassing notes in the classroom!

Ward staff felt that neither students nor the patient had continuity, in that students did not always return to nurse the same patient on a second morming. Students in one college developed an interesting coping strategy for this, which is discussed in the next chapter.

\subsubsection{Emfects of Experiment upon Patients}

All respondents considered patients both enjoyed and benefited from the individualised attention, the supervised care. Patients were also considered to have enjoyed the experience of giving, of helping the students. One important criticism, al though it referred to the care of only 2 patients, was that, because the students were with their patients for a longer and more uninterrupted time than was usual, there was the risk that patients could become overtired. 
It was concluded that the advantages to the patients were considerable, both in the improved standard of care and in the fact that some were enabled to meet higher order needs, e.g. for self-actualisation and for self-esteem. It was also concluded that, as a result of the experimental method, some students were alerted to the, at times, detrimental effects of their own well-intentioned efforts to 'care'.

No untoward effects were noted by any respondents upon the other patients in the wards.

\subsubsection{Effects upon Ward Staff}

By a marked majority of opinion, effects of the experiment upon the ward staff were considered to be beneficial - workload was lighter, more time was available for other patients, and there was evidence that ward staff interest was stimulated. In two hospitals, both affected by ancillary staff strike action, two staff nurses feared experience might be taken away from ward student nurses.

\subsubsection{Supervision}

$64 \%$ of students considered the supervision they received was 'just right?. However, $30 \%$ of the sample felt they required less supervision, in particular when they were giving basic care. All but one of that number were in their first year of training. 
Of the ward staff, $78 \%$ considered the amount of supervision was correct, and $18 \%$ felt that more was required. A majority of the teachers were satisfied with the provision of supervision but four felt more was necessary for some students. They instanced occasions when students were required to carry out procedures with which they were unfamiliar.

Pre-experiment opinions of students about a lack of supervision while working in the wards appeared corroborated by the post-experiment findings that several students were clearly unused to supervision.

\subsubsection{Function of Teachers}

There was no difference in the role or function of the registered nurse teachers and the clinical teachers throughout the period of the experiment, and none considered they were required to do any work which was inconsistent with their appropriate role and function.

Those tutors who had not undergone a clinical teacher training course considered that their tutor training had prepared them adequately for the type of teaching required of them during the experiment. Four tutors who were also qualified clinical teachers considered that a clinical teaching course was essential preparation for the experimental teaching method, and that the tutor training course was not a suitable preparation for that type of teaching. 
Job satisfaction was enhanced for $82 \%$ of the teachers, mainly due to increased communication with patients, ward staff and students and also to closer working relationships with teacher colleagues.

\subsubsection{Learning and Remembering}

$84 \%$ of students felt that they had learned more as a result of the experimental method of teaching/learning, than they normally did using entirely college-based methods. One student, who had not enjoyed the experimental method, felt she had learned less than usual. Although there was nothing to indicate that this was so, insofar as her test scores were concerned, from various other evidence in the data supplied by this student, she clearly valued college-based teaching methods and appeared to dislike any reduction of her time in college. Following completion of the tests and essays at the retention stage of the experiment, slightly more than half of the students (57\%) considered that they had recalled more than they normally did, following the more usual methods of teaching and learning.

\subsubsection{No Ward Work other than had been Planned}

A fear, expressed before the commencement of the experiment by both teachers and students, that they would be required to carry out work on the wards other than had been previously arranged and which linked directly to their theoretical teaching, proved unfounded. 


\subsubsection{Total Patient Care}

During the experiment students at no time went to the wards to carry out nursing procedures per se, but always to give individualised patient care. All but one of the students preferred total patient care to task assignment because they considered the former method (a) was better for the patient in that it provided possibilities for improved standards of care, (b) enhanced their own learning and increased their job satisfaction, and (c) facilitated teaching of junior nurses.

It was concluded that, for a majority of the students, the learning (affective) objectives (see Appendix III) were attained insofar as these students were aware of the two different methods of organisation of patient care, i.e. patient assignment and task assignment, and valued the concept of individualised patient care. There was some evidence that the third of these affective objectives had been achieved by a small number of the students who had had the opportunity to practise total patient care in the period intervening between the experiment and their completion of the follow up questionnaire. $45 \%$ of the student sample had practised total patient care, and of that number half had done this on their own initiative.

\subsubsection{Achievement of Objectives of the Experiment}

There was a most encouragingly positive evaluation of the experimental method, not only from the experimental group students and their teachers, but also from the ward staff. The main 
objective, that of the facilitation of integration of theory and practice, received an entirely positive response from ward staff and teachers and from all but one of the students.

\subsubsection{Feasibility of the Experimental Method}

All but one of the experimental group teachers, and all but one of the control teachers considered the method to be feasible within the present system of nurse education and training. One teacher was known to have already used the method, in slightly modified form, with more senior students, in circumstances unconnected with the research.

\subsection{The Experience of the Control Group Teachers and Students}

There were control group students in four of the five colleges. Fifty six students and eight teachers provided opinions as to their experience. The main difference as a result of the experiment was that class size was reduced, and lectures were concentrated into a shorter span of days than usual for that subject matter, i.e. nursing care of patients with gastro-intestinal disease. On most days, control group students received three teaching sessions per day on the subject, during the period of the experiment. Few found their experience disrupting. Those who did, complained of cramming, of intensive lectures and of feeling bored. Other comments were of the opposite vein, and evidenced Hawthorne effect, i.e. in increased interest as a result of the research. 
Given the opportunity to take part in a similar experiment, $69 \%$ of the control group students would prefer to be in the experimental group. The reasons related to the type of active learning which they considered their peers in the experimental group had experienced, and to a desire to 'see for themselves? ${ }^{2}$ of the $31 \%$ who preferred to remain in the control group, many appeared to be threatened by the prospect of change and there was evidence that, as a group, these students preferred the more passive type of teaching/learning which predominated in the colleges.

\subsection{Results of the Tests and Essays}

\subsubsection{Fffectiveness of the Course of Instruction}

Fffective pairing of students in the experimental and control groups, in terms of their knowledge of the subject matter of the course as measured by the objective test, was demonstrated prior to the experiment. There was a statistically significant gain score for students in both experimental and control groups from pre-test to post-test, and from pre-test to retention test $(p<.001)$. It was concluded that both courses of instruction were effective.

The essays proved to be the more sensitive of the two measurements (i.e. objective test and essay type of test) in demonstrating forgetting between post-experiment and retention stages.

There was no statistically significant difference between students taught by the experimental method and those taught by the control method, nor was there any statistically significant difference 
at retention stage between students, in either group, for whom the intervening practical experience of nursing had been relevant to the subject matter of the experiment, and those for whom it had not.

There was a consistent trend for students from the experimental group to perform better than those in the control group on both tests and essays. This trend was extremely small at the post-experiment stage of immediate recall, but was more marked at the retention stage, though still not statistically significant.

2.3.2 Relationship between Tests and Essays and Reliability of Essay Marking

Although the mean scores on the essays were, in every college, lower than the mean scores on the objective test, correlations between these two measures, when viewed across all colleges, were high, indicating a similar ordering of students on both measures. With regard to the marking of the essay scripts, there were significant differences between the means, and thus the marks awarded by the three neutral markers. There was very little difference however in the rank ordering of the students by the three markers.

\subsection{Student Nurses? Study Patterns}

As a result of the findings in regard to study carried out during the admittedly abnormal period of the experiment, it was concluded that very little study was either required of the students 
in the sample, or done by these students in their own time. Many students appeared to rely heavily upon their notes, and many studied by means of 'rewriting notes neatly'. $76 \%$ of the sample studied by reading from textbooks. Study, insofar as the pre-experiment sample of students were concerned, was the least popular method of teaching/learning, and for those of that number who took part in the experiment, either as experimental or control students, it was only very infrequently made use of in their daily work in college. 


\section{CHAPTHER 24}

\section{DISCUSSION AND RECOMIIENDATIONS}

This research produced evidence, within the present system of nurse education and training, of various factors relevant to the problems of integration of theory and practice in nursing, but also produced evidence of one possible solution to certain of the problems. This was in the form of a method of teaching and learning about nursing in which theoretical teaching and relevant ward practice were combined in such a way as to provide an effective learning experience for the students concerned, enhanced job satisfaction for their teachers (both registered nurse teachers and registered clinical teachers shared an identical teaching role) and which had the support, approval and interest of the ward staff. What of the patients ...?

\section{Teaching of Nursing in the Ward - the 'Use' of Patients}

When the research experiment was in the early stages of planning, discussions between the researcher and colleagues in both education and service revealed that several feared there would be detrimental effects upon the patients directly involved. The view of the experimental method held by these nurses, as it transpired, was of a 'medical model' - of student nurses gathered around a patient's bedside, listening to a nurse teacher, i.e. passive learning, which 'used' patients. The reverse was true. Students learned by doing, by giving total care, as a result of which it appeared that the 
students became more aware of, more sensitive to the patients? individual needs, not just for basic physical care, but for some patients, self-esteem needs, e.g. to feel important and of help to the students, and the need for a listening ear. Students not only commented upon this, but were found to spend time, of their own initiative, in trying to meet these needs for their patients. Given the situation of the experiment, students created opportunities to sit with patients, and 'just listen' because they felt that was the priority for the patient at the time. Several students, of their own accord, made a practice of returning each morming to see their patients of the day or days before, simply to talk with them.

There is a fairly widespread belief in nursing that students, and trained staff too, tend to busy themselves in tasks, and shy away from other than superficial and brief communication with their patients. This was not found to be the case for the students in the experimental groups. They showed sensitivity to patients' higher order needs as well as to those for basic care.

It is important in nursing that teachers, ward staff and students should be as aware of these higher order needs, as most are of the basic needs, and that these should be taught to and discussed with students, not only in relation to patients but to themselves and their co-workers. It is the researcher's experience, as it is of other writers (Birch, 1972) that the behavioural sciences are not taught in nursing to a sufficient extent. It is recommended that skills of communication, and such subjects as psychology should be 
taught by those skilled in, and with advanced knowledge of these matters, and then the students helped to apply their theoretical knowledge to nursing, by their nurse teachers, in giving care to patients.

Students in the experimental groups were also sufficiently perceptive to note the possible effects of their greater involvement with patients as a result of providing total patient care. Altschul (1980) points out that while involvement may be good for patients, nurses need support so that they do not become over anxious at their possible inability to satisfy the patients needs. A critical factor in such support is the understanding of the teacher, but also possession of background knowledge by the student, and the use of such teaching methods as involve small group discussion of these issues.

Factors contributing to Problems of Integration of Theory and Practice and some possible Solutions to these Problems

In this research, which took place in a quarter of the colleges of nursing in Scotland, and their associated hospitals, the trained teachers of nursing made little or no impact upon the teaching of nursing in the place where $77 \%$ of the students in the sample considered that they learned most about nursing, i.e. in the wards. Students had also voted their best liked method of teaching/learning, the ward tutorial; yet both grades of teacher, when compared with the ward sister, staff nurse and student nurses, contributed least of them all to the giving of ward tutorials. The implications, in terms of lost 
opportunities for teaching are considerable. Where learning is most likely to be seen as meaningful, where student motivation to learm is high, the untrained (in teaching skills) are left to make use of the most fertile ground. One cannot but wonder what might be achieved if the expert teacher was present in the wards to a greater extent, both to share in the teaching of students and also to support and guide the ward staff who are teaching. However, to wonder is not enough. In spite of improved teacher/learner ratios, in spite of the recommendations of the Briggs' Report (1972) and of the General Nursing Council (Scotland) (1976) that teachers of the practical activity of nursing should not be divorced from the wards, the trained teacher is divorced from the wards. This has been a fact in nursing for more than a century, and it is no longer relevant or useful to deplore the fact - what must be done is to accept it, to make explicit the implications, and to deal with them constructively. It is the researcher's considered opinion that this does not need legislation, or any major reshuffle, but that it can be done within the system of nurse education and training as it exists at present. The barriers to change, the difficulties lie not in limited resources of finance or of manpower, but - "the greatest impediments are found in the heart, not in the purse" (MoGaghie, 1978, p.89). One of the first steps in removing the impediments is to understand the fears of those, in any group, who are afraid of change, and for those who are leaders in nursing to aim for a flexible organisation in the colleges of nursing which will make full use of those who perform best in the 
status quo, as well as those who realise their full potential in more creative or experimental work. There are also very practical ways of dealing with impediments and these are to take them one by one and in examining them, endeavour to understand the causes and take steps to correct them.

One of the very clear findings of this study was the extent to which the totally untrained in teaching were undertaking the ward teaching of the students in the sample. What were they teaching? The discrepancies between theory and practice noted in this, and in many other studies (Jones, 1975, Hunt, 1974, Bendall, 1975a) must, to a considerable extent, have been connected with the fact that the staff nurses and student nurses did most of the ward teaching, yet these nurses are the most recently qualified, the most recent to emerge from the system of training, or, as is the case with the students, are still within that system. Is it peer group pressure to reject what has been taught in the college, is it lack of understanding of principles as was seen at one point in this study, or is the teaching which emanates from the colleges unrealistic? There must be elements of this, and more, in the problem. One important implication of the evidence herein of the extent of the teaching done by staff nurses and student nurses must be that we begin, now, to teach student nurses to teach. This should be done from the very beginning of their education in nursing; it must be done explicitly, not implicitly as often it is at present, and assessed regularly. For staff in post, workshops on teaching skills should 
be provided and their attendance encouraged. Preparation courses for future ward sisters should deal, in equal proportion, with the techniques of management and the techniques of teaching. The profession should debate the possibility, in the near future, of an identical preparation for the nurse teacher and the sister of a ward. The potential in terms of an interchangeable work force, and all that that would mean in promotion of understanding and communication is exciting to contemplate.

There was evidence of both lack of understanding of the role or function of the tutor as a ward teacher, and of a lack: of communication generally between education and service staff in this study. Almost half of the staff nurses, and more than one third of all the ward trained staff sample had no communication with those who taught in the college of nursing and $70 \%$ of ward staff did not know whether or not a student coming to their ward had had the relevant theoretical preparation. A majority of ward staff considered that, in a situation where no clinical teacher was available, they held the responsibility for teaching students in the ward, and not the tutor. Although most felt the tutor had some role to play in ward teaching, a minority were not at all sure of this or considered the tutor's place to be in the classroom not the ward. The implications of the above points are far-reaching and serious. Firstly - for the student, they mean that any ward teaching she is given, or practice she carries out, is unlikely to be planned in accord with her learning needs, or with her current 
knowledge-base in mind - in fact teaching and practice must proceed on an ad hoc basis. That this may well be so, is implied in the way in which the experimental method of teaching/ learning was seen, in all but one college, as a novel development and in the interest shown and the questions asked by the ward staff involved in the choice of suitable patients for the students, with the researcher and the teachers.

Secondly - implications for future recruitment to nurse teaching must be considered. As a factor in improving communications, current efforts to bring ward staff to the college of nursing are helpful, but limited in usefulness because such visits tend to be of passive observation, rather than of active involvement in teaching. The latter was found, for this study, to be carried out by very few indeed of the ward staff. The answer to more effective communication must lie, principally, in an increase of traffic in the other direction, because of the important implications of a nurse teacher role model who is not in the wards, but, as one ward sister respondent said - 'in the peace and calm of the classroom'. Potential teachers, seeing the current situation, may be drawn to a career which they see as quite apart from nursing practice, and pursue it because they wish to leave the practical areas altogether - thus maintaining the status quo in teaching or altematively, other potential recruits may be lost because they cannot see how teaching and practice of nursing can be combined. 
It was considered that there were a number of reasons apparent in the data which might in part explain the virtual seclusion of many nurse teachers in the colleges. Teachers, both tutors and clinical teachers, were generalists not specialists. Most tutors taught 'most of the subjects' in the General Nursing Council (Scotland) syllabus for general nursing. Many, in addition, were required to take administrative responsibility for one or more intakes of students. What are the effects of this formal organisation upon a newly qualified teacher of nurses who may wish to include ward teaching in her daily work? She is, as Birch (1972) pointed out, unlikely to be qualified, in terms of advanced knowledge, in any subject other than nursing, so she will inevitably have to spend much time and attention in preparing classes and in teaching subjects with which she is not wholly familiar or at ease. She enters a system where it is certainly not required, nor is it likely to be accepted practice to incur a responsibility for ward teaching indeed she enters a system where there is already a teacher with a specific responsibility for ward teaching, namely the clinical teacher. The system is therefore such as to provide more disincentives than incentives for ward teaching by tutors, and in the vital early days of teaching a new tutor has less time available, and less power, as an inexperienced member of the teaching staff, to make or effect changes in the system in which the more experienced teachers are not themselves teaching in the wards. Her generic role as a registered nurse teacher - previously 
noted in this study and corroborated by the fact that it is the exception rather than the rule to see a college advertisement for teachers with specialist knowledge - will combine with the above mentioned factors to make it difficult for her to avoid spending almost all of her time in the college of nursing. A pattern of work, once established, is more difficult to change, and as time goes by, a returm to ward teaching becomes more problematic.

It is therefore recommended that Directors of Nurse Education endeavour, together with their staff, to formulate a policy which will permit all future appointments to be advertised, and made, on a specialist basis, as a first step towards facilitating an increased contribution to ward teaching by nurse tutors.

It appeared also from findings in this study that the creation of the clinical teacher grade had made it easier for the registered nurse teacher to opt out of ward teaching - surely an ironic and unforeseen result of the innovation of the late 1950s, intended as it was to improve links between theory and practice, college and ward. The teachers in this sample, who ranked various reasons why tutors did not teach in the wards, considered the fact that the clinical teacher was there, specifically to carry out ward teaching, to be the most likely reason for the non-appearance of many tutors on the wards. They considered it a more likely reason than pressure of college commitments, or even the possibility that the tutor had gradually lost contact with ward work. 
In view of this finding, it is recommended that in Scotland, further research must be done, using more sophisticated techniques than were possible in this study, in order to decide whether the continuation of two grades of nurse teacher is of value, or counter-productive to the General Nursing Council's stated aim to have tutors assume some responsibility for ward teaching. The question must be raised - is one of the answers to the problem of integration of theory and practice simply to have one grade of teacher - no 'middleman' between the classroom lesson and the practical application of that lesson. It is important to bear in mind in this discussion that many of the more senior nurse teachers today are products of a time in nursing when the struggle was to procure set times when students were freed from responsibilities to give service, in order that they might attend lectures and study. The Block system was a hard-won achievement of many of those who today are reluctant to erode any of the time a student has away from the wards and in the college. It is interesting to reflect whether the crammed timetables of many Block programmes (noted in this and other studies) may be a relic of days when the sign of progress in nurse education was a student nurse, seated in a classroom, learning by listening, not leaming by doing - the very passivity of her role as a learner seen as a welcome improvement to her general highly active role in the wards. Is it therefore surprising to find the main emphasis, in the current suggestions for improvements in nurse education, not upon tutors leaving college to teach in the wards, nor upon the Block students leaving college in order to make links 
between teaching and practice (although there are pockets of such innovations), but upon improved ordering of theory and practice, upon modular programmes, upon preserving if not increasing the proportion of the students' training spent in the classroom, vis a vis the time spent in practice?

Such improvements, in particular the modular programmes, while important, are not of themselves adequate to improve integration of theory and practice in nursing. While the formal organisation of work in the colleges is unaltered, while the generic role of both grades of teacher continues, while the whole accent in teaching is on the didactic, rather than on involving the student in active, participative forms of teaching and learning, many of the problems of integration will remain largely unsolved. It is therefore recommended, that following upon the first step of the appointment of specialist nurse teachers, all newcomers to teaching be enabled, and expected to undertake responsibilities for ward teaching in which active experiential learning is the predominant method of teaching and leaming for the subject of nursing. It is suggested, on the evidence of this research, that this be done, for the present, with students who are in Block, and not with students who are on the ward staff. By taking Block students, i.e. working within the system as it exists, teachers have the best possibilities for the carrying out of planned and co-ordinated teaching of theory and practice in nursing.

Although ratios of trained staff to learners on the wards in the hospitals in this study were never less than $1: 2$, and in many 
general wards were 1 : 1 , nonetheless, the considerable fluctuations in the numbers of learmers, and their short stay in each ward, give problems which mitigate against either teachers or ward staff giving regular and planned teaching to the constant flow of new learners. However, if Block students do attend in wards, certainly ward staff should not be required, as was the case in one hospital in the study, to assume responsibility for the teaching of such students.

Ratios of teachers to students on the other hand merit closer examination. These may not be what they seem. Figures quoted in the General Nursing Council (Scotland) Reports refer to all teaching staff and ratios are quoted (excluding the Directors and Assistant Directors of Education) in relation to learners in training, i.e. a period of 144 weeks. Results in this research, and borme out by the literature, show that on the whole very little classroom teaching is done by clinical teachers and very little ward teaching is done by registered nurse teachers. If therefore one considers ( 1 ) that many tutors are working with students only while they are in Block, and (2) that only approximately one sixth of the student's time is spent in Block throughout training, then one may be justified in looking at the ratios a little differently.

General Nursing Council (Scotland) figures for 1978 state that there are 519 teaching staff, giving a ratio of $1: 19.268$, or approximately half of the total teaching staff are registered nurse tutors, giving a ratio of 1 : 38 , but if these tutors are primarily in the college and only one sixth of the students' time is spent 
there, then one can postulate a ratio of $1: 6$ while the student is in college or Block. If one were to abandon, for an experimental period, the use of the clinical teacher in teaching learners who were part of the ward staff, and, as was done in the research experiment, concentrate her activities upon the teaching and supervision of students attending wards from college, this would permit the inclusion of both grades of teacher in the ratio - the result, a ratio of $1: 3$ - much more favourable than appeared at first sight. It would concentrate skilled resources where and when the student is potentially most able to benefit, i.e. free from ward work and responsibilities and currently receiving theoretical teaching, i.e. she is a student not only in name but in reality, and the priority is her teaching and her leaming. It is suggested therefore that the method used in the experiment is a reasonable and feasible altemative to the present deployment of teachers of nursing, and that it may eradicate some of the present problems of ward teaching and of integration, by increasing communication between college and ward staff, fostering closer working relationships between tutors and clinical teachers, and involving students in active learning at a time when they have no other responsibilities in their work other than to their own learming.

An important and overdue change in nursing education towards more involvement of students in their own leaming would also be facilitated by the method above proposed. Active, rather than passive learning would be predominant, and there would be 
opportunities for much more participation between student and teacher in the learning process. It is essential that the type of thinking which is basic to discovery learning, to problem-solving in relation to the needs of individual patients, be fostered and developed in students of nursing, simply because so much of the knowledge required in nursing is contextual and relative, rather than, to use Perry's term (1975) 'a collection of discrete rightnesses'. (This matter is discussed in Chapter 3 of this thesis).

There were clues within the research that there was a lack of appreciation by students of the relative nature of nursing. Also the fact that so many saw classroom teaching as helpful, yet not relating well to practice may indicate that, as Wong (1979) pointed out, they fail to see the necessity to transfer knowledge from classroom to work, or that classroom leaming is 'leaming from the neck up' (Rogers, 1969). A disturbing finding was of how little study was required of and done by students in the sample, and also the finding that they did not like any form of study; in particular they disliked self-directed study. Such attitudes, though understandable, in that most students enjoy 'spoonfeeding', are of course of concerm when the students' task in learning to nurse is integrational. Most of the behaviour required of the nurse at work is too complex to specify precisely, and thus she must transfer what she has learmed to the performance of behaviour it has not been possible to analyse. To do this successfully she must be able to think things out for herself. - At work on the wards she is expected to make decisions, to apply principles, yet how can she do 
this if she is not actively involved in the process of learning, if the predominant teaching methods in the college are directed to passive reception on the learners ${ }^{2}$ part, to safely covering the syllabus on the teachers ${ }^{2}$ part?

The experimental method of leaming was based upon the principles of active experiential and meaningful learning put forward by C. Rogers, Ausubel and Maslow. Students were placed in direct confrontation with nursing care and problems which were a part of normal daily nursing work. The structure of the course was such that advance organisers (Ausubel and Robinson, 1969) were provided in the form of medical staff lectures on the subject matter of the experimental course, together with preparatory nursing lectures by nurse teachers. Students were presented with the whole care of individual patients rather than with separate parts, i.e. procedures per se, and expected, with help and under supervision, to work out the best way of providing the required nursing care for their particular patient, to implement the care, and to evaluate their provision of that care critically thereafter. Students were explicitly encouraged to transfer classroom leaming to their ward practice and to pay attention to the individual needs of the different patients. The results of the experiment were consistent with the theories of Rogers that much significant learning is acquired by doing. This type of approach, including as it did the participation of students and teachers in a seminar following each period of ward practice, has been documented as both exacting and stimulating for the teacher, as well as for the student, 
but, it is pointed out, the quality of the instructors is decisive (World Health Organisation, 1966).

The role of the teacher in such teaching is quite different from her role as 'lecturer' or 'demonstrator'. It is the role of the 'facilitator' described by both Rogers and Maslow above referred to, enabling students to grow towards their full potential. It is a difficult role, one which many teachers are afraid of as they have less control over what will occur in the classroom. In the reluctance of many to embark on such teaching may be seen one of the problems at the root of ward teaching for tutors. There is no doubt that the teacher must be prepared for such a role in her teacher training course. Teachers in the experiment found their role both exacting and stimulating, and they were divided in their opinions as to whether they had received adequate preparation for this in their own trainings. It is recommended that the content, and teaching methods in which experience is gained in these courses, should be examined by those concemed in the profession, and that determined efforts be made both to secure able candidates for the more difficult role of the facilitator and to provide an appropriate and adequate preparatory course, for there is no doubt that the more relevant role for the teacher of nurses is that of the facilitator rather than the spoon-feeder.

Although the emphasis in this discussion has been upon the benefits of the active leaming of the experimental method, it is stressed that variety of methods of teaching is important. Only 
in this way, can the wide individual differences among students be catered for; can all be enabled to leam. While some members of a class of student nurses are leaming how to nurse in the method described and carried out in the experiment, others in the same class could be employed in other forms of active learning. There should be more use of essay writing, project work, possibly small research projects. There should be much more encouragement of study, and expectation, by teachers, of evidence of study by their students. Clearly, from the commencement of training, students would require to be introduced to such active, participative forms of learning.

Teachers will always debate what is the best use of their own, and the students' time while in the Block, and there is little doubt that some of the methods herein advocated are more timeconsuming than the lecture method, with its attractive air of economy, in that an entire class of students can be addressed in a period which can, if desired, be packed with factual information. While lectures will always have some place in nursing education, are they the medium of choice for teachers of nursing when teaching the subject of nursing? In the opinion of the researcher that is very doubtful. If experts in the fields of biological sciences and behavioural sciences were employed to teach theoretical aspects of these subjects, would not the teacher of nursing be freed for the more exacting, more time-consuming but surely more relevant task of helping the student to apply that knowledge in the care of patients? Even more importantly, would the nurse teacher 
not be freed to go to the wards, there very deliberately to teach the student to learm how to learn from the richness of experience available to her in the wards, or indeed the homes of the patients. There is potential in such a system for continuity of care in that students might be able to follow patients from hospital to home, to achieve their heretofore problematic community care experience in a much more personal and relevant way than occurs in nurse training at present. The use of computer records of student nurse experience would make straightforward the calculation of experience of community work for individual students, so that any necessary arrangements could be made to ensure adequate amounts of such experience.

It would be most interesting to see research done on the ways in which students learn about nursing, on the leaming processes they adopt in whatever studying they do. There have been two recent studies on learning environment in nursing (Fretwell, 1978, and Ogier, 1980), but to the researcher's knowledge, no work akin to that of Marton and Säljö, or of Pask on styles and strategies of learning, has been carried out with student nurses. It would also be of interest to see the present research replicated, perhaps with students at different stages of training, or preparing for registration on other than the General Register, and also with pupil nurses; i.e. those preparing for Fnrolment rather than the Register.

In summary, there were four main recommendations in the substance of the above discussion - 
(1) that teachers of nursing must teach nursing where nursing is carried out - that they must do this primarily with students who are temporarily freed from the pressures of responsibility for providing service, i.e. are in Block, but who remain within the apprenticeship system of nurse education and training;

(2) that teaching methods which actively involve the student in her own leaming must become the rule rather than the exception within a richer variety of teaching methods used in nursing curriculae;

(3) attention must be directed to the effects, within nurse education and training, of the existence of two grades of nurse teacher; and

(4) as a matter of urgency, attention must be given to teaching ward staff and student nurses to teach.

Nisbet and Entwistle (1973) state:

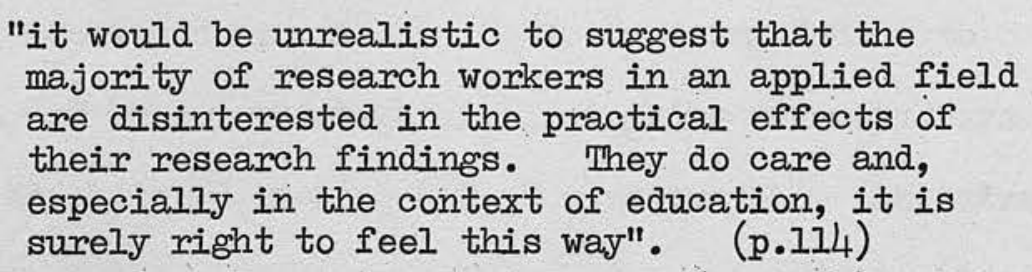

Although the research design was chosen very carefully in order to maximise the objectivity of the results of this study, there can be no doubt of the subjective nature of much of the data, and in particular of the interest of the researcher in the field of nurse education. Her values are also apparent, especially in the final chapter of this thesis. That the leaming experience proved 
effective for the students, and that there was such clear endorsement of this method of teaching and learning by all groups of nurses involved, was of course important to the researcher. Education and service staff and student nurses will always be interdependent in any ward teaching programme, so it is essential that, whatever method is adopted, it must be acceptable to the majority of people in each of these groups. One dissenting group would make a ward teaching programme, such as envisaged in this research, unworkable. There was no indication that this would be so with this particular experimental method of teaching and learning to nurse.

\section{In Conclusion}

This research was about nursing - the experiment was about learming to nurse; learning to establish positive links between what was taught and what was practised in nursing; learning to integrate theory and practice. There are many facets to integration of theory and practice in nursing and many ways in which it can be facilitated or hindered, but ultimately, the actual achievement of integration is a matter for the individual student. It is a part of the active, dynamic process of individual learning, and as such, it neither can be measured, nor appropriately expected or sought, as a result of the very brief learning experience of the experimental group students. Gagné (1971) states:

\footnotetext{
"One does not 'teach the student to think" by means of a single course in thinking. Instead, if he is properly challenged, he continues to become a better thinker all his life long"t. (p.522)
} 
One does not teach student nurses to integrate theory and practice by means of a single course in integrating, but, properly challenged ...?

"It brought out all the simple little things that made everything fit in".

(Student in the experimental group) 


\section{REFEREHICES}

ABDEL-AL, H (1975) Relating Education to Practice Within a Nursing Context. Unpublished Ph.D Thesis, University of Edinburgh

ABDHELAH, F.G. and IEHVNE, E. (1979) 2nd edition. Better Patient Care Through Nursing Research. The Macmillan Co. London

ALIFEN, M (1977) Evaluation of Educational Programmes in Nursing. World Health Organisation, Geneva

ALTFEN, H.0. and MURREHL, J. (eds) (1978) Nurse Training. Macdonald \& Evans Itd., Plymouth

ALTEN, M and REIDY, M (1971) Leaming to Nurse : The First Five Years of the Ryerson Nursing Program. Registered Nurses Association of Ontario, Toronto

ALTSCHUL, A (1978) A Measure of Education. Unpublished paper given at annual conference of Royal College of Nursing Association of Nursing Education, London

ALTSCHUL, A.T (1980) Hints on Maintaining Patient-nurse Interaction. Nursing Times, Vol. 76, No.15, pp.650-652

AUSUBEL, D.P. (1968) Educational Psychology : A Cognitive View. Holt, Rinehart and Winston, New York

AUSUBEH, D.P and ROBINSON, F.G (1969) School Leaming : An Introduction to Educational Psychology. Holt, Rinehart and Winston, New York

AUSUBEH, D.P (1975) Cognitive Structure and Transfer in How Students Learm. Eds. Fntwistle, N.J. and Hounsell, D.J. Institute for Research and Development in Post-compulsory Education, University of Iancaster

BATINE, H. (1937) A Criticism of Nursing Education, Oxford University Press, Iondon

BALSON, D.M (1969) The Effectiveness of Programmed Learning in Promoting Transfer in a Training Situation. Programmed Leaming and Educational Technology, Vol. 6, pp.159-163

BALY, M.E (1973) Nursing and Social Change. Heinemann Medical Books Itd., London

BECK, F (1958) Basic Nursing Education. International Council of Nurses, London

BENDALI, E (1971) The Leaming Process in Student Nurses. Nursing Times Occasional Papers 1 and 2, Vol. 67, Nos. 43 and 44 , 28.10 and 4.11 .71 
BENDALI, E (1973) The Relationship between Recall and Application of Learming in Trainee Nurses. Unpublished Ph.D Thesis, University of London

BENDALL, E (1975) Leaming in A Guide for Teachers of Nurses. Ed. Raybould, E. Blackwell Scientific Publications, Edinburgh

BENDALI, E (1975a) So You Passed, Nurse. Royal College of Nursing and National Council of Nurses of the U.K., London

BENDALI, E (1977) The Future of British Nurse Education, Joumal of Advanced Nursing, Vol. 2, No.2, pp.171-181

BIGGE, M.I (1971) Leaming Theories for Teachers. Harper and Row, New York

BIRCH, J.A (1972) An Investigation into the Cause of Wastage During Nurse Training. Unpublished M.Ed Thesis, University of Newcastle-upon-Tyne

BIRCH, J.A (1975) To Nurse or Not to Nurse. Royal College of Nursing and National Council of Nurses of the U.K., London

BIRCH, J.A (1978) Anxiety in Nurse Education. Unpublished Ph.D Thesis, University of Newcastle-upon-Tyne

BLOOM, B.S (ed) (1956) Taxonomy of Educational Objectives. Book 1 Cognitive Domain Paperback Edition. Iongman Group Itd., London

BLOOM, B.S (1963) Testing Cognitive Ability and Achievement in Handbook of Research on Teaching. A Project of the American Educational Research Association. Ed. Gage, N.I. Rand McNally and Co., Chicago

BOYDHLL, T (1976) Experiential Leaming. Manchester Monographs. Department of Adult Education, University of Manchester

BROTHERSTONE, J (1960) Research mindedness and the Health Professions in Learning to Investigate Nursing Problems. Report of an International Seminar on Research in Nursing, Delhi, India. International Council of Nurses and Florence Nightingale International Foundation, London

BROWN, E.I (1948) Nursing for the Future. Russell Sage Foundation, New York

BRUNER, J.S (1975) Beyond the Information Given in How Students Learm. Eds. Entwistle, N.J and Hounsell, D.J. Institute for Research and Development in Post-compulsory Education, University of Lancaster

BURROUGHS, G.E.R (1975) Design and Analysis in Educational Research. 2nd edition. Educational Monograph No. 8 University of Birmingham 
CAMIPBELL, D.T. and STANLEY, J.C (1966) Experimental and Quasiexperimental Designs for Research. Rand McNally \& Co., Chicago. (Reprinted from Handbook of Research on Teaching, 1963, by the American Educational Research Association)

CARO, F.G (ed) (1977) Readings in Evaluation Research. 2nd edition. Russell Sage Foundation, New York

CARTHER, G.B (1939) A New Deal for Nurses. V. Gollancz Itd., London

CHAMPION, A (1974) Either/Or Leaming by Discovery. Adult Education $46: 6, p p \cdot 383-6$

COHEH, J (1960) A Coefficient of Agreement for Nominal Scales. Educational and Psychological Measurement, Vol. XX, No.I, pp. 37-46

COLUINS, H.W., JOHANSEN, J.H., JOHNSON, J.A (1976) 2nd edition. Educational Measurement and Evaluation. Scott, Foresman \& Co., Glenview, Illinois

COOPER, K (1976) Curriculum Evaluation Definitions and Boundaries in Curriculum Evaluation Today: Trends and Implications.

Schools Council Research Studies, Macmillan Education, Iondon

cox, C (1979) Unpublished paper given at Community Outlook Conference, York University and reported in Nursing: Times (Community Outlook Supplement) Vol. 75 , No.45, p.348

CRONBACH, I.J (1977) Educational Psychology. 3rd edition. Harcourt, Brace, Jovanovich Inc., New York

DAGSLAND, H (1965) Lederskap i Skolen. Norsk Sykepleierforlund, Oslo

DALTON, B.M (1969) Withdrawal from Training of RNMS Student Nurses. Nursing Times Occasional Paper 2, August 14th 1969, Vol.65, No.33

DAVIES, I.K (1971) The Management of Leaming. McGraw-Hill Publishing Co. Ltd., London

DE IANDSHEHER, V (1979) On Defining Educational Objectives. Evaluation in Education, Vol. I

DHSS (1977) 3rd edition. Directory of Schools of Nursing, HIVSO, London

DODD, A.P (1974) Towards an Understanding of Nursing. Unpublished Ph.D Thesis, University of London

DU BOIS, P.H (1966) A Test-dominated Society : China 1115 BC - AD 1905 in Testing Problems in Perspective. American Council on Education, Washington, D.C 
EBBH, R.I (1979) Essentials of Educational Measurement. 3rd edition. Prentice Hall, Finglewood Cliffs, N.J

FWWARDS, M.M (1962) Some Nursing Reports (Nursing Times Reprint). Macmillan \& Co., London

ENTWISTTE, N.J (1973) The Nature of Educational Research.

(Block 1 of Educational Studies : A Third Level Course, Methods of Educational Enquiry), Open University Press, Bletchley

ENTWISTLE, N and HOUNSEHL, D (1975) How Students Leam : Implications for Teaching in Higher Education in How Students Learm. Eds. Entwistle, N.J and Hounsell, D.J. Institute for Research and Development in Post-compulsory Education, University of Lancaster

FHRGUSON, A.C (1976) De-schooling Nurses. Nursing Times, Vol. 72 , No.48, p.1864

FINLAYSON, D.S (1951) The Reliability of the Marking of Essays. The British Joumal of Educational Psychology, Vol. XXI, pp.126-134

FISHER, D (1976) Adult Education Theory Necessary in Health Education Practice. Intermational Journal of Health Education, Vol. 19, pp.129-135

FOX, D.J (1976) Fundamentals of Research in Nursing. 3rd edition. Appleton Century Crofts, New York

FRETWELI, J.E (1978) Socialisation of Nurses : Teaching and Learning in Hospital Wards. Unpublished Ph.D Thesis, University of Warwick

GAGNÉ, R.M (1970) The Conditions of Learning. 2nd edition. Holt, Rinehart and Winston, New York

GAGNE, R.M (1971) Instruction Based on Research in Iearming. Engineering Education, Vol. 61, pp.519-523

GFHNERAL NURSING COUNCII FOR SCOTHAND (1973) Reprint Syl1abuses for Nursing, General Nursing Council for Scotland, Edinburgh

GEINERAL NURSING COUNCII FOR SCOTLAND (1976) Annual Report,

General Nursing Council for Scotland, Edinburgh

GENVERAL NURSING COUNCII FOR SCOTIAND (1977) The Future Scheme of Student Nurse Training. A Discussion Document issued to Area Nurse Training Committees and Colleges of Nursing and Midwifery in Scotland, General Nursing Council for Scotland, Edinburgh

GENERAI NURSING COUNCII FOR SCOTIAND (1978) Schemes of Training for the Register of Nurses. Document issued to the Area Nurse Training Committees and Colleges of Nursing and Midwifery in Scotland, General Nursing Council for Scotland, Edinburgh

GENERAL NURSING COUNCII FOR SCOTHAND (1978a) Annual Report, General Nursing Council for Scotland, Edinburgh 
GIJUIES, D.A and ALYN, I.B.(1973) Saunder's Tests for SelfEvaluation of Nursing Competence. 2nd edition. W.B. Saunders \& Co., Philadelphia

GLASER, R (1962) Psychology and Industrial Technology in Training, Research and Education. Ed. Glaser, R. J. Wiley \& Sons Inc., New York

GLASER, R (1963) Instructional Technology and the Measurement of Learning Outcomes - Some Questions. American Psychologist, Vol. 18, pp.519-521

GOLDMARK, J (1923) Nursing and Nursing Education in the United States. Report of the Committee on the Study of Nursing Education, New York

GOLDTHORPE, J.H., LOCKWOOD, D., BECHHOFER, F and PLATT, J (1970) The Affluent Worker : Industrial Attitudes and Behaviour. Cambridge University Press

GOODWIN, W.I and KT.AUSIVEIER, H.J (1975) Facilitating Student Learning. Harper and Row, New York

GOTT, M (1979) Student Nurses : Introductory Course Preparation and Work World Expectations. Report of a Pilot Study. Intermational Journal of Nursing Studies, Vol. 16, No.4, pp.307-317

GREHEN, J.I (1974) The Relationship between Membership in a Curricular Preference Typology and Selected Performance Outcomes. Unpublished Ph.D Thesis, University of Califormia

GREHEN, J.I and STONE, J.C (1977) Curriculum Evaluation, Theory and Practice." Springer Publishing Co. Inc., New York

GRIBBLE, H.E (1977) Gastro-enterological Nursing. Nurses Aids Series, Special Interest Text. Bailliere Tindall, London

GUIMEI, M.K (1977) Effectiveness of a Programmed Instruction Module on Oral Contraceptives. Nursing Research, Vol. 26, No.6, pp. $452-455$

HATE, S.I (1974) An Investigation of Patient Satisfaction and Psycho-social Aspects of Nursing Care. Unpublished Ph.D Thesis, University of Maryland

HALEY, A (1977) Roots. Hutchinson \& Co. Itd., London

HATLIBURTON, J.C (1976) Internal Evaluation of an Experimental Dacum Curriculum in a Diploma School of Nursing. Unpublished Ed.D Thesis, Boston University School of Education

HARDING, I (1979) The Role of the Teacher in the Clinical Field in Teaching Clinical Nursing. Ed. Hinchliff, S.M. Churchill Iivingstone, Edinburgh 
HARIEEN, W (1976) Change and Development in Evaluation Strategy in Curriculum Evaluation Today : Trends and Implications. Schools Council Research Studies) Macmillan Education Itd., London

HARRISON, J., SAUNDERS, M.E and SIMS, A (1977) Integrating Theory and Practice in Modular Schemes for Basic Nurse Education, Jourmal of Advanced Nursing, Vol. 2, No.5, pp.503-519

HARTOG, P and RHODES, E.C (1936) The Marks of Examiners. McMilian, London

HARTOG, P and RHODES, E.C (1936) An Examination of Examinations. McMilian, London

HAUF, B.J (1975) An Evaluative Study of a Non-traditional Field Placement for Community Health Nursing Students. Unpublished Ed.D Thesis, University of Montana

HFATH, J (1979) Tomorrow's Approach to Learming. Nursing Mimror, Vol. 149 , No.6, pp.22-23

HEHDERSON, V (1966) The Nature of Nursing. McMillan Co., New York

HILIS, P (1979) Teaching and Leaming as a Communication Process. Croom Helm, London

HMSO (1966) Report of the Committee on Senior Nursing Staff Structure (Salmon Report), HMSO, London

HIVSO (1972) Report of the Committee on Nursing (The Briggs Report) Cmnd.5115, HIVSO, London

HOCKHY, I (1976) Women in Nursing. Hodder \& Stoughton, London

HOCKEY, I (1980) Challenges for Nursing. Nursing Times, Vol. 76, No.21, pp.908-911

HOPKINS, R and WRIGHT, V (1978) The Best Way to Lecture in Rheumatology. Nursing Times, Vol. 74, No. 51, pp.2115-2116

HOŪE, $\mathrm{E}$ (1978) Aspects of Nursing Education in the United Kingdom : A Study with particular reference to Innovation, Change, Evaluation and Research. Unpublished Report prepared for Nursing Research Unit, University of Edinburgh

HOUSE, V (1977) Evaluation Research : The Need for Mrltiple Criteria. Journal of Advanced Nursing, Vol. 2, No.1 pp.15-20

HOUSE, V (1977a) Survival of the Fittest : A Summary of an Attempt to Evaluate Experimental Schemes of Nurse Training. Joumal of Advanced Nursing, Vol. 2, No.2, pp.157-170 
HUBBARD, J.P and CLFHIANS, W.V (1961) Mrltiple Choice Examinations in Medicine. Lea and Febiger, Philadelphia

HUGHES, E.C., THORNE, B., DE BOGGIS, A.M. GURIN, A and WILLIAMS, D (1973) Education for the Professions of Medicine, Law, Theology and Social Welfare. McGraw Hill Book Co., New York

HUNT, J.M (1971) The Teaching and Practice of Basic Nursing Procedures in Three Hospitals. Unpublished M.Phil Thesis, University of Surrey

HUNT, J.M (1974) The Teaching and Practice of Surgical Dressings in Three Hospitals. Royal College of Nursing, London

HUTCHINGS, M (1979) A Critique of Bendall's 'So you passed Nurse'. Unpublished paper presented to Joint Board of Clinical Nursing Studies, Nursing Education Seminar, London

HUTTY, H.E (1965) Student Nurses : First Year Problems. Unpublished M.Sc Thesis, University of Manchester

INFORMATION SERVICES DIVISION (1978) Scottish Health Statistics issued by Common Services Agency for the Scottish Health Service, HIVSO, Edinburgh

ISAACS, B.J and HULI, E.J (1975) Programmed Learning in A Guide for . Teachers of Nurses, Ed. Raybould, E. Blackwell Scientific Publications, Edinburgh

JACKSON, B and MARSDEN, D (1969) Education and the Working Class. Penguin Books Ltd., Middlesex

JAMIESON, E.M and SEWALU, M.F (1954) Trends in Nursing History. Saunders \& Co., London

JOINT BOARD OF CLINICAL NURSING STUDIES (1978) Course Evaluation Package. Occasional Publication 2. Joint Board of Clinical Nursing Studies, London

JONES, D.C (1975) Food for Thought. The Study of Nursing Care Project Reports, Series 2, No.4. Royal College of Nursing, London

JORDAN, W (1979) Education. Talk with R.F. Mackenzie. Interview reported in The Scotsman, 6.11 .79

JUDD, C.H (1939) Educational Psychology. G. Allen \& Unwin Ltd., Iondon

KATZ, F.II (1978) Guidelines for Evaluating a Training Programme for Health Personnel. World Health Organisation, Geneva

KसHLY, E。M (1980) Bolton's Introductory Course. Nursing Times, Vol. 76 , No.5, pp.213-214 
KIRKWOOD, I (1979) The Clinical Teacher. Nursing Times Occasional Paper, Vol. 75, No.12, pp.49-51

KRAVIER, M (1974) Reality Shock. C.V. Mosby Co., St Louis

KRATHWOHL, D.R., BLOOM, B.S. and MASIA, B.B (1964) Taxonomy of Educational Objectives : II Affective Domain. D. McKay Co. Inc., New York

KULHAVY, R.W and ANDERSON, R.C (1972) Delay retention effect with multiple choice tests. Joumal of Educational Psychology 63: $505-572$

IAAMOND, N (1970) The Registered Nurses ${ }^{8}$ View of General Student Nurse Education. Unpublished M.Litt Thesis, Aberdeen University

IAAMOND, N (1974) Becoming a Nurse. Royal College of Nursing, National Council of Nurses of the UK, London

IAANCET LTD. (1932) The Report of the Lancet Commission on Nursing. The Lancet Itd., London

LOGAN, W.W and GROSVENOR, P.A (1970) Students' Reactions to an Educational Programme I and II. Occasional Paper. Nursing Times, 26.2.72, Vol. 66, Nos. 9 and 10

MCGAGHIE, W.C., MILIER, G.E., SAJID, A.W and THE.DER, T.V (1978) Competency-based Curriculum Development in Medical Education. (Public Health Papers No.68) World Health Organisation, Geneva

MACGUIRE, J (1969) Threshold to Nursing. Occasional Papers on Social Administration, No.30. G. Bell \& Sons Ltd., Iondon

MCKFACHIE, W.J (1975) The Decline and Fall of the Laws of Leaming in How Students Learn. Eds. Fintwistle, N.J and Hounsell, DoJ. Institute for Research and Development in Post-compulsory Education, University of Lancaster

MACMILIAN, P (1980) Paid to Think? Nursing Times, Vol. 76, No.3, p.101

MACE, C.A (1968) The Psychology of Study. Penguin Books, Middlesex

MAGER, R.F (1962) Preparing Instructional Objectives. Fearon Publishers Inc. Belmont, Califormia

MARTIN, J.I (1973) The Scope for Leaming. Nursing Times Occasional Paper, Vol. 69, No.29, p.113-116

MARTON, F (1975) What Does it Take to Learn? in How Students Leam. Ed.s. Fntwistle, N.J and Hounsell, D.J. Institute for Research and Development in Post-compulsory Education, University of Iancaster 
MARTON, F and SÄ\JÖ, R (1976) On Qualitative differences in Learming : I Outcome and Process. The Broitish Jourmal of Educational Psychology, Vol. 46, Part 1, pp.4-11

MARTON, F and SÄLJÖ, R (1976a) On Qualitative differences in Learning : II Outcome as a Function of the Learner's Conception of the Task. The British Journal of Educational Psychology, Vol. 46, Part 2, pp.115-127

MASLOW, A.H (1968) Some Educational Implications of the Humanistic Psychologies. Harvard Educational Review; 38, No.4, pp.685-696

MASLOW, A.H (1970) Motivation and Personality. 2nd edition. Harper and Row, New York

MASLOW, A.H (1974) What is a Taoistic Teacher? in Facts and Feelings in the Classroom. Ed. Rubin, L.J. Ward Lock Educational, London

MASLOW, A.H (1975) Goals and Implications of Humanistic Education in How Students Learn. Eds. Fntwistle, N.J and Hounsell, D.J. Institute for Research and Development in Post-compulsory Education, University of Lancaster

MEHRENS, $W_{\circ} A$ and IEHIMANN/ $/{ }_{\Lambda}(1978)$ Measurement and Evaluation in Education and Psychology. 2nd edition. Holt, Rinehart and Winston, . New York

NFHUEIS, A.I and BENNERR, P (1975) Process or Product Evaluation. Nursing Outlook, Vol. 23, No.5, pp.303-307

MERTON, R.K and KENDALL, P.I (1946) Research Instrument. American Jourmal of Sociology, Vol. 51, No.6, pp.541-557

MILIERR, C.M.I and PARLETT, M (1974) Up to the Mark. Society for Research into Higher Education, London

MOSBY'S COMPREHEHVIVE REVIEW OF NURSING (1977) 9th edition. C.V. Mosby Co., St Louis

MOSER, C.A and KALTON, G (1977) 2nd edition. Survey Methods in Social Investigation. Heinemann Educational Books Ltd., London

MUNN, N.I (1966) Psychology. 5th edition. Houghton Mifflin Co., Boston

NEWSON, J and NEWSON, $\mathrm{E}$ (1965) Patterns of Infant Care in an Urban Community. Penguin Books Itd., Middlesex

NIE, N.H., HULL, C.H., JEHNTINS, J.G., STHETNBREHNNER, $K$ and BEW, D.H (1975) SPSS - Statistical Package for the Social Sciences. 2nd edition. McGraw Hill Book Co., New York 
NIE, N.H and HULL, C.H (1977) SPSS Batch Release 7.0 Update Manual. Programme Library Unit, Edinburgh University

NISBET, J.D (1974) Educational Research, The State of the Art. Paper presented at the Inaugural Meeting of the British Educational Research Association in Manchester. Cited by McDonald, B (1976) Evaluation and the Control of Education in Curmiculum Evaluation Today : Trends and Implications, Ed. Tawney, D. Macmillan Education Itd., Iondon

NISBET, J.D and FHIWISTLE, N.J (1973) The Psychologists Contribution to Educational Research in Research Perspectives in Education. Ed. Taylor, W. Routledge and Kegan Paul, London

NUFFIFHD PROVINCIAI HOSPITALS TRUST (1953) Work of Nurses in Hospital Wards. Report of a Job Analysis. Nuffield Provincial Hospitals Trust, London

OGIER, M.E (1980) Personal communication with regard to as yet unavailable though completed thesis. A Study of the Ward Sister's Leadership Style and Verbal Interaction with Nurse Leamers. Unpublished Ph.D Thesis, University of London

OGUNDEYIN, W.M (1980) Effectiveness of Self Instructional Units in Post-basic Nursing Education. Journal of Advanced Nursing. Vol. 5, No.2, pp.169-178

OPPENHETM, A.N (1968) Questionnaire Design and Attitude Measurement. Heinemann Educational Books Itd., London

OVERTON, P and STINSON, S.M (1977) Programme Evaluation in Health Services : The Use of Experimental Designs. Jourmal of Advanced Nursing, Vol. 2, No.2, pp.137-146

PARLETT, M and HAMILTON, D (1972) Evaluation as Illumination : A New Approach to the Study of Innovatory Programmes. Occasional Paper 9, Centre for Research in the Educational Sciences, University of Edinburgh

PARNELI, D (1973) In Flementary and Secondary Education Amendments of 1973 : Hearings before the General Subcommittee on Education of the Committee on Education and Labor, House of Representatives. 93rd Congress, First Session in Measurement and Evaluation in Education and Psychology (1978) Eds. Mehrens, W.A and Lehmann, I.J. 2nd edition. Holt, Rinehart and Wins ton, New York

PASK, G (1969) Strategy, competence and conversation as determinants of learning. Programmed Leaming, Vol. 6, No.4, pp.250-267

PASK, G (1976) Conversational Techniques in the Study and Practice of Education. British Journal of Educational Psychology, Vol. 46, pp.12-25 
PASK, G (1976a) Styles and Strategies of Leaming. Bxitish Joumal of Educational Psychology, Vol. 46, pp.128-148

PASK, G and SCOTT, B.E (1972) Learning Strategies and Individual Competence. Intermational Jourmal of Man machine Studies, Vol. 4, pp.217-253

PHINSTVY, B.A (1977). Traditional versus Individualized Nursing Instruction. Journal of Nurse Education, Vol. 16, No.2, pp.14-23

PERRY, S.E (1979) Teaching Strategy and Learner Performance. Journal of Nurse Education 18 (1) pp.25-27

PERRY, W。G Jr., (1975) Intellectual and Ethical Development in the College Year's in How Students Learm. Eds. Entwistle, N.J and Hounsell, D.J. Institute for Research and Development in Post-compulsory Education, University of Lancaster

PETHRS, R.S and WHITE, J.P (1973) The Philosophers' Contribution to Educational Research in Research Perspectives in Education. Ed. Taylor, W. Routledge and Kegan Paul, London:

PIIJINER, A.E.G (1973). Experiment in Educational Research. (Block 5 of Educational Studies : A Third Level Course, Methods of Educational Enquiry). Open University Press, Bletchley

PILIINER, A.E.G (1977) Report to the Vice Chancellor of Tribhuvan University and to the British Council University Examinations in Nepal. Internal publication by The Godfrey Thomson Unit for Academic Assessment, The Centre for Research in the Educational Sciences, University of Edinburgh

PONIERANZ, R (1973) The Lady Apprentices. Occasional Paper on Social Administrátion, No.51. G. Bell \& Sons, London

POPHAM, J (1978) Criterion Referenced Measurement. Prentice Hall Inc., N.J

RAYBOULD, E (ed) (1975) A Guide for Teachers of Nurses. Blackwell Scientific Publishers, Edinburgh

ROBBINS, E (1975) Examining Examinations $1-8$ (Series of 8 articles). Nursing Times, Vol. 71, No.43-49. October 23rd 1975 to December 4 th 1975

ROBERTSON, C.M (1979) The Development of Clinical Teaching. Nursing Times, Vol. 75, No.25, pp.1063-4

ROETHLISBERGER, F.J and DICKSON, W.J (1939) Management and the Worker. Harvard University Press, Cambridge, Mass 
ROGERS, C (1969) Freedom to Learm. C.E. Mermill Publishing Co.,

ROGERS, J (1977) Adults Leaming. 2nd edition. Open University Press

ROGERS, J (ed) (1978) Adults in Education. B.B.C. Publication, Iondon

ROPER, N (1976) Clinical Experience in Nurse Education.

University of Edinburgh, Department of Nursing Studies Monograph No.5. Churchill Livingstone, Edinburgh

ROUECHE, J.E (1975) New Learning Principles in How Students Learn. Eds. Fntwistle, N.J and Hounsell, D.J. Institute for Research and Development in Post-compulsory Education, University of Iancaster

ROWNTREE, D (1974) Educational Technology in Cumriculum Development. Harper and Row, Iondon

ROYAL COLIEGE OF NURSING AND NATIONAL COUNCII OF NURSES OF THE U.K (1964) A reform of nursing education : first report of a special committee on nurse education. Royal College of Nursing and National Council of Nurses of the U.K. Iondon

ROYAL COLIEGE OF NURSING AND NATIONAT COUNCII OF NURSES OF THE U.K (1977) Ethics Related to Research in Nursing, p.3. Royal College of Nursing and National Council of Nurses of the U.K. London

SCHERER, J.C (1977) . Introductory Medical Surgical Nursing. 2nd edition. J.B. Iippincott Co., Philadelphia

SCHNEIDER, H.I (1974) Development of a Test based on a Simulated Clinical Setting. Unpublished Ed.D Thesis, Teacher College, Columbia University

SCOTT, W。A (1955) Reliability of Content Analysis : The Case of Nominal Scale Coding. Public Opinions Quarterly, Vol. 19, No.V, pp.321-325

SCOTT WRIGHT, M (1961) A Study of the Performance of Student Nurses in relation to a new method of training with special reference to the evaluation of an experimental course of basic nursing education being conducted in Scotland. Unpublished Ph. Thesis, University of Edinburgh

SCRIVEN, M (1972) Pros and Cons about Goal-free Evaluation. Evaluation Comment, Vol. 3, No.4, pp.1-4

SHHD (1963) Experimental Nurse Training at Glasgow Royal Infirmary. HMSO, Edinburgh 
SHIHHDS, D (1978) Nursing care in Labour and Patient Satisfaction : A Descriptive Study. Joumal of Advanced Nursing, Vol. 3, pp. $535-550$

SIEGEM, S (1956) Nonparametric Statistics for the Behavioral Sciences. McGraw Hill Book Co. Inc., New York

SILVEY, H.M (1951) Student reaction to the Objective and Essay Test. School and Society, Vol. 73, pp.377-378

ST. AUGUSTINE'S IAAMEHT quoted in Rowntree, D (1977) Assessing Students. How Shall We know Them? Harper and Row Itd., London

STATINAKER, J.M (1951) The Essay Type of Examination in Educational Measurement. Ed. Lindquist, E.F. George Banta Publishing Co., Menasha, Wisconsin

STANLEY, J.C and HOPKINS, K.D (1972) Educational and Psychological Measurement and Evaluation. 5th edition. Prentice-Hall Inc., Englewood Cliffs, N.J

STROHIANN, R (1977) Improving Student Clinical Experiences. Nursing Outlook, July 1977

STURGES, P.T (1972) Information Delay and Retention : Effect of Information in Feedback and Tests. Journal of Educational Psychology, Vol. 63, pp.32-43

SUCHMAN, E.A (1977) Evaluating Educational Programs in Readings in Evaluation Research. Ed. Caro, F.G. Russell Sage Foundation, New York

TABA, H (1962) Cumriculum Development : Theory and Practice. Harcourt, Brace and World Inc., New York

TAYLOR, $J$ (1979) The Opinions and Expectations of the Staff and Students Involved in an Experimental Introductory Course for Student Nurses. Unpublished Dissertation towards the Award in Advanced Study in Technical Education of the University of Manchester

THOMPSON, S (1979) A Question of Choice. (Report of an interview between Nursing Mirror Deputy Editor and F. Holden, Professional Adviser (Examinations and Assessments) to General Nursing Council (Fingland and Wales). Nursing Mimror, Vol. 75, No.30, pp. $27-29$

THORNDIKE, E.I (1924) Mental Discipline in High School Studies. Journal of Educational Psychology, Vol. 15, pp.1-22 and 83-98

THORNDIKE, R.I and HAGEH, E (1977) 4th edition. Measurement and Evaluation in Psychology and Education. J. Wiley \& Sons, New York 
TIBBITIS, G.E., NICHOIAS, J.R. and MCKAY, R.J. (1978) Unpublished Paper - synopsis of which was published as Five Teaching Methods : A Comparative Study in Nurse Education. The Australian Journal of Education, Vol. 22, No.1, pp.91-92

TUCKMIAN, B.W (1975) Measuring Educational Outcomes : Fundamentals of Testing. Harcourt, Brace, Jovanovich Inc., New York

TUCKMAN, B.W (1978) Conducting Educational Research. 2nd edition. Harcourt, Brace, Jovanovich Inc., New York

TYLER, R。W (1942) General Statement on Evaluation. Joumal of Educational Research XXXV, pp.492-501

UNIVERSITY OF EDINBURGH/CENTRE FOR FHUCATIONAL SOCIOLOGY (1977) Collaborative Research Questionnaires. Printed by Research Centre for Social Sciences, University of Edinburgh

VERNNON, P.E (1940) The Measurement of Abilities. University of London Press Ltd., London

VICKERS, G (1973) Educational Criteria for Mimes of Change. Journal of Curriculum Studies, Vol. 5, pp.13-24

WARWICK, D.P and IININGER, C.A (1975) The Sample Survey: Theory and Practice. McGraw Hill Book Co., New York

WEISS, C.H (1972) Evaluation Research. Prentice-Hall Inc, N.J

WHITIY, G and YOUNG, M (Eds) (1976) Explorations in the Politics of School Knowledge. Studies in Education Ltd., Nafferton, Fingland

WIISON, S (1977) The Use of Ethnographic Techniques in Educational Research. Review of Educational Research, Vol. 47, No.1, pp. $245-265$

WISEMAN, S (1949) The Marking of English Composition in Grammar School Selection. The British Journal of Educational Psychology, Vol. XIX, pp.200-209

WONG, J (1979) The Inability to Transfer Classroom Learning to Clinical Nursing Practice : A Learning Problem and its Remedial Plan. Joumal of Advanced Nursing, Vol. 4, No.2, pp.161-168

WORLD HFALTH ORGANISATION (1966) Expert Committee on Nursing : Fifth Report. Technical Report Series No. 347, World Health Organisation, Geneva

WRIGHT, B.D (1977) Solving Measurement Problems with the Rasch Model. Joumal of Educational Measurement, Vol. 14, No.2, pp.97-116

WRIGHT, B.D and MEAD, R.J (1977) Bical : Calibrating Items and Scales with the Rasch Model. Research Memorandum, No.23. University of Chicago, Department of Education 


\section{BIBLIOGRAPHY}

AGUILERA, D.C. (1975) The Relationship of Performance in Selected Problem Solving Tasks to Participation in a Crisis. Intervention Course for a Sample of Nurses in a University Baccalaureate Program. Unpublished Ph.D Thesis, University of Southerm Califormia

BAR, M.R (ed) (1969) Cumiculum Innovation in Practice. Edge Hill College of Education, Ormskirk, Lancashire

BARR, D.W. (1979) A Realistic Assessment of Examination Scores. Australian Nursing Journal, Vol. 8, No.7, pp.34-35

BARROWS, H.S and MITCHELL, D.I.M (1975) An Innovative Course in Undergraduate Neuroscience Experiment in Problem Based Learning with 'Problem Boxes'. British Joumal of Medical Education, Vol. 9, pp.223-230

BASSETT, M.B (1976) The Creative Thinking Ability and Problem Solving Skill of Associate Baccalaureate Degree Nursing Students. Unpublished Ed.D Thesis, University of Alabama

BEHABIN, R.M (1969) "CRAMP": a System Approach to Training. Industrial Training International, Vol. 4, pp.160-163

BLIGH, D.A. (1971) What's the Use of Lectures. D.A. and B. Bligh, Publishers, New Barnet

BORHEAM, N.C (1977) The Use of Case Histories to Assess Nurses' Ability to Solve Clinical Problems. Jourmal of Advanced Nursing, Vol. 2, No.1, pp.57-66

CARTHR, S.I (1979) Teaching the Nursing Process : The Nurse Educator. Nursing Times, Vol. 75, No.31, pp.1315-1317

CHATHR, S (1975) Understanding Research in Nursing. World Health Organisation, Geneva

CTARKE, M (1977) Research in Nurse Education. Nursing Times Occasional Paper, Vol. 73, No.7, pp. 25-28

COMBES, R.B (1977) Educating the Learner to Work on the Ward. Nursing Times, Vol. 73, No.2, pp.46-47

COX, D.R (1968) Designing Experiments in Teaching in Innovations and Experiments in University Teaching Methods. University of Iondon Institute of Education, pp.125-131

CRAWSHAW, C.A (1978) Selected Nurse Tutors' Perceptions of their Actual and Potential Clinical Involvement with their Leamers. Unpublished M.Sc Thesis, University of Manchester 
CROCKHR, A.C (1969) Statistics for the Teacher. Penguin Books Ltd., Middlesex

CULLINAN, J (1979) The Approach to Post-basic Teaching. Nursing Times, Vol. 75, No.17, p.693

DAVIES, M.A॰, GALE, J., CI.ARKE, W.D. (1977) Audiotape and booklet self-instructional materials in physiology : an evaluation of their effectiveness and acceptability in the pre-clinical curriculum in Medical Education, Vol. 11, No.6, pp.370-373

DIEIRICH, G (1978) Teaching Psychiatric Nursing in the Classroom. Joumal of Advanced Nursing, Vol. 3, No.6, pp.525-534

EDDMONDS, G., MUSSON, V., DIXON, E. (1979) The Specialist Nurse Teacher. Nursing Times, Vol. 75, No. $37, \mathrm{pp} .1586-1587$

EHLIS, L., PODURGEII, M., PALMER, C (1979) Implementing a Conceptual Framework. Nursing Outlook, Vol.27, No.2, pp.127-130

ENIWISITE, N.J and NISBET, J (1972) Educational Research in Action. University of London Press, London

ENIWISTIE, N (1977) Changing Approaches to Research into Personality and Leaming: . Institute of Education, University of Göteborg

ERICKSON, B.H and NOSANCHUK, T.A (1977) Understanding Data. McGraw Hill, Toronto

ESTHER, C.A.A and BRYANT, R.J (1977) Educating Learner to Work on Ward. Nursing Times, Vol. 73 , No.2, pp.46-47

FIVARS, G and GOSNELL, D (1966) Nursing Evaluation : The Problem and the Process. The Macmillan Co., New York

GAGE, N.I (ed) (1963) Handbook of Research on Teaching. Rand McNally \& Co., Chicago

GAGE, N.I (1967) Psychological Conceptions of Teaching. International Journal of Educational Science, Vol. I,pp.151-161

GEDDES, J.D.C (1969) Telling isn't teaching - and listening isn't leaming. Nursing Times, Vol. 65, No.4, pp.116-117

GRFAVES, F (1979) Teaching Nurses in Clinical Settings I and II. Nursing Mirror Supplements, Vol. 148, No.s 8 and 9,

HABER, A and RUNYON, R.P (1977) General Statistics. Addison-Wesley Publishing Co., London

HALI, D.C (1979) A Position Paper on Nursing. World Health Organisation, Copenhagen. (EURO/NURS/75.I Rev.I) 
HALL, D.C (1980) The Nature of Nursing and the Education of the Nurse. Jourmal of Advanced Nursing, Vol. 5, No.2, pp.149159

HAMILTON, D (1976) , Curriculum Evaluation. Open Books, Iondon HAYTER, J (1979) How Good is the Lecture as a Teaching Method? Nursing Outlook, Vol. 27, No.4, pp.274-277

HEHDGERRKHN, L.E (1965) Teaching and Leaming in Schools of Nursing. Pitman Medical Publishing, Co. Itd., London

HINCHLIFF, S.M (ed) (1979) Teaching Clinical Nursing. Churchill Livingstone, Edinburgh

HUCKABAY, L。M (1978) Cognitive and Affective Consequences of Formative Evaluation in Graduate Nursing Students. Nursing Research, Vol. 27, No.3, pp.190-194

IANNI, F。A.J (ed) (1975) Conflict and Change in Education. Scott, Foresman \& Co., Glenview, Illinois

INFANTÉ, M (1975) The Clinical Laboratory in Nursing Education. J. Wiley \& Sons, New York

JACKSON, S (1974) A Teacheris Guide to Tests and Testing. Longman Group Ltd., London

KERSHAW, J.E.M (1978) The Ward Sisters' Awareness of a Recently Introduced Change in Nursing Practice and their Opinions of the Role of the Nurse Teacher in Implementing such Change. Unpublished M.Sc Thesis, University of Manchester

KILTY, J.M (1974) Objective Testing and Item Banking at the Royal College of Midwives. Midwive's Chronicle, Vol. 87, No.40, pp. 318-320

KIITY, J.M (1976) Can Nursing Research leam from Educational Research? International Journal of Nursing Studies, Vol. 13, pp. $97-102$

LEWHAN, S.R (1973) Ready for Report, Nurse. Royal College of Nursing, Iondon

IESSER, G.S (ed) (1971) Psychology and Educational Practice. Scott, Foresman \& Co., London

IEWIS, D.G (1974) Assessment in Education. University of London Press, London

LINDEMAN, R。H (1967) Educational Measurement. Scott, Foresman and Co., Glenview, Illinois

IINDQUIST, E.F (1940) Statistical Analysis in Educational Research. Houghton Mifflin Co., Boston 
IITILE, D.E and CARNEVALI, D.I (1976) Nursing Care Planning.

J.B. Lippincott Co., Philadelphia

LONGMAN, A.J (1974) Professional Nurse Behaviour demonstrated in Caring for a Patient with Chronic Obstructive Pulmonary Disease. Unpublished Ed.D Thesis, Columbia University

MCCARTHY, M (1974) Functions and Responsibilities of Incumbents of Joint Appointments in Baccalaureate Nursing Programs in University Medical Centers. Unpublished Ed.D Thesis, Columbia University

MALLICK, M.J (1977) Do Nursing Educators Preach what they want Practised? Nursing Outlook, Vol. 25, No.4, pp.244-247

MARSON, S.N (1979) Nursing, a Helping Relationship? Nursing Times, Vol. 29, No.3, pp.541-544

MIIJER, A.E (1979) Nurses ${ }^{8}$ Attitudes towards their Patients. Nursing Times, Vol. 75, No.45, pp.1929-1933

MILLFR, V (1979) Helping the Patient Leam. Nursing Times, Vol. 75, No.24, pp.1016-1017

OPEN UNIVERSITY (1973) Educational Studies: A Third Level Course. Methods of Educational Finquiry. Open University Press, Bletchley

OSKAMP, S (1977) Attitudes and Opinions. Prentice Hall Inc., N.J

PEIIBREY, S.E.M (1978) The Role of the Ward Sister in the Management of Nursing. A Study of the Organisation of Nursing on an Individualised Basis. Unpublished Ph.D Thesis, University of Edinburgh

PHILIIPS, C 。, BARTHOLOMEW, R.S., MACMICHAFH, I.M (1975)

Tape-slide Course in Ophthalmology for Undergraduates. British Journal of Medical Education, Vol. 9, pp.231-235

POPHAM, WoJ (1975) Educational Evaluation. Englewood Cliffs, New Jersey, Prentice Hall Inc.,

QUENZER, R (1974) The Devielopment of Patient-centred Behaviour Patterns in Nurse Training. Unpublished M.Ed Thesis, University of Manchester

REID, W.A and WATKER, D.F (eds) (1975) Case Studies in Curriculum Change. Routledge and Kegan Paul, London

REVANS, R.W (1978) The A.B.C. of Action Leaming. R.W. Revans, Publishers, Altrincham, Manchester 
ROSS, M (1979) Accountability for Nursing Care - towards a new structure. Nursing Times, Vol. 75, No.27, pp.1478-80

ROYAL COLLEGE OF NURSING OF THE UNITEED KINGDOM (1976)

New Horizons in Clinical Nursing, RCN, London

SCHNEIDER, H.I (1979) : Evaluation of Nursing Competence. Little, Brown \& Co., Boston

SHFAHAN, J (1978) Educating Teachers of Nursing : the contribution of Educational Stridies. Joumal of Advanced Nursing, Vol. 3, No.5, pp.447-455

SHFAHAN, J (1978) Educating Teachers of Nursing : the contribution of Pedagogical Studies. Joumal of Advanced Nursing, Vol. 3, No.6, pp.515-524

SHFAHAN, J (1979) Measurement in Nursing Education. Jourmal of Advanced Nursing, Vol. 4, No.1, pp.47-56

SHFAHAN, J (1980) Educating Teachers of Nursing : a survey of the Opinions of Students. Journal of Advanced Nursing, Vol. 5, No.1, pp.71-81

SIANN, G and PIILINER, A (1974) SQA Students' Questionnaire on Assessment. University of Edinburgh

SIMS, A (1976) Teachers of Nursing in the United Kingdom: some Characteristics of Teachers and their Jobs. Journal of Advanced Nursing, No.5, Vol.I, pp.377-389

SORGEN, I.M (1979) Student learning following an Educational Experience at an Alcohol Rehabilitation Centre in Saskatoon, Saskatchewan, Canada. International Joumal of Nursing Studies, Vol. 16, No.1, pp.41-50

SPENCER, M (1979) Did the Student Learn? Nursing Times, Vol. 75, No.1, SPERRY, I (1972) Learning Performance and Individual Differences. Scott, Foresman \& Co., Glenview, Illinois

STEHNHOUSE, I (1975) An Introduction to Cumiculum Research and Development. Heinnemann, London

TAWNEY, D (ed) (1976) Cumriculum Evaluation Today : Trends and Implications. Macmillan Education, Iondon

TAYLOR, W (ed) (1973) Research Perspectives in Education. Routledge and Kegan Paul Itd., London

THOMAS, M.C (1979) Study Difficulties in Undergraduate Nursing Students a British Perspective. International Joumal of Nursing Studies, Vol. 16, No.4, pp.299-305 
TIERNEYY, A.J (1976) Behaviour Modification in Mental Deficiency Nursing. Unpublished Ph.D Thesis, University of Edinburgh

TRAVERS, R.M.W (1969) An Introduction to Educational Research. The Macmillan Co., Iondon

TYLER, R., GAGNÉ, R and SCRIVHAN, M (1967) Perspectives of Cumriculum Evaluation. Rand McNally \& Co., Chicago

UNIVERSITY OF EDINBURGH (1974) Register of Educational Research. Committee on Teaching, Leaming and Assessment, Univ. of Edin.

VERHONICK, P.J (ed) (1975) Nursing Research I. Little, Brown \& Co., Boston

WARCABA, B (1976) An Experimental Scheme in Nurse Education. Jourmal of Advanced Nursing, Vol. I No.3, pp.243-252

WELLIS, T (1975) Towards Understanding Nurses: Problems in Care of the Hospitalised Fiderly. Unpublished Ph.D Thesis, University of Manchester

WHITLEY, T.W (1979) Some Common Flaws in Mrultiple Choice thxamination Questions. Nursing Outlook, Vol. 27, No.7,pp.466-469

WILIIANSON, J.A (ed) (1976) Cumrent Perspectives in Nursing Education : The Changing Scene. Vol. I (1976), Vol.II (1978)

WONG, S (1978) Nurse-teacher Behaviours in the Clinical Field : Apparent Effect on Nursing Students' Learning. Joumal of Advanced Nursing, Vol. 3, No.4, pp.369-372

WORLD HEALTH ORGANISATION (1977) Report of the Technical Advisory Group on the Education of Nursing/Nidwifery Personnel. Copenhagen WHO

WORID HFALTH ORGANISATION (1977) Medium Term Programme in Nursing/ Midwifery in Europe. Munich. WHO

YOUNG, J.T (1965) Technicians Today and Tomomow. Fitman, London

YURCHUCK, E.R (1976) Planning Nursing Care : Competence and Attitudes of Senior Students in Selected Baccalaureate Programs. Unpublished Ed.D Thesis, Columbia University Teachers' College

ZURCHUR, I.A (Jr) and BONJEAN, C.M (eds) (1970) Planned Social Intervention. Chandler Publishing Co., London 
I General Nursing Council for Scotland : Registration on the General Part of the Register. Revised Requirements for Training

II Interview Schedule for Exploratory Survey

III Care of Patients with Gastro-intestinal Conditions : Medical/Surgical Nursing. Leaming Objectives

IV Guide to the Use of the Nursing Care Plan Form

V Nursing Care Plan and Continuation Sheet

VI Care of Patients with Gastro-intestinal Diseases : Medical/Surgical Nursing and Related Biology. Nurtiple Choice Test

VII Student Nurse Opinion Questionnaire - Pre-experiment

VIII Ward Sister and Staff Nurse Opinion Questionnaire

IX Registered Nurse Teacher (Tutor) Opinion Questionnaire

X Registered Clinical Teacher Opinion Questionnaire

XI Student Nurse Opinion Questionnaire - Post-experiment

XII Control Group Students' Questionnaire - Post-experiment

XIII Ward Sister and Staff Nurse Questionnaire - Post-experiment

XIV Opinion Questionnaire for Participating Registered Nurse Teachers and Registered Clinical Teachers - Post-experiment

XV Opinion Questionnaire for Teaching Staff involved with the Control Group of Students

XVI Student Nurse Opinion Questionnaire - Follow up

XVII Retention of Learning Assessment. Part B - Multiple Choice Test (Frontispiece)

XVIII The College-set Essays

XIX Student Diary - Control Group

XX Student Diary - Experimental Group

XXI Attendance Sheet and Diary Collection

XXII Diagnosis of Patients given Care by Student Nurses in

XXIII Available Patients Information

XXIV College Staff Name List

XXV Ward Staff Name List

XXVI Record of Classes - Experimental Group

XXVII Record of Classes - Control Group

XXVIII Experiment in Nurse Education

XXIX Covering letters for Questionnaires

XXX Covering letter for Essay txaminers

XXXI Letter to Students re Test Results

XXXII Pilot Study College : Lectures and Ward Practice

XXXIII Test and Essay Raw Scores for Parts A and B 


\section{APPFHDIX I}

GENERAL NURSING COUNCII FCR SCOTTAND

REGISTRATION ON THE GENERAL PART OF THE REGISTHER

REVISED REQUIREIVENISS FOR TRATNING

(Phase 1 programme of Comprehensive Training)

The Training Period to be 144 weeks exclusive of Annual Leave and Sick/Special Leave

PERIODS TO BE SPENT IN

1. THEORETICAL INSTRUCTION
TOTAL ALIOCATION

24 weeks (study blocks) and 16 study days or equivalent periods of study

Study blocks should normally be 8 weeks in length. Some modification is permitted for the first study block, but a total of 8 weeks' theoretical instruction must be given during the first 16 weeks in training.

In addition to 24 weeks of study blocks, study days or seminars must be arranged during all secondment programmes, the total time so allocated to be equivalent to 16 study days.

2. GEMVERAL MEDICAI NURSING

24 weeks

3. GENERAL SURGICAL NURSING

24 weeks

may include Gynaecology

4. SPECIAIISED SURGICAL NURSING

16 weeks

Experience to be given in two approved clinical areas

5. CARE OF CHIIIRENN *

8 weeks

6. PSYCHIATRIC NURSING .

8 weeks

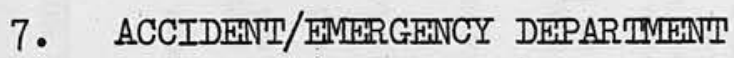

4 weeks

OPERATING THEATRE

4 weeks

8. COMIUNITY CARE SERVICES

4 weeks

OBSTIEIRIC NURSING

4 weeks

120 weeks

24 weeks

9. PRE-REGISTRATION PERIOD

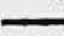

TOTAJ TRATNING PERIOD

144 weeks

* Care of Children in Children's Hospital, Unit or Ward;

Children's Ward of Mental Deficiency Hospital; Local Authority Services 


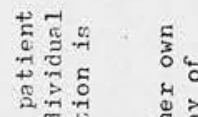

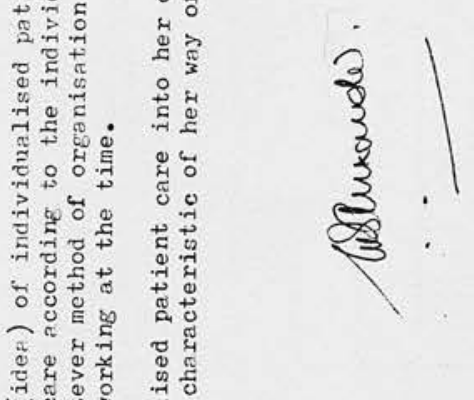

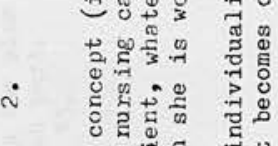

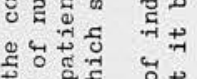

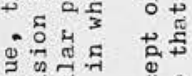

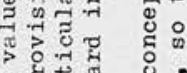

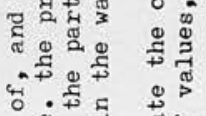

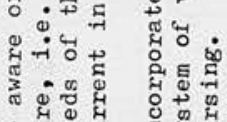

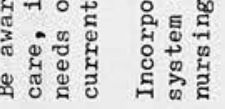

$\stackrel{\infty}{\frac{\infty}{5}}$

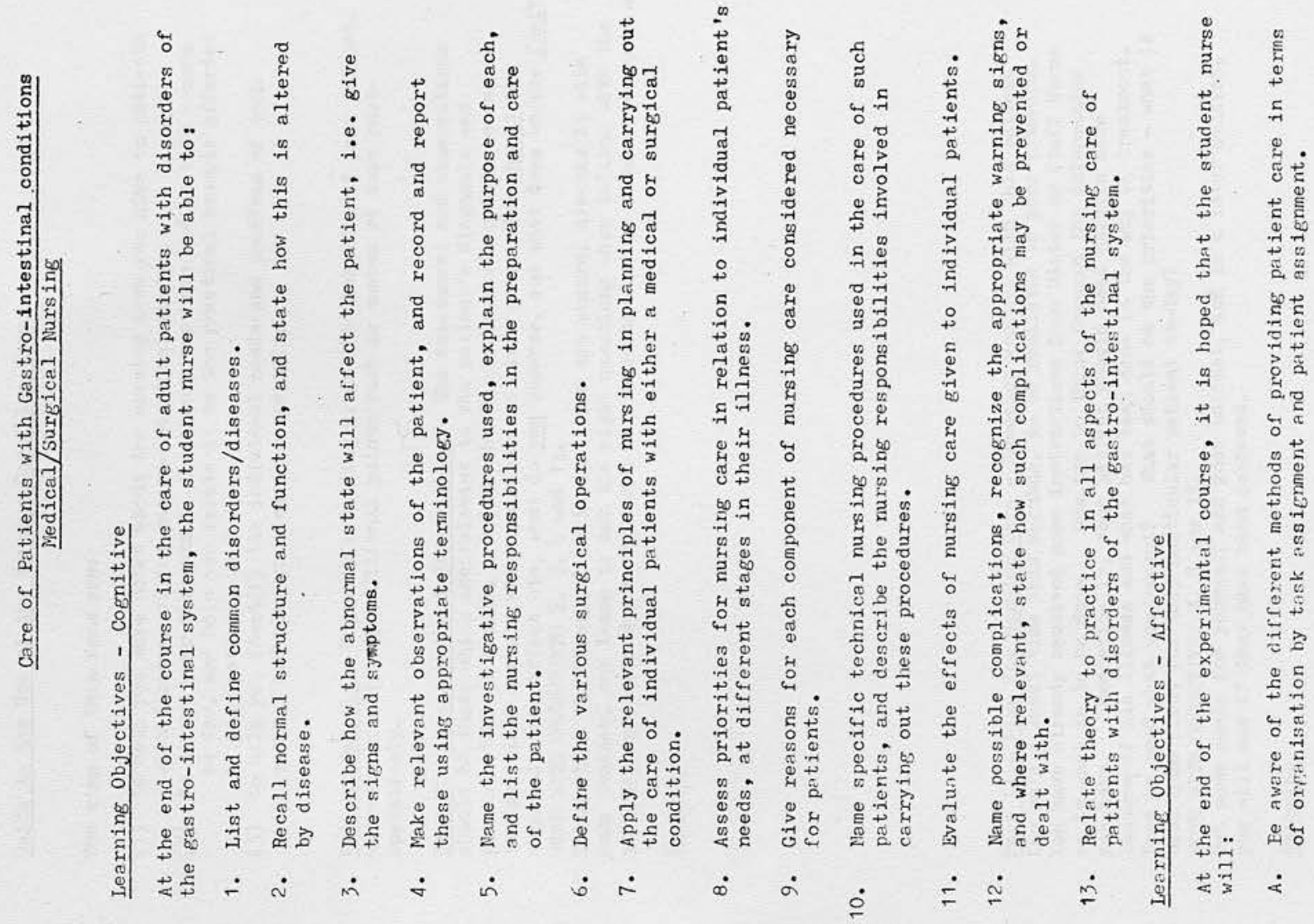



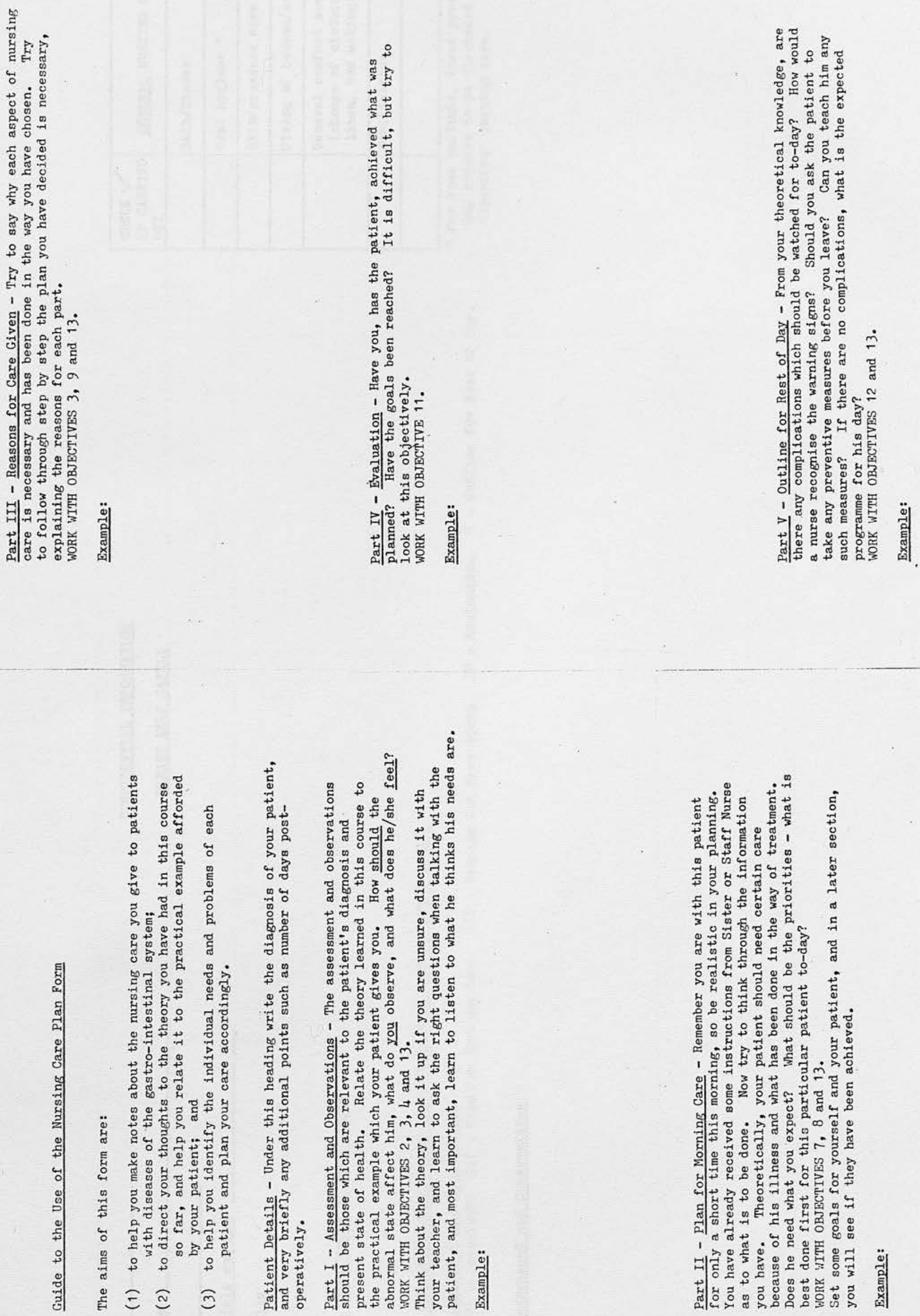

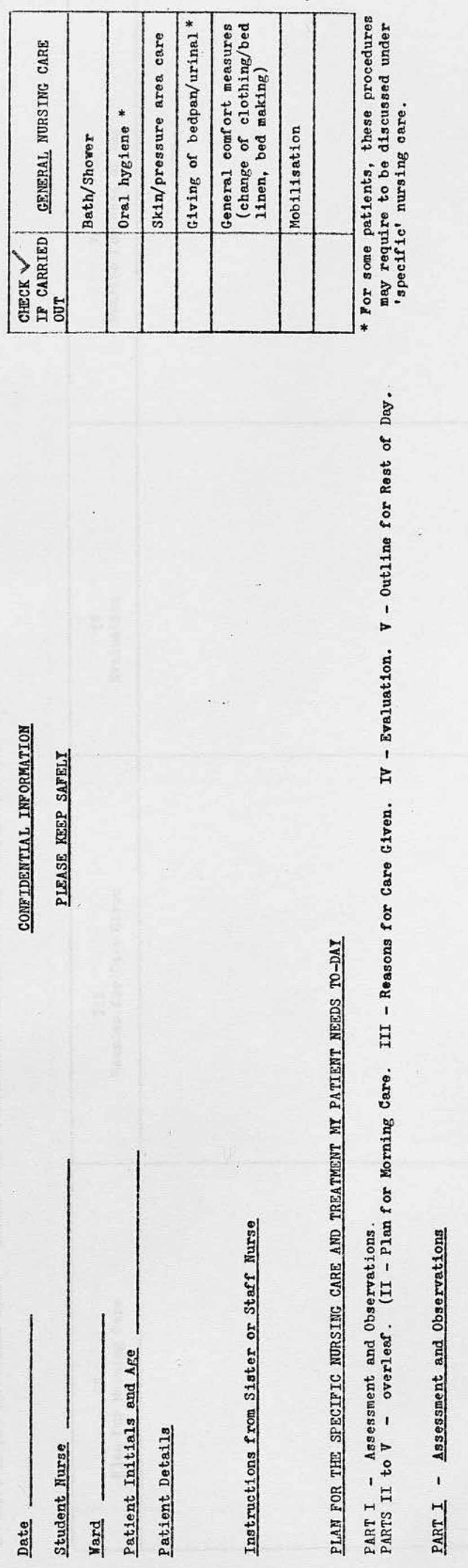

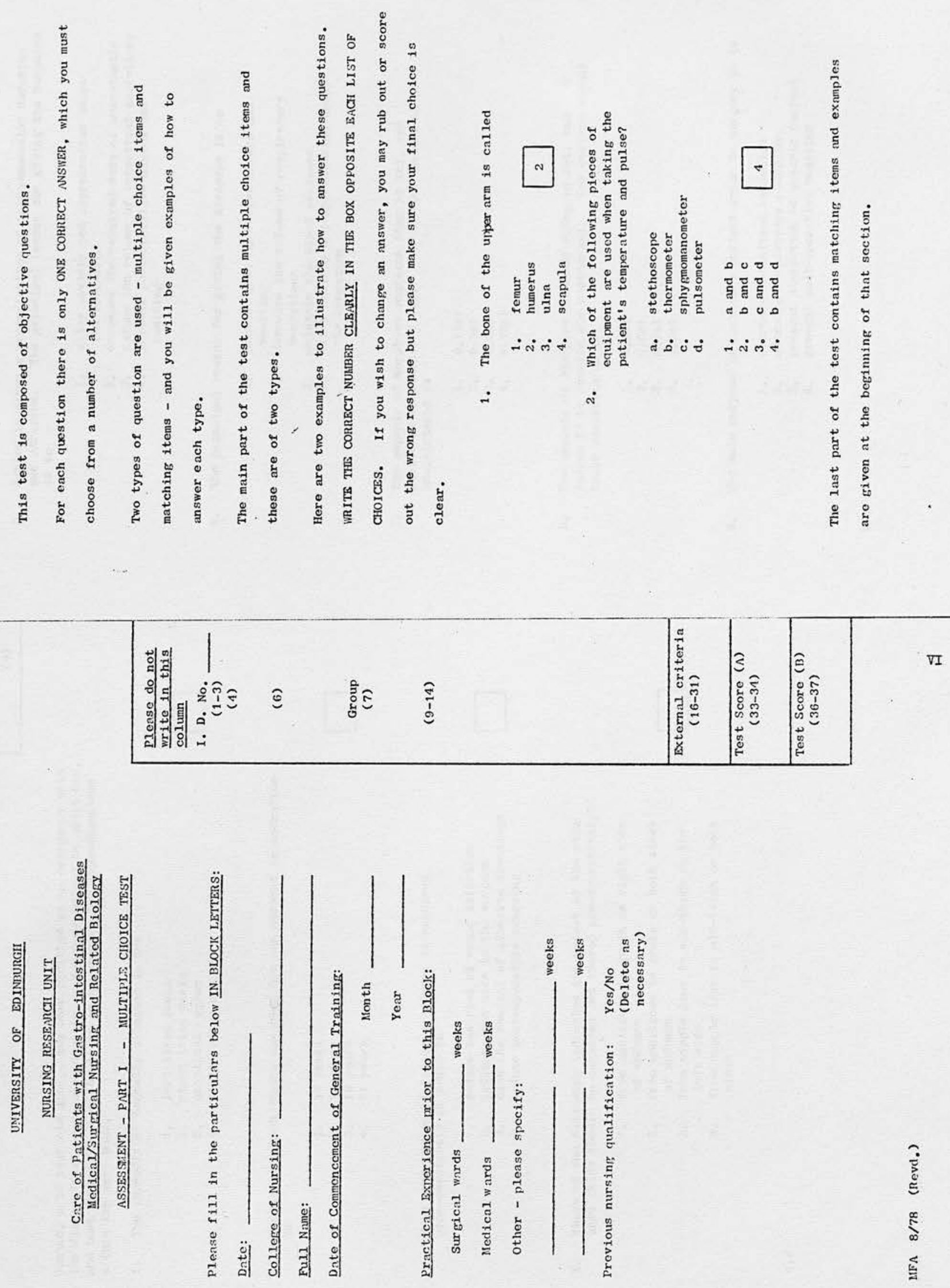

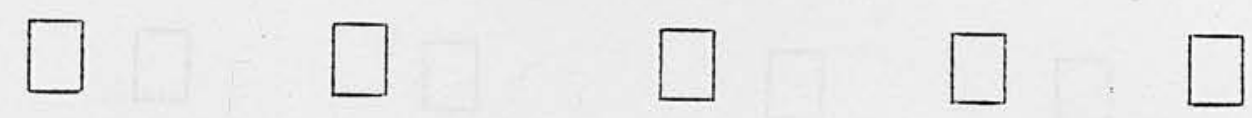

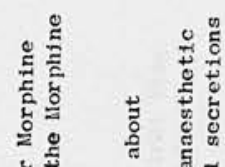

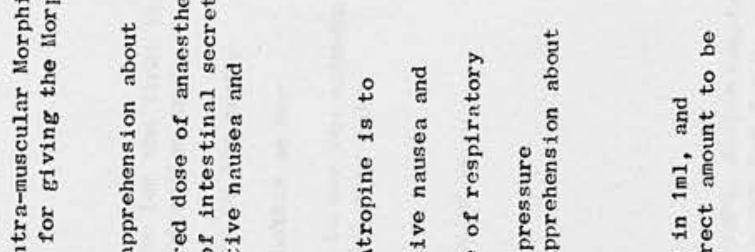

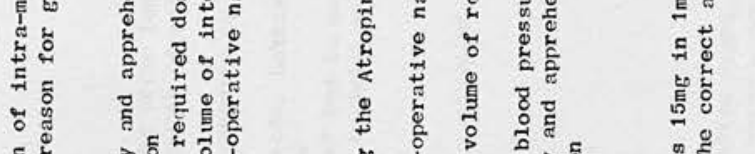

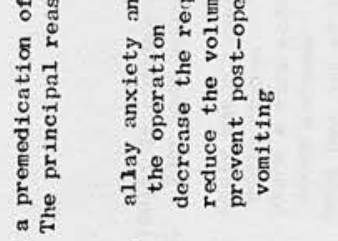

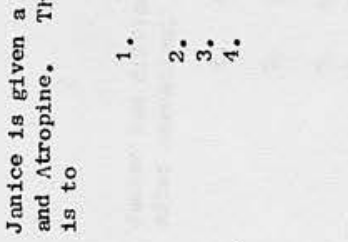

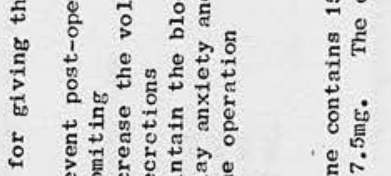

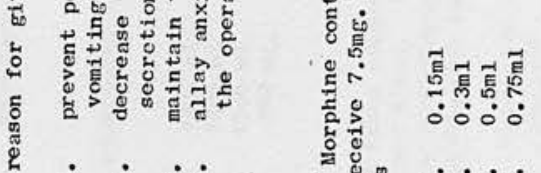

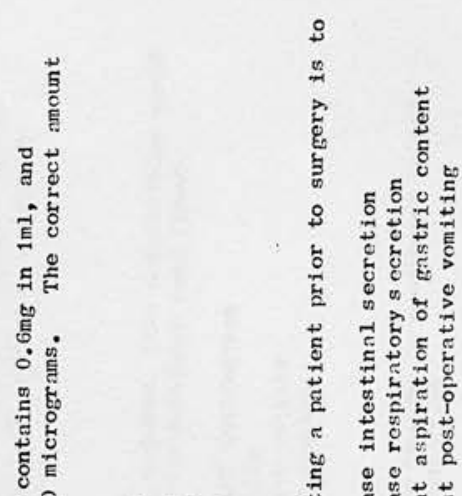

i - त में

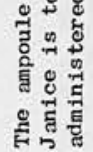

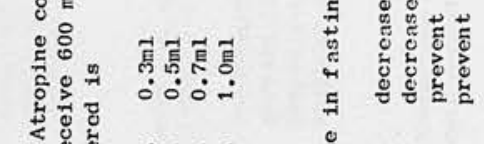

है

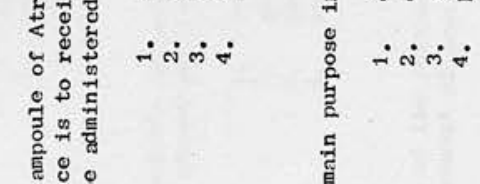

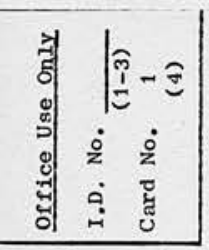
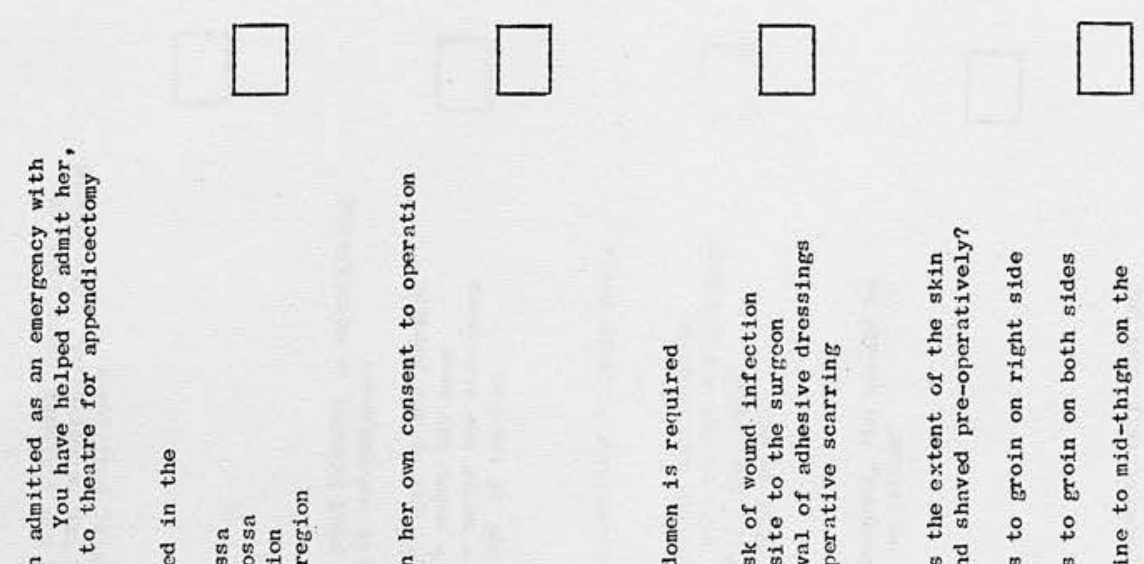

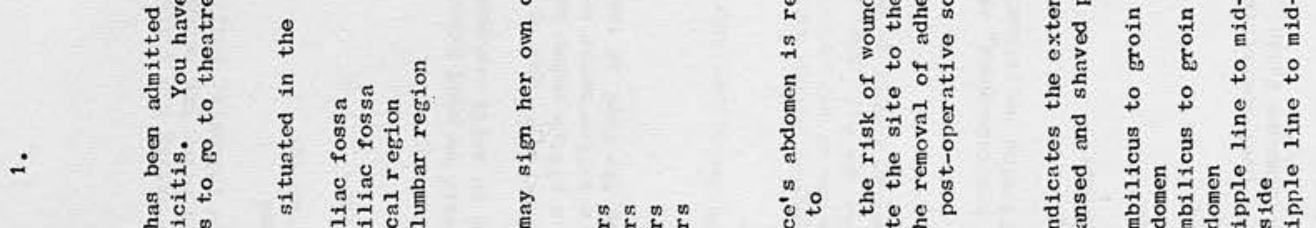

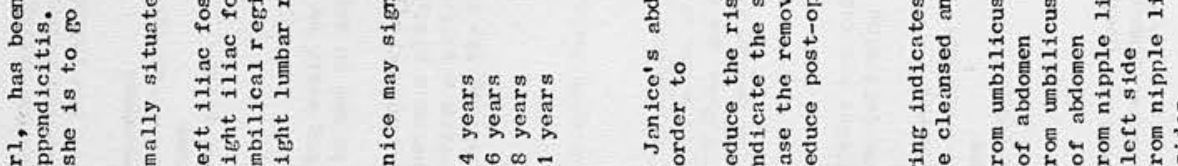

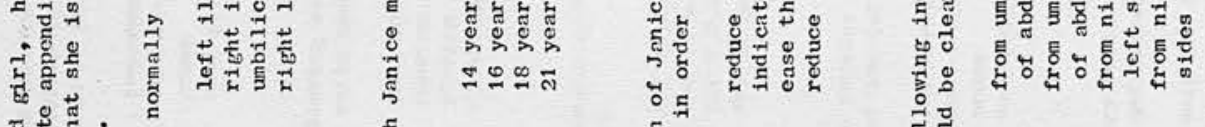

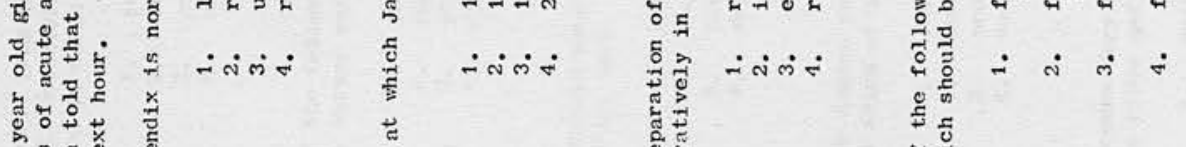

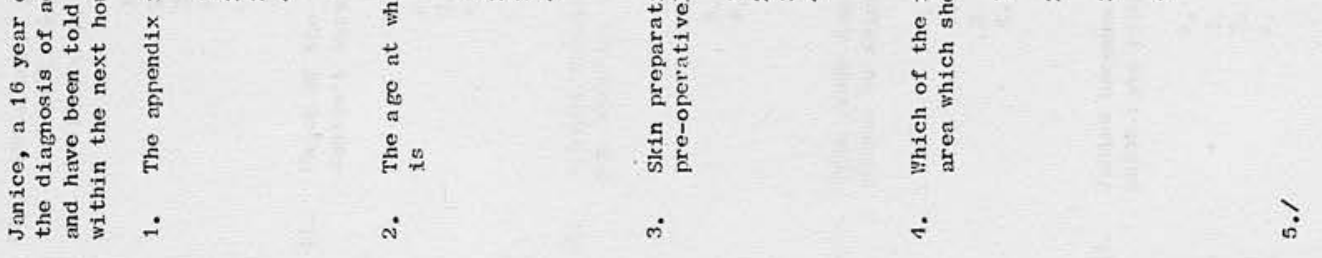



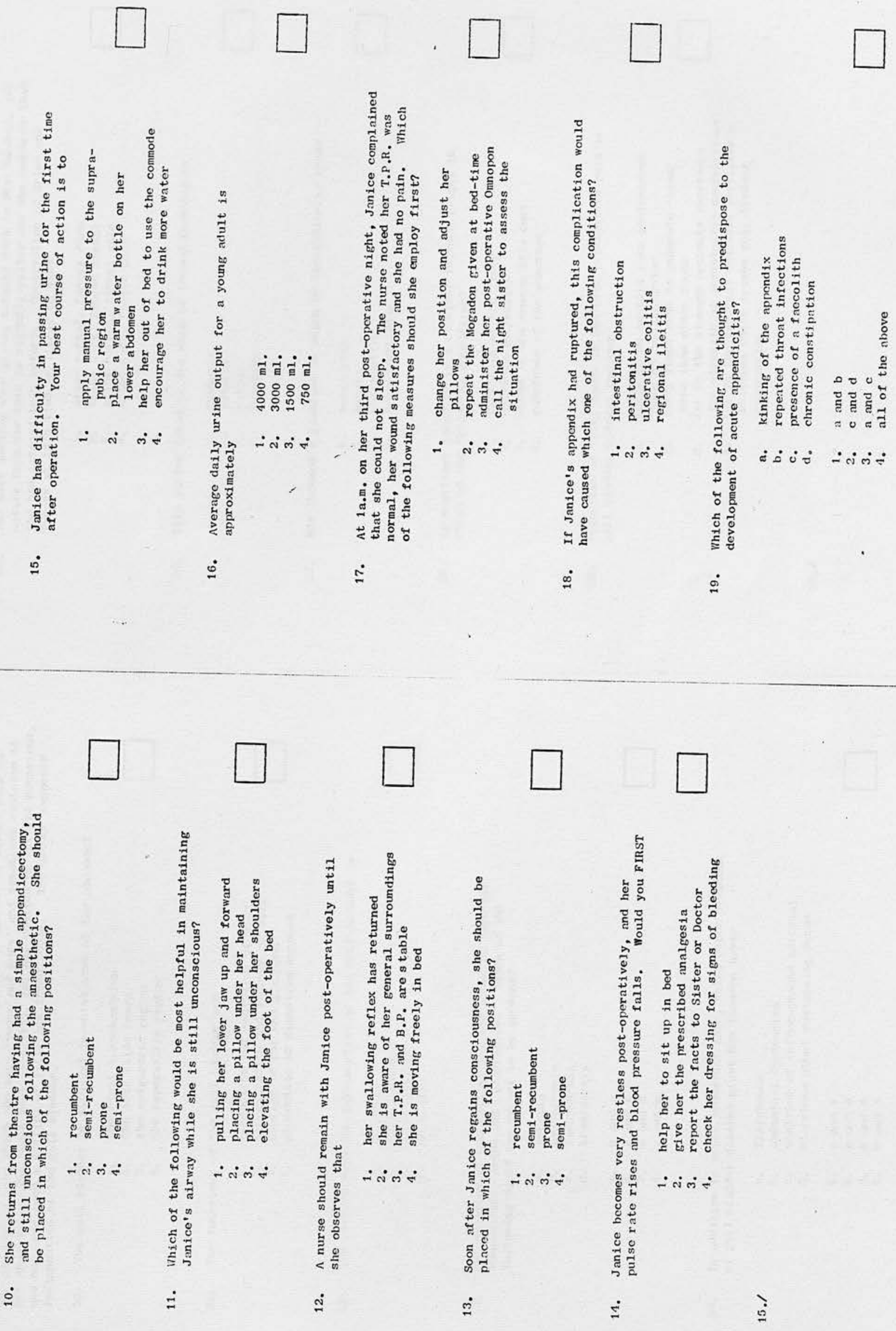

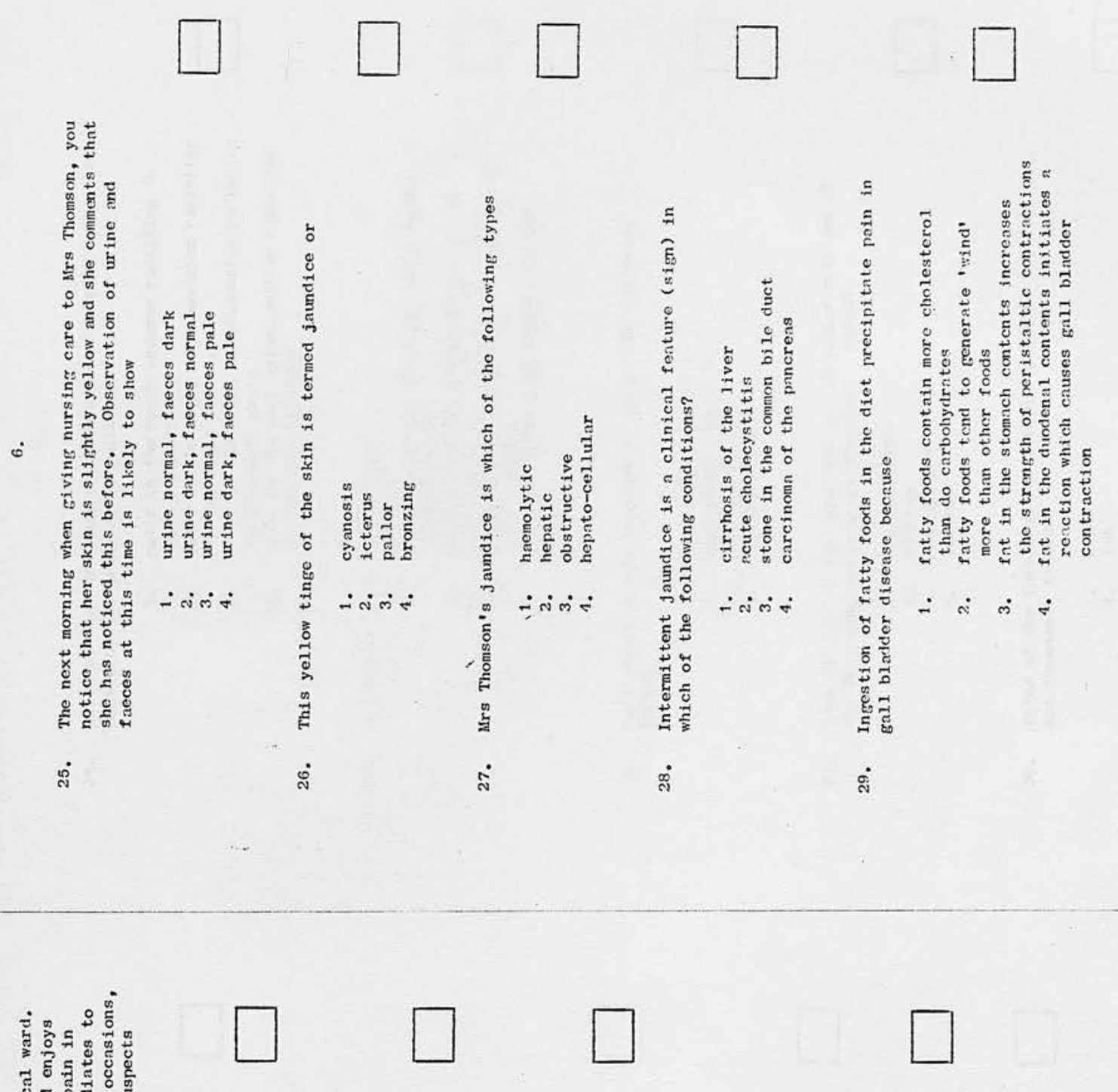

चี

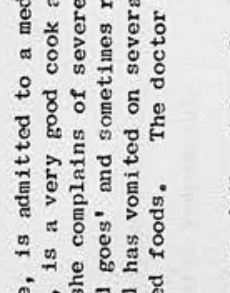

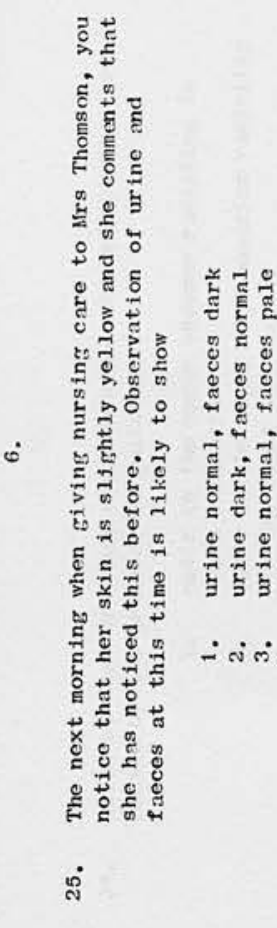

ญั

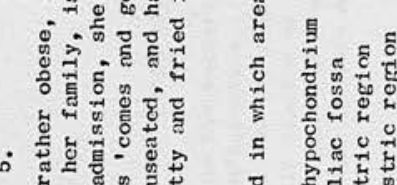

कि

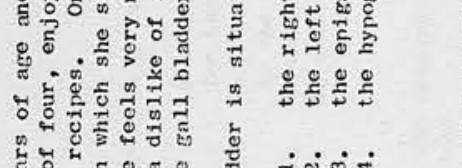

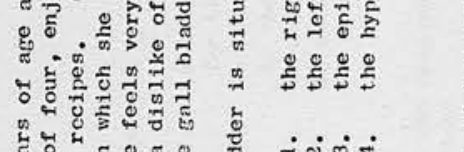

냅

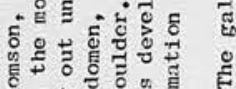

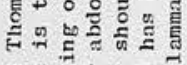

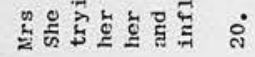
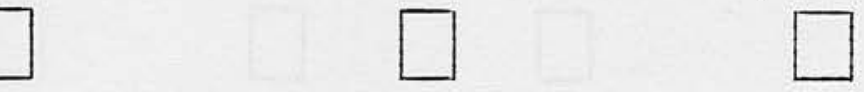

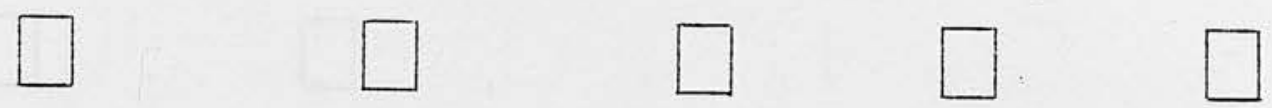

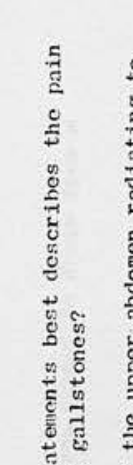

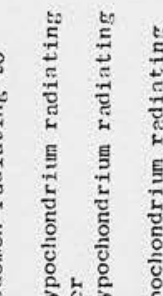

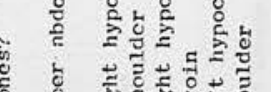

ह

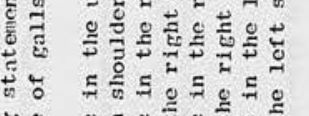

है:

要

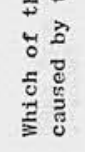

ले
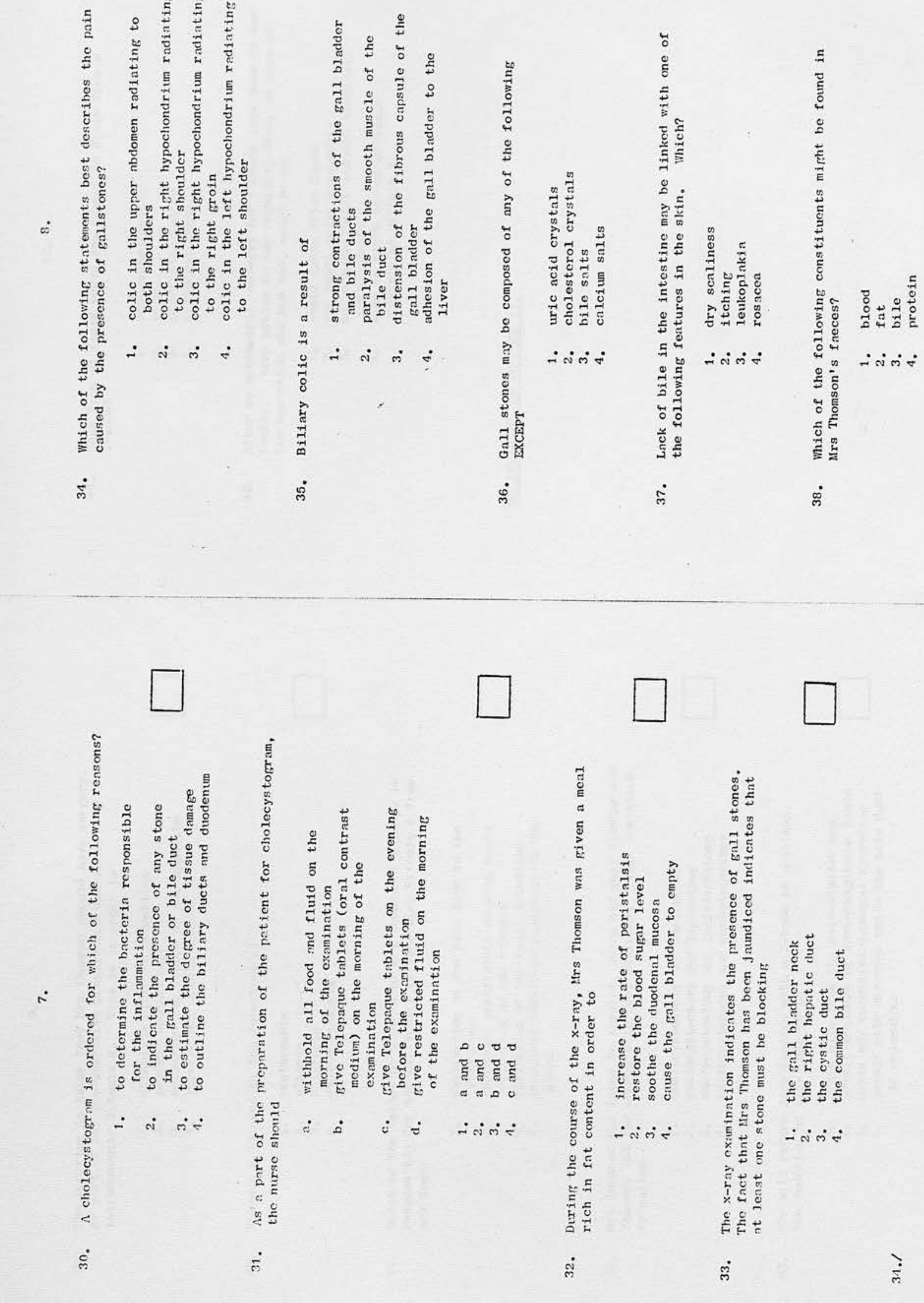

อें 

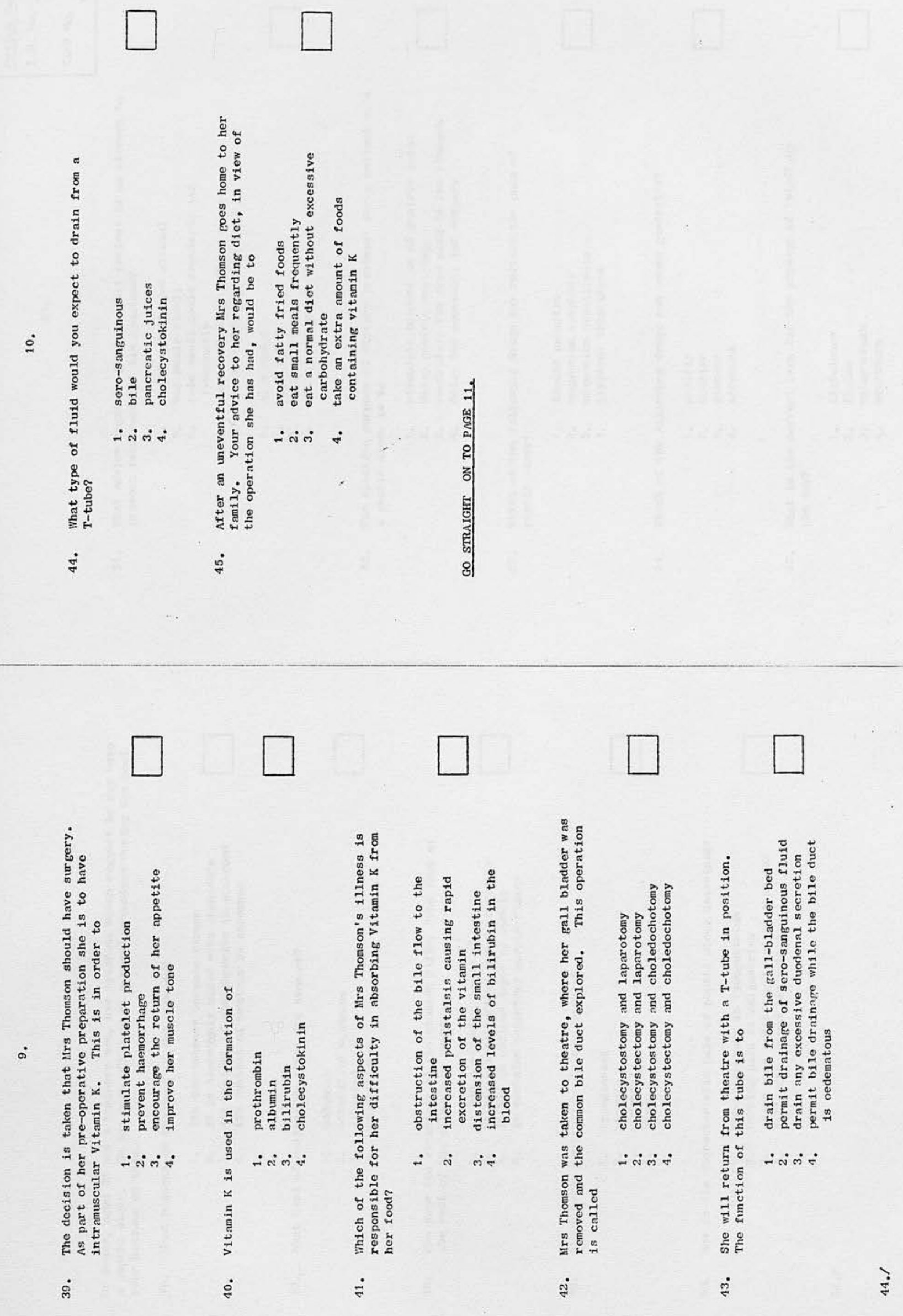

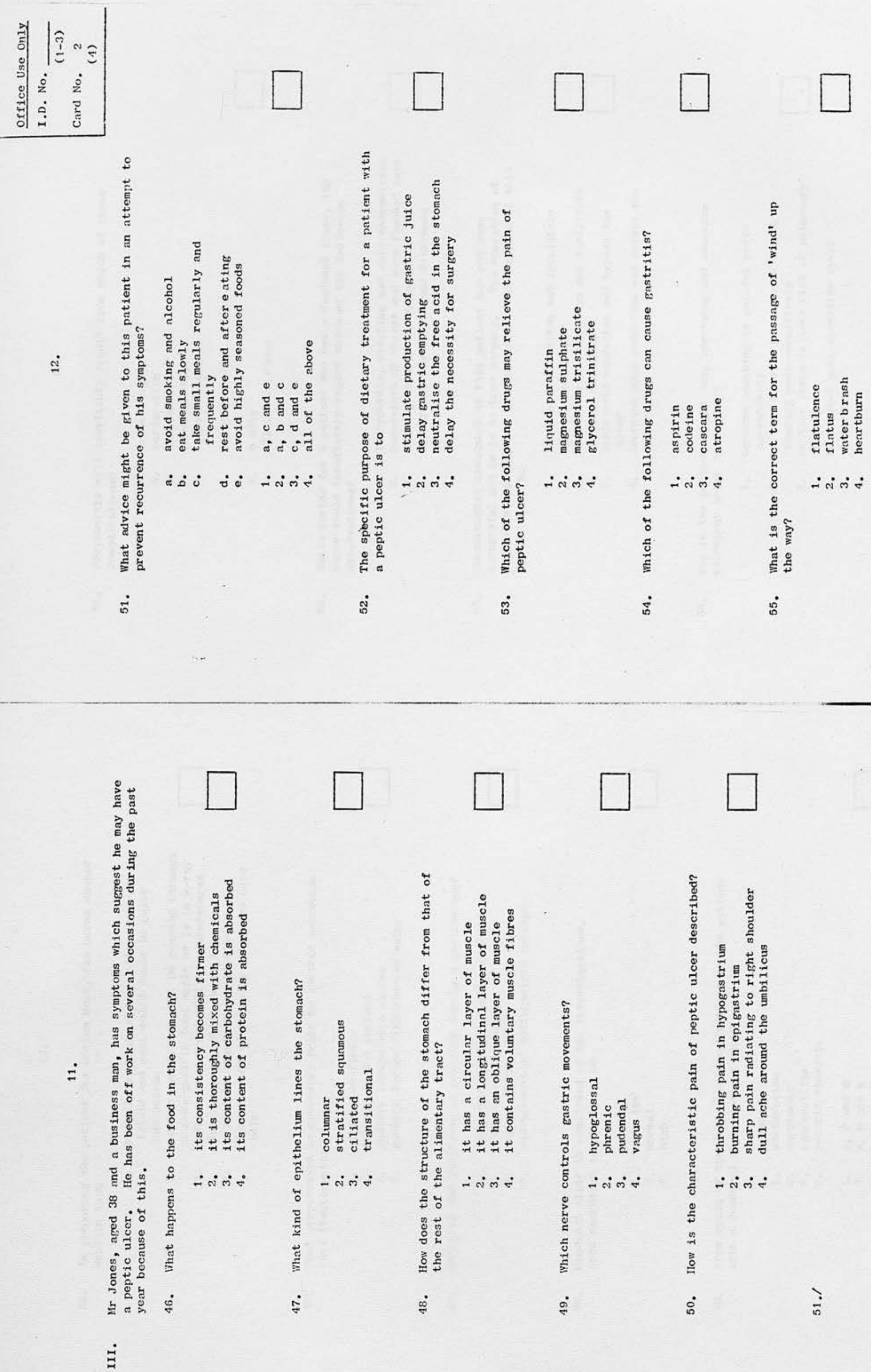


$$
\begin{aligned}
& \square \quad \square \quad \square \quad \square
\end{aligned}
$$

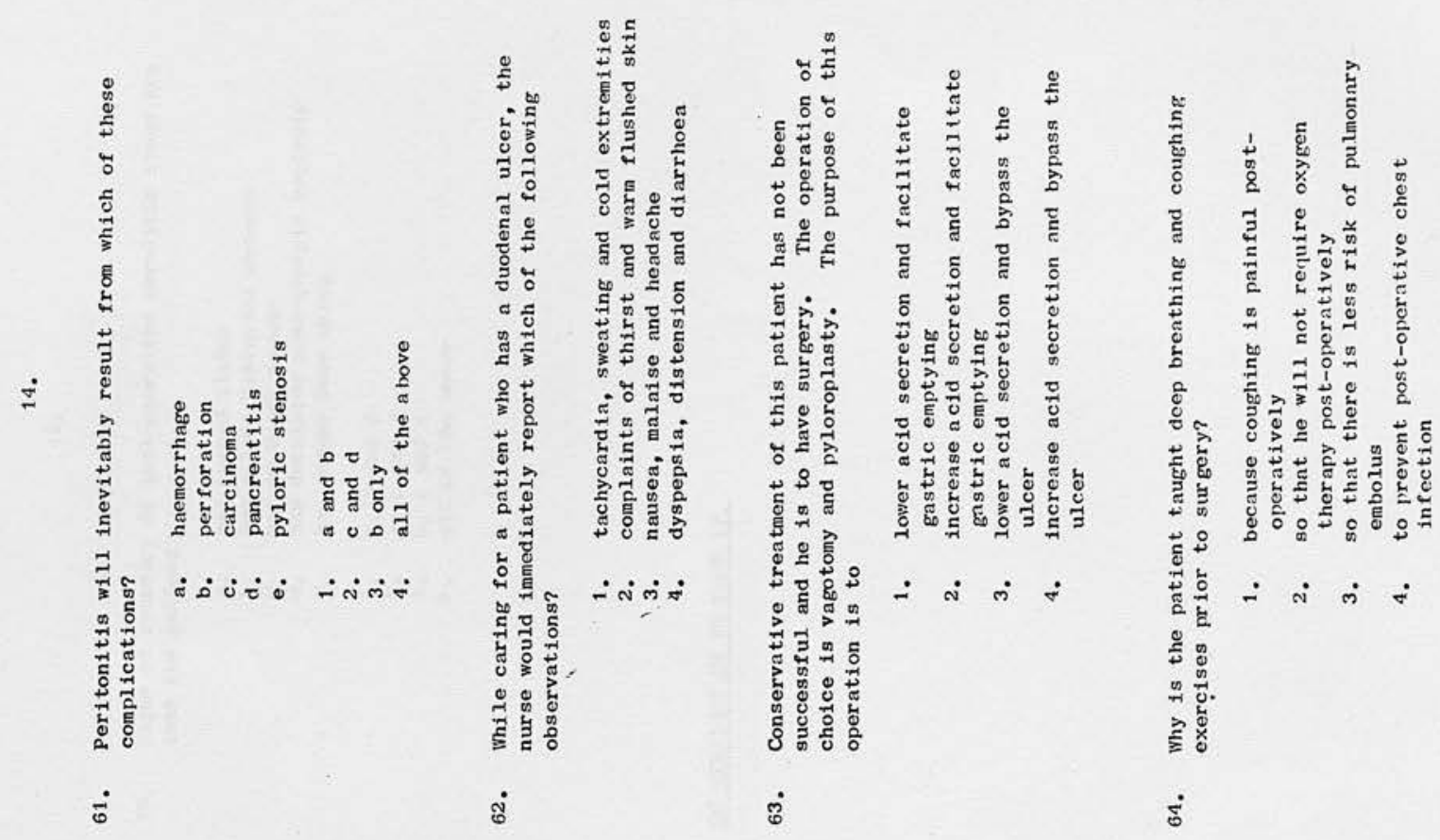

$$
\begin{aligned}
& \grave{3}
\end{aligned}
$$

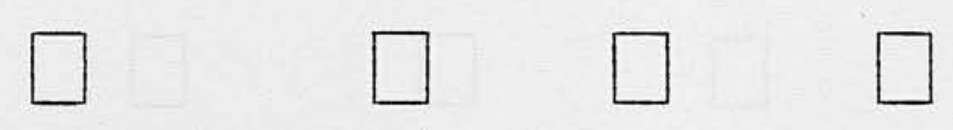

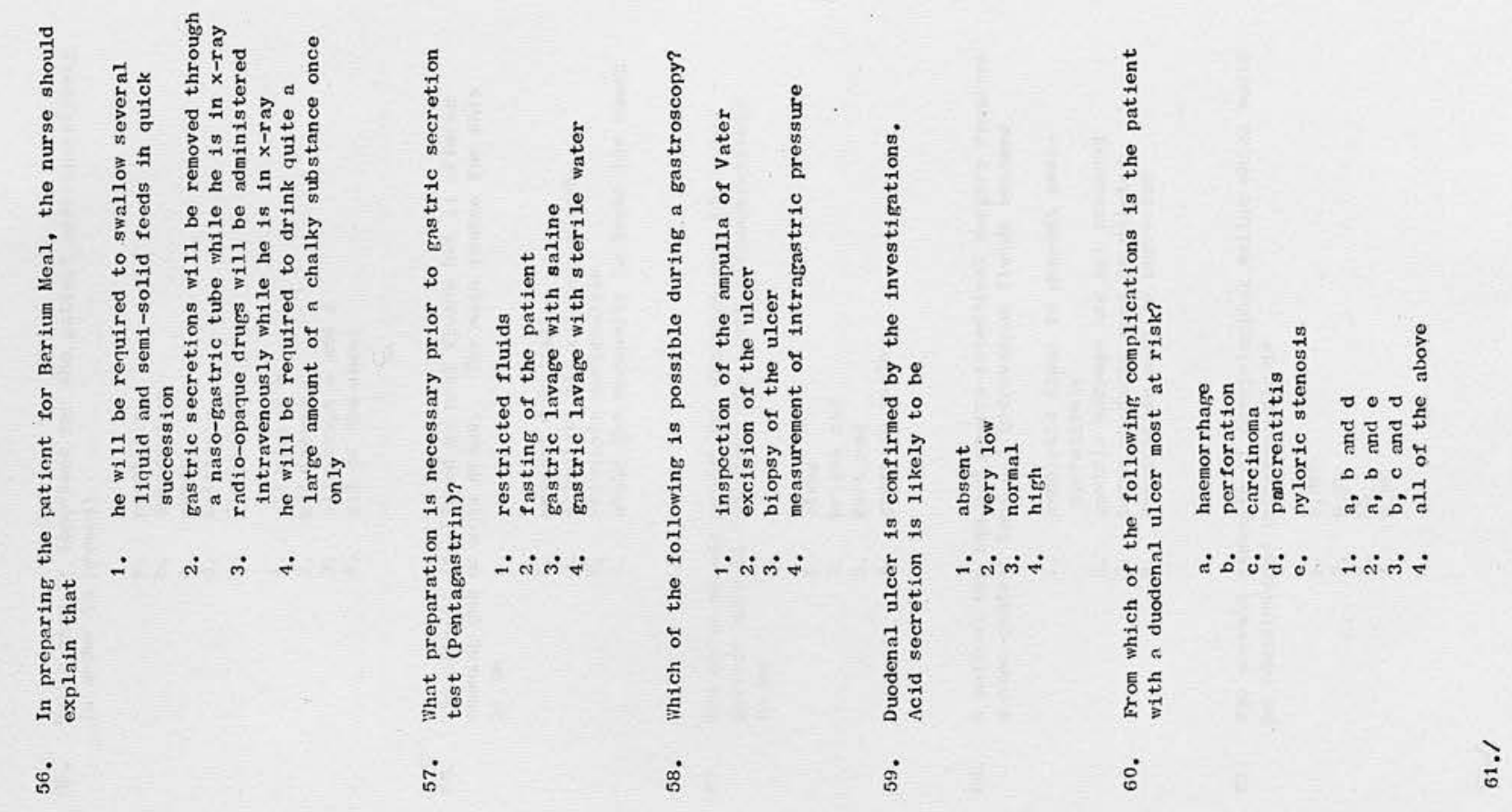



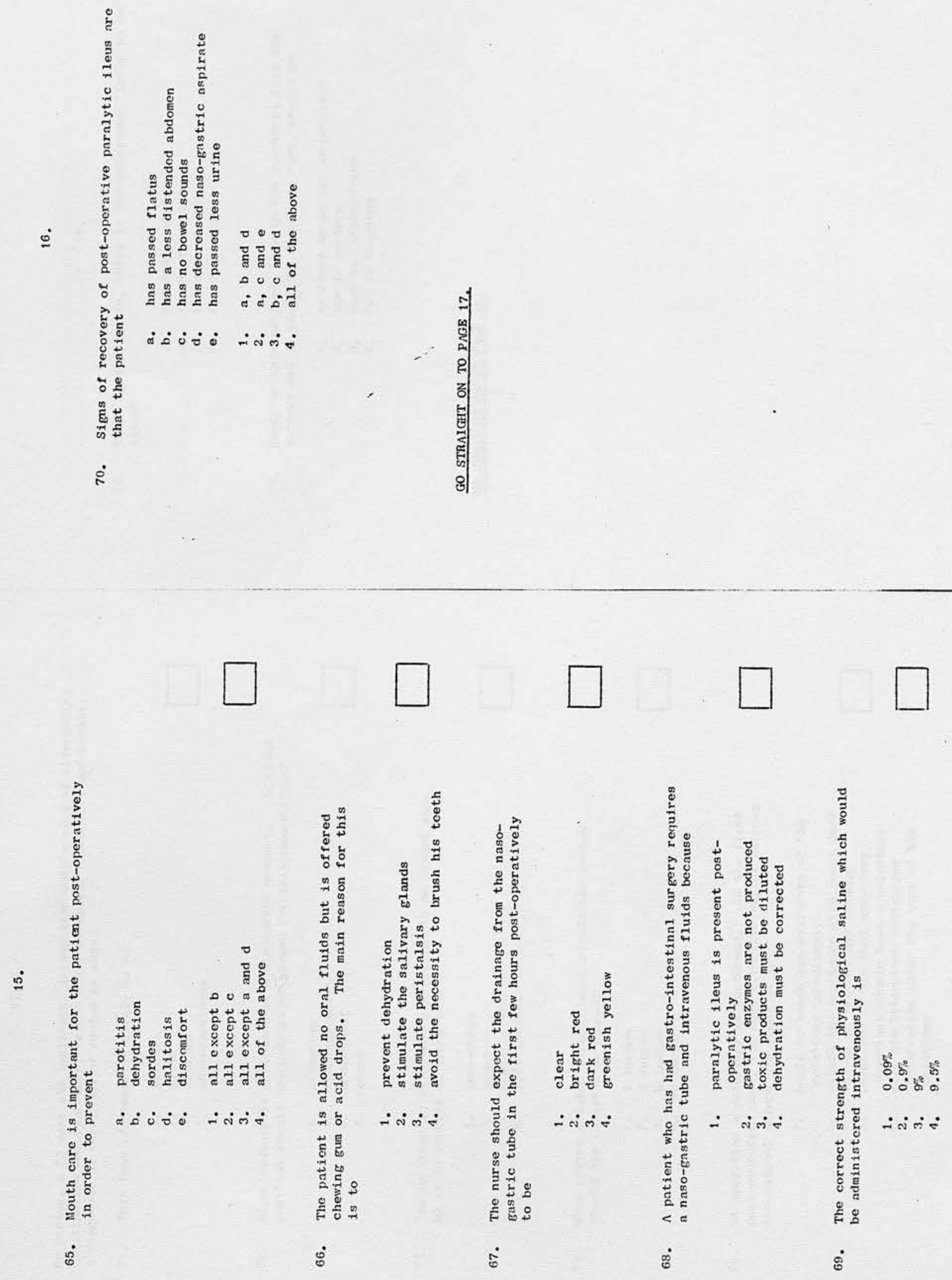

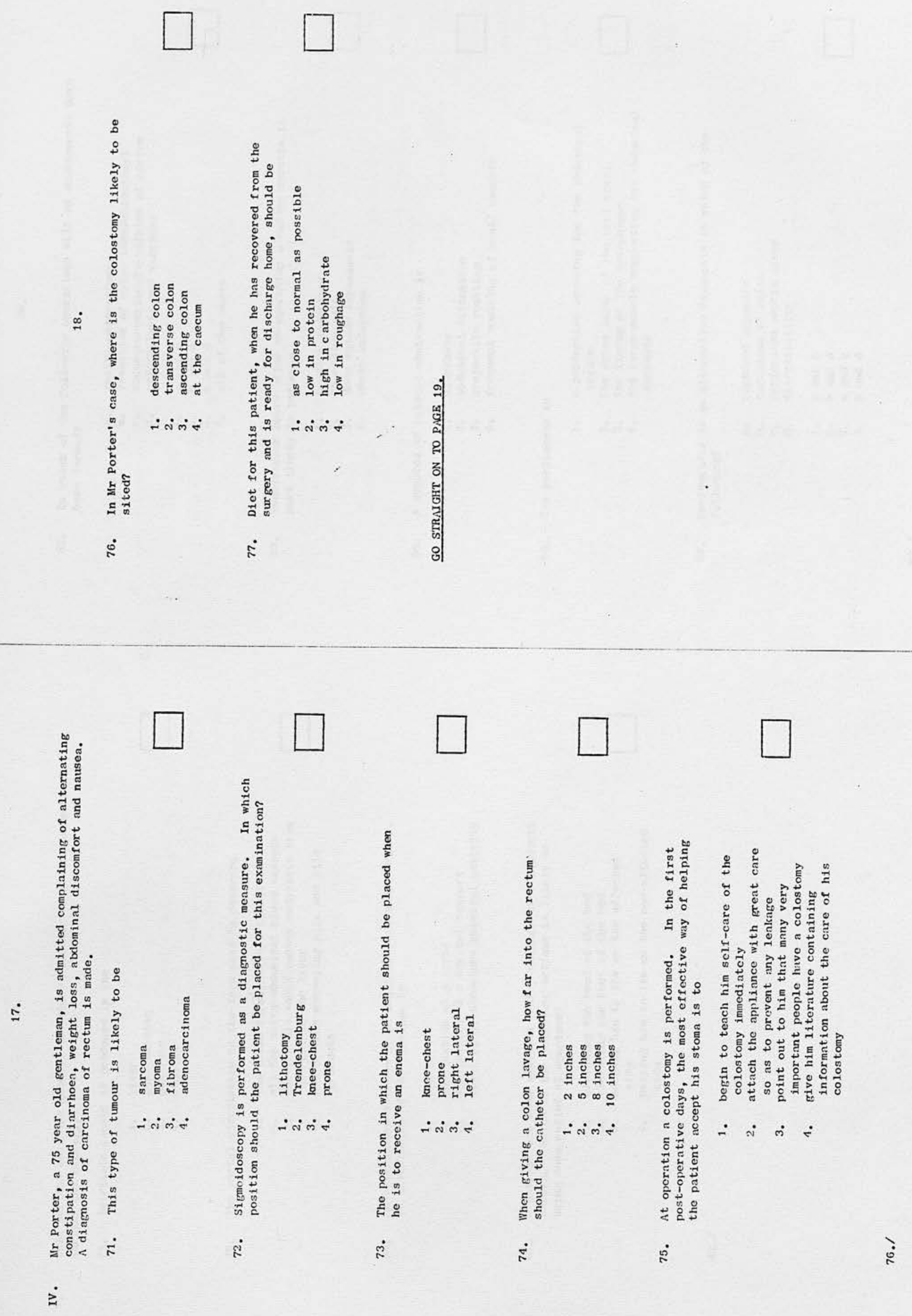

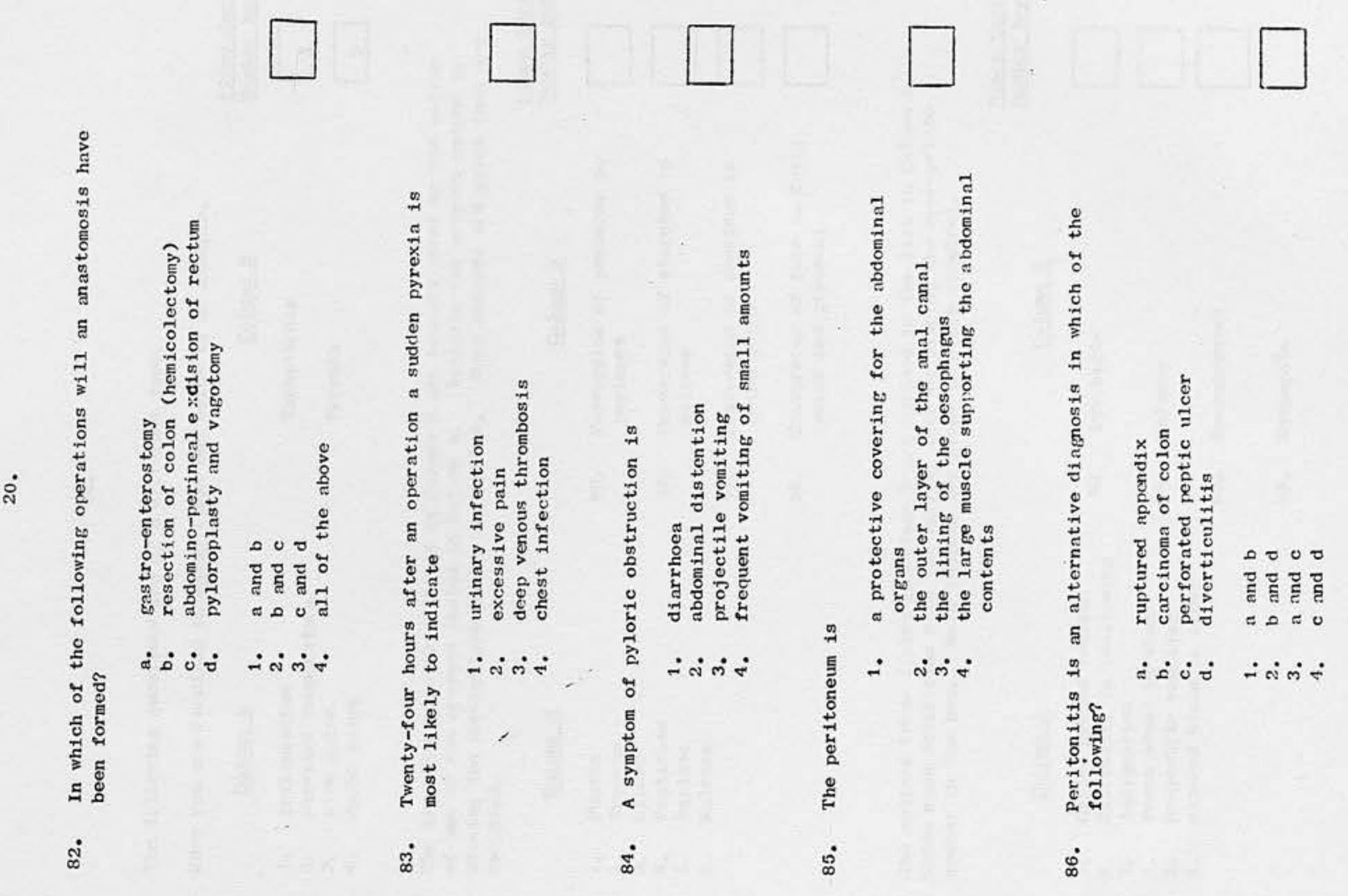

$\underset{\infty}{\grave{\infty}}$
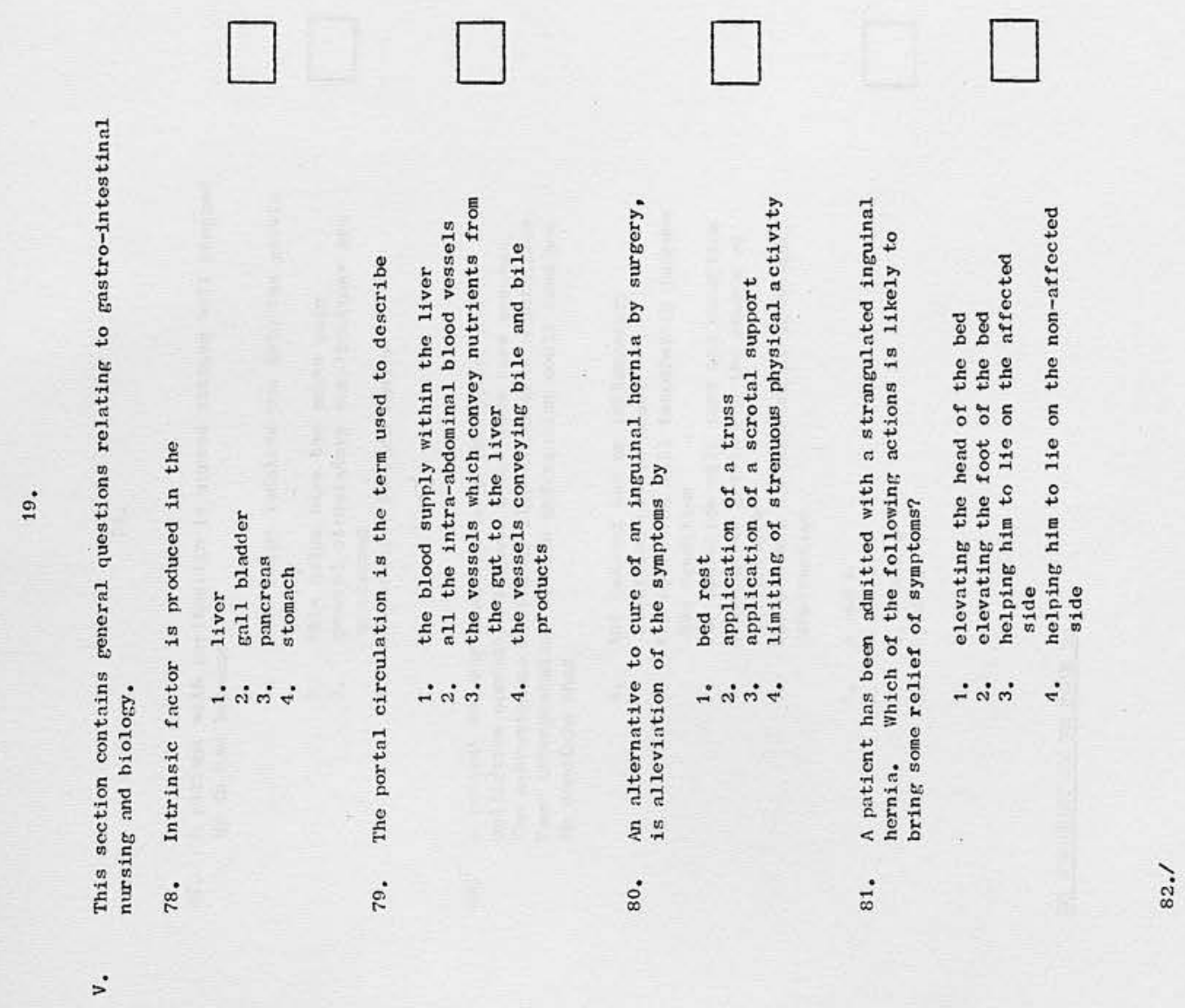


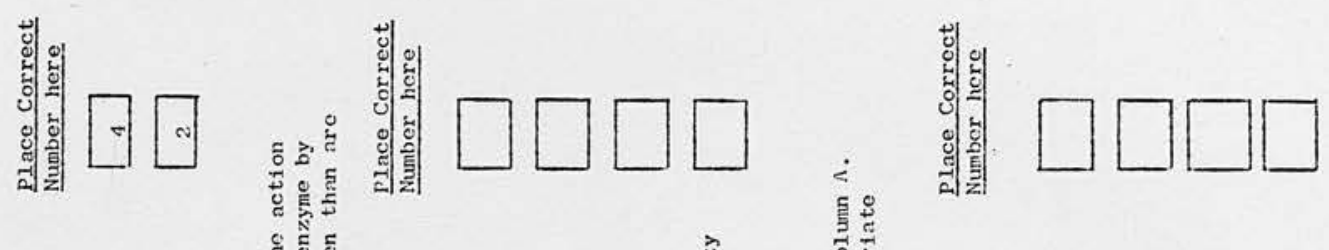

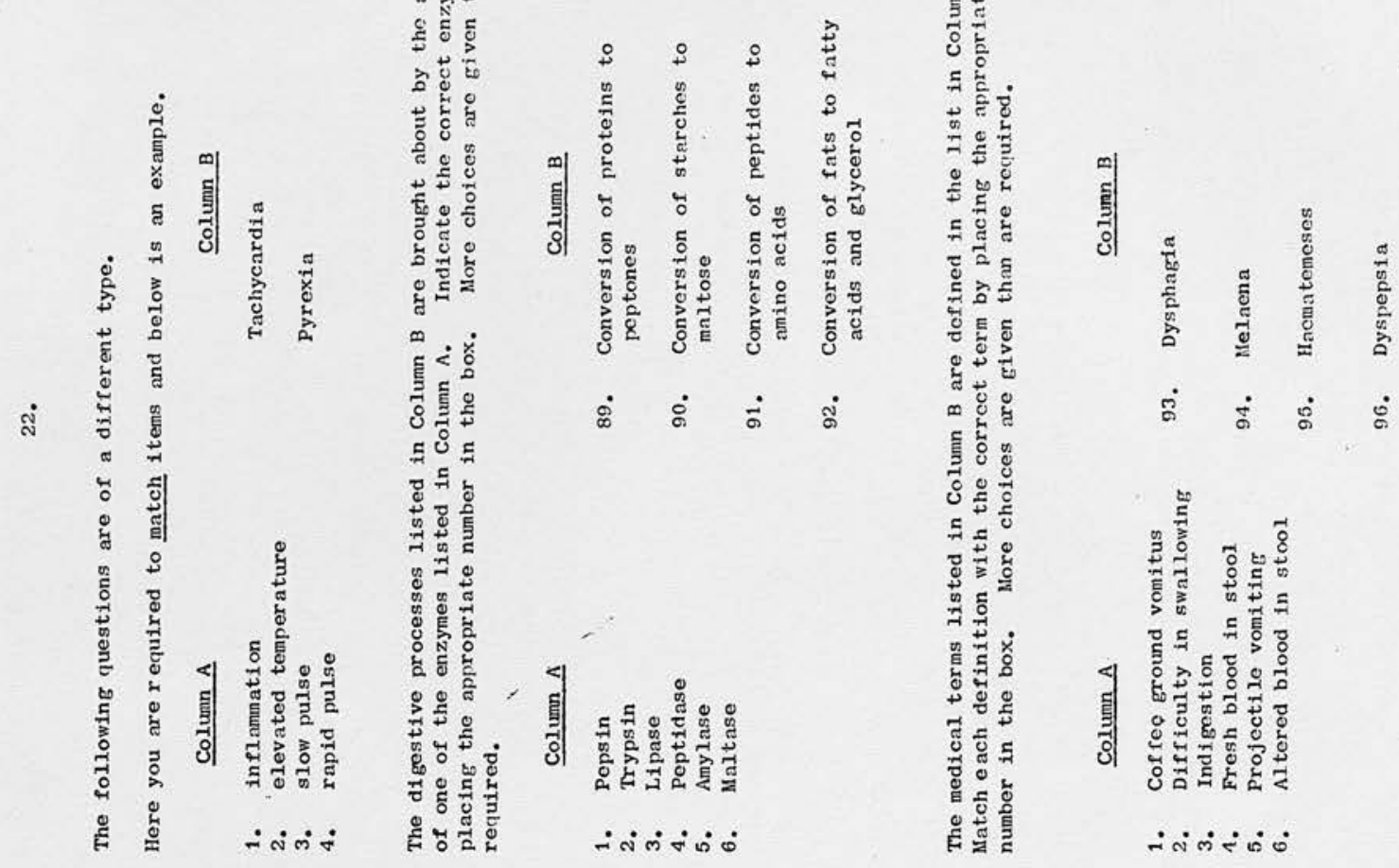
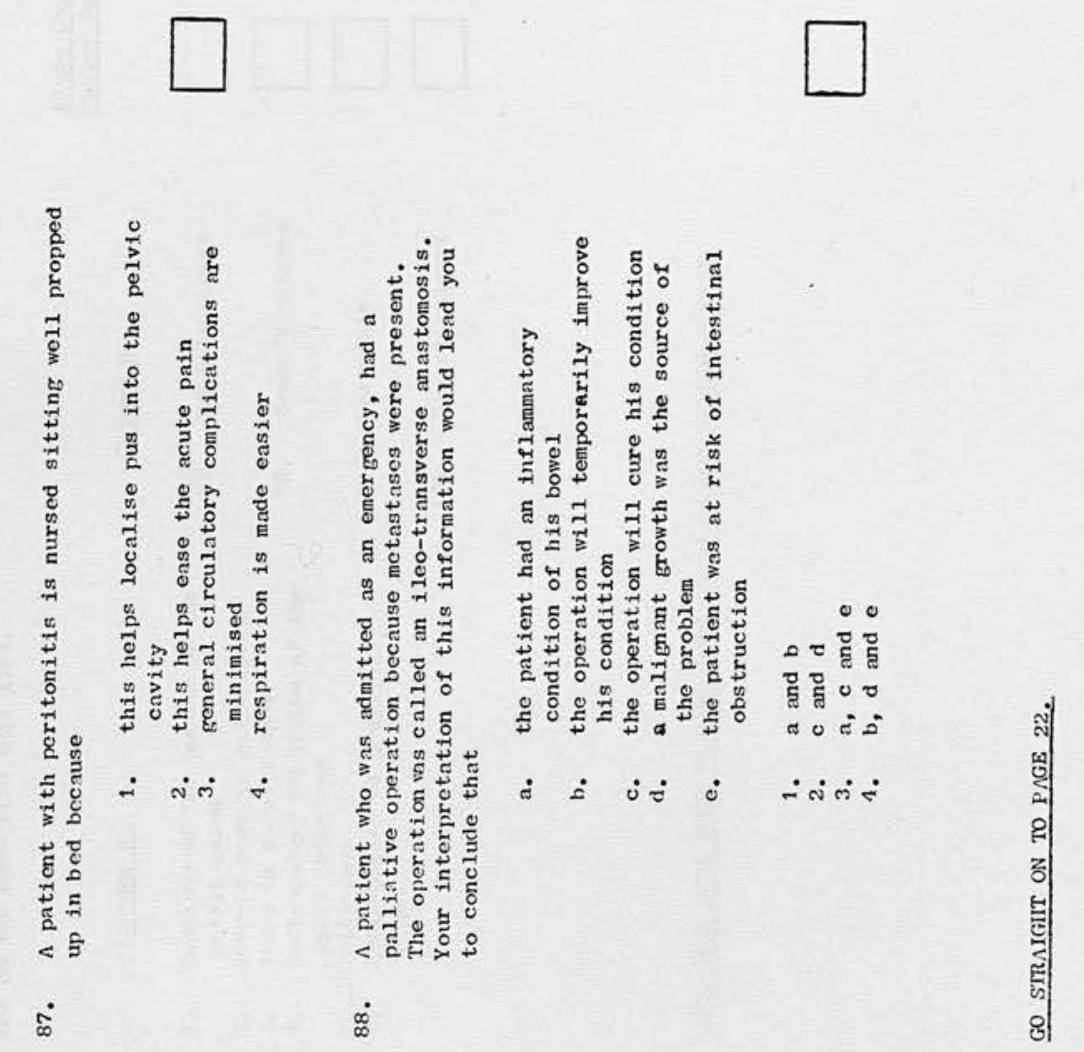


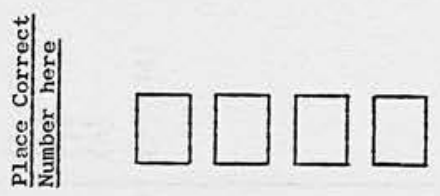

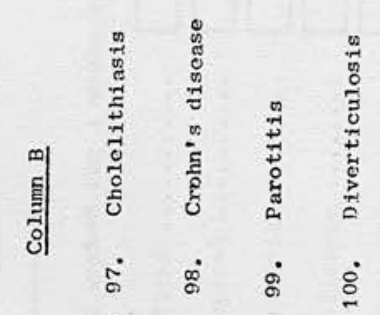

ช่

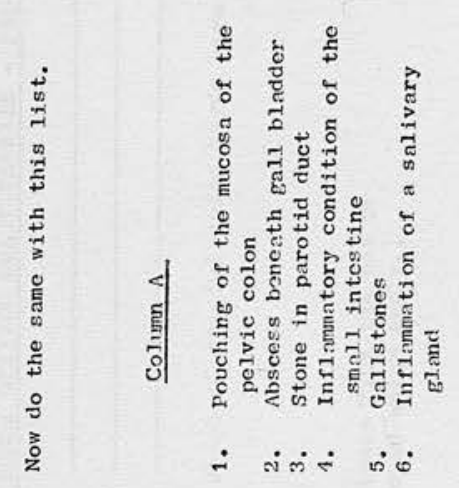

웅 


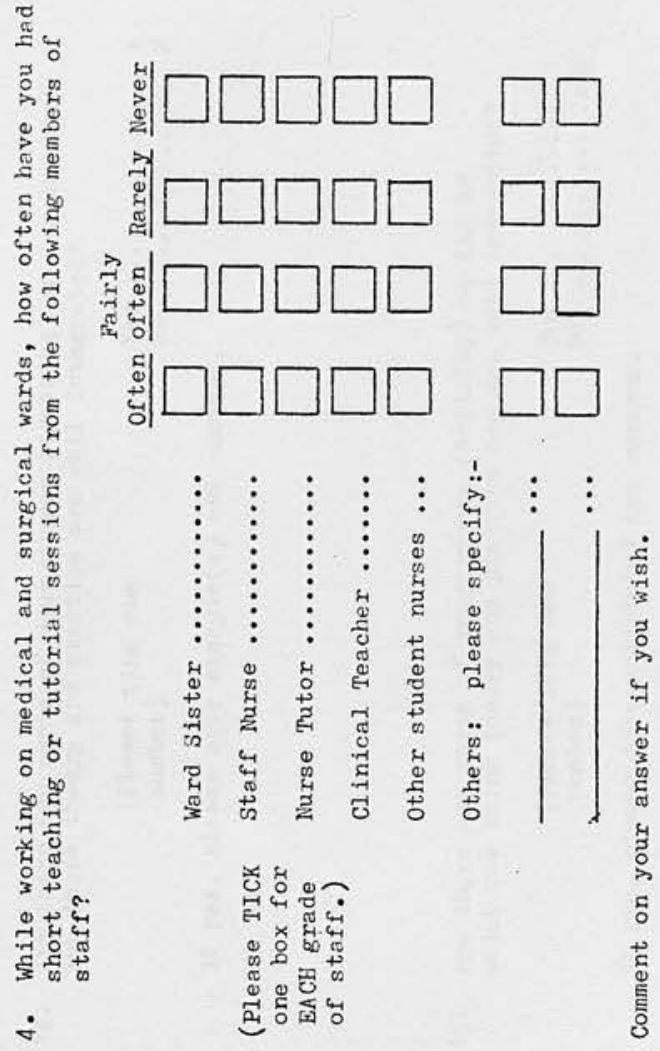

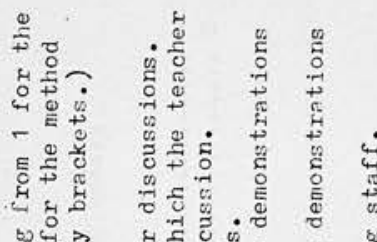

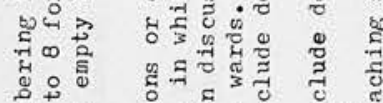

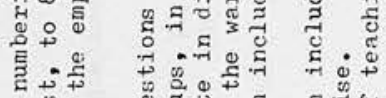

跣.

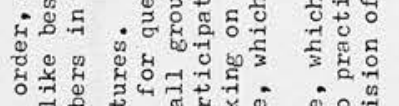

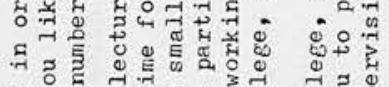

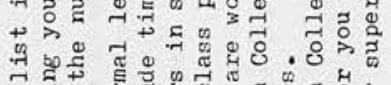

质

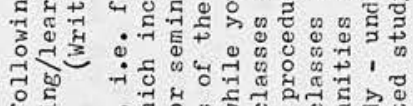

눙 है

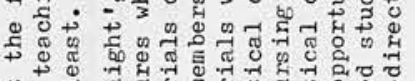

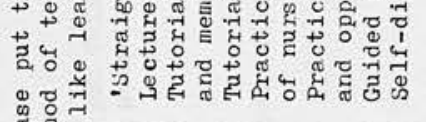

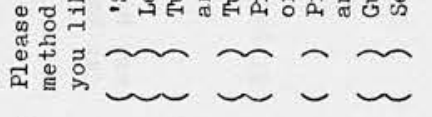

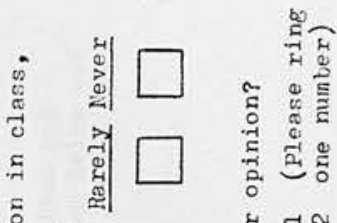

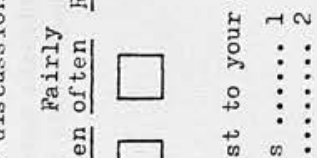

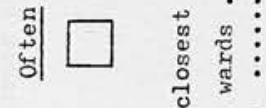

궁

욜 듕

造苛

कै

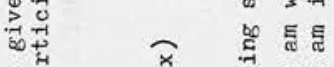

न्त क्ष

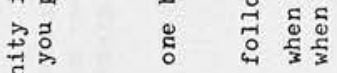

芹。 冚

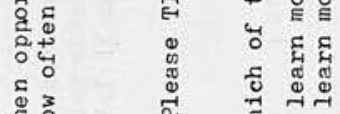

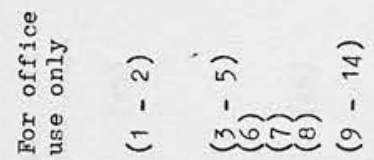

$\begin{array}{ll}\vdots & \vdots \\ \vdots & \vdots\end{array}$

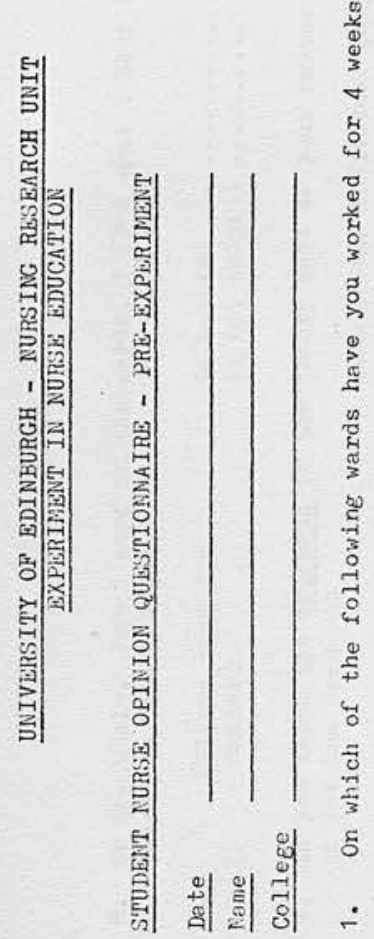

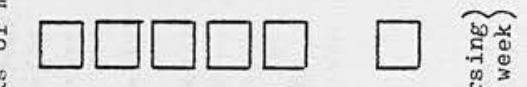

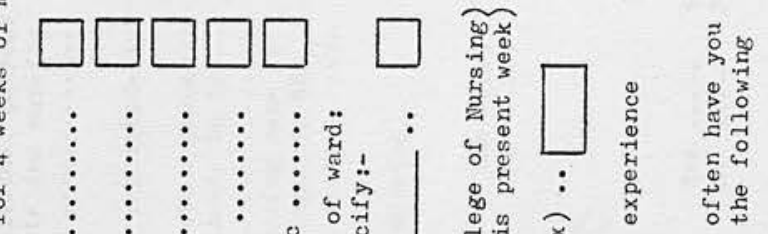

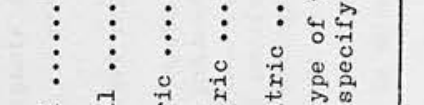

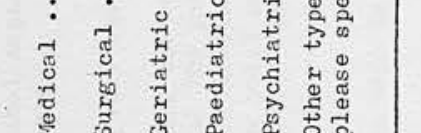
.

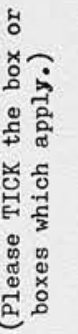

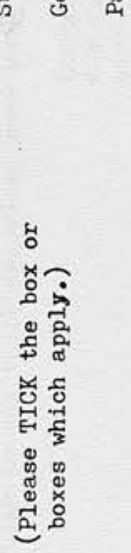




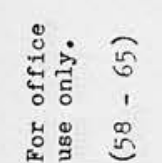

政

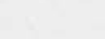

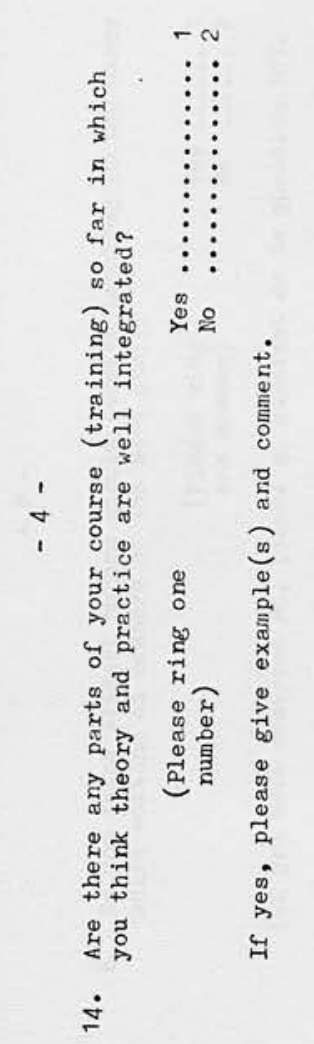
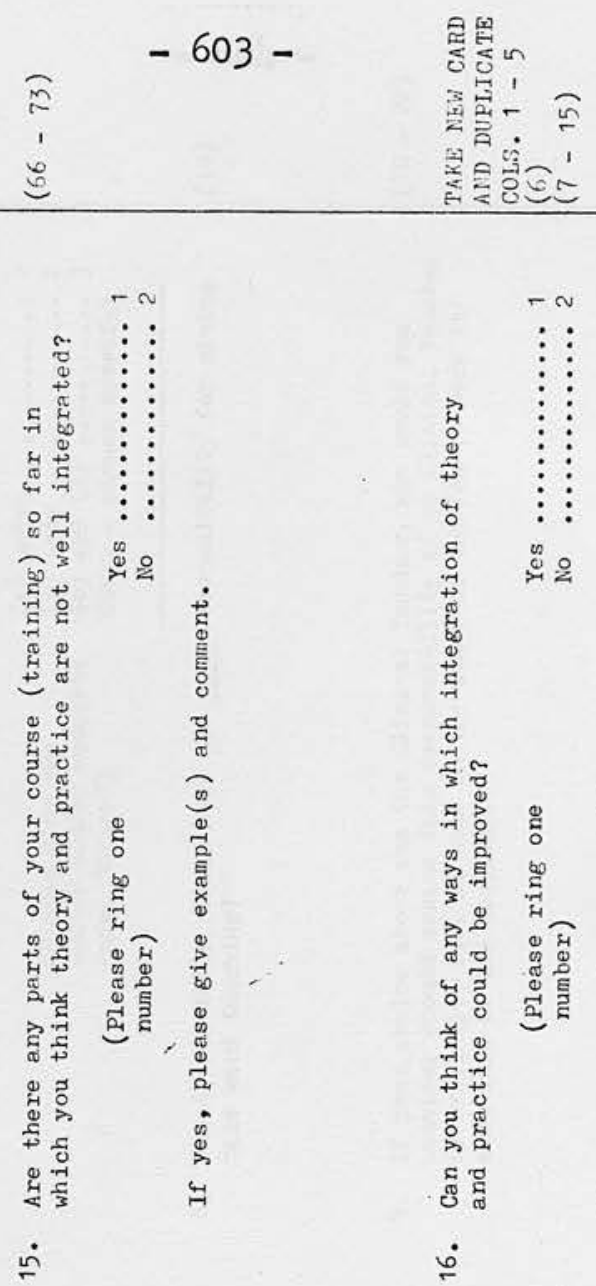

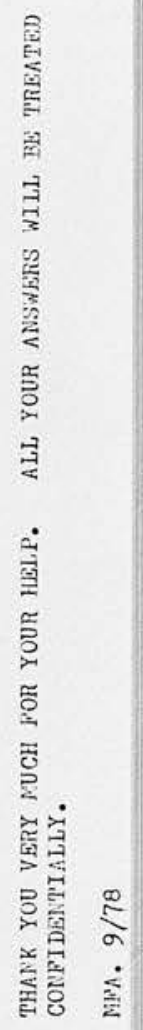

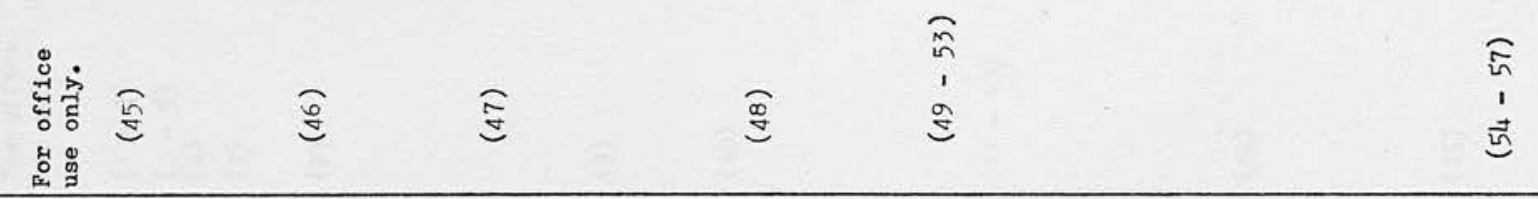
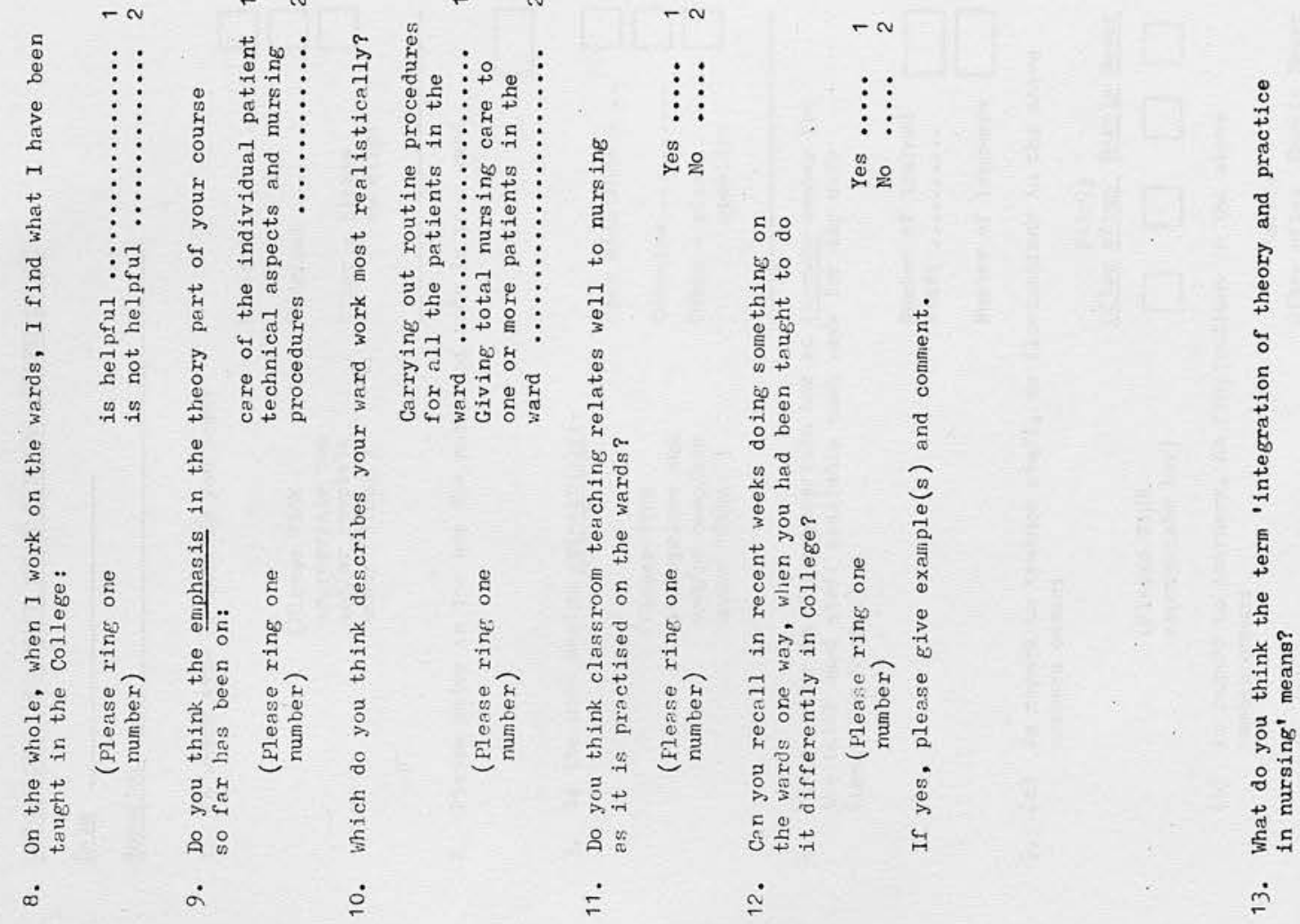


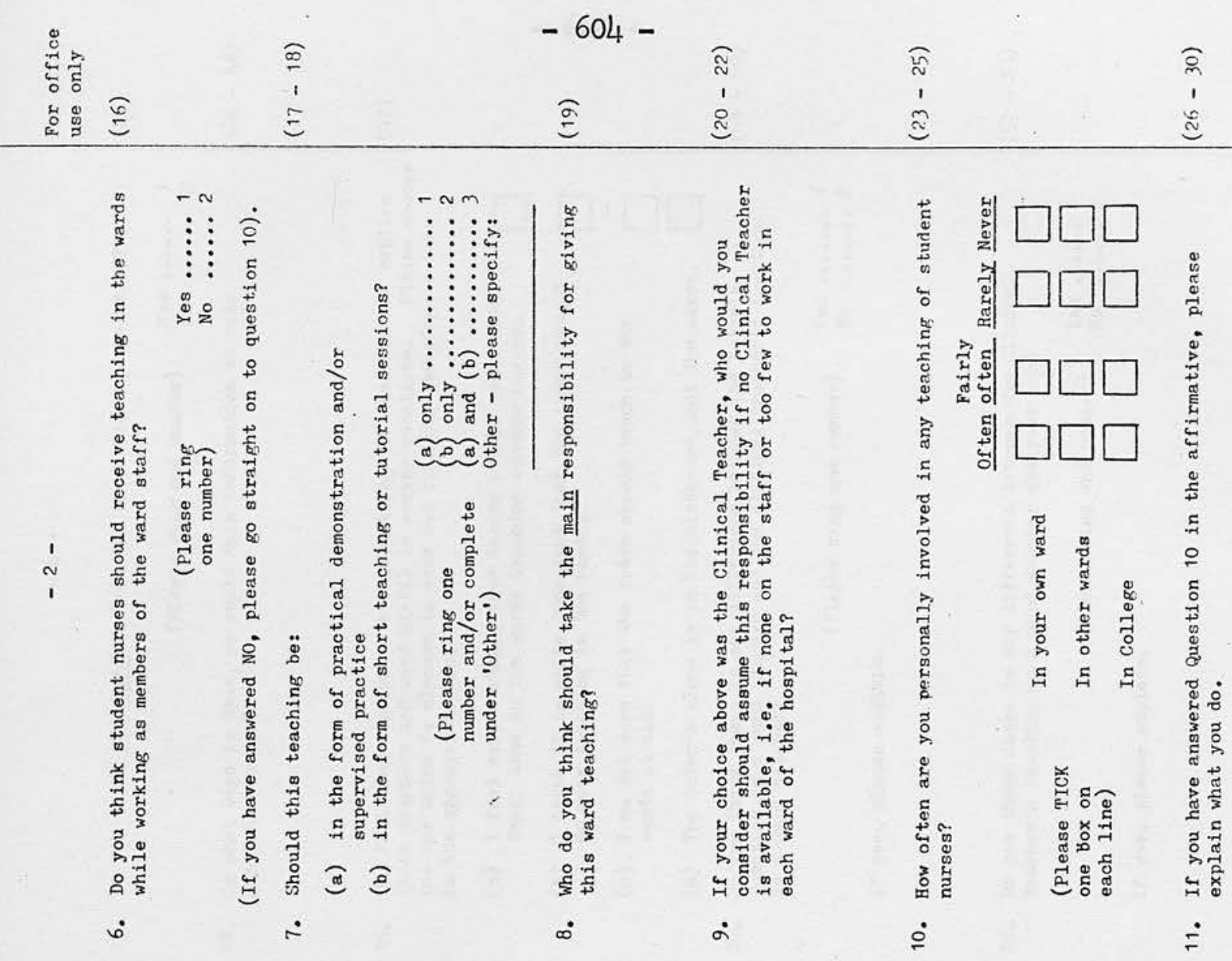

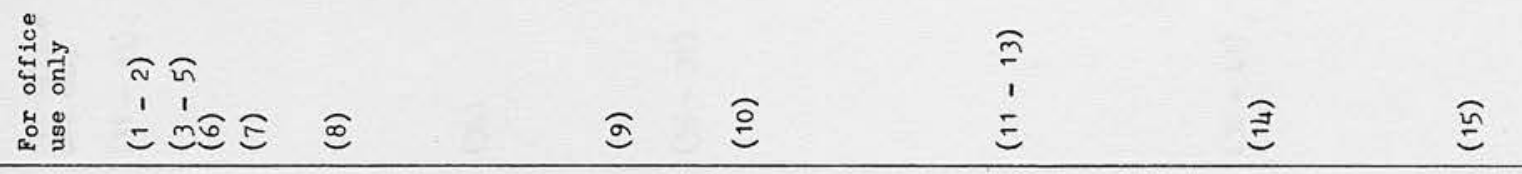

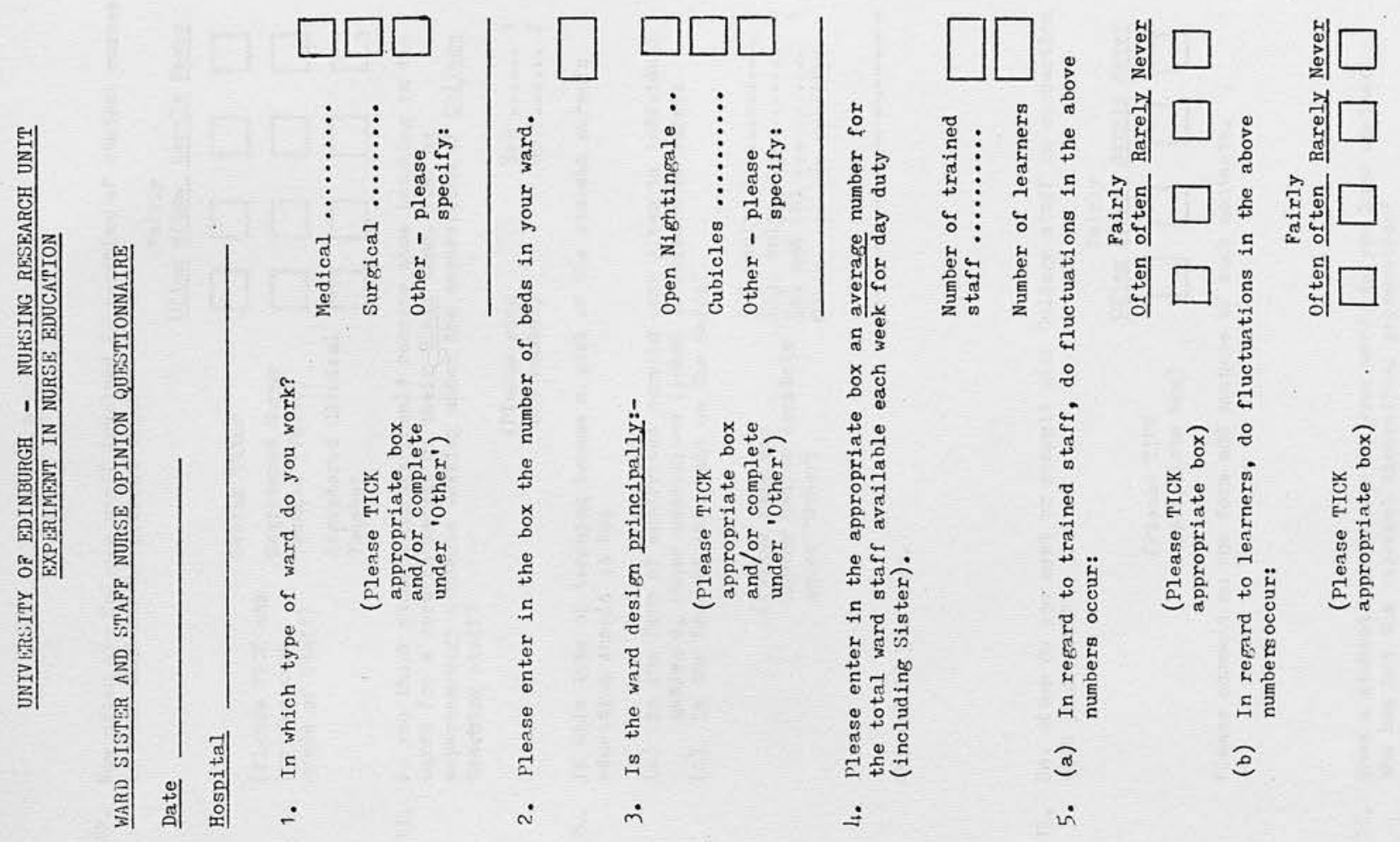




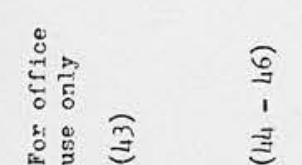

$-605-$

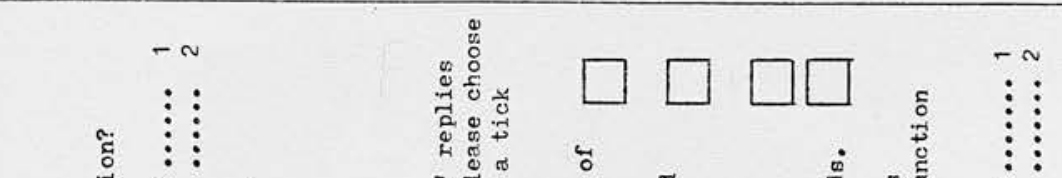

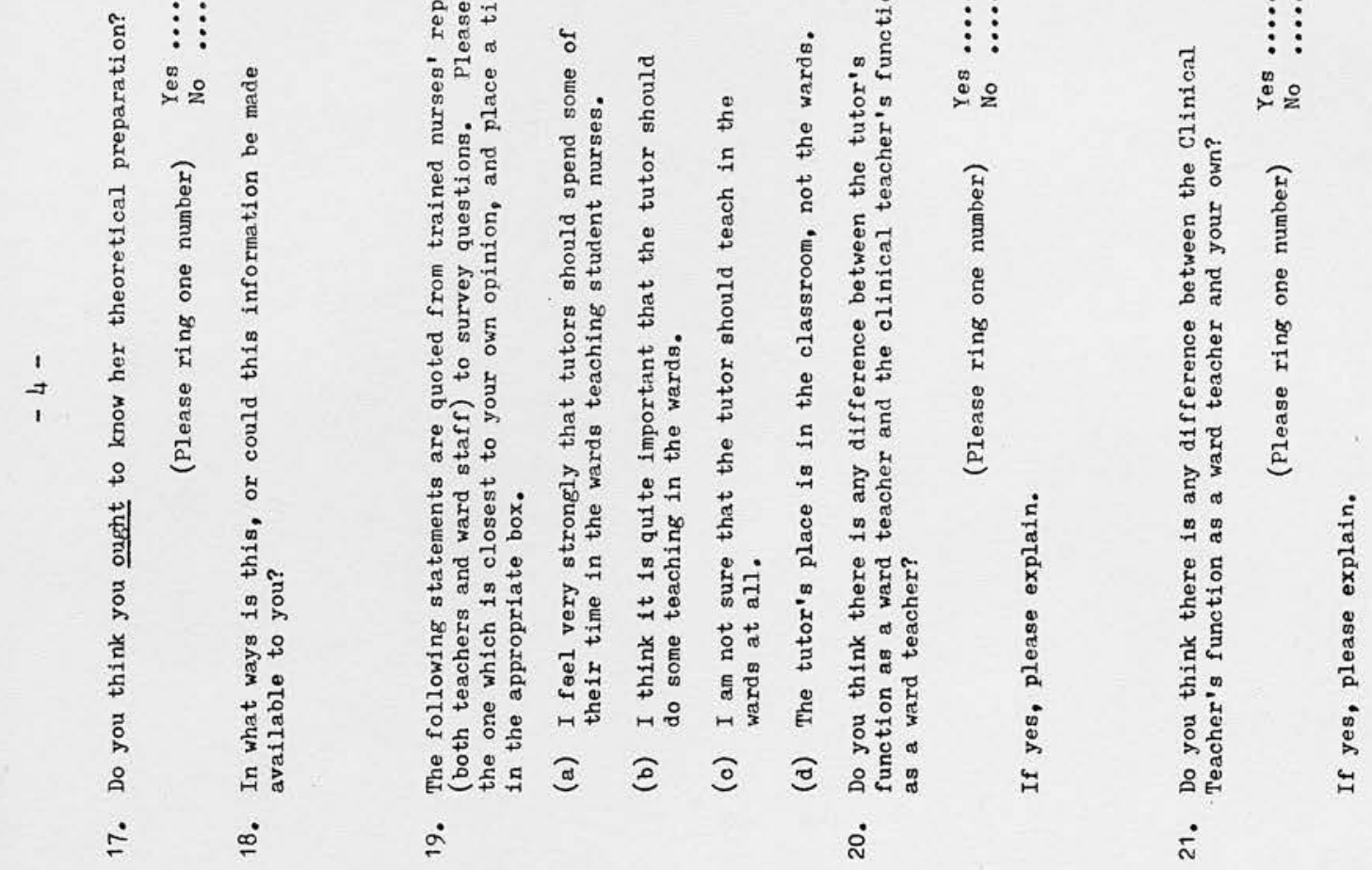

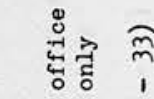

葆高

흘

Э

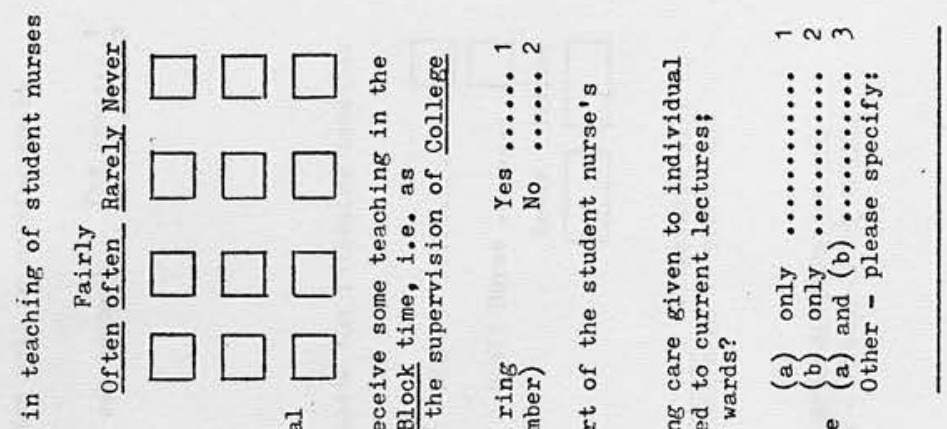

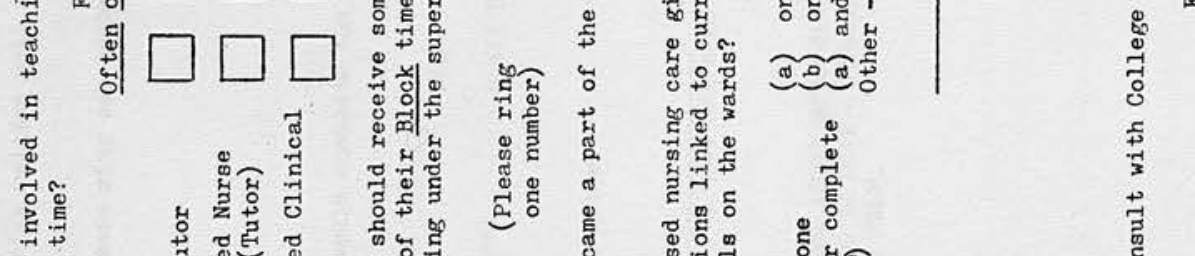

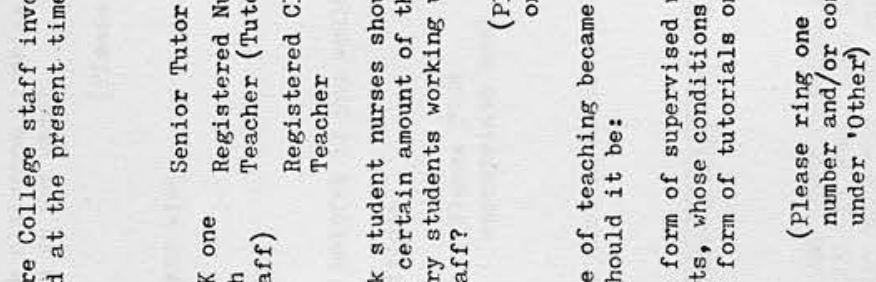

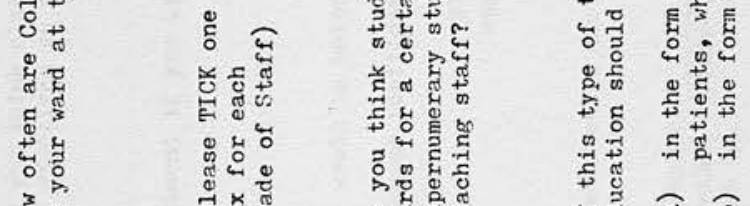

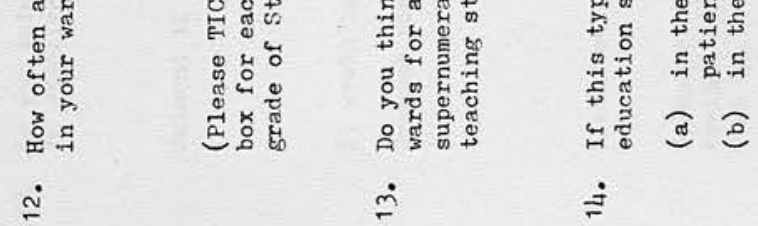

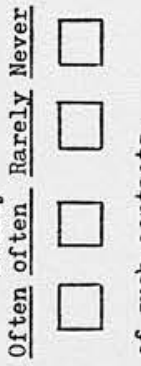

$\dot{\sim}$

‡ 


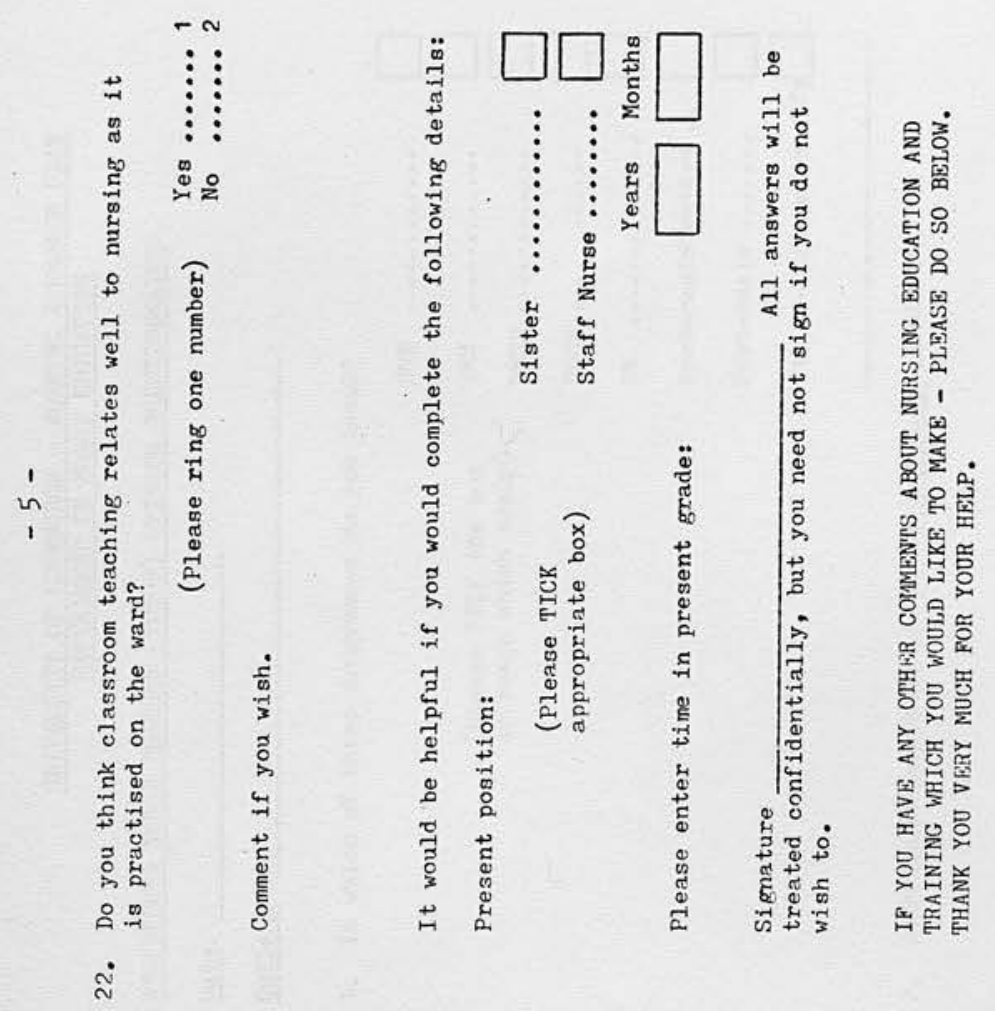




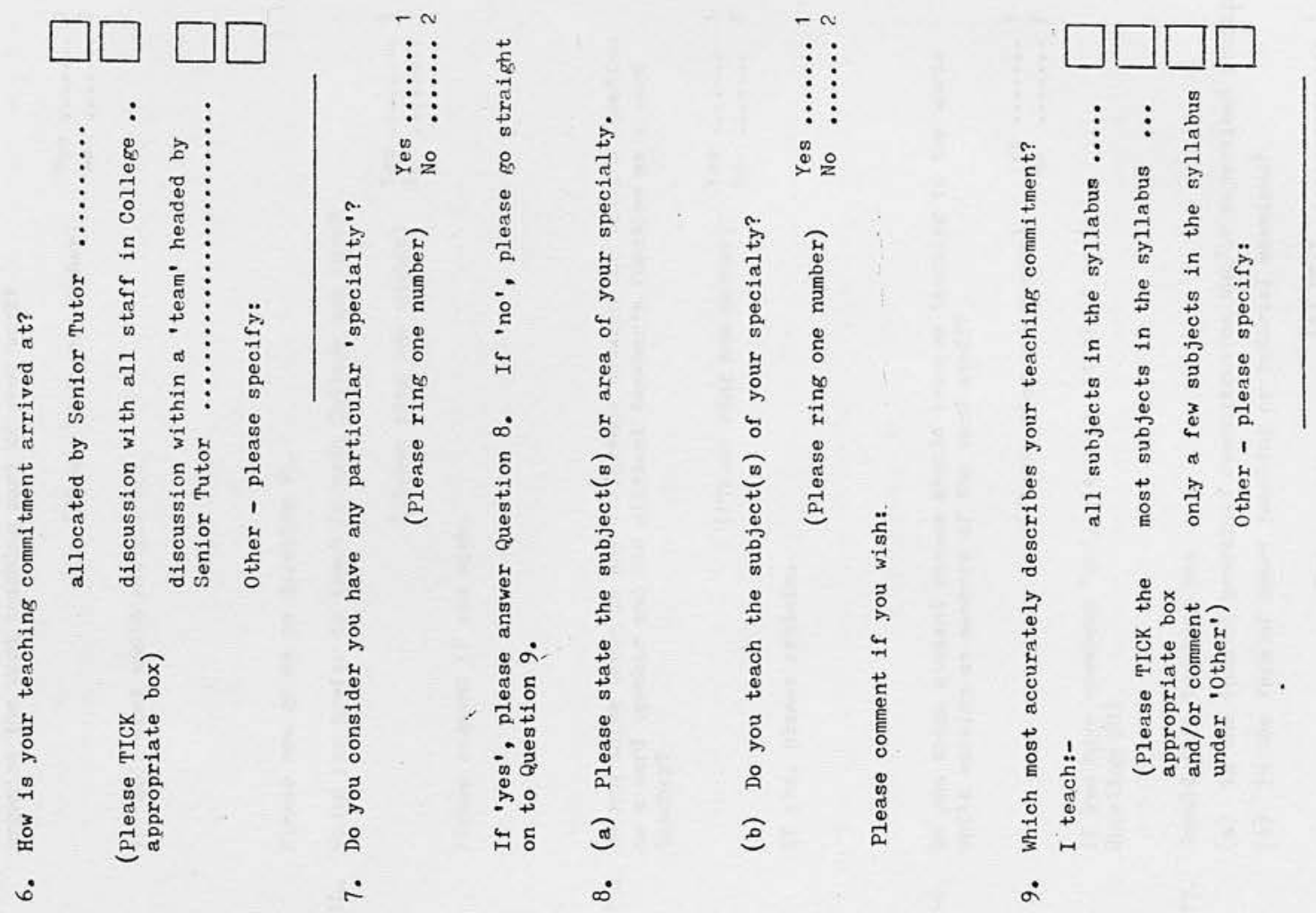

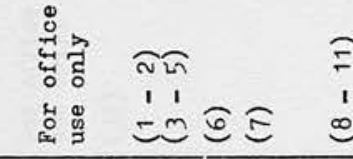

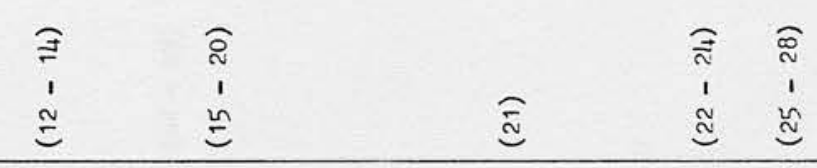
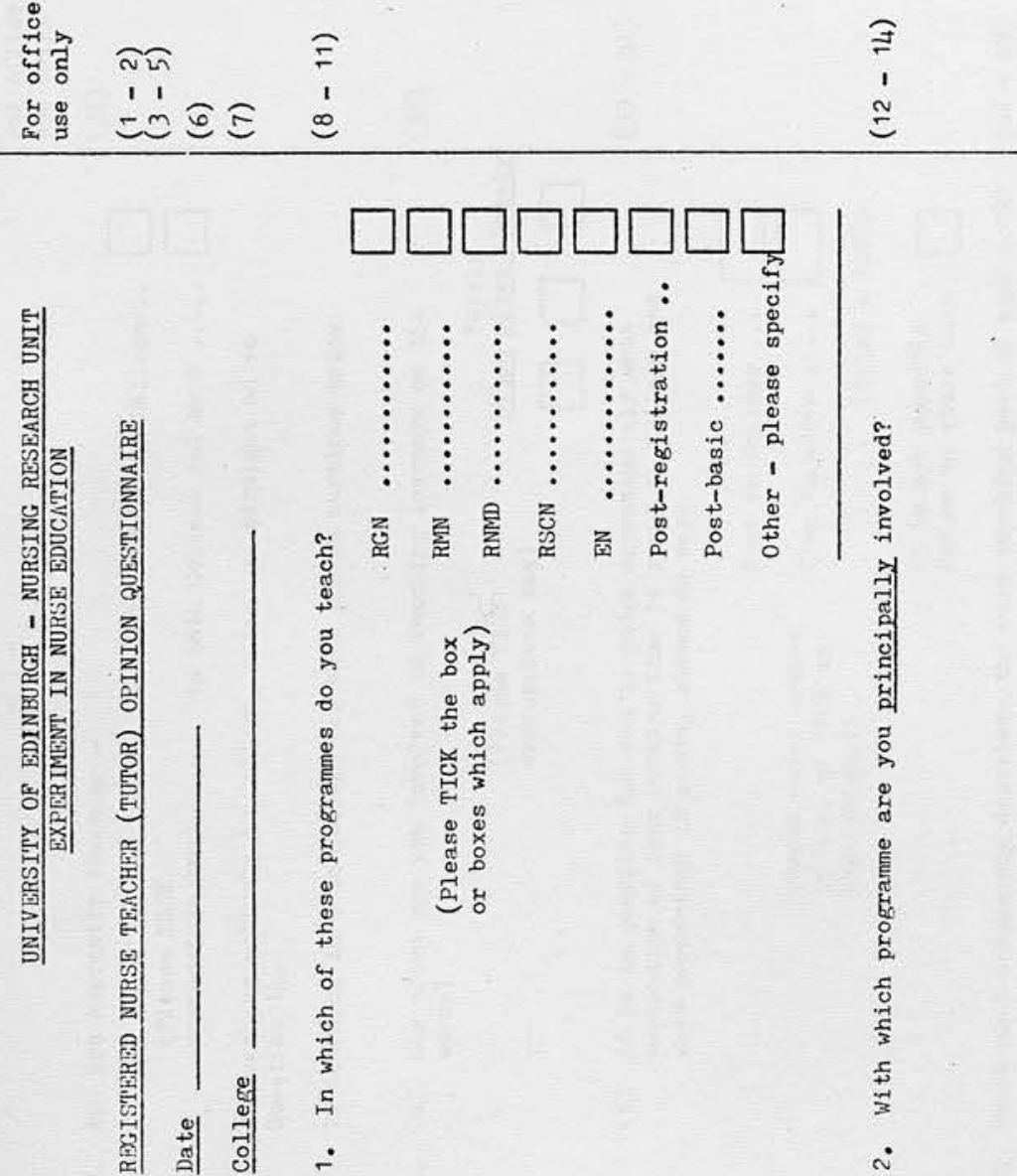

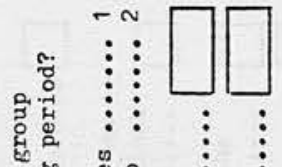

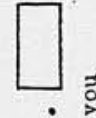

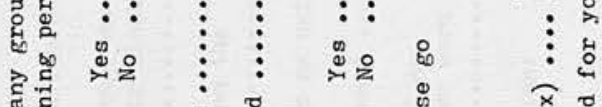

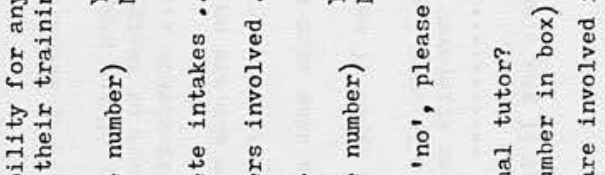

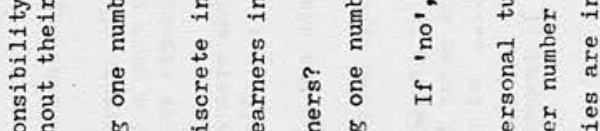

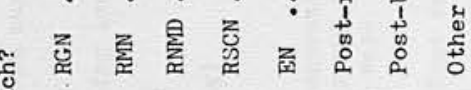

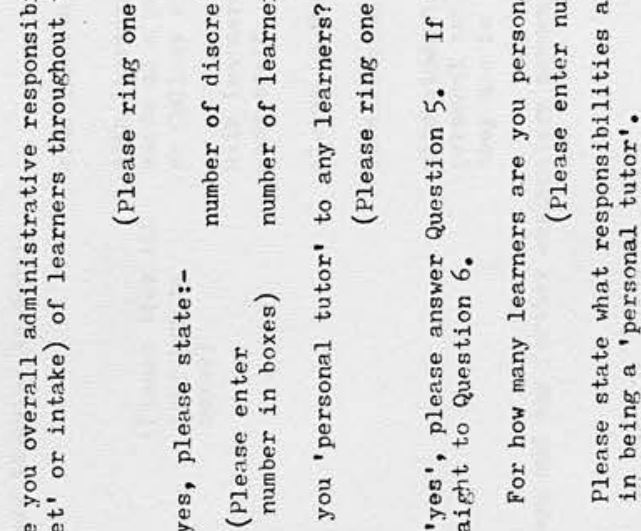

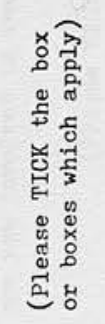



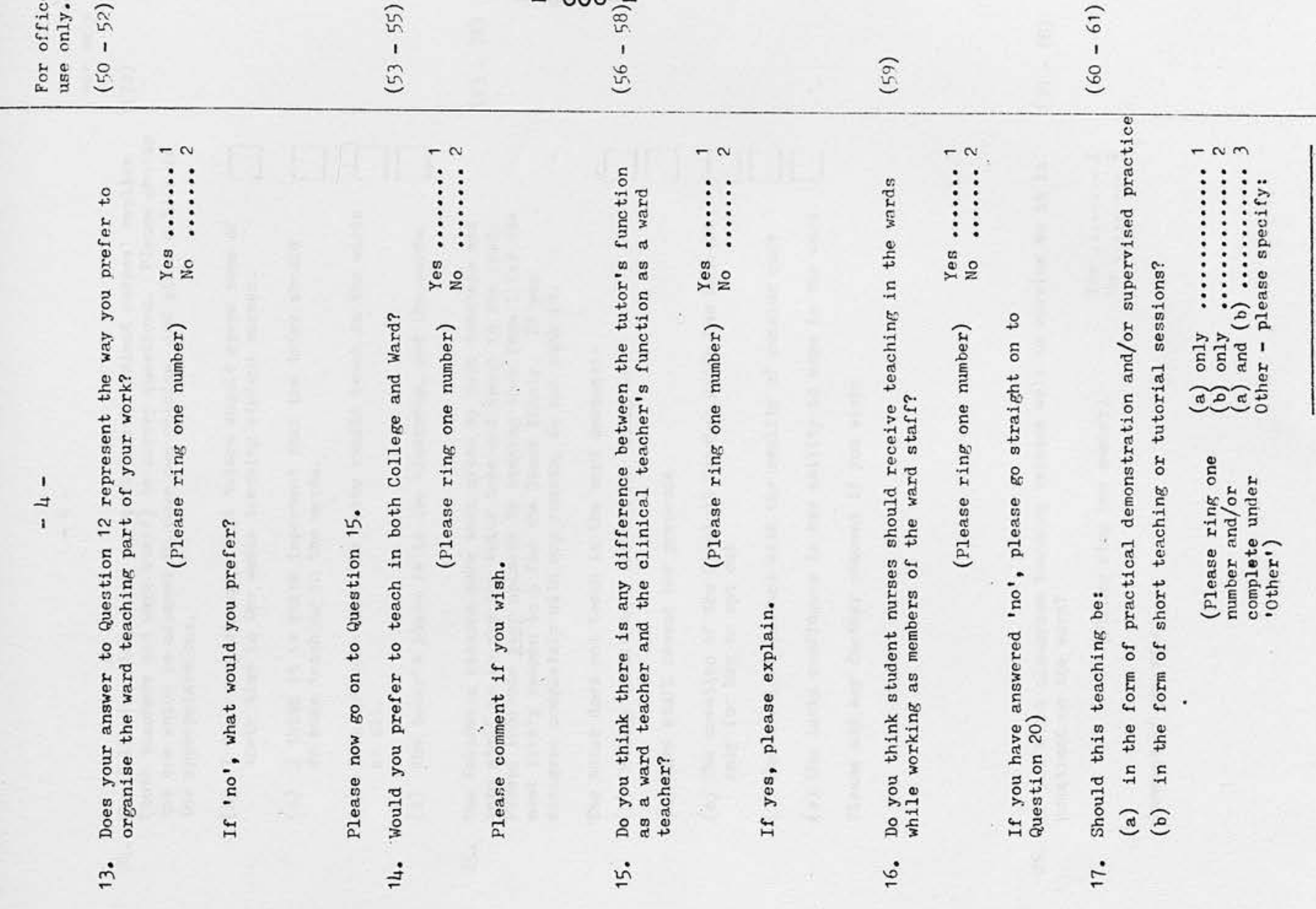

影

高

台哭 ह

$\fallingdotseq \quad \overline{9}$

ळु

\%

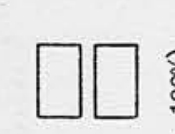

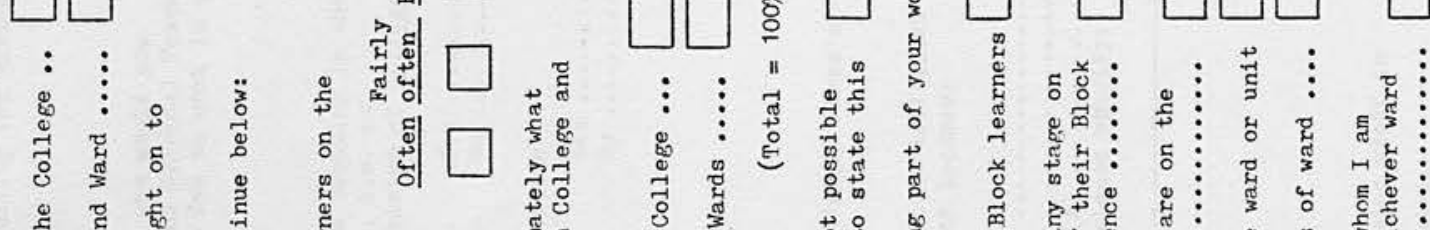

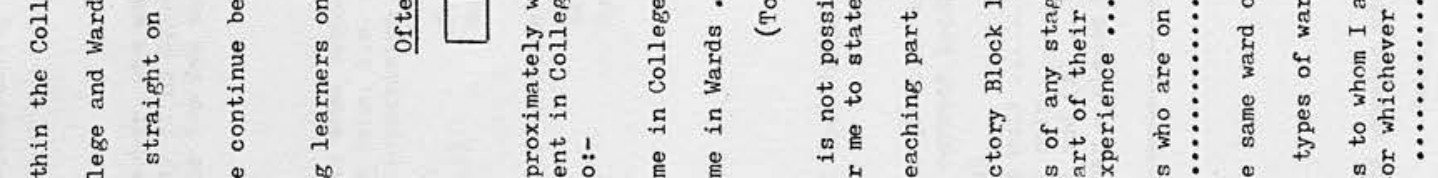

(1)

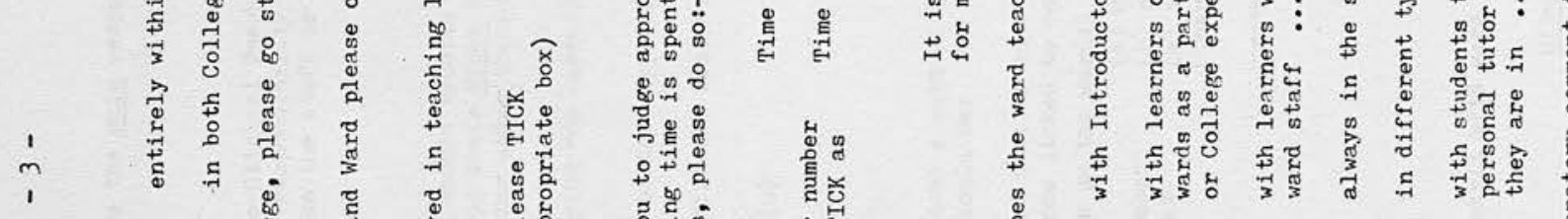

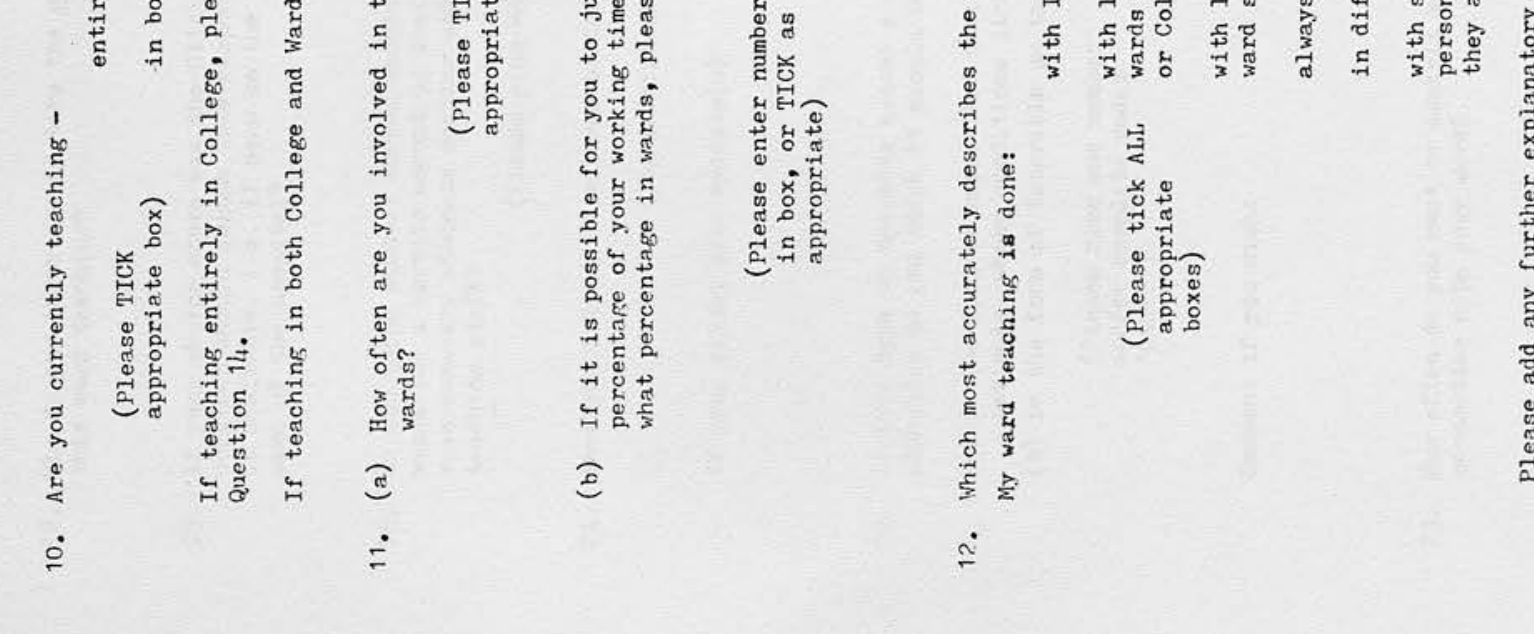

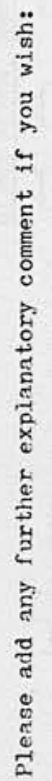




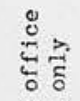

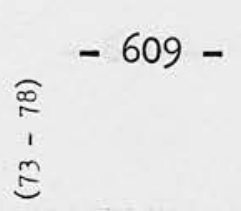

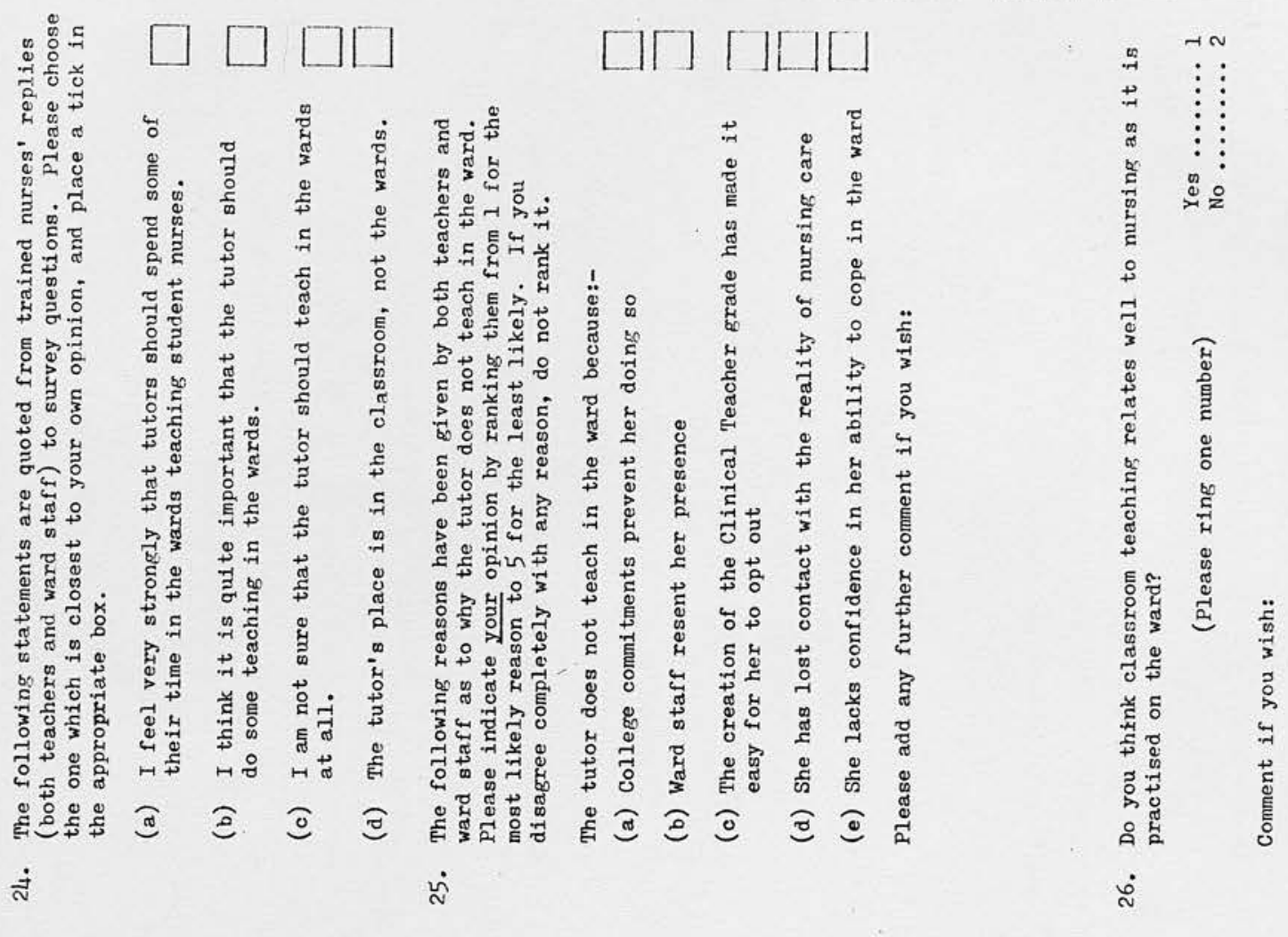

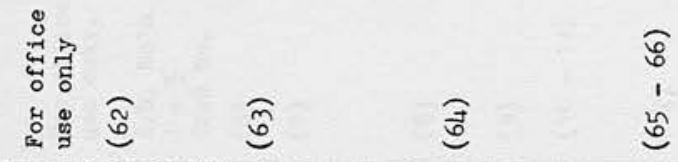

它

ล

\section{政}

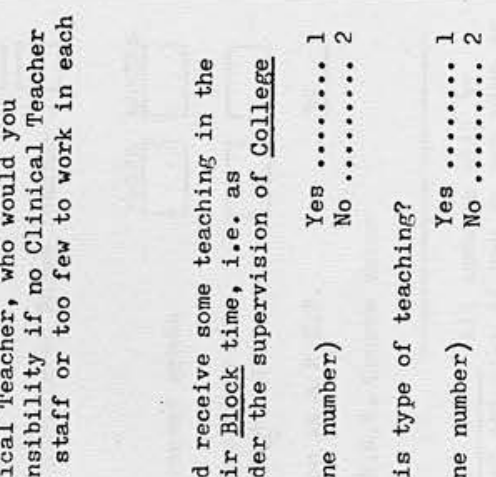

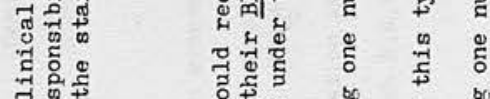

,

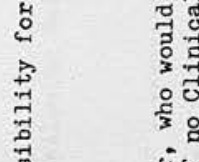

量

章 g.

年

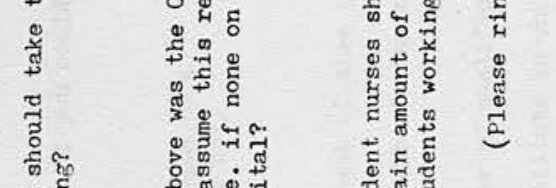

辛

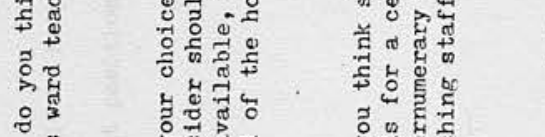

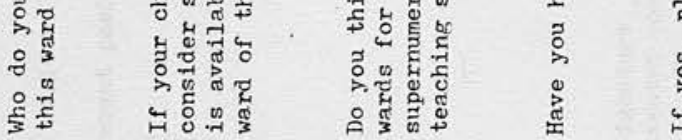

क

¿

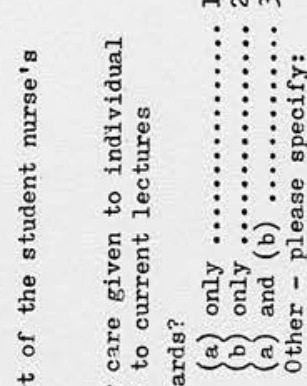

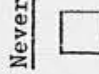

善

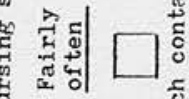

.

ํํำ

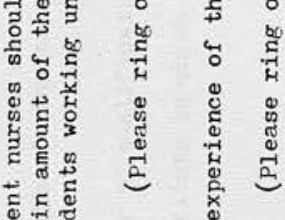

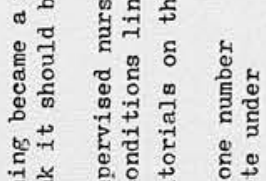

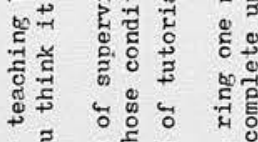

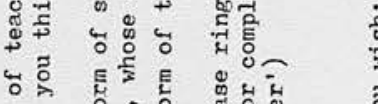

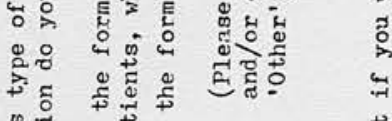

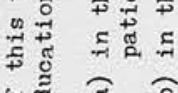

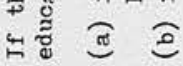

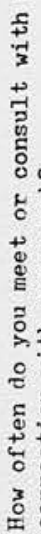

¿ 


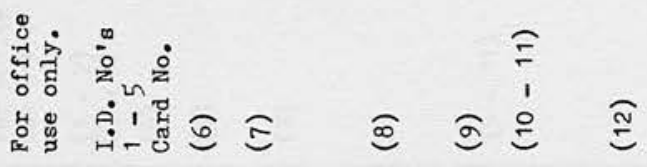

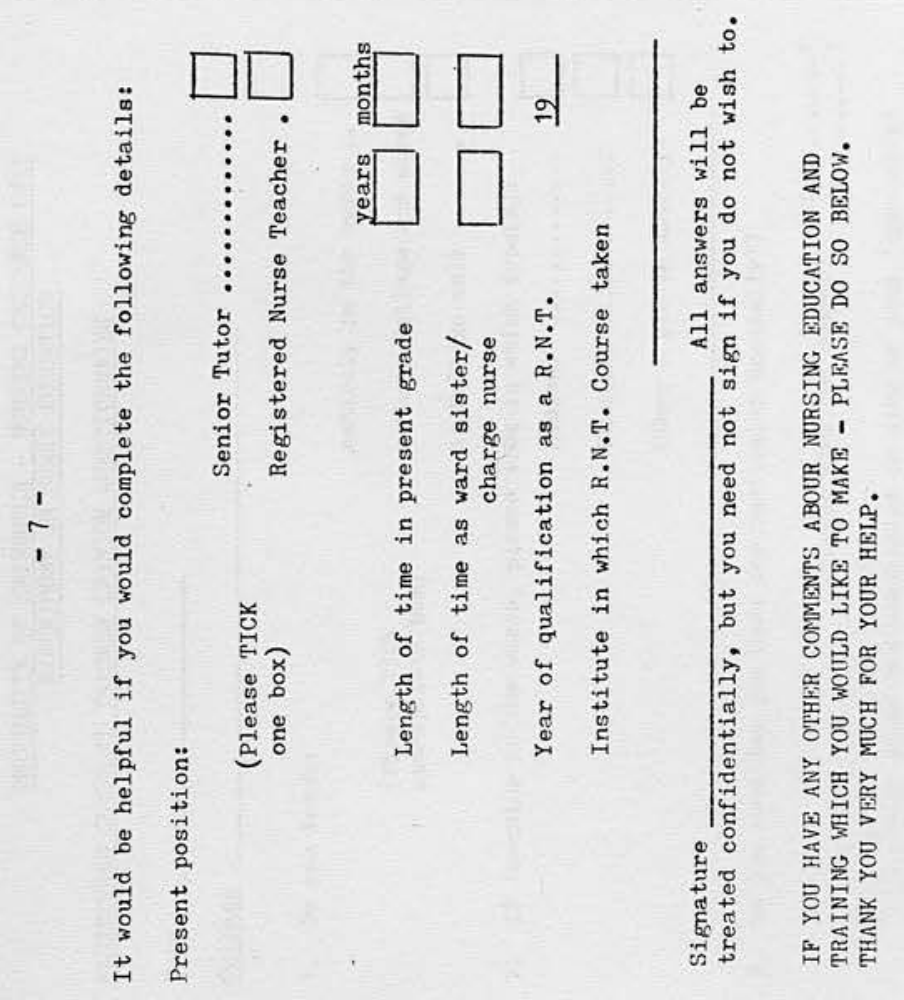


ํㅗㅇ

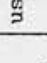

产

d

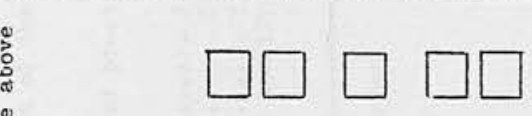

$\begin{array}{ll}\widehat{N} & \bar{N} \\ 1 & \vdots \\ 0 & 0\end{array}$

$\widehat{\hat{~}}$

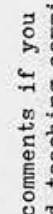

,

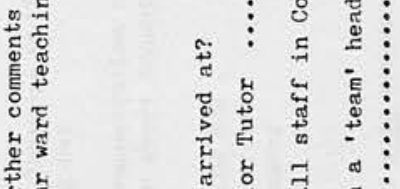

:

章

喅

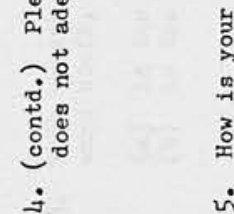

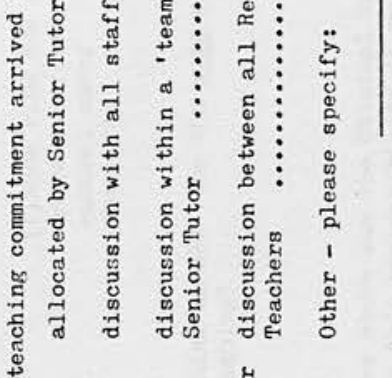

卷

8

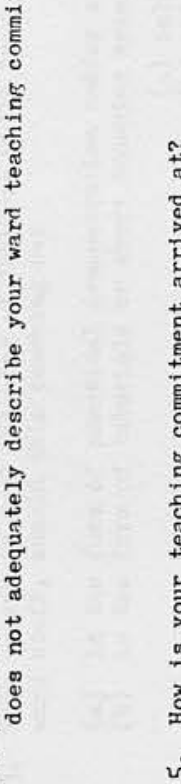

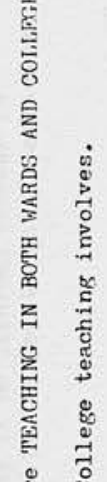

ณั

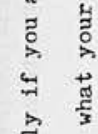

है

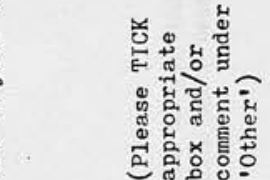

范

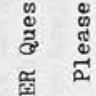

i

旅

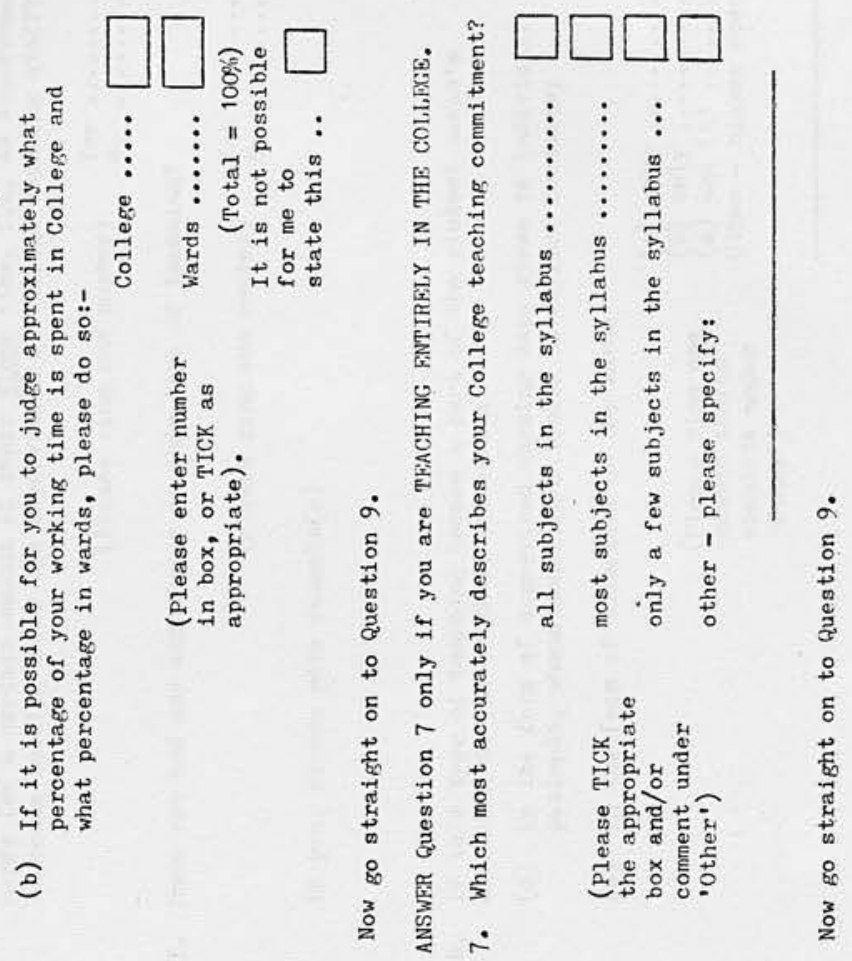

¿ัँ

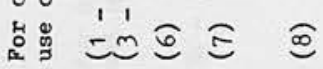

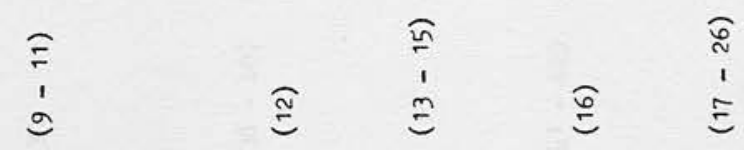

:

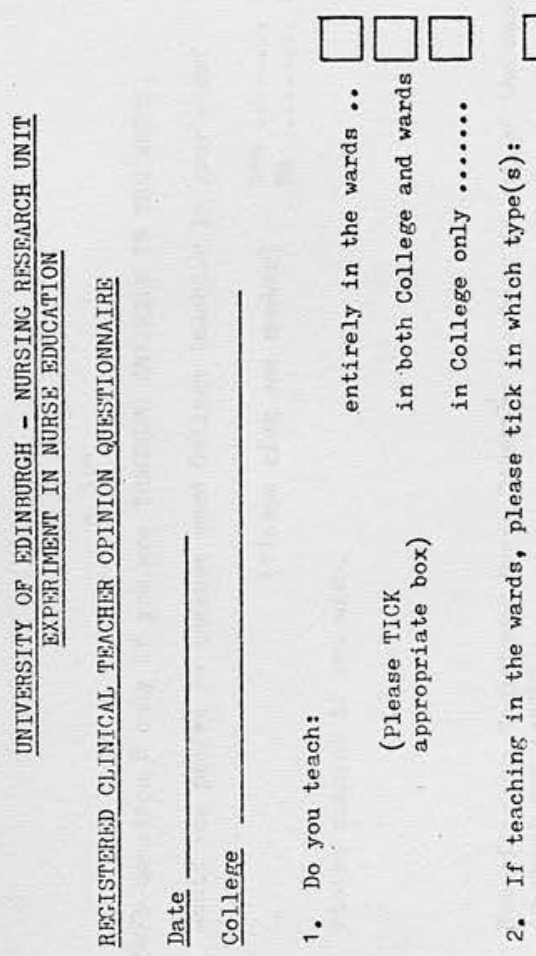

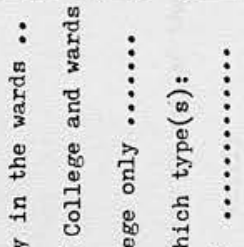

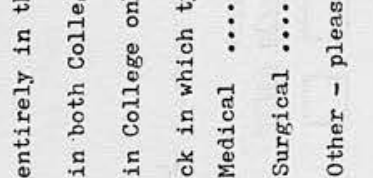

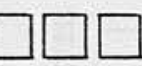

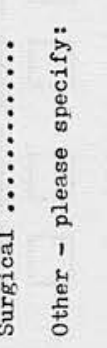

$\dddot{\vdots} \vdots \vdots$

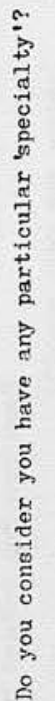

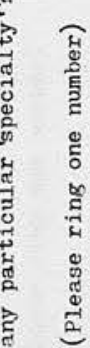

है

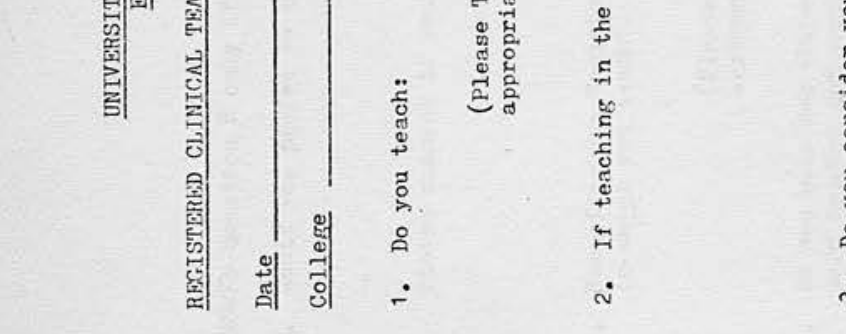

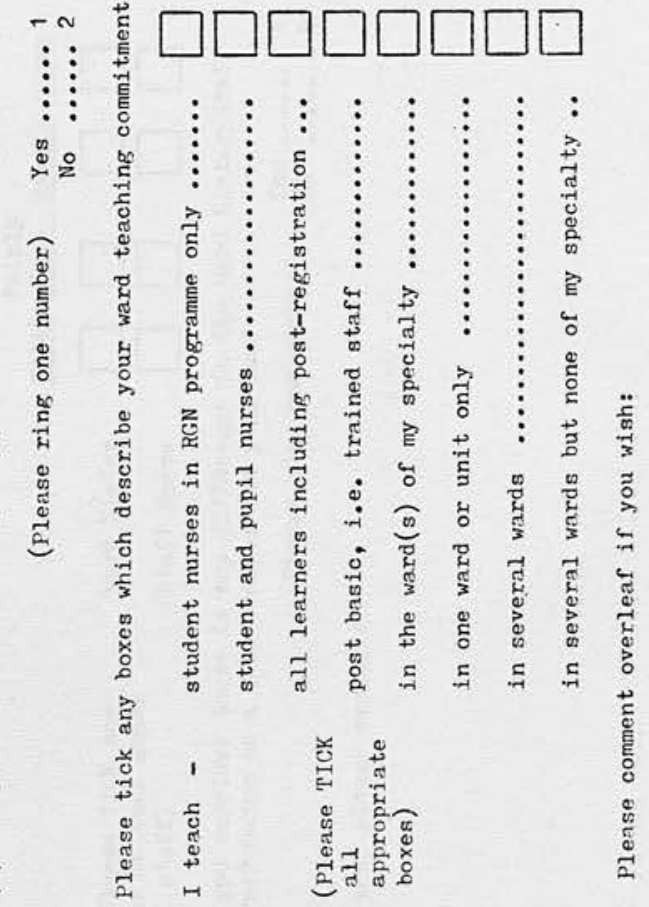


铰产高

点易

ब ब

$\sqrt{2}$
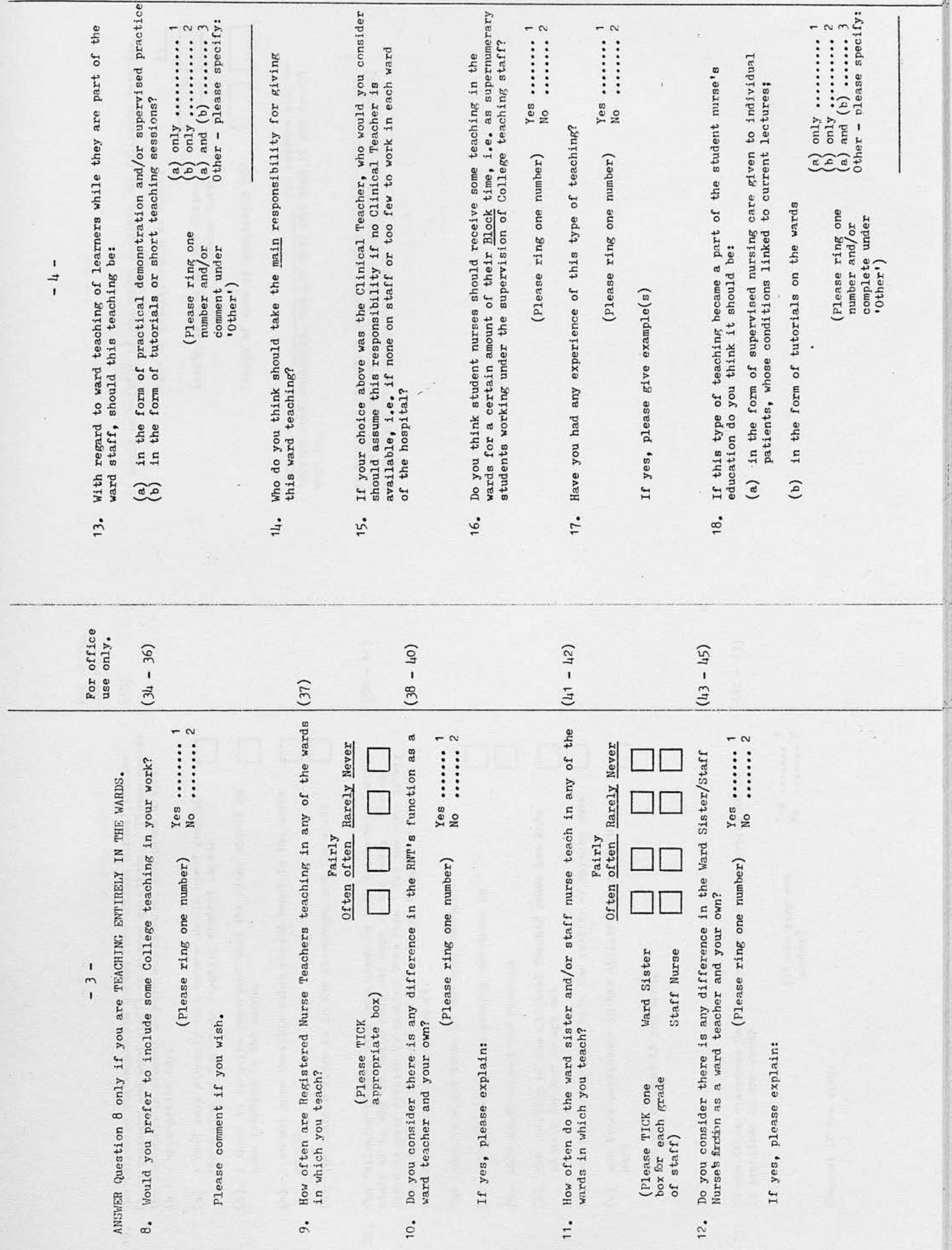

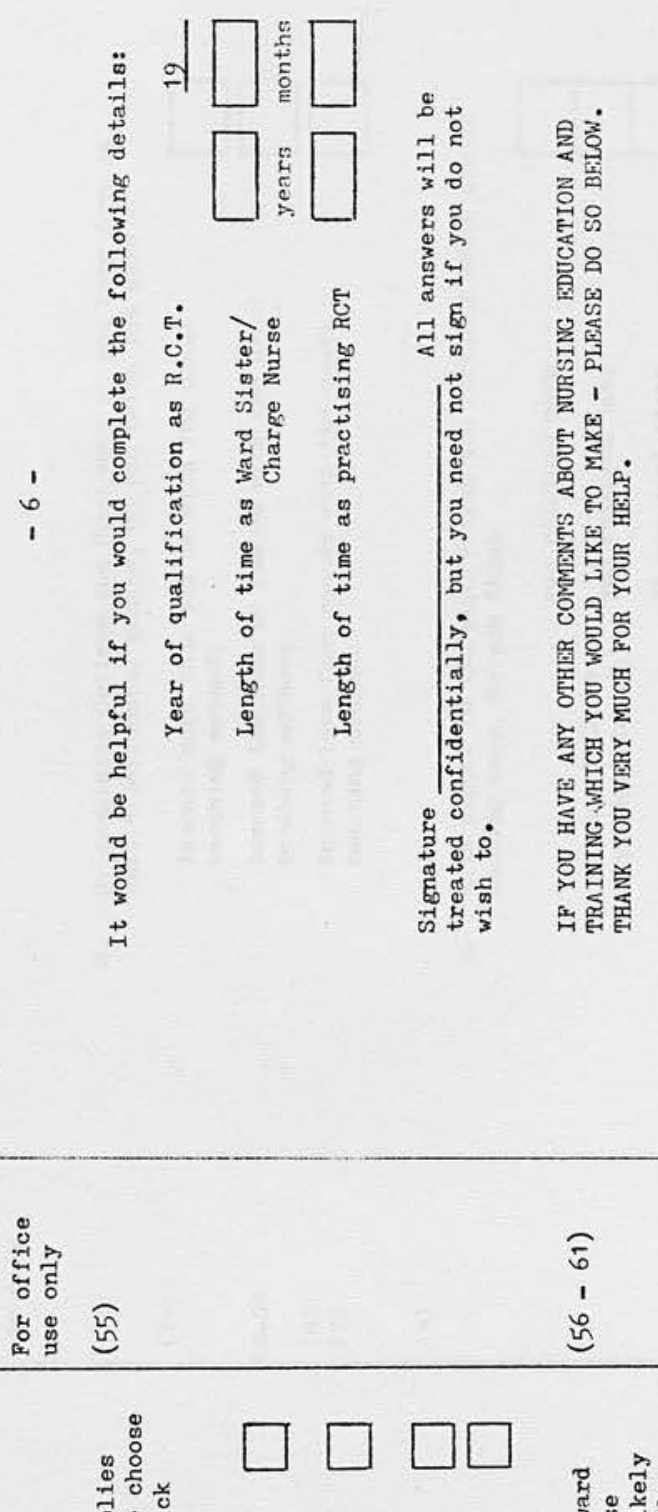
$=\square \square \square$

,

a

MIII

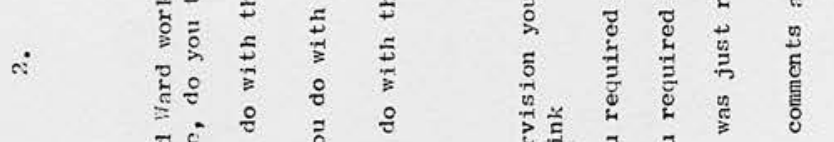

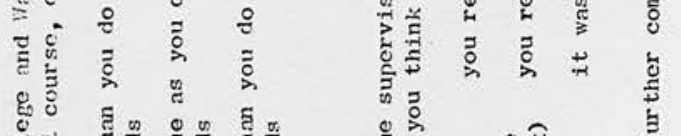

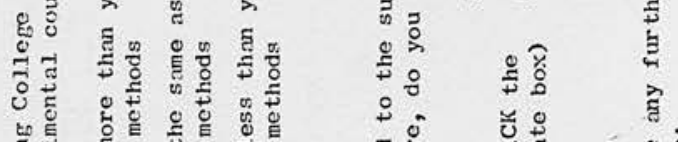

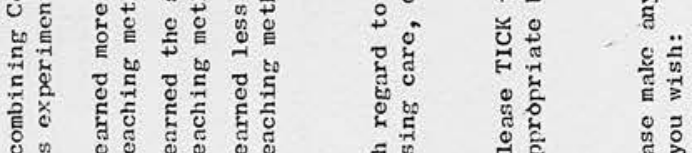

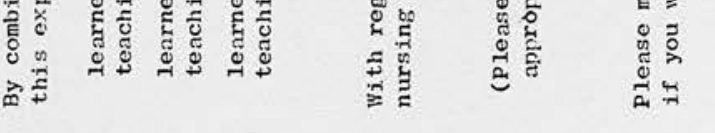

is

䇏

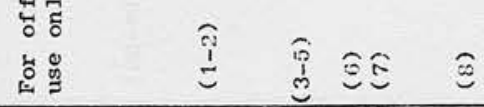

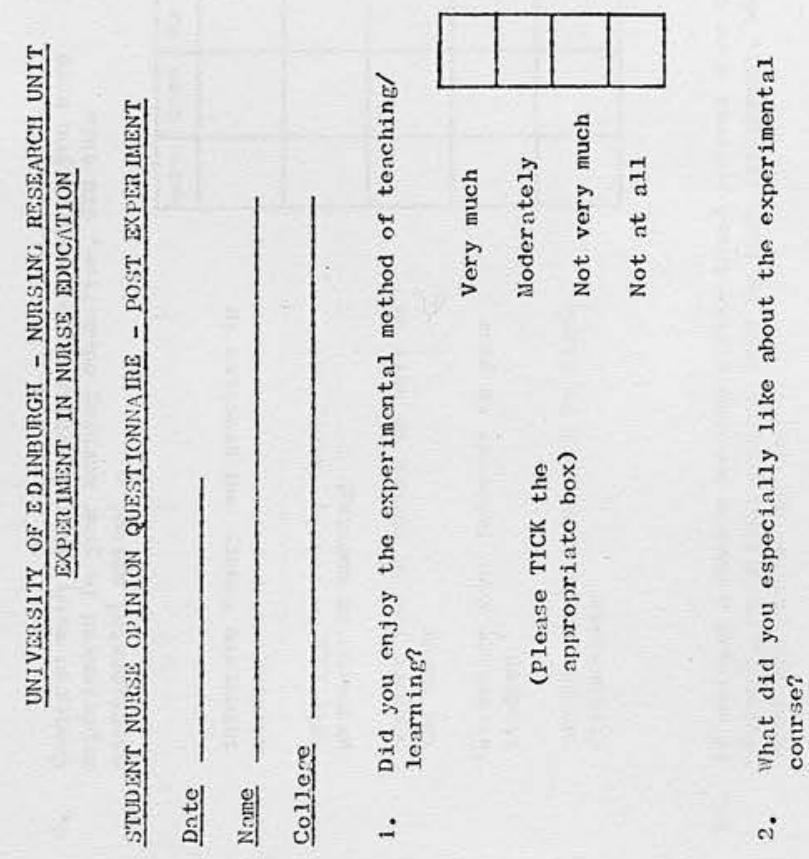

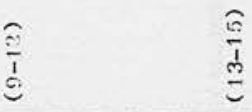

$\frac{c}{5}$

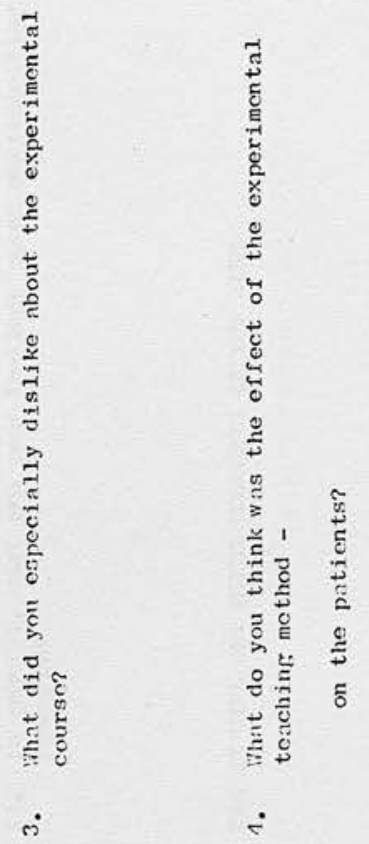

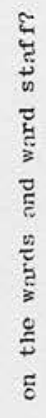




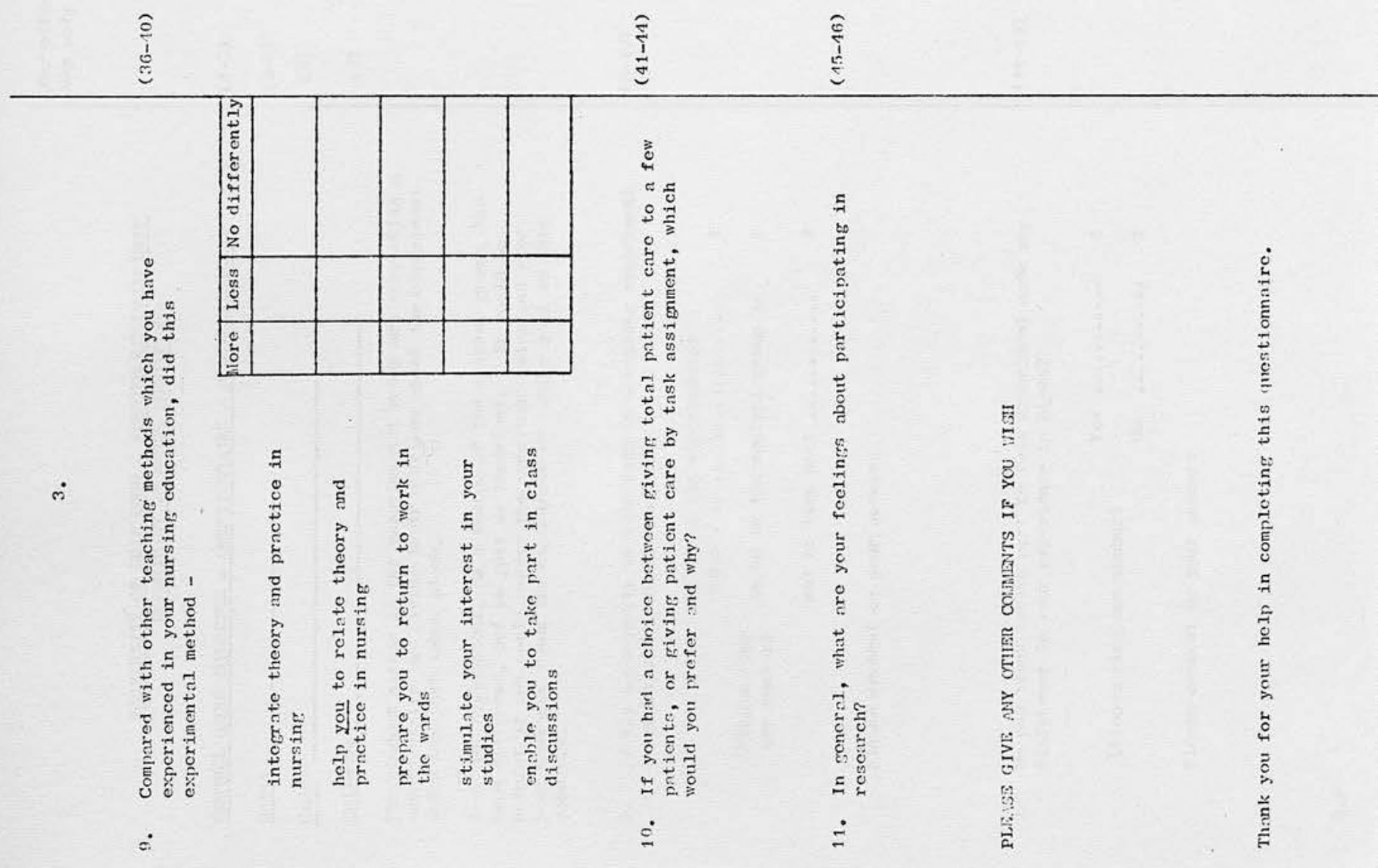



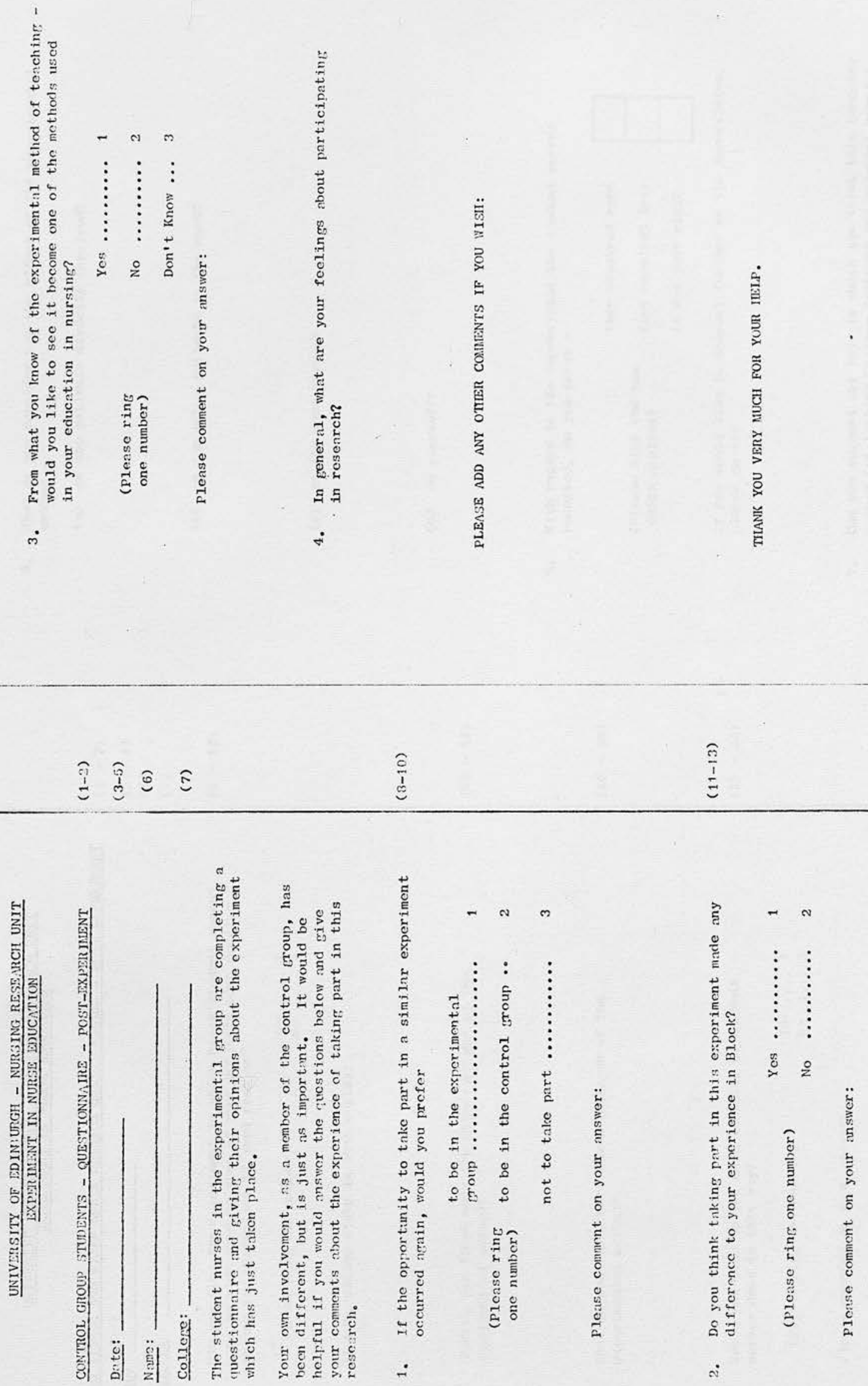

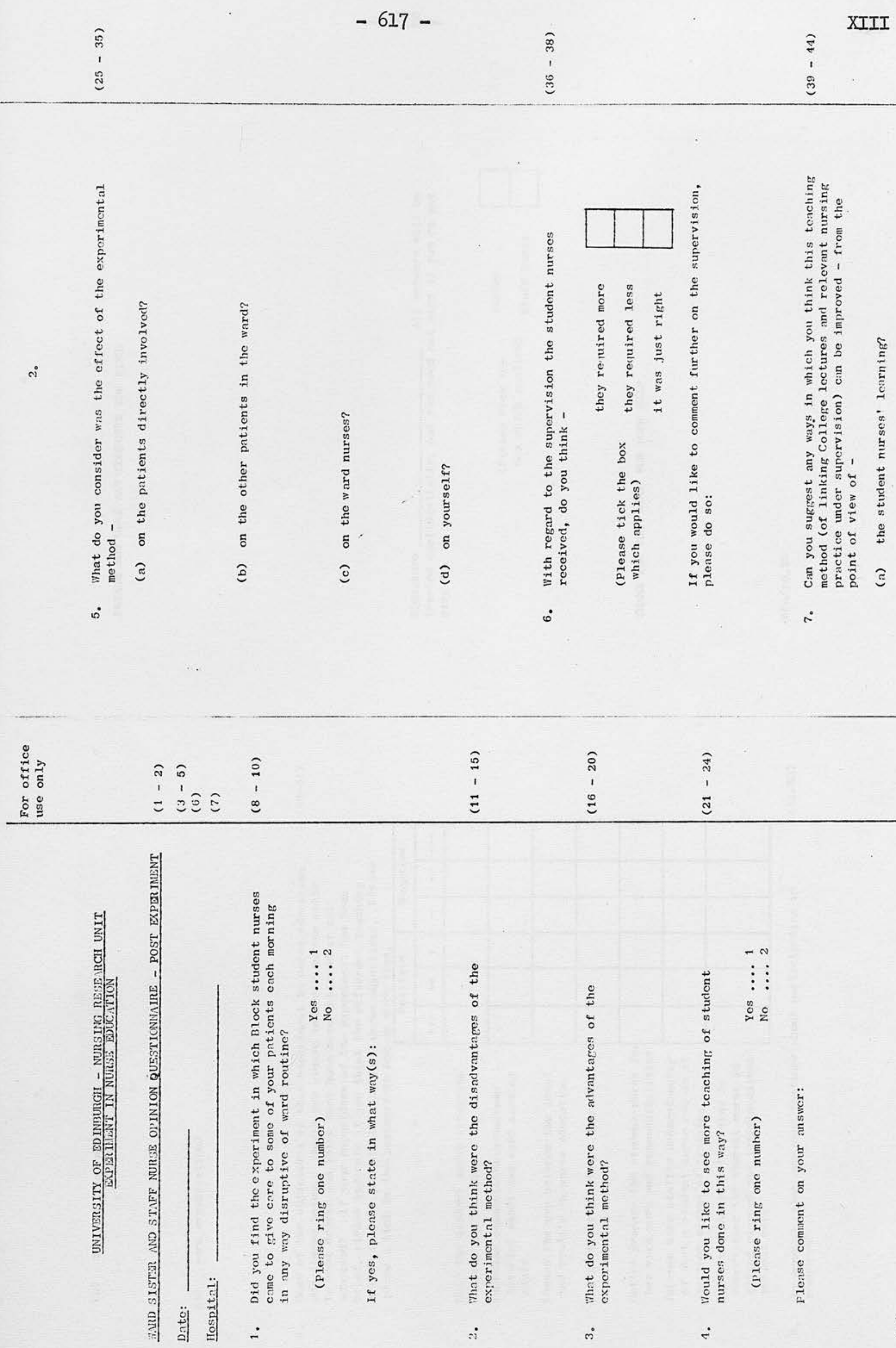


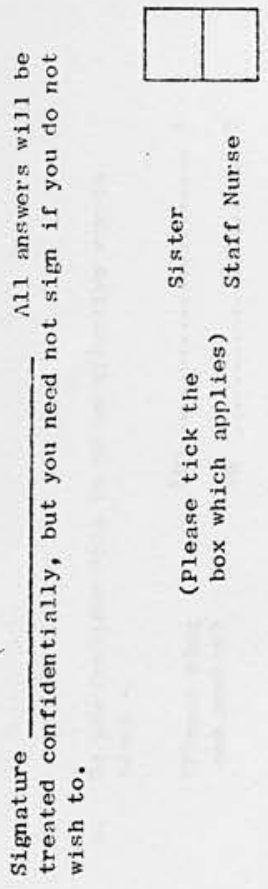

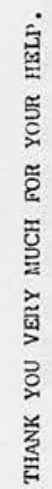

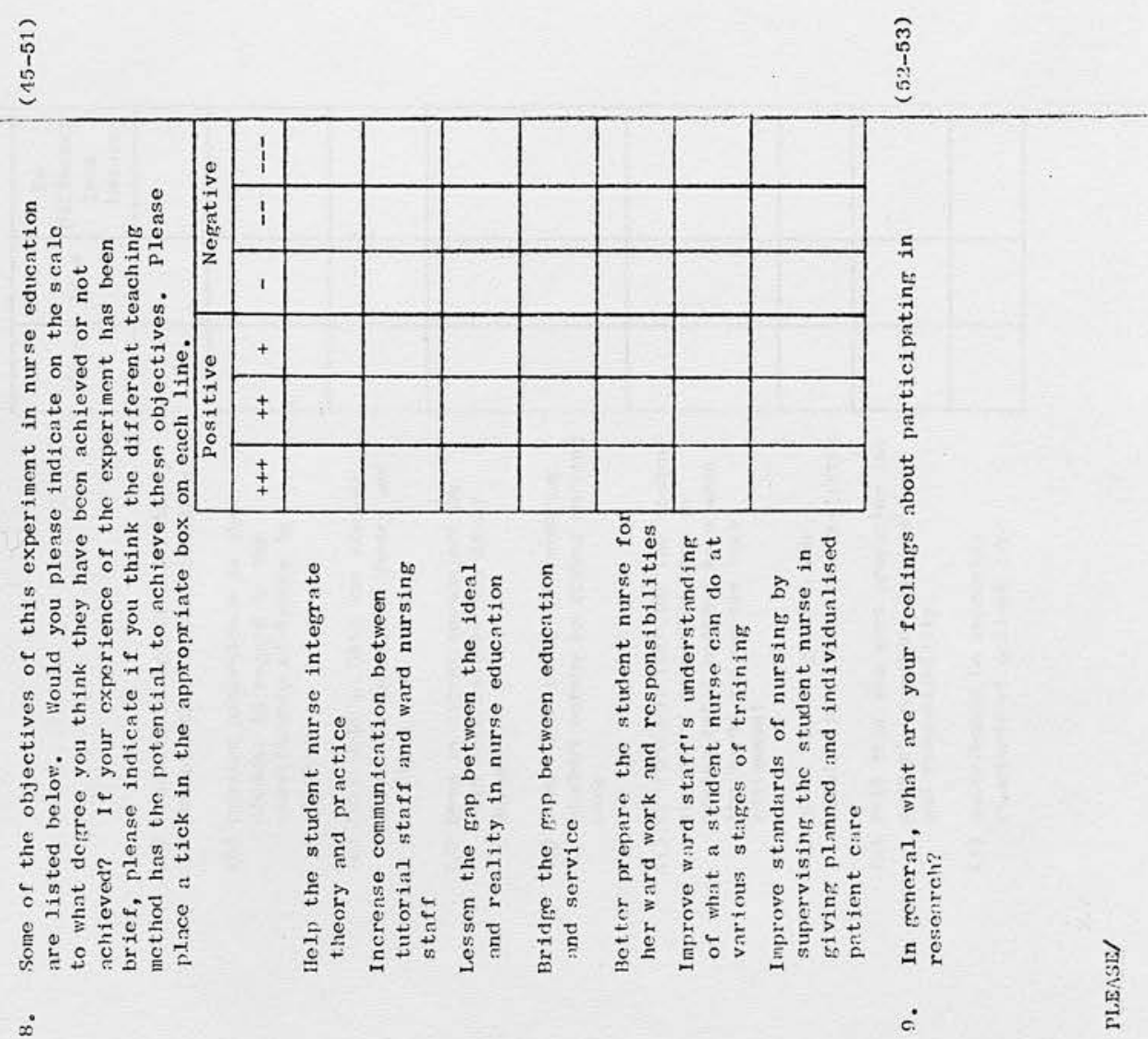




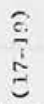

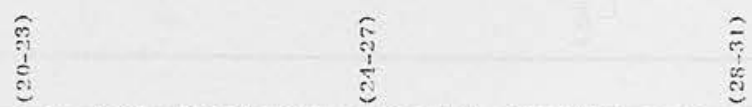

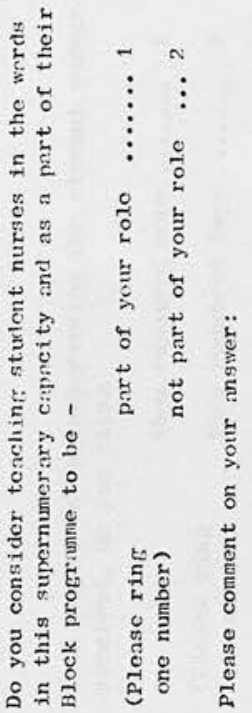

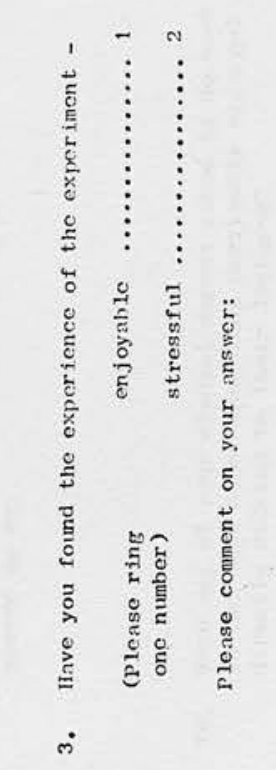

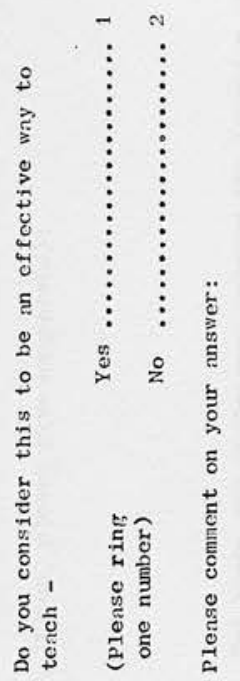

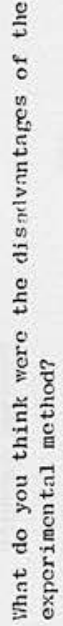

i
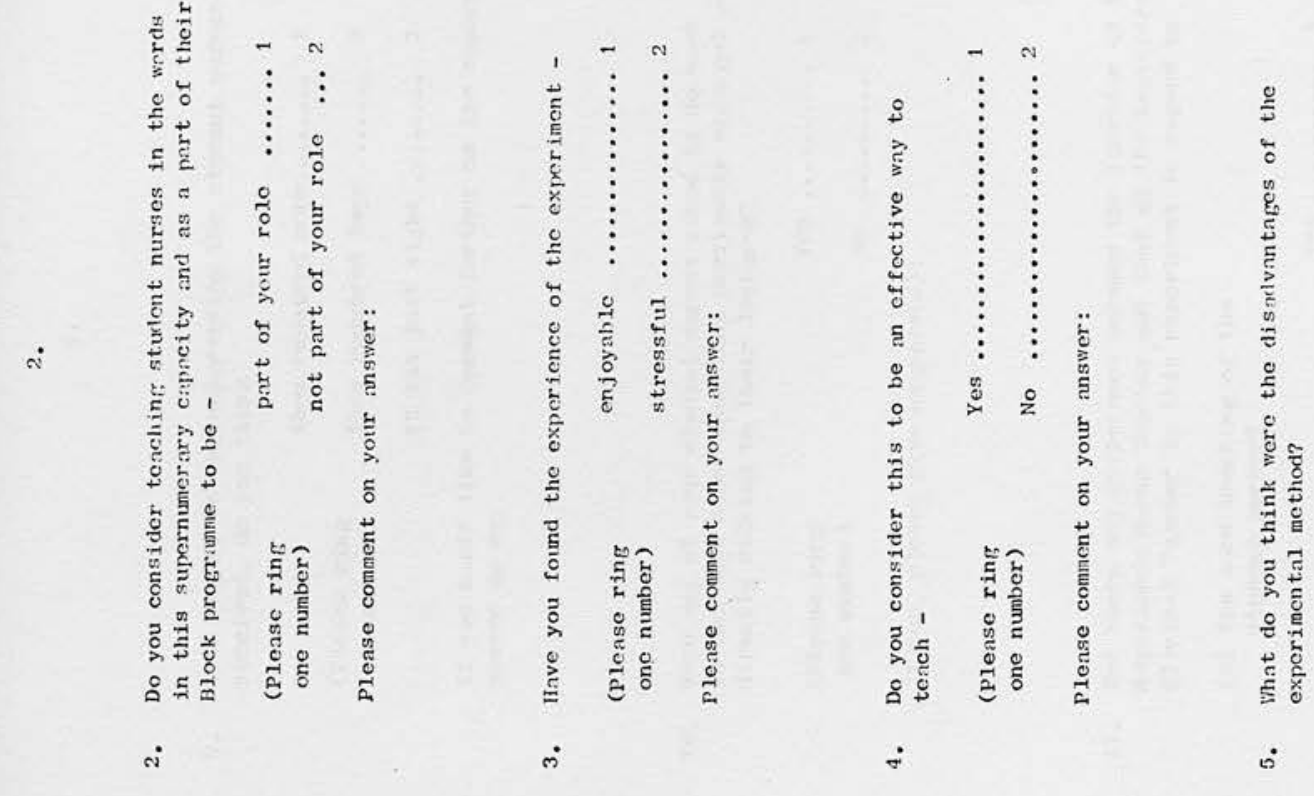

¿े

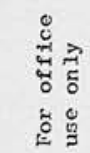

ริก
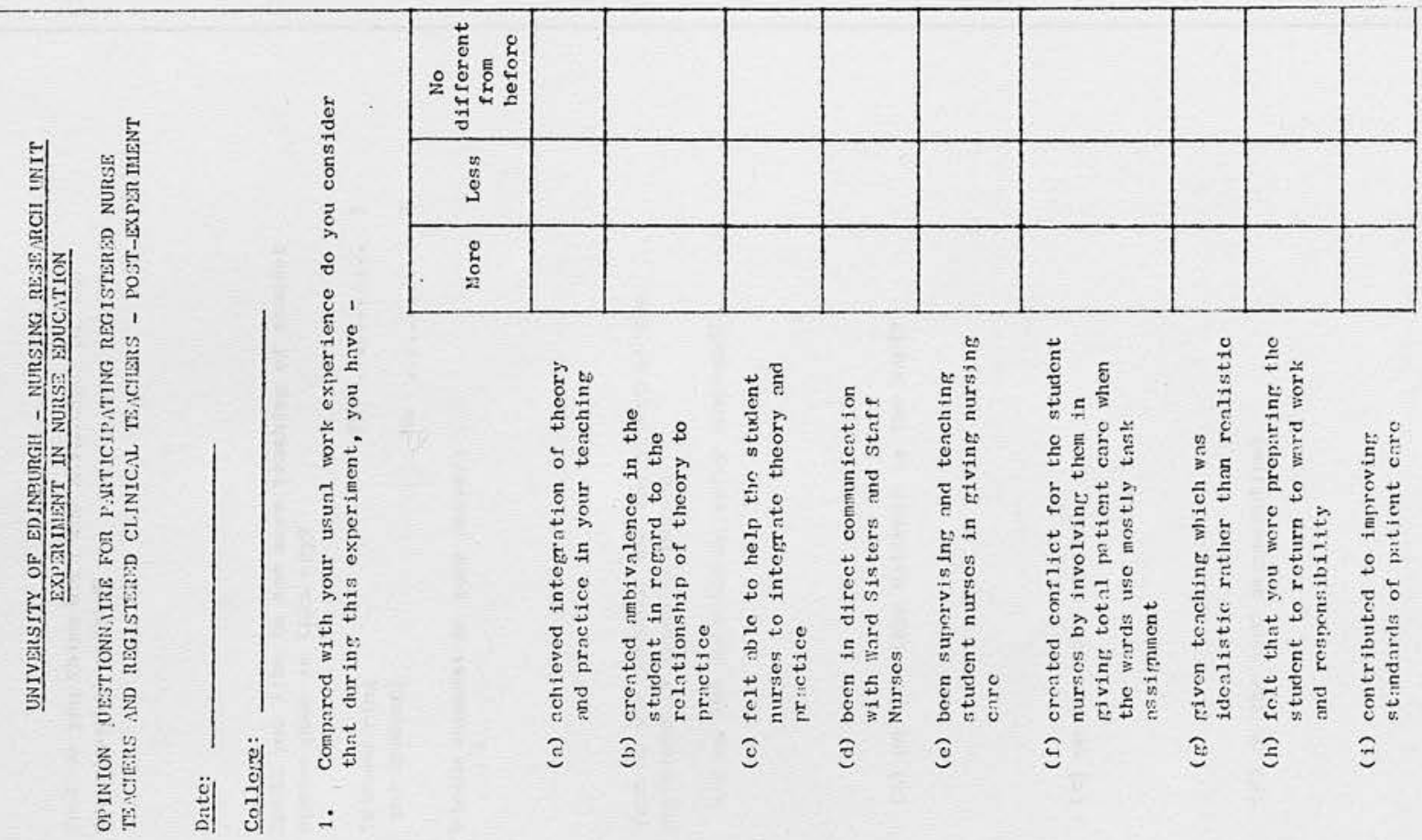

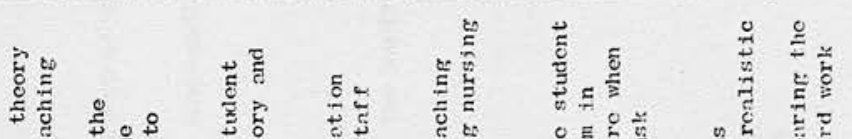

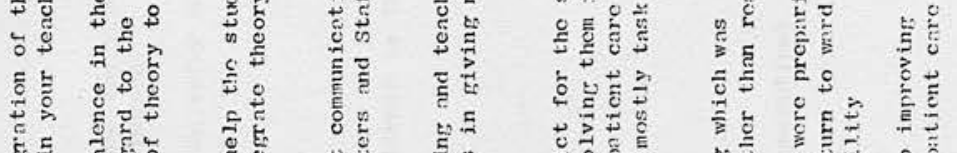

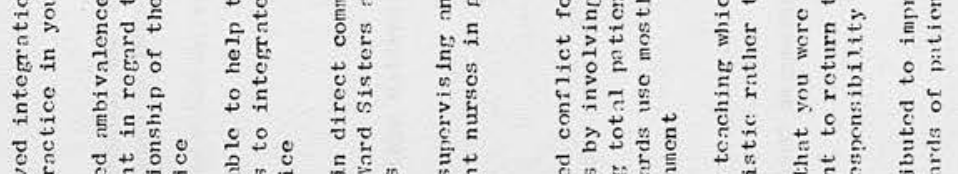

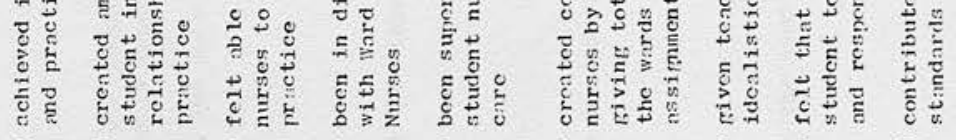
๖ 

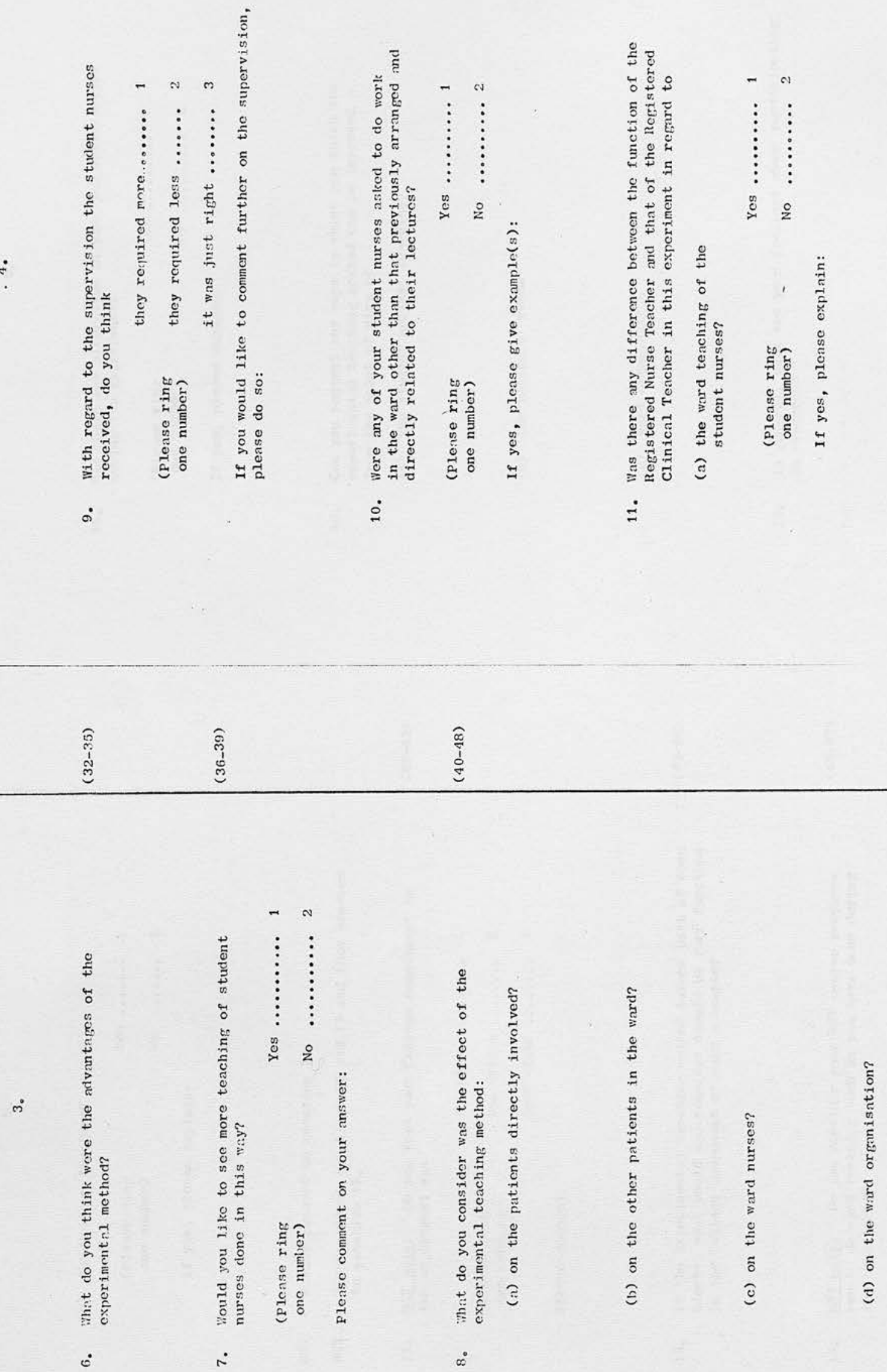
1ิ

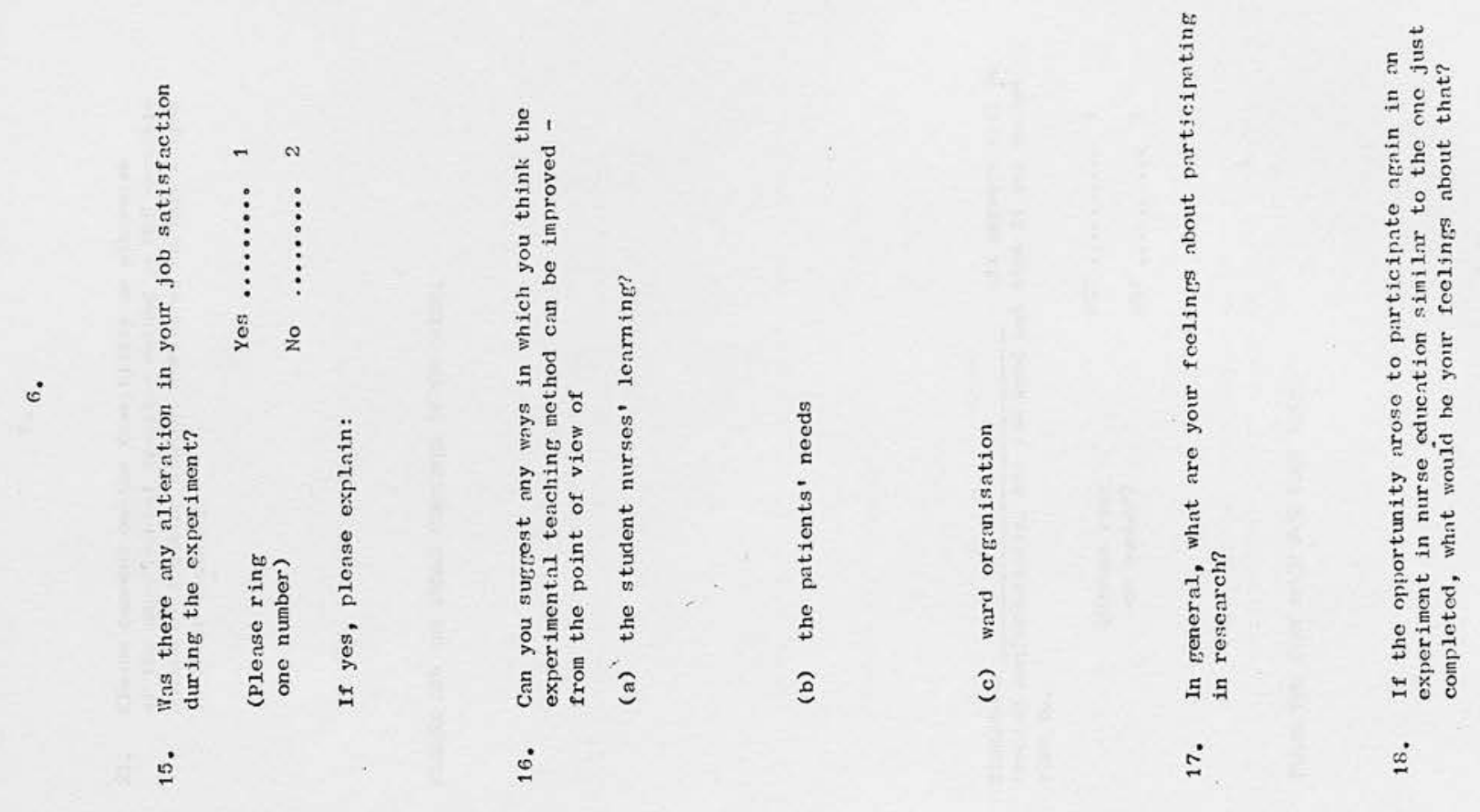

ปิ

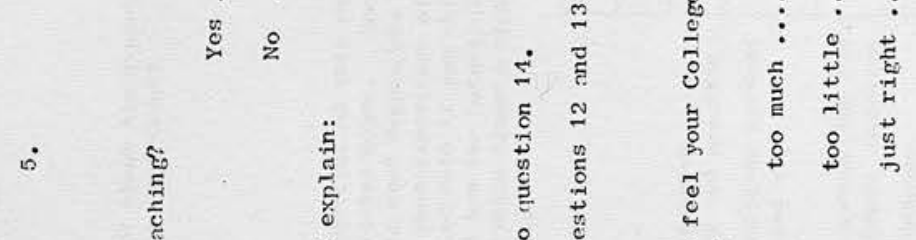

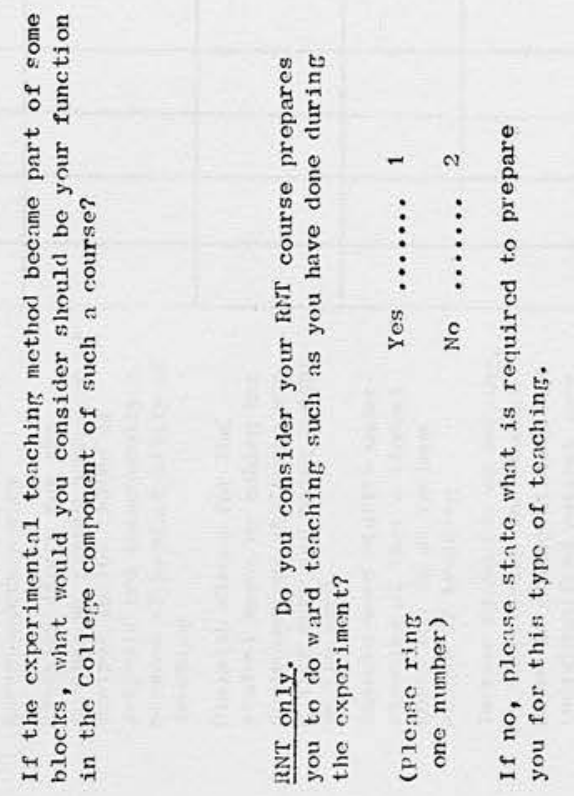

ह

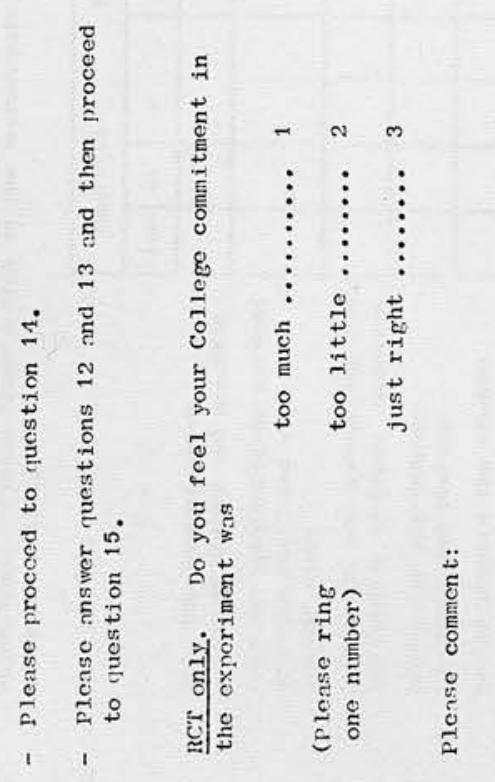

芩

ळ. 

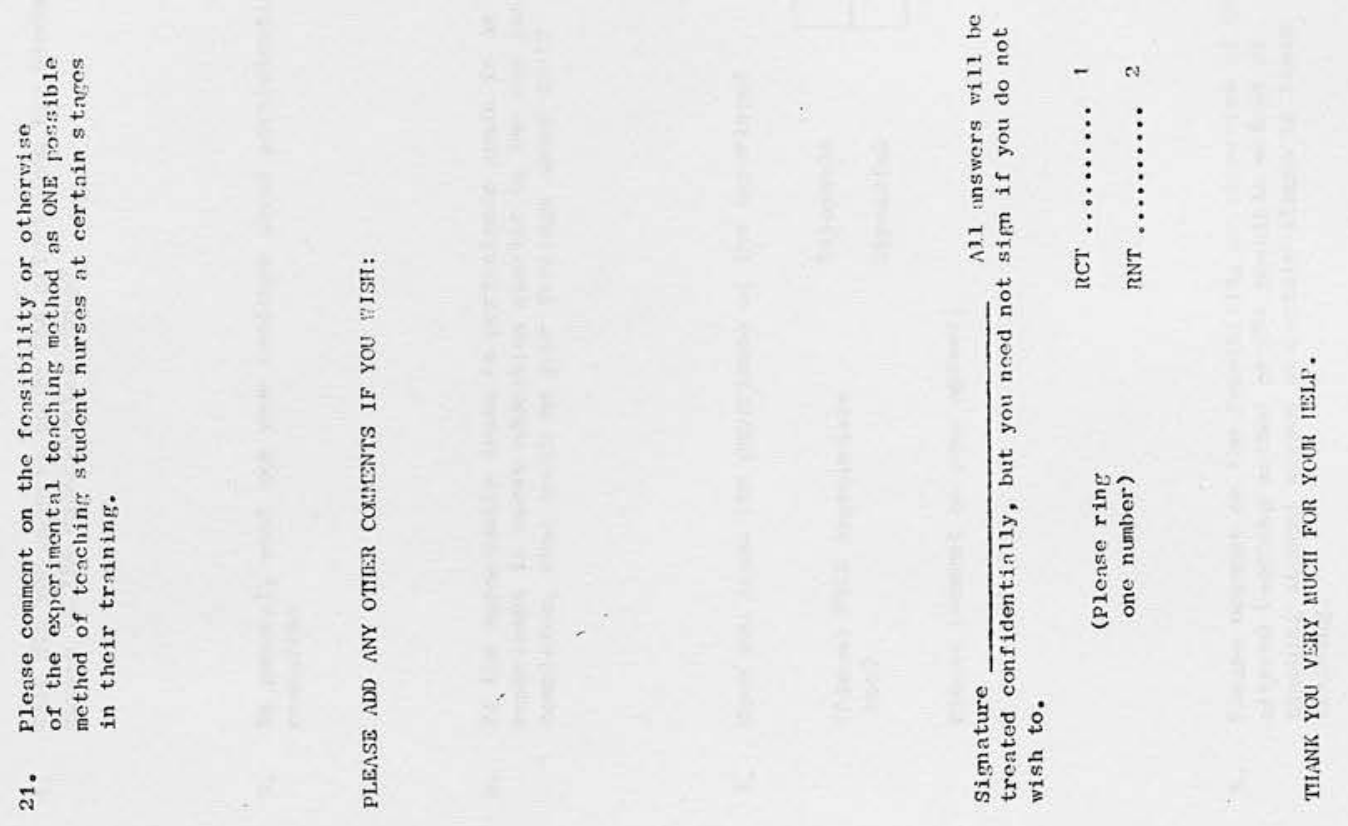

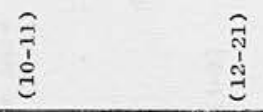

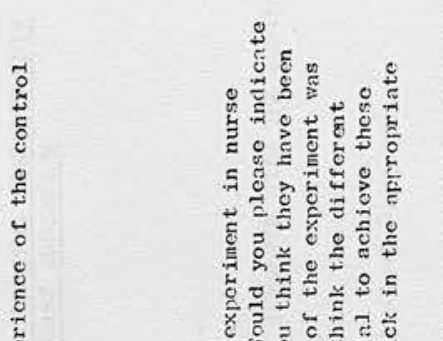
है दे

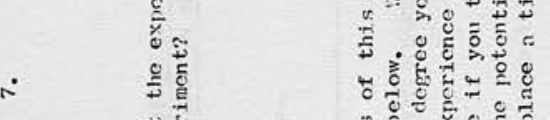
范范

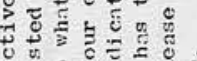
¿ू

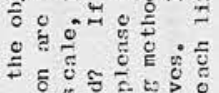

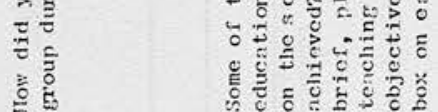

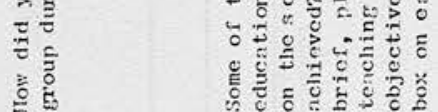

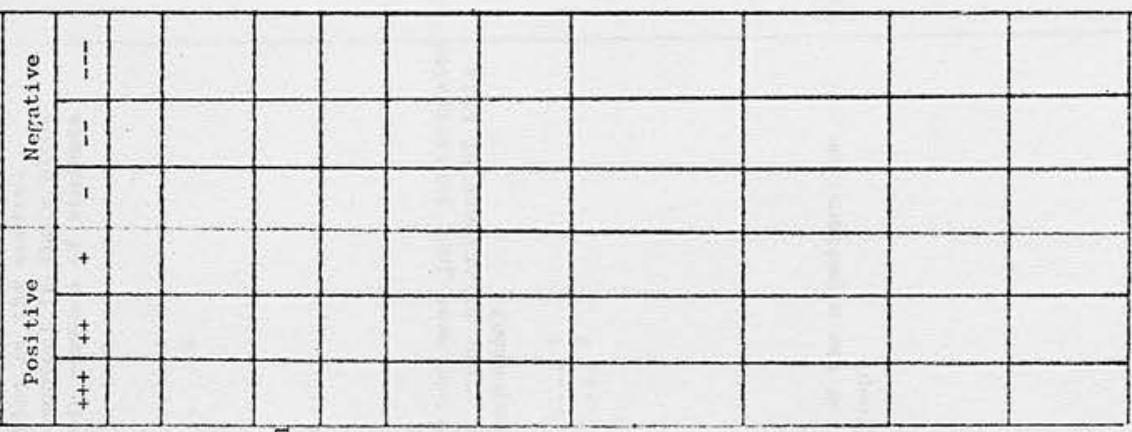

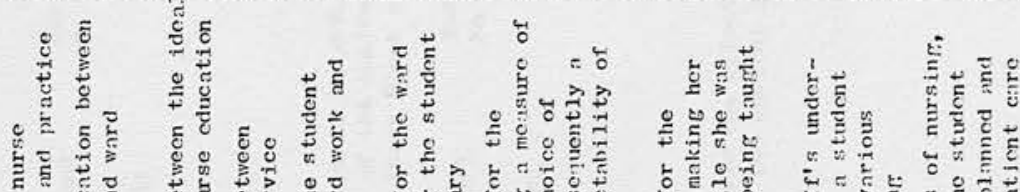
ह 5 हु

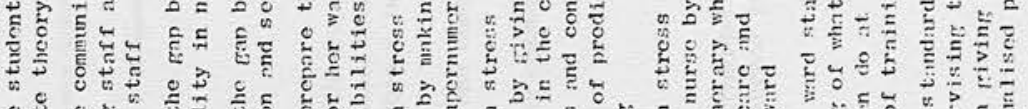
O

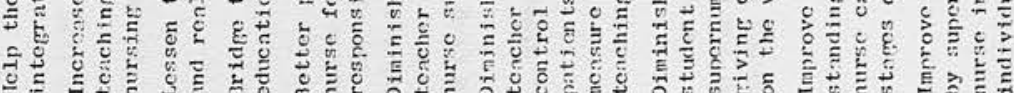
$\therefore \quad \dot{\circ}$ 

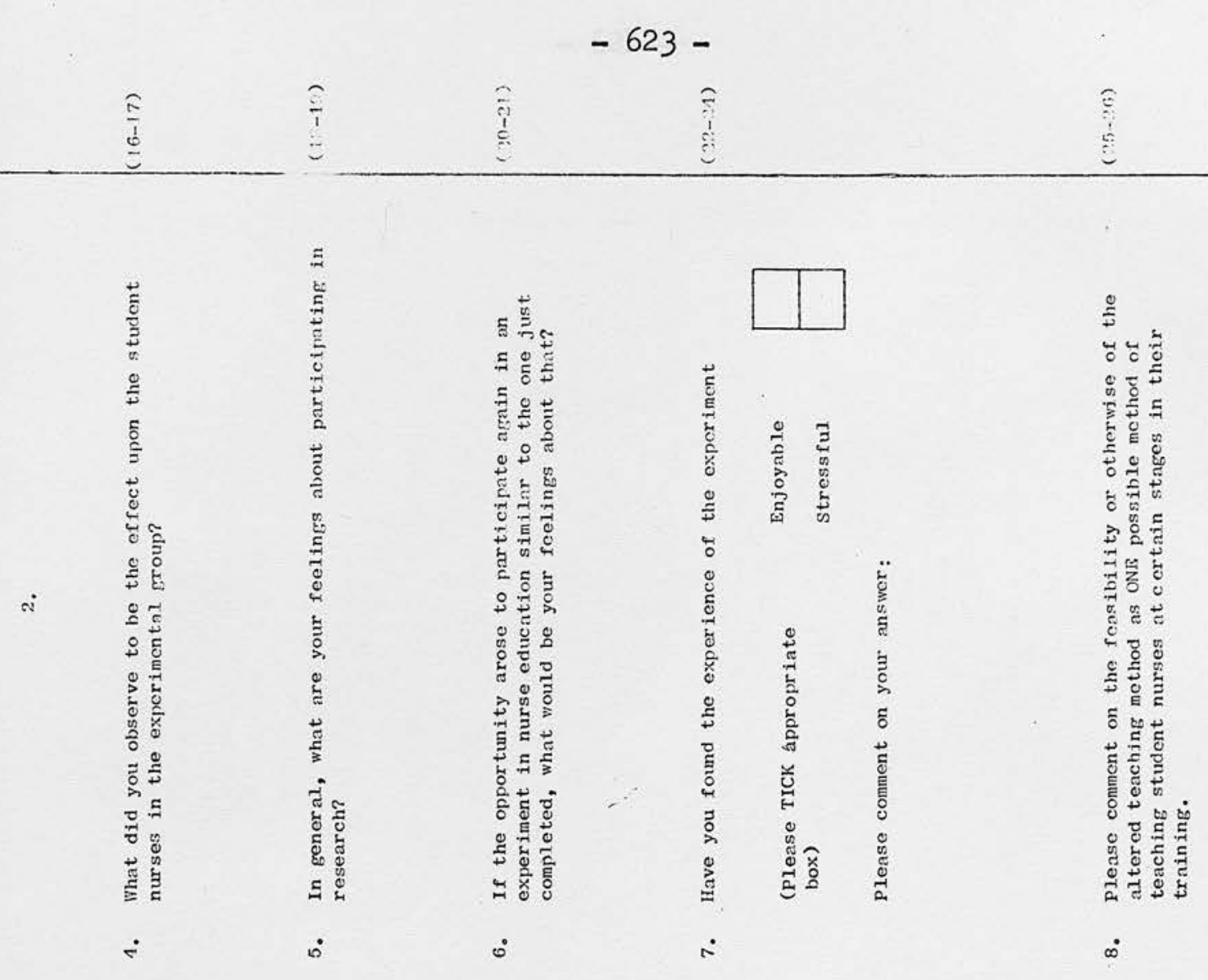

: ㅇํㅇ

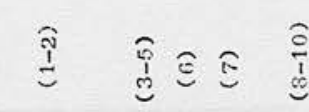

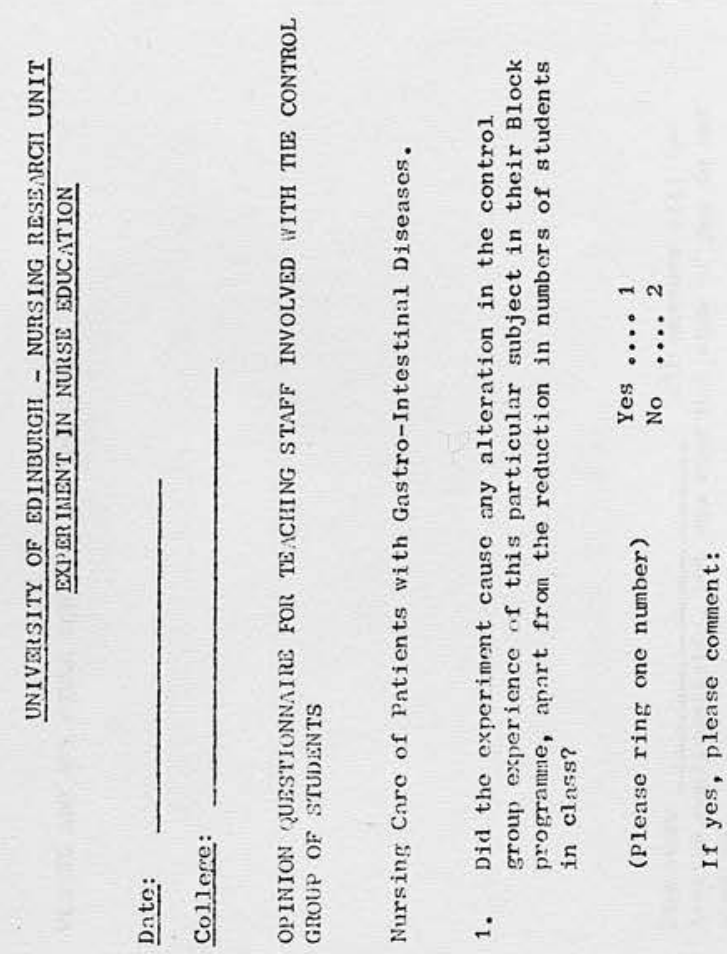

产告

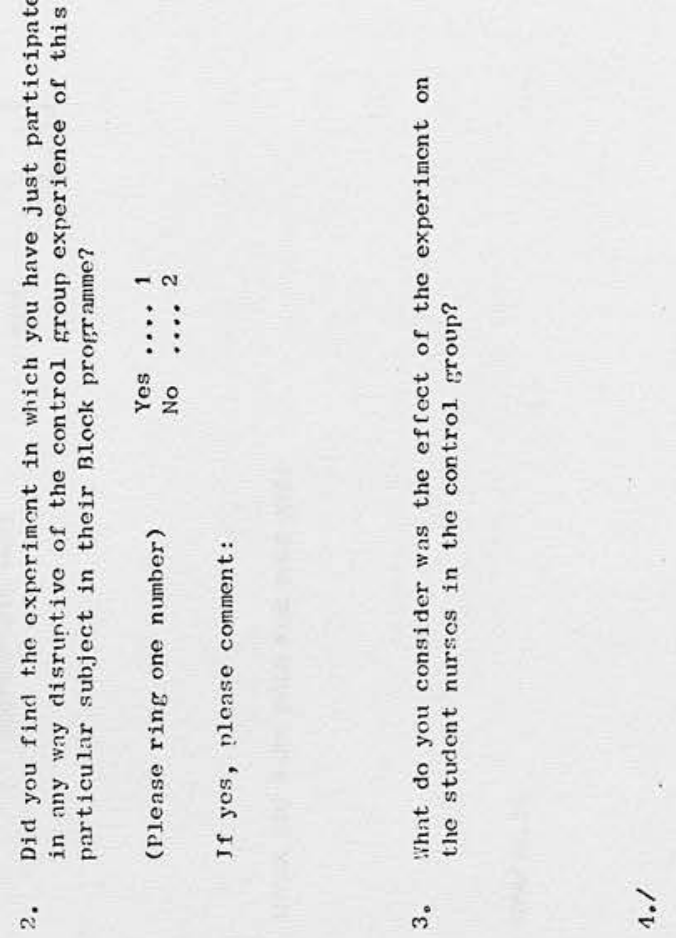




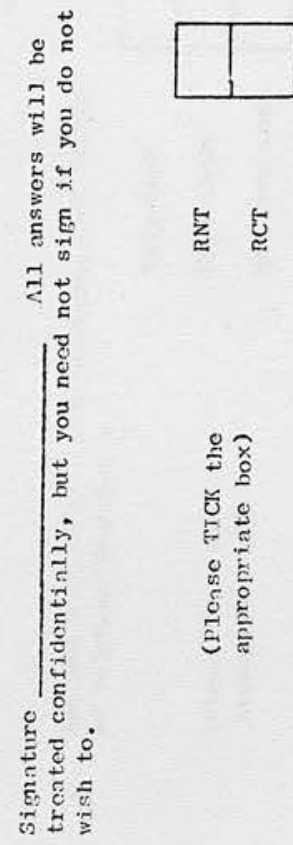



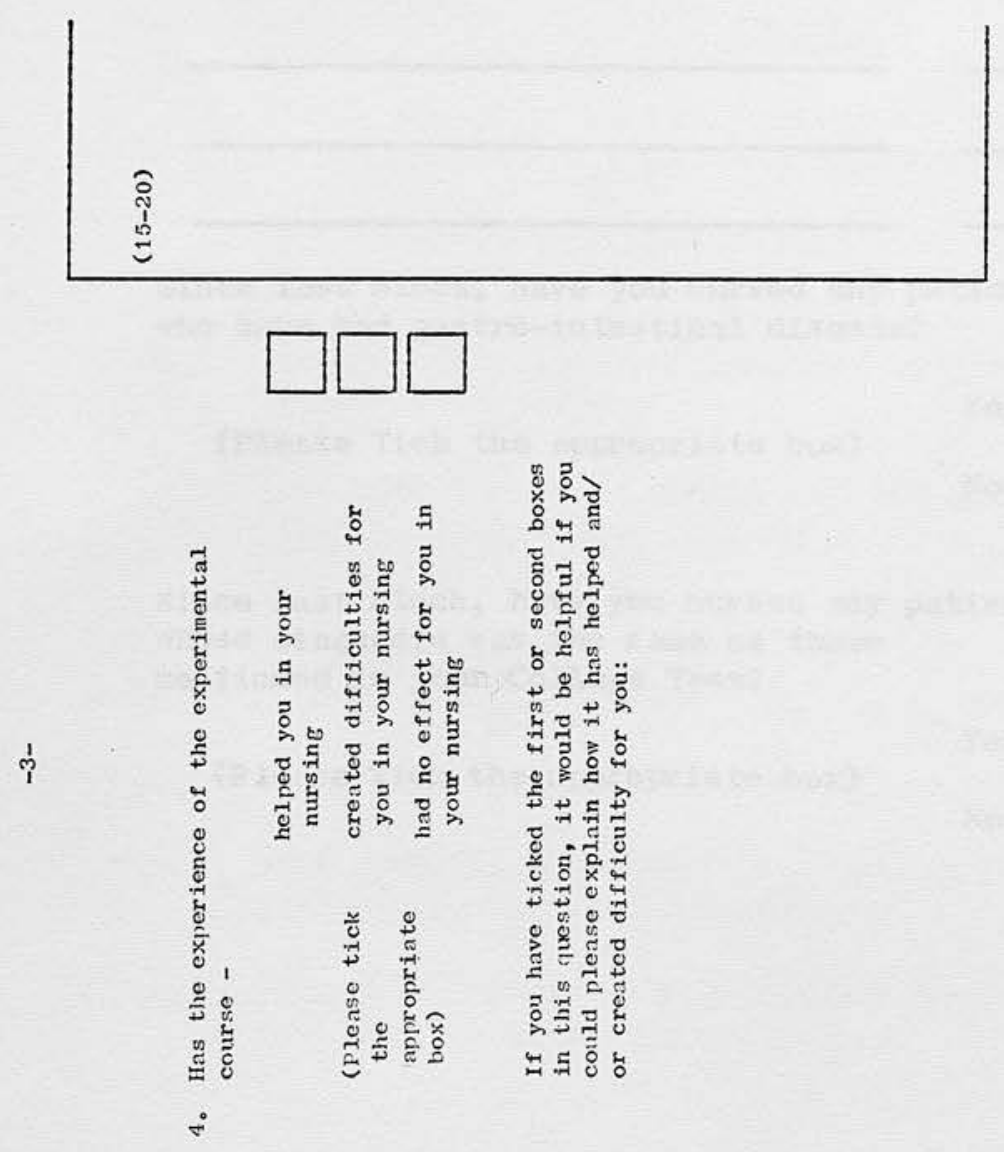
UNIVIRSITY OF EDINBURGH - NURSING RESEARCH UNIT

RITENTION OF LERNING ASSESSMENT

PART B - NULTIPLE CHOICE TEST.

This is the test which you completed before and after the research experiment.

Please work through it for the final time and, as before, try to resist the temptation to make an outright guess if you do not knov the answer to any particular question.

TIME ALLOVED - 45 minutes

Please fill in your Research Number here

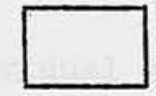

Practical Experience since last Block:

(Please mark an ' $X$ ' beside the experience which came first after leaving Block)

Psychiatric wards

weeks

Please do not write in this column

Surgical wards

weeks

Medical wards weeks

Other wards or departments please specify:

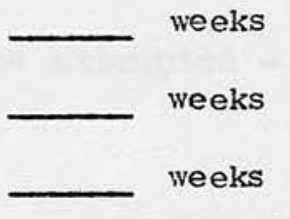

$(1-3)$ :

(4)

$(6-7)$

$(8-19)$

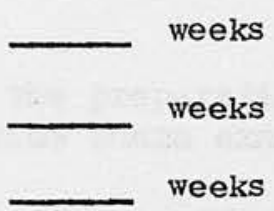

Since last Block, have you nursed any patients who have had gastro-intestinal disease?

(Please Tick the appropriate box) Yes No

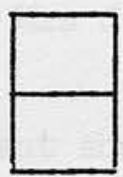

(20)

Since last. Block, havé you nursed any patients whose diagnosis was the $\mathrm{s}$ ame as those mentioned in your College Test?

(Please Tick the appropriate box)

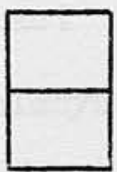

(21)

Score A:

$(22-29)$

Score B:

$(30-31)$ 
Each essay examination had a brief preamble. The instructions placed at the head of all Retention of Learning essays are given below. For Post-essays, instructions were similar, but followed the patterm used by each individual college.

This test is an exact repeat of the one you completed in ... last, at the end of your lectures on nursing of patients with gastro-intestinal disease. Please work through it once more and complete it to the very best of your ability.

Results will be confidential - no individual student nurse's mark will be given to the College, but you will receive the marks yourself, if you would like them.

hand cormer.

ON EACH PAGE - please write your number in the top right labelled please.

Each part of the question to be attempted - and clearly

TIME ALLOWED - 1 hour

\section{COLIEEGE I}

1 (a) State the principles involved in the preparation and after care of the patient for barium enema examination

Mrs Jones is admitted to the ward with a severe attack of ulcerative colitis

(b) Outline the clinical features with which Mrs Jones is likely to present

(c) Describe the nursing and medical management she will require during her stay in hospital

2 (a) Draw a labelled diagram of the biliary tract

(b) List the clinical features of chronic cholecystitis

A 40 year old housewife is admitted to the ward for cholecystectomy and exploration of the common bile duct

(c) Give an account of the nursing care she should receive for 12 days after the operation 


\section{COLLEGE II}

1 (a) Describe, or by means of a diagram, illustrate the route of bile excretion

A 45 year old woman has been diagnosed as suffering from chronic cholecystitis

(b) What are the clinical features of chronic cholecystitis?

(c) Describe in detail the post-operative nursing care this patient will require following a cholecystectomy and exploration of bile duct

2 (a) What are the functions of the rectum?

(b) List the signs and symptoms of a malignant tumour of the rectum

A 45 year old man is admitted to hospital five days prior to undergoing an abdo-perineal excision of rectum

(c) Describe the role of the nurse in his pre-operative management

\section{COLTEGE IV}

1 Draw and label a diagram of the large bowel and describe its functions

3 What medications may be prescribed in the conservative management of a patient with ulcerative colitis? State the functions of each medicine

4 Describe the management of a patient following surgery for this condition 


\section{COLUEGE V}

1 A young woman, recently engaged, is in your ward recovering from surgical treatment for Ulcerative colitis

(a) Discuss the physiology of the large bowel

(b) What changes occur in the bowel in ulcerative colitis

(c) Describe the special care required for this patient in whom ileostomy has been performed

(d) What psychological problems may present in this patient and how could you, as a nurse, help overcome these problems

2 (a) What are gallstones and what factors are thought to predispose to their development? Name one method by which their presence in the body can be diagnosed

(b) State the clinical features of chronic cholecystitis

(c) Describe the post-operative care of a patient who has had a cholecystectomy and exploration of the common bile duct performed 


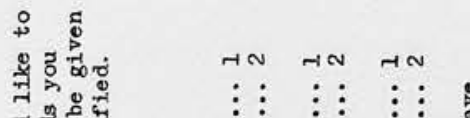

望

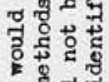

列

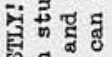

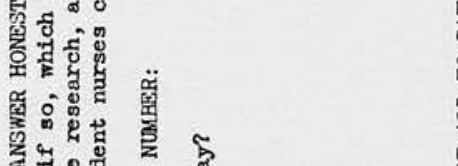

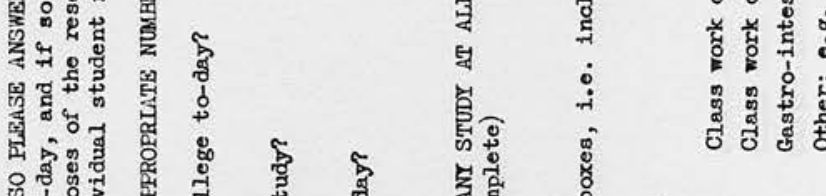

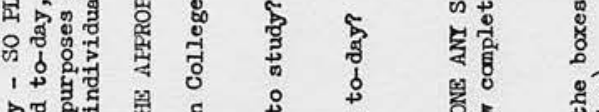

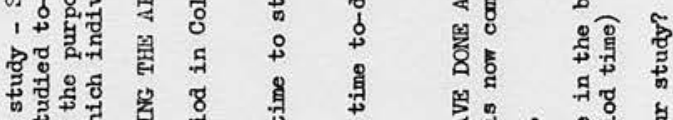

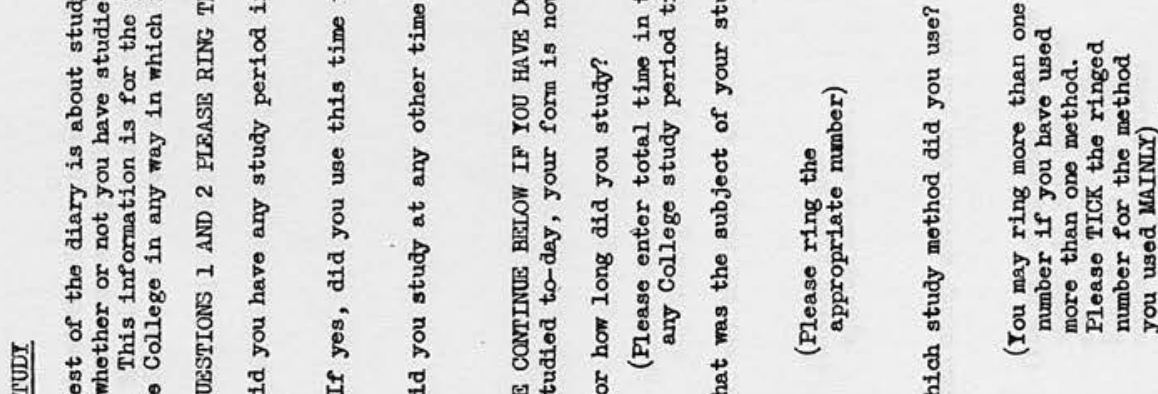

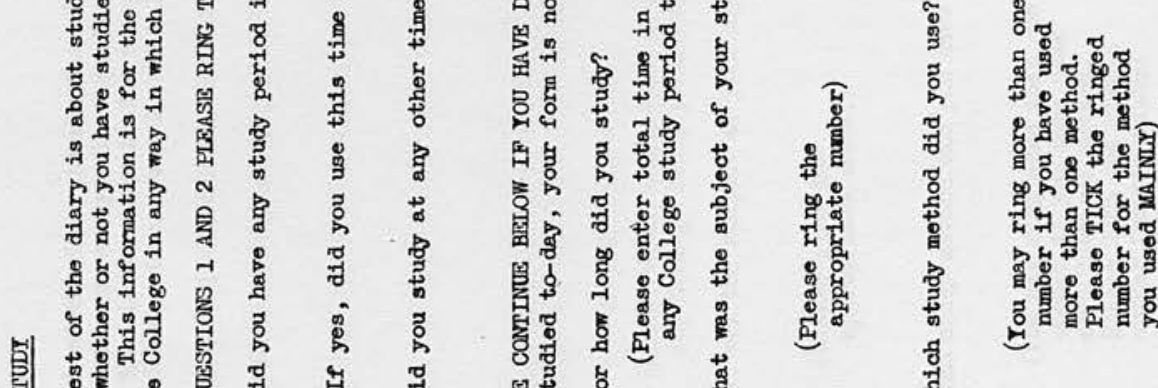

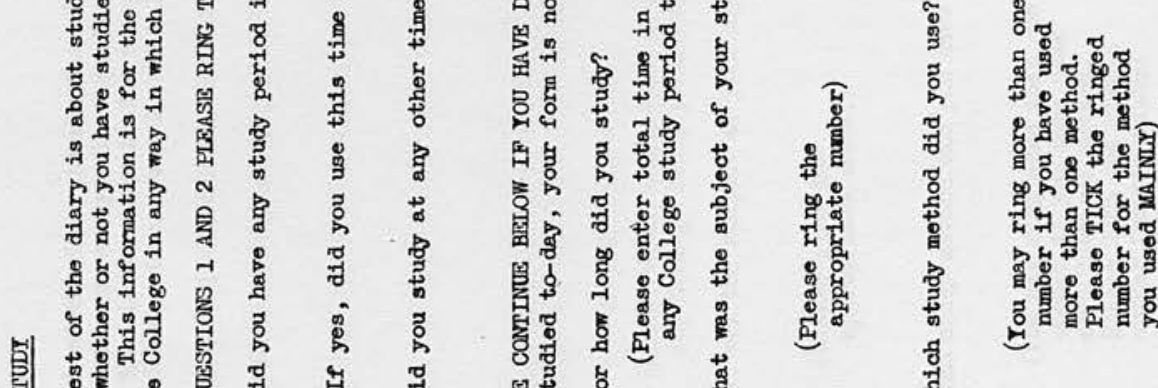

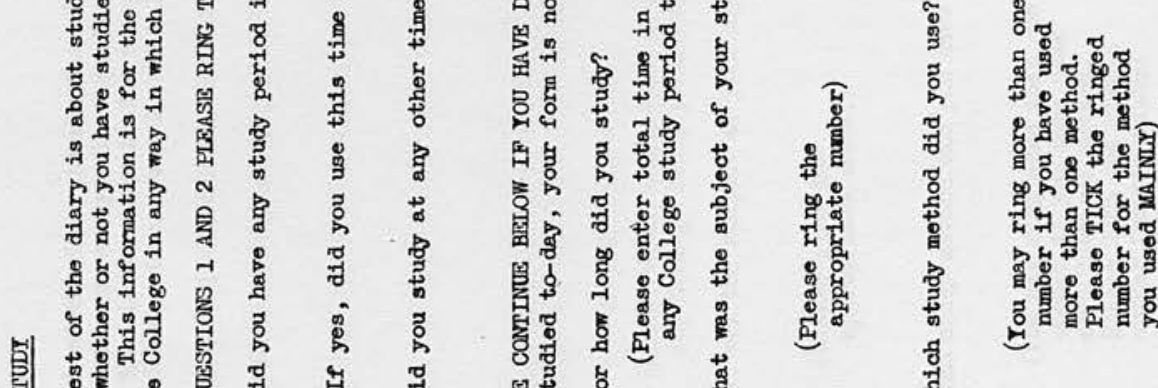

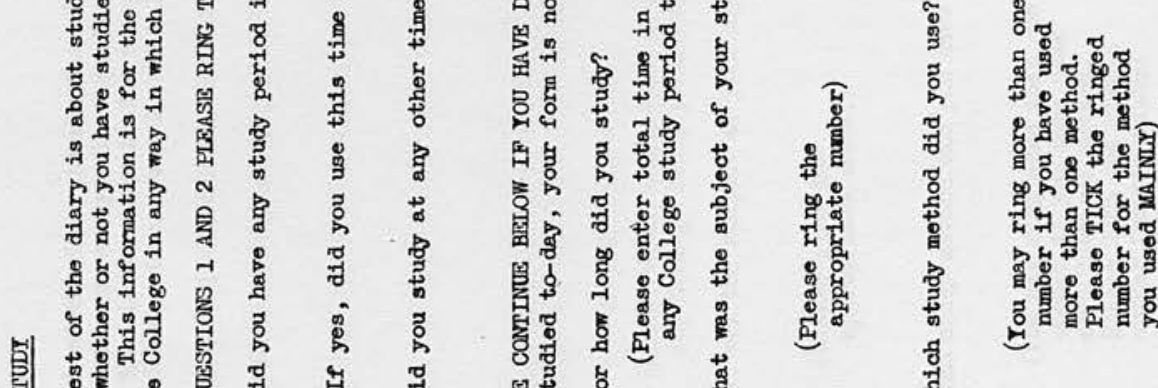
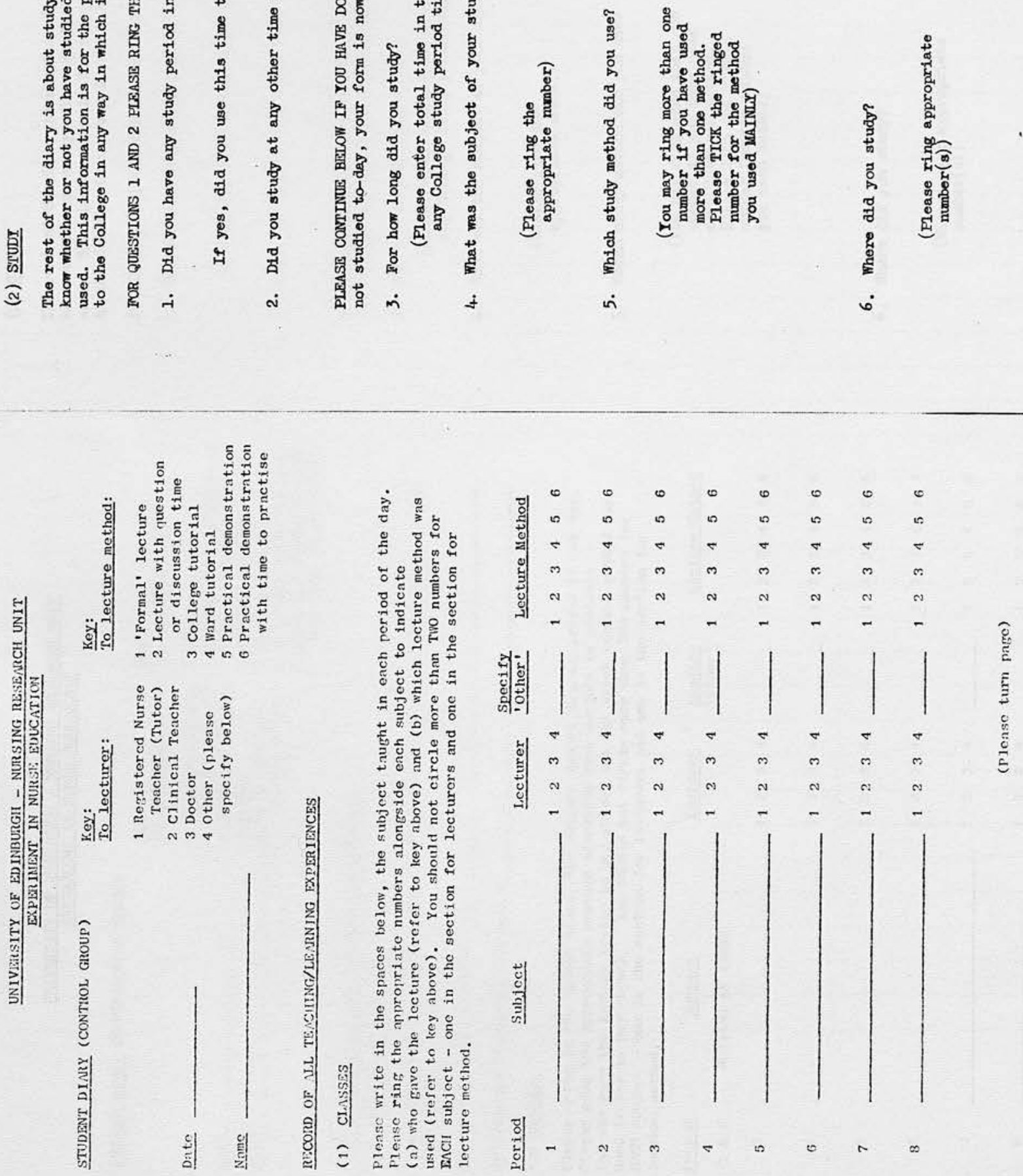


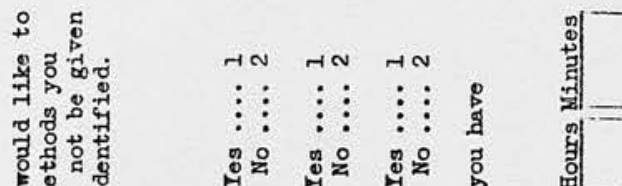

年

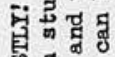

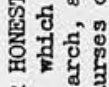

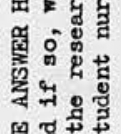

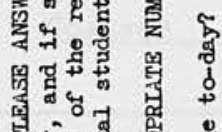

嚃

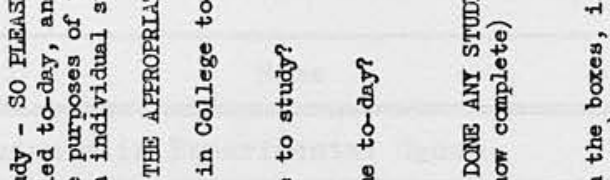

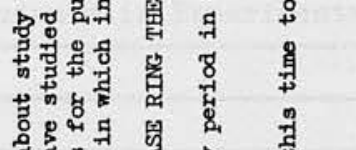

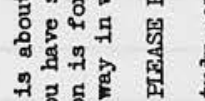

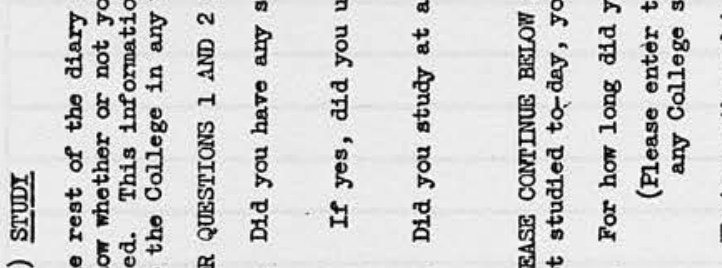

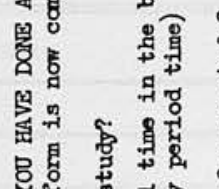

芒

시욜

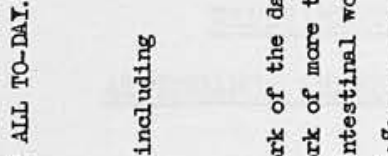

范范节:

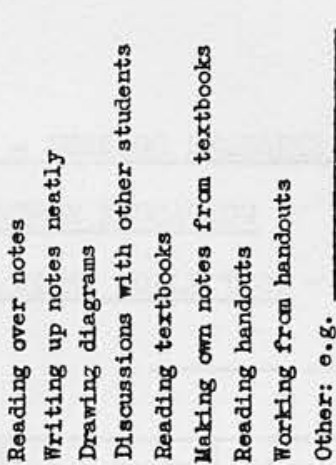

$\mathrm{xx}$

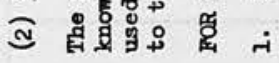
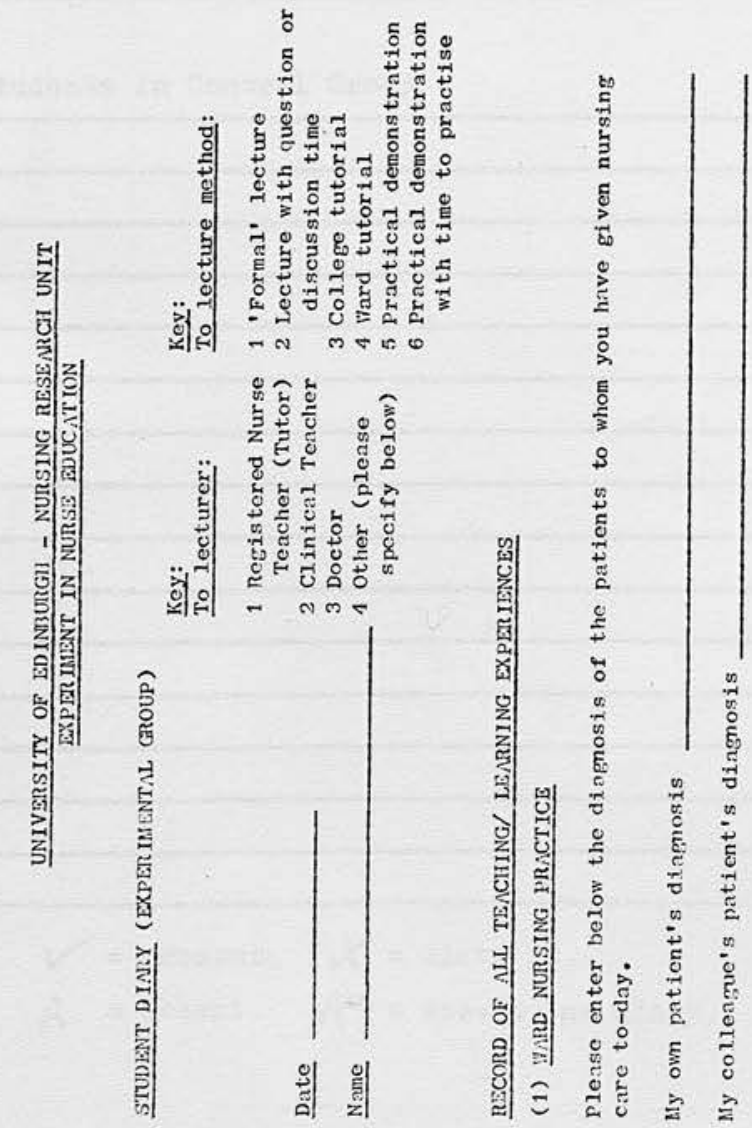

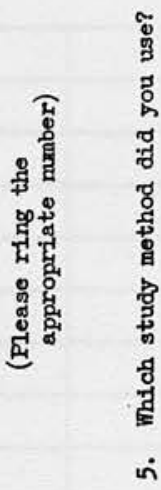
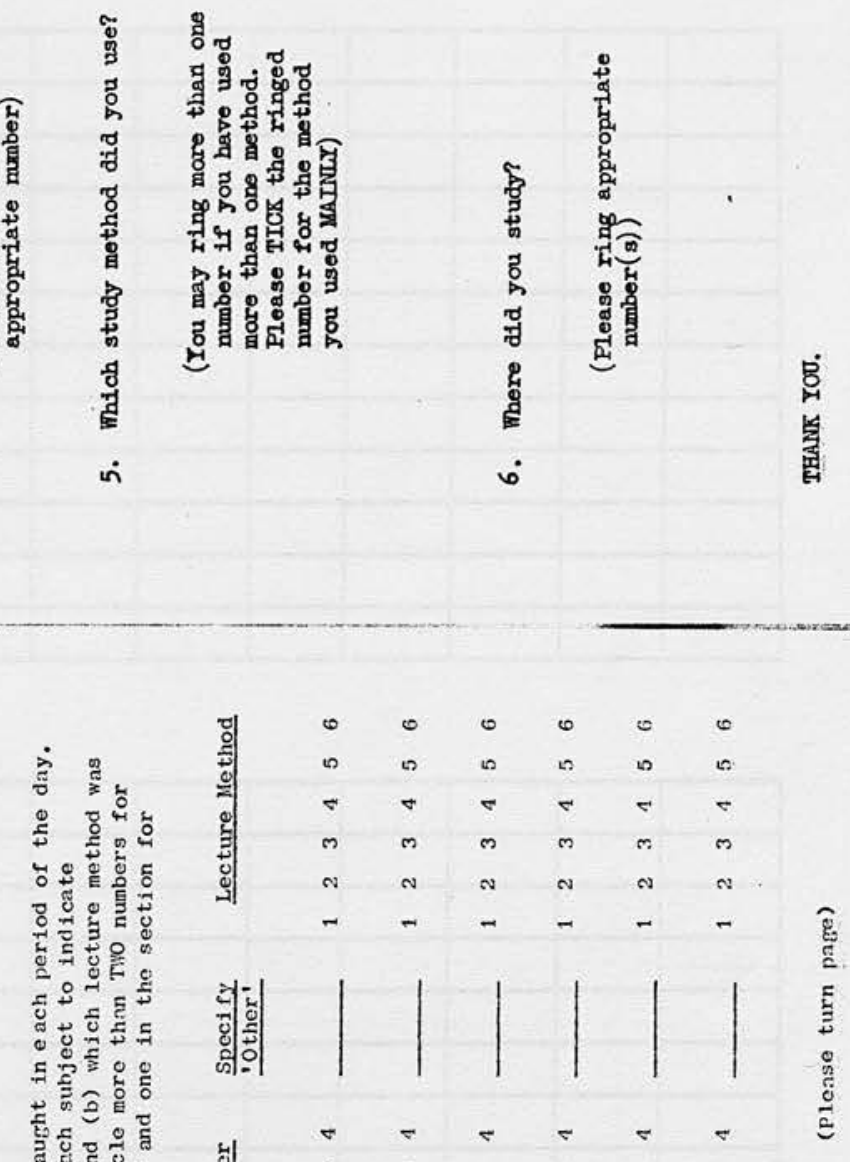

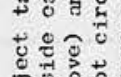

施

एक

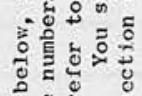

0
0

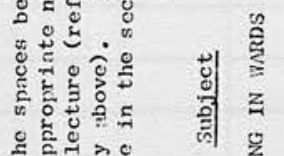

के हैं

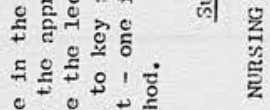

聄

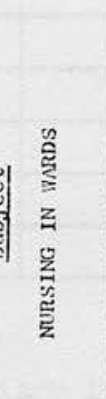

造

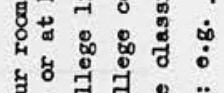

总息 


\section{UNIVERSITY OF EDINBURGH - NURSING RESEARCH UNIT}

EXPERIMENT IN NURSE EDUCATION

ATTENDANCE SHEET AND DIARY COLLECTION

College

\begin{tabular}{|l|l|l|l|l|l|l|l|}
\hline Name & 12 th & 13 th & W/E & 16 th & 17 th & 18 th & 19 th \\
\hline
\end{tabular}

Students in Experimental Group

\begin{tabular}{|l|l|l|l|l|l|l|l|}
\hline & & & & & & & \\
\hline & & & & & & & \\
\hline & & & & & & & \\
\hline & & & & & & & \\
\hline & & & & & & & \\
\hline & & & & & & & \\
\hline & & & & & & & \\
\hline & & & & & & & \\
\hline & & & & & & & \\
\hline & & & & & & & \\
\hline & & & & & & & \\
\hline
\end{tabular}

Students in Control Group

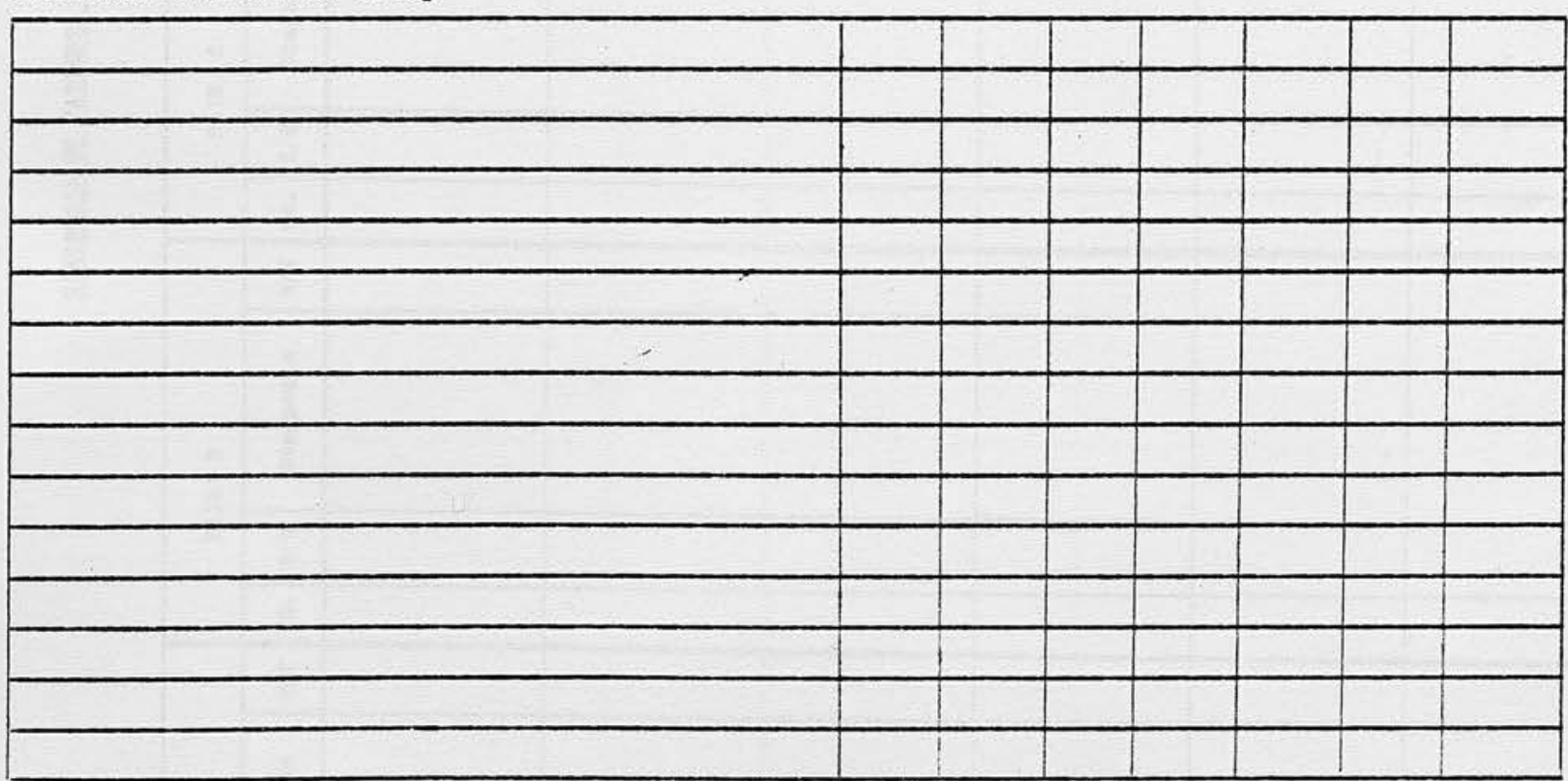

$V=$ present. $\quad X=$ diary in.

$A$ =absent. $A^{0}=$ absent, no diary. $\mathbb{A}=$ absent, diary in. 


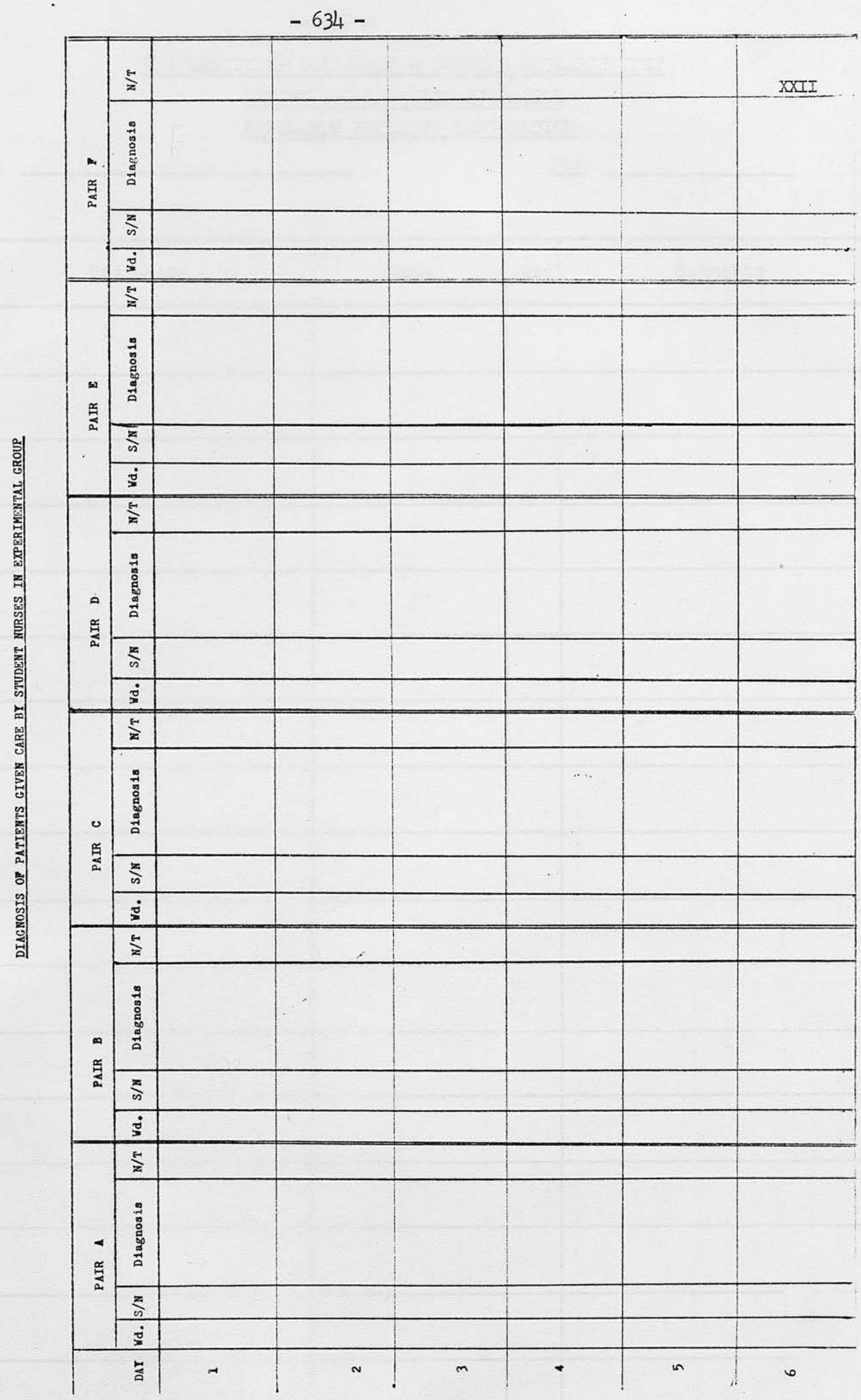




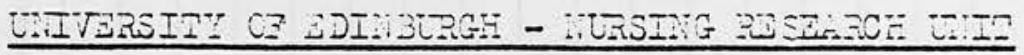

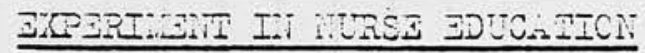

AVATHABLE PATIINNTS INFORMATICN

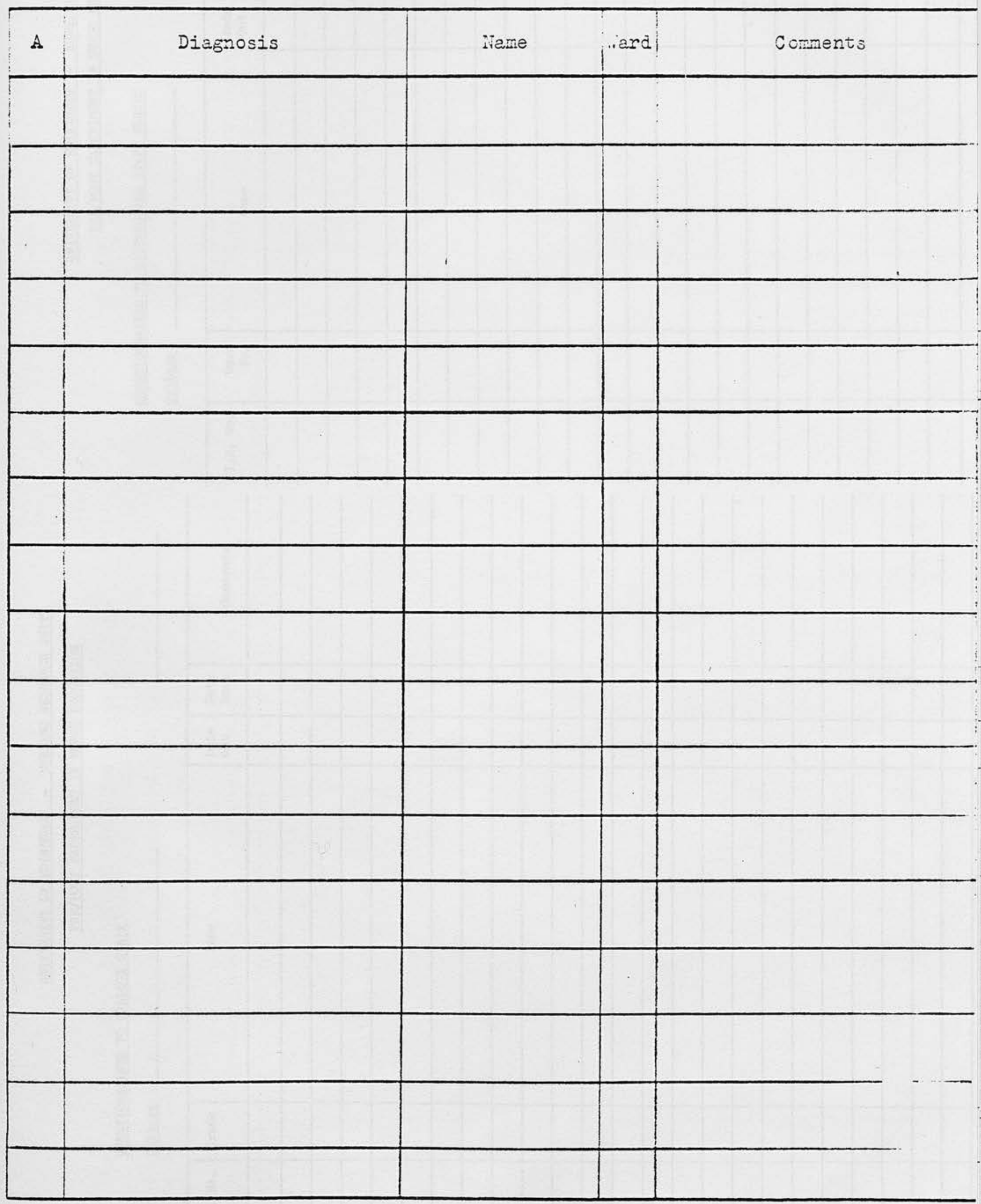

$A=A l l o c a t e d$ to student nurses, indicated by a tick. 


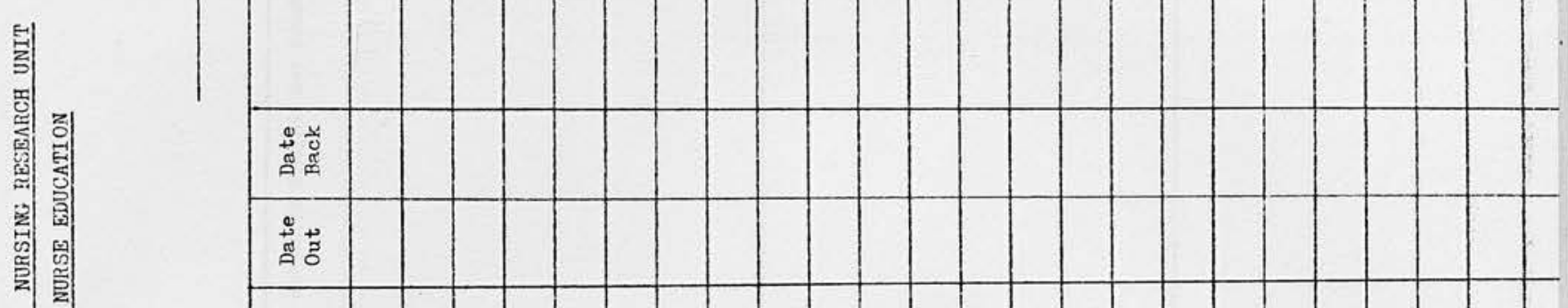

13

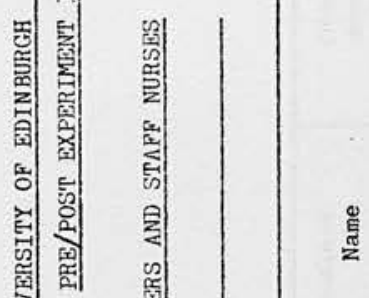

닉

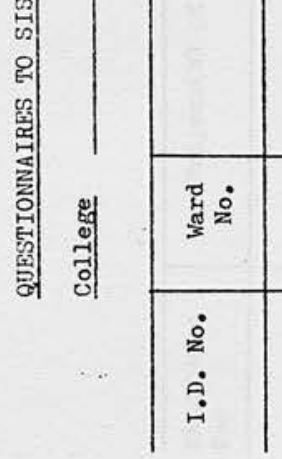

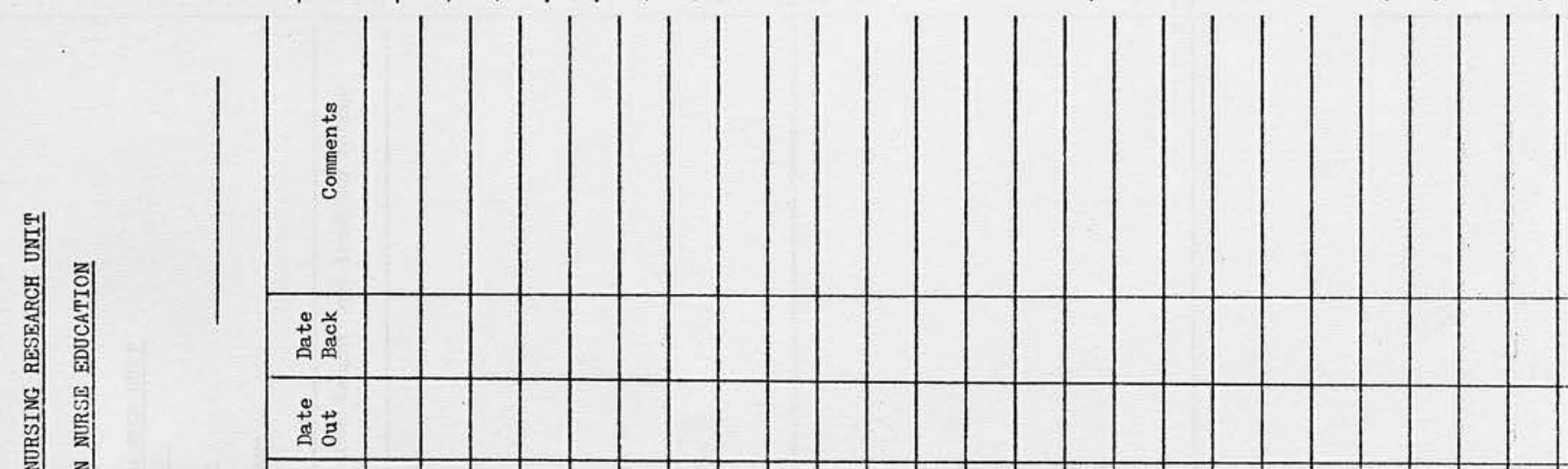

휜 분

|

๕్

$\stackrel{\circ}{z}$

$\dot{\leftrightarrow}$ 


\section{EXPER IMENT IN NURSE EDUCATION}

An experiment, which involves a change of teaching method in the education of student nurses, is to be carried out in the college of Nursing and the wards of the (hospital).

The wards involved will be those which can provide experience in the nursing care of patients with diseases of the gastro-intestinal system.

Details are as follows:-

1. The research experiment will take place during mornings, i.e. from (day and date) until (day and date) inclusive.

2. Student nurses from Block II (approximately 6 months in training) will come to the wards to give nursing care to individual patients whose conditions link directly with the course of lectures the student nurses are receiving in the college.

3. The student nurses will come on duty at a.m. (time to be finalised after discussion with ward Sisters) and remain on the wards for two hours. During that time they will carry out all the nursing care their patient requires, under the supervision of a nurse teacher.

4. Students will require a brief report and instructions as to what is to be done for their patient, when they come on duty. This report they can receive with the ward nurses if that is ward practice.

5. They will require access to the Kardex and the patient's case notes, as these periods on the ward take the place of nursing lectures in the college and the students will require to make notes from which to study later.

6. Before leaving the ward, students will report to the sister or Nurse in charge as to all they have done for their patient.

7. The Ward Sister will remain responsible for her patients, but will not be required to supervise the Block student nurse.

8. It is unlikely that there will be more than 2 student nurses in each ward at a time and they will work together. One memier of the teaching staff will supervise 4 students and she/he will therefore work between 2 wards.

9. The choice of appropriate patients for each student nurse will be done by the researcher, in consultation with the Ward Sister and the Teacher. Gravely ill patients or those suffering from rare disorders are unlikely to be suitable for student nurses at this stage of training, but they will be able to give care to both elective and emergency patients with the more common gastro-intestinal disorders.

10. It is hoped that ward stafe should have nothing to do for the Block nurses' patient between $\mathrm{a} . \mathrm{m}$. and a.m. (Hours experimental group students on ward)

11. Ward staff will know the evening before, which patients will be required by the Block nurses for the following day.

I hope that you will be prepared to have your ward participate in the research experiment. 

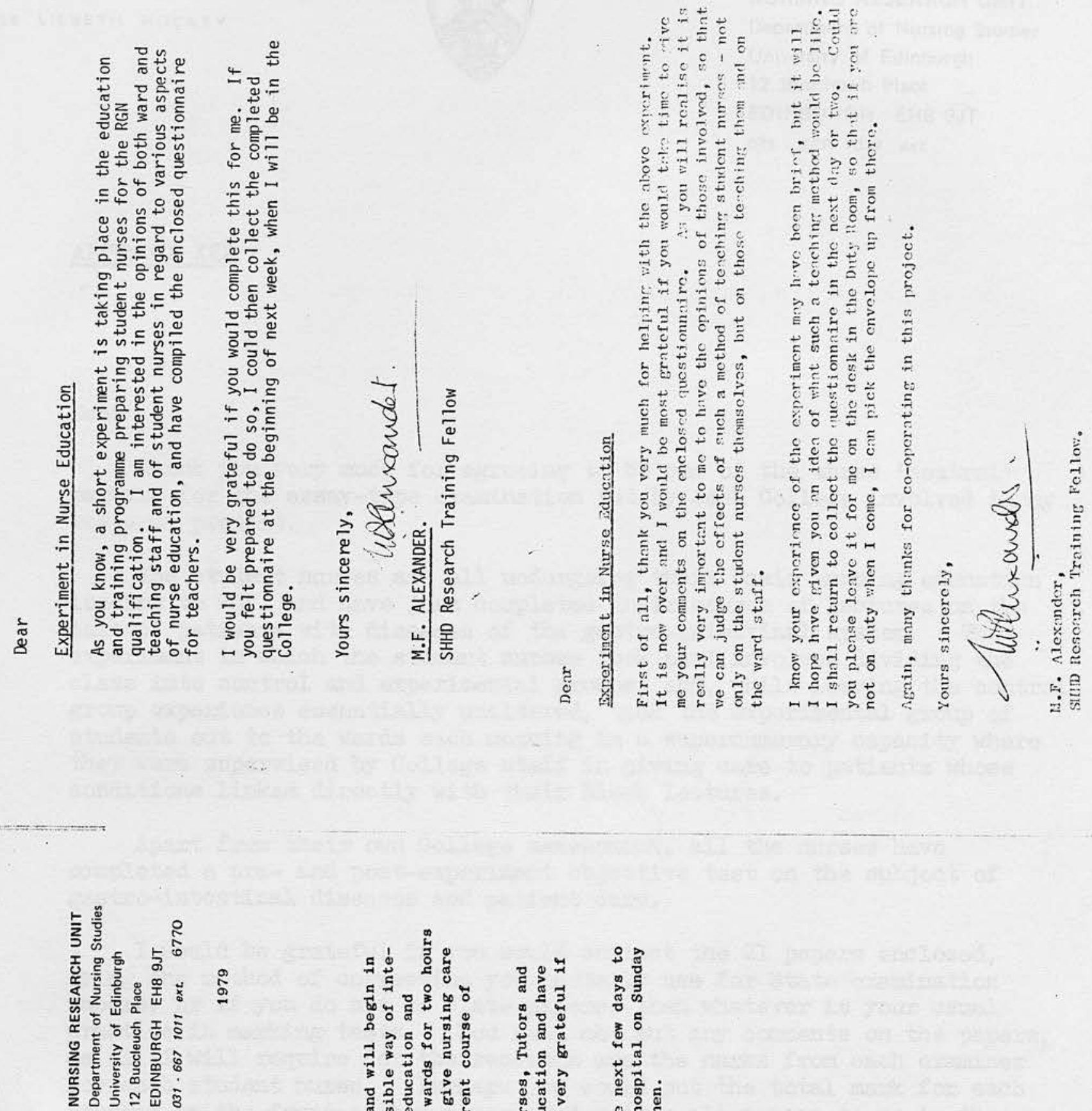

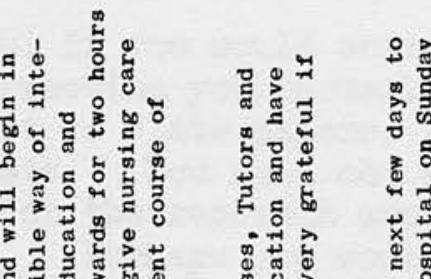

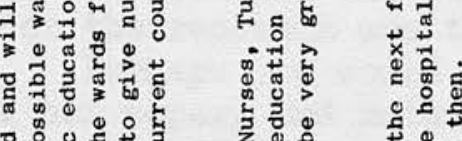

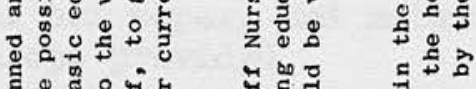

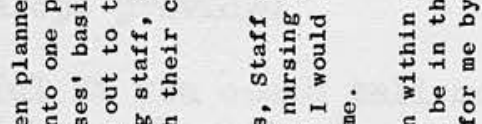

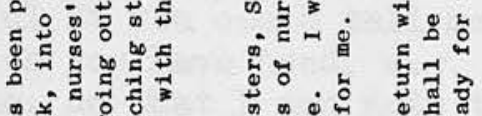

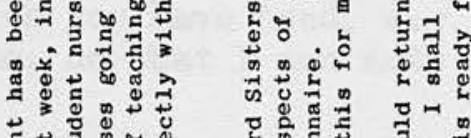

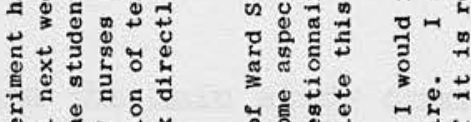

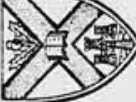

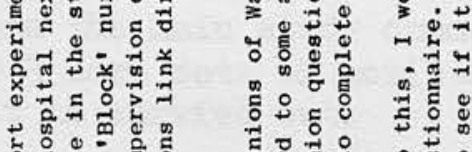

ติ

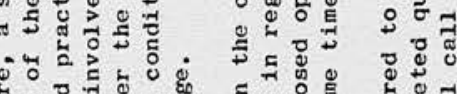

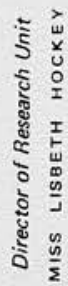

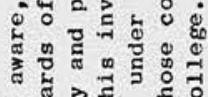

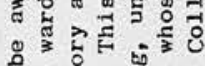

है

इ के

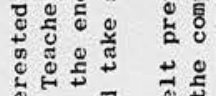

范

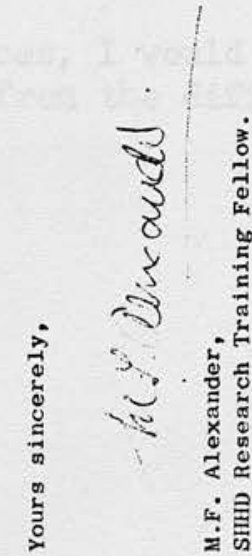




\section{APPENDIX XXX}

Dear

Thank you very much for agreeing to be one of the three 'neutral' markers for the essay-type examination set by each College involved in my research project.

The student nurses are all undergoing their basic nursing education leading to RGN, and have just completed their course of lectures on the care of patients with diseases of the gastro-intestinal system. The experiment in which the student nurses took part involved dividing the class into control and experimental groups, and, while leaving the control group experience essentially unaltered, took the experimental group of students out to the wards each morning in a supernumerary capacity where they were supervised by College staff in giving care to patients whose conditions linked directly with their Block lectures.

Apart from their own College assessment, all the nurses have completed a pre- and post-experiment objective test on the subject of gastro-intestinal diseases and patient care.

I would be grateful if you would correct the 21 papers enclosed, using the method of correction you normally use for State examination papers, or if you do not do State papers, then whatever is your usual practice in marking tests. You need not put any comments on the papers, as all I will require for the research are the marks from each examiner for each student nurse. Perhaps you could put the total mark for each student on the front of her paper, and return all papers to me in the stamped addressed envelope provided.

It would be helpful if you could tell me, when you returm the papers, the method of correction you have used, e.g. a marking key, impression marking or other scheme, so that I can note this when I do the statistical work.

In due course, when the main study commences, I would hope there should be perhaps 2 or 3 more sets of scripts from the different Colleges in which the experiment is carried out. 
I am sorry I cannot offer payment for the work of correction, but I will be very pleased to meet with you when I have analysed the material, and discuss the results. If possible, I would like to have the papers back by ... but if work commitments or holidays make this impossible, I will be glad to have them back as soon as convenient to you.

If there is anything further you would like to know, please do not hesitate to contact me at the above extension.

I look forward to hearing from you.

Yours sincerely,

* At a later date, when the researcher's Fellowship was extended for a further year, it was possible to arrange an honorarium to be paid to the neutral markers.

(All subsequent letters to markers were brief covering letters accompanying each batch of scripts) 
Director of Research Unit

MISS LISBETH HOCKEY
NURSING RESEARCH UNIT

Department of Nursing Studies University of Edinburgh

12 Buccleuch Place

EDINBURGH EH8 9JT

031. 6671011 ext. 6770

1979.

\section{Dear}

As promised, here are your marks for the tests you did during the research experiment: -

Objective Test (multiple choice)

$\begin{array}{ll}\text { pre-experiment } & \% \\ \text { post-experiment } & \% \\ 6 \text { months later } & \%\end{array}$

Essay Test - average over neutral markers

post-experiment
6 months later

Thank you very much for co-operating in the project.

Yours sincerely,

M.F. Alexander,

SHHD Research Training Fellow. 


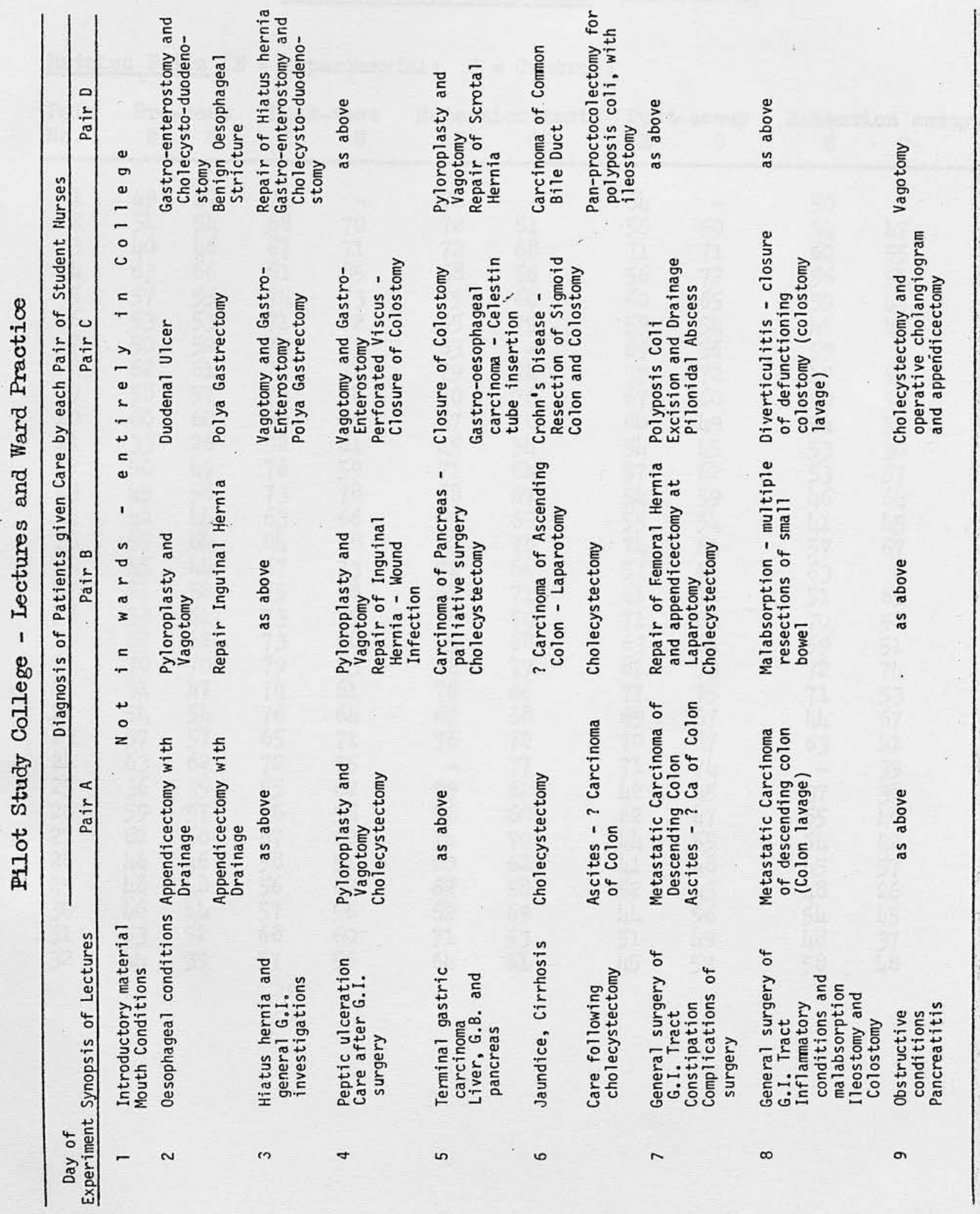


APPENDIX XXXIII

TEST AND ESSAY RAW SCORES (For Part A)

Matched Pairs ( $\mathrm{E}=$ Experimental; $\mathrm{C}=$ Control)

Pair Pre-test Post-test Retention test Post-essay Retention essay

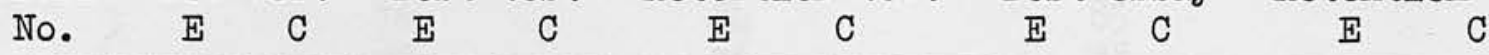

$\begin{array}{rrrrrrrrrrr}1 & 49 & 47 & 74 & - & 72 & - & 64 & - & 50 & - \\ 2 & 54 & 54 & 68 & 70 & 72 & 61 & 56 & 50 & 54 & 47 \\ 3 & 40 & 46 & 67 & 71 & 72 & 68 & 71 & 71 & 60 & 55\end{array}$

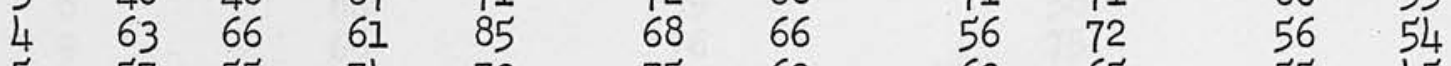

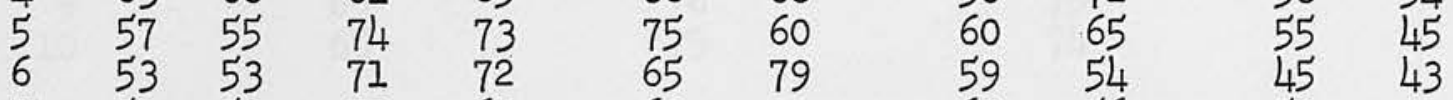

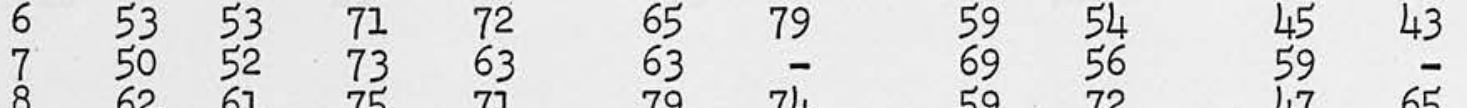

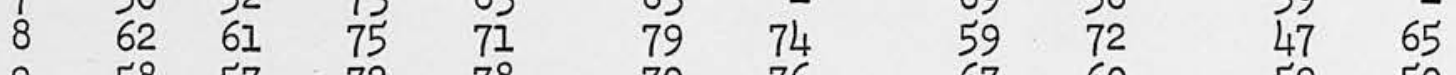

$\begin{array}{lllllllllll}9 & 58 & 57 & 72 & 78 & 70 & 76 & 67 & 60 & 59 & 50\end{array}$

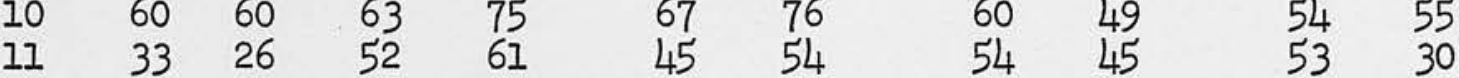

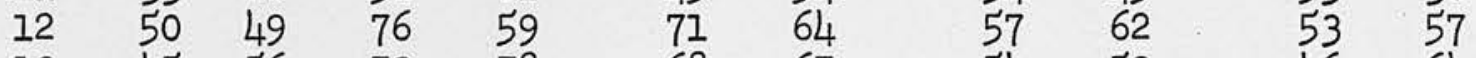

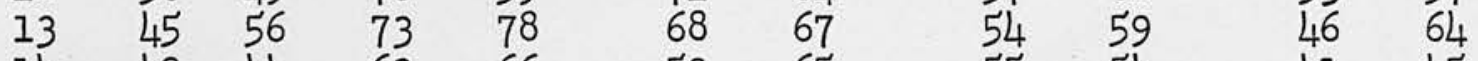

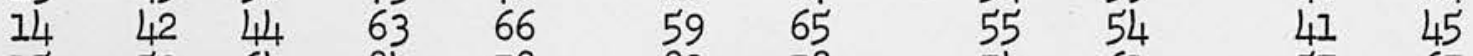

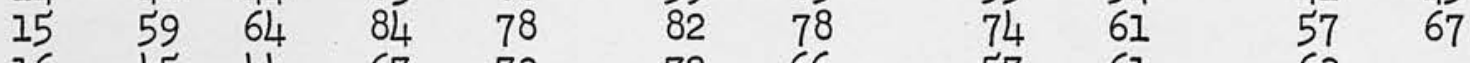

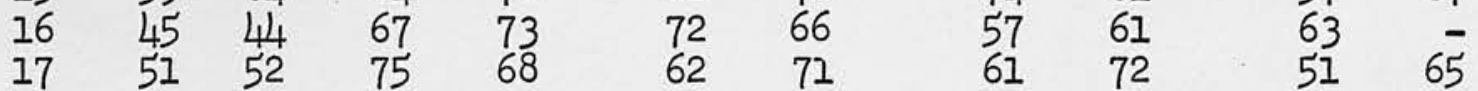

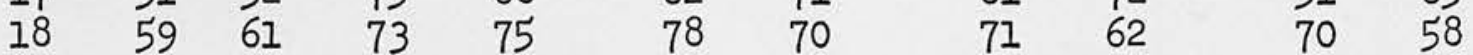

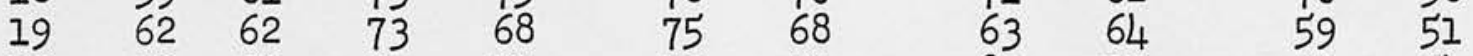

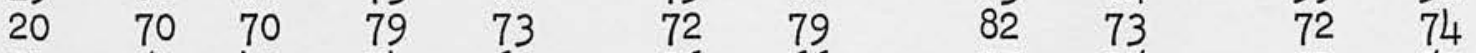

$\begin{array}{lllllllllll}21 & 51 & 47 & 74 & 61 & 76 & 66 & 77 & 75 & 71 & 53\end{array}$

$\begin{array}{lllllllllll}22 & 54 & 54 & 76 & 64 & 69 & 68 & 69 & 67 & 44 & 67\end{array}$

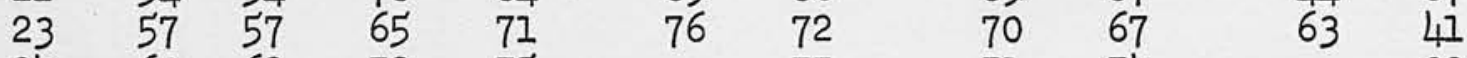

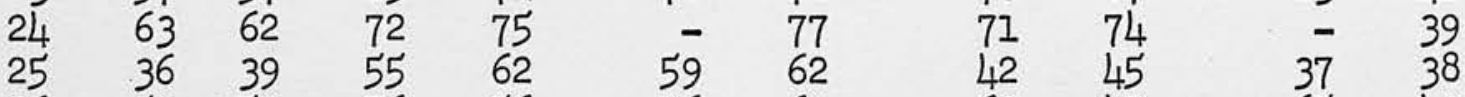

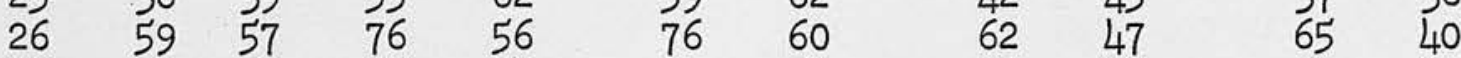

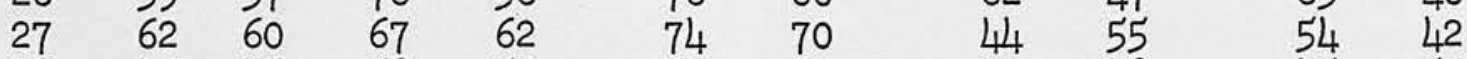

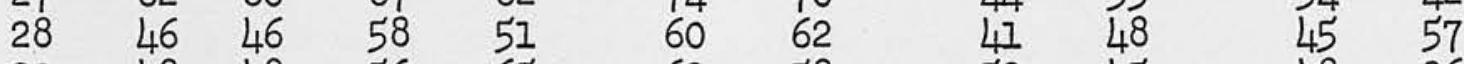

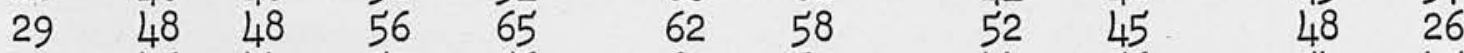

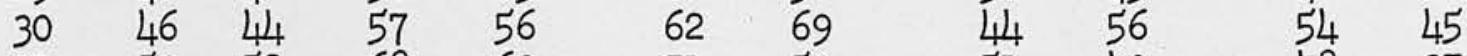

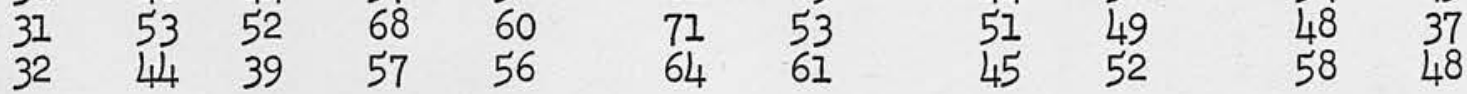


COILEGE III - TPEST SCORES (For Part A)

Student Pre-test Post-test $\quad$ Retention test

$\begin{array}{rlll}1 & 67 & 71 & 74 \\ 2 & 63 & 57 & 71 \\ 3 & 76 & 84 & 85 \\ 4 & 58 & 76 & 78 \\ 5 & 67 & 78 & 83 \\ 6 & 62 & 73 & 83 \\ 7 & 75 & 77 & 77 \\ 8 & 60 & 59 & 56 \\ 9 & 66 & 76 & 75 \\ 10 & 65 & 75 & 74\end{array}$


TEST AND ESSAY RAW SCORES (For Part B)

\begin{tabular}{|c|c|c|c|c|c|c|c|c|c|}
\hline \multirow{2}{*}{$\begin{array}{l}\text { Students' } \\
\text { Identity } \\
\text { No. }\end{array}$} & \multirow[b]{2}{*}{ Pre-test } & \multirow[b]{2}{*}{ Post-test } & \multirow[b]{2}{*}{ Retention test } & \multicolumn{3}{|c|}{$\begin{array}{l}\text { Post-essay } \\
\text { Markers }\end{array}$} & \multicolumn{3}{|c|}{$\begin{array}{l}\text { Retention essay } \\
\text { Markers }\end{array}$} \\
\hline & & & & $\mathrm{B}$ & C & $D$ & $B$ & C & $D$ \\
\hline $\begin{array}{r}1 \\
2 \\
3 \\
4 \\
5 \\
6 \\
7 \\
8 \\
9 \\
10 \\
11 \\
12 \\
13 \\
14 \\
15 \\
16 \\
17 \\
18 \\
19 \\
20 \\
21 \\
22 \\
23 \\
24 \\
25 \\
26\end{array}$ & $\begin{array}{l}49 \\
54 \\
59 \\
40 \\
55 \\
54 \\
53 \\
63 \\
46 \\
57 \\
53 \\
49 \\
52 \\
66 \\
50 \\
60 \\
62 \\
61 \\
59 \\
58 \\
60 \\
33 \\
50 \\
26 \\
55 \\
57\end{array}$ & $\begin{array}{l}74 \\
68 \\
77 \\
67 \\
64 \\
70 \\
72 \\
61 \\
71 \\
74 \\
71 \\
59 \\
63 \\
85 \\
73 \\
75 \\
75 \\
71 \\
76 \\
72 \\
63 \\
52 \\
76 \\
61 \\
73 \\
78\end{array}$ & $\begin{array}{l}72 \\
72 \\
76 \\
72 \\
74 \\
61 \\
79 \\
68 \\
68 \\
75 \\
65 \\
64 \\
- \\
66 \\
63 \\
76 \\
79 \\
74 \\
78 \\
70 \\
67 \\
45 \\
71 \\
54 \\
60 \\
76\end{array}$ & $\begin{array}{l}66 \\
57 \\
71 \\
76 \\
42 \\
50 \\
58 \\
56 \\
73 \\
68 \\
61 \\
69 \\
65 \\
77 \\
68 \\
55 \\
61 \\
72 \\
60 \\
67 \\
62 \\
54 \\
58 \\
54 \\
79 \\
61\end{array}$ & $\begin{array}{l}58 \\
52 \\
66 \\
64 \\
40 \\
50 \\
54 \\
52 \\
62 \\
56 \\
54 \\
50 \\
52 \\
58 \\
64 \\
44 \\
60 \\
70 \\
50 \\
66 \\
58 \\
48 \\
62 \\
38 \\
56 \\
58\end{array}$ & $\begin{array}{l}74 \\
61 \\
72 \\
72 \\
43 \\
53 \\
48 \\
58 \\
75 \\
56 \\
59 \\
64 \\
48 \\
72 \\
73 \\
51 \\
61 \\
75 \\
60 \\
67 \\
60 \\
62 \\
63 \\
38 \\
61 \\
62\end{array}$ & $\begin{array}{l}47 \\
55 \\
55 \\
68 \\
18 \\
48 \\
52 \\
62 \\
56 \\
58 \\
46 \\
64 \\
- \\
53 \\
62 \\
49 \\
46 \\
57 \\
60 \\
61 \\
49 \\
52 \\
57 \\
23 \\
45 \\
51\end{array}$ & $\begin{array}{l}50 \\
55 \\
54 \\
60 \\
35 \\
50 \\
42 \\
54 \\
54 \\
53 \\
50 \\
54 \\
5 \\
53 \\
55 \\
62 \\
47 \\
64 \\
53 \\
58 \\
60 \\
50 \\
55 \\
36 \\
45 \\
52\end{array}$ & $\begin{array}{l}54 \\
51 \\
47 \\
53 \\
36 \\
43 \\
36 \\
53 \\
54 \\
54 \\
38 \\
54 \\
55 \\
61 \\
53 \\
48 \\
73 \\
58 \\
57 \\
53 \\
56 \\
47 \\
32 \\
44 \\
48\end{array}$ \\
\hline $\begin{array}{l}27 \\
28 \\
29 \\
30 \\
31 \\
32 \\
33 \\
34 \\
35 \\
36\end{array}$ & $\begin{array}{l}74 \\
45 \\
42 \\
44 \\
59 \\
54 \\
444 \\
56 \\
45 \\
64\end{array}$ & $\begin{array}{l}80 \\
73 \\
63 \\
73 \\
84 \\
57 \\
66 \\
78 \\
67 \\
78\end{array}$ & $\begin{array}{l}75 \\
68 \\
59 \\
66 \\
82 \\
63 \\
65 \\
67 \\
72 \\
78\end{array}$ & $\begin{array}{l}81 \\
66 \\
57 \\
57 \\
78 \\
66 \\
64 \\
62 \\
56 \\
63\end{array}$ & $\begin{array}{l}66 \\
56 \\
58 \\
62 \\
66 \\
60 \\
52 \\
60 \\
60 \\
62\end{array}$ & $\begin{array}{l}60 \\
33 \\
51 \\
56 \\
69 \\
44 \\
47 \\
52 \\
50 \\
46\end{array}$ & $\begin{array}{l}64 \\
46 \\
37 \\
55 \\
43 \\
42 \\
70 \\
64 \\
70\end{array}$ & $\begin{array}{l}64 \\
52 \\
50 \\
50 \\
52 \\
52 \\
60 \\
64 \\
62\end{array}$ & $\begin{array}{l}65 \\
39 \\
35 \\
67 \\
47 \\
47 \\
63 \\
60 \\
68\end{array}$ \\
\hline $\begin{array}{l}37 \\
38 \\
39 \\
40 \\
47 \\
42\end{array}$ & $\begin{array}{l}51 \\
62 \\
59 \\
72 \\
62 \\
67\end{array}$ & $\begin{array}{l}75 \\
75 \\
73 \\
80 \\
73 \\
72\end{array}$ & $\begin{array}{l}62 \\
77 \\
78 \\
80 \\
75 \\
74\end{array}$ & $\begin{array}{l}78 \\
84 \\
80 \\
82 \\
68 \\
76\end{array}$ & $\begin{array}{l}60 \\
72 \\
76 \\
68 \\
64 \\
64\end{array}$ & $\begin{array}{l}46 \\
68 \\
60 \\
72 \\
56 \\
66\end{array}$ & $\begin{array}{l}60 \\
46 \\
80 \\
84 \\
60 \\
72\end{array}$ & $\begin{array}{l}56 \\
48 \\
64 \\
68 \\
64 \\
56\end{array}$ & $\begin{array}{l}36 \\
22 \\
66 \\
74 \\
52 \\
62\end{array}$ \\
\hline
\end{tabular}


Students' Identity

Post-essay Markers

$\begin{array}{ll}43 & 42 \\ 44 & 55 \\ 45 & 65 \\ 46 & 70 \\ 47 & 70 \\ 48 & 77 \\ 49 & 47 \\ 50 & 51 \\ 51 & 29 \\ 52 & 54 \\ 53 & 52 \\ 54 & 61 \\ 55 & 57 \\ 56 & 62 \\ 57 & 54 \\ 58 & 56 \\ 59 & 57 \\ 60 & 63\end{array}$

$42 \quad 76$

61

62

63

64

65

66

67

68

69

70

71

72

73

74

76

77

78

79

80

81
55

70

70

77

51

29

54

52

57

62

54

57
63

63

79

73

81

61

74
48

64

68

75

71

76

77.

65

72

36

57

39

59

49

62

46

48

39

46

52

44

60

47

46

53

44

61

68
55

56

62

76

57

67

58

56

56

51

60

56

62

61

65

57

68

57

76
73

71

$7 \overline{9}$

72

83
66

76

42

68

71

70

72
68

69

66

76

B C D

B C D

$\begin{array}{llllll}70 & 76 & 50 & 68 & 64 & 60\end{array}$

$\begin{array}{llllll}80 & 60 & 68 & 70 & 56 & 56\end{array}$

$\begin{array}{llllll}78 & 80 & 74 & \overline{7} & \overline{8} & -\end{array}$

$\begin{array}{llllll}82 & 72 & 84 & 76 & 68 & 76\end{array}$

$\begin{array}{llllll}82 & 64 & 66 & 74 & 60 & 40\end{array}$

$\begin{array}{llllll}92 & 76 & 60 & 60 & 56 & 42\end{array}$

$\begin{array}{llllll}88 & 72 & 70 & 82 & 64 & 66\end{array}$

$\begin{array}{llllll}62 & 52 & 40 & 46 & 50 & 18\end{array}$

$\begin{array}{llllll}84 & 60 & 62 & 66 & 64 & 72\end{array}$

$\begin{array}{llllll}78 & 72 & 70 & 76 & 69 & 50\end{array}$

$\begin{array}{llllll}80 & 60 & 50 & 70 & 64 & 40\end{array}$

$\begin{array}{llllll}82 & 64 & 64 & 48 & 46 & 30\end{array}$

$\begin{array}{llllll}78 & 64 & 62 & 60 & 50 & 42\end{array}$

$\begin{array}{llllll}84 & 68 & 56 & 50 & 50 & 32\end{array}$

$\begin{array}{llllll}86 & 54 & 58 & 58 & 50 & 32\end{array}$

$\begin{array}{llllll}78 & 68 & 58 & 76 & 56 & 56\end{array}$

59

69

60

62

76

61

74

60

62

61

62

53

69

70

63

58

62

71

64

69
866066 - -

$\begin{array}{llllll}39 & 46 & 44 & 36 & 40 & 34\end{array}$

$\begin{array}{llllll}39 & 50 & 36 & 47 & 51 & 43\end{array}$

$\begin{array}{llllll}47 & 52 & 49 & 45 & 44 & 31\end{array}$

$\begin{array}{llllll}36 & 50 & 46 & 37 & 47 & 31\end{array}$

$\begin{array}{llllll}57 & 64 & 64 & 66 & 67 & 62\end{array}$

$\begin{array}{llllll}45 & 46 & 42 & 57 & 54 & 50\end{array}$

$\begin{array}{llllll}43 & 44 & 35 & 43 & 49 & 42\end{array}$

$\begin{array}{llllll}53 & 54 & 52 & 54 & 46 & 44\end{array}$

$\begin{array}{llllll}53 & 50 & 51 & 47 & 52 & 46\end{array}$

$\begin{array}{llllll}45 & 54 & 44 & 55 & 60 & 55\end{array}$

$\begin{array}{llllll}48 & 52 & 44 & 36 & 47 & 27\end{array}$

$\begin{array}{llllll}55 & 52 & 64 & 52 & 44 & 40\end{array}$

$\begin{array}{llllll}69 & 55 & 55 & 41 & 43 & 43\end{array}$

$\begin{array}{llllll}28 & 48 & 37 & 35 & 44 & 31\end{array}$

$\begin{array}{llllll}44 & 51 & 48 & 28 & 26 & 25\end{array}$

$\begin{array}{llllll}51 & 44 & 39 & 58 & 54 & 50\end{array}$

$\begin{array}{llllll}53 & 52 & 44 & 47 & 57 & 41\end{array}$

$\begin{array}{llllll}50 & 50 & 40 & 57 & 60 & 57\end{array}$

$\begin{array}{llllll}61 & 54 & 59 & 47 & 49 & 50\end{array}$ $\begin{array}{llllll}60 & 50 & 49 & 46 & 46 & 42\end{array}$ 